Florida International University FIU Digital Commons

FIU Electronic Theses and Dissertations

University Graduate School

7-14-2010

\title{
Hindutva Meets Globalization: The Impact on Hindu Urban Media Women
}

Monalisa Gangopadhyay

Florida International University, monalisaganguly@hotmail.com

DOI: $10.25148 /$ etd.FI10112010

Follow this and additional works at: https://digitalcommons.fiu.edu/etd

\section{Recommended Citation}

Gangopadhyay, Monalisa, "Hindutva Meets Globalization: The Impact on Hindu Urban Media Women" (2010). FIU Electronic Theses and Dissertations. 305.

https://digitalcommons.fiu.edu/etd/305

This work is brought to you for free and open access by the University Graduate School at FIU Digital Commons. It has been accepted for inclusion in FIU Electronic Theses and Dissertations by an authorized administrator of FIU Digital Commons. For more information, please contact dcc@fiu.edu. 


\section{FLORIDA INTERNATIONAL UNIVERSITY}

Miami, Florida

HINDUTVA MEETS GLOBALIZATION:

THE IMPACT ON HINDU URBAN MEDIA WOMEN

A dissertation submitted in partial fulfillment of the

requirements for the degree of

DOCTOR OF PHILOSOPHY

in

INTERNATIONAL RELATIONS

by

Monalisa Gangopadhyay

2010 
To: Dean Kenneth Furton

College of Arts and Sciences

This dissertation, written by Monalisa Gangopadhyay, and entitled Hindutva Meets Globalization: The Impact on Hindu Urban Media Women, having been approved in respect to style and intellectual content, is referred to you for judgment.

We have read this dissertation and recommend that it be approved.

Elisabeth Prugl

Francois Debrix

Laura Ogden

Gail Hollander, Major Professor

Date of Defense: July 14, 2010

The dissertation of Monalisa Gangopadhyay is approved.

Dean Kenneth Furton
College of Arts and Sciences

Interim Dean Kevin O’Shea University Graduate School

Florida International University, 2010 


\section{DEDICATION}

To Sanjay and Veer 


\section{ACKNOWLEDGMENTS}

This is truly a work of collaboration. As I make a neat list of people I want to thank, I realize how deeply they have influenced my academic endeavors and supported me through my personal trials and tribulations.

In my journey through Florida International University, I have been fortunate to study and learn from some of the finest teachers in the academy but my deepest intellectual debts are to the members of my dissertation committee. My chair, Dr. Gail Hollander is an inspiring mentor. With innate patience and unwavering support, Dr. Hollander has encouraged and guided me through my research work. For her insightful intellectual advice, incisive reading of my material and great humor, I don't have enough words to express my thankfulness. To Dr. Elisabeth Prugl, I owe a debt of gratitude for bringing me into the program and then teaching me the importance of theoretical thinking. I deeply appreciate her for allowing me to walk into her office, without an appointment, to bounce off ideas that have deeply influenced my work and thought processes. I have been doubly fortunate to have Dr. Francois Debrix, as a teacher and a supervisor. He led some of the most interesting and intellectually explosive classes I have attended. Equally important was his support through my three years of working for the Ruth K. and Shepard Broad Lecture Series, during which, he extended complete support and guidance as I balanced classes, the assistantship and new motherhood. Finally, to Dr. Laura Ogden, I owe a special debt as my conversations with her strengthened my belief in interdisciplinary research. In her class, I experienced firsthand, the flexibility that working mothers deeply desire, which allowed me to balance academics and impending motherhood. 
I want to thank my wonderful friends and colleagues in the department, whose curiosity about India kept me on my toes and whose humor kept me in splits. I specially want to thank Serena Cruz and Diana Ter-Ghazaryan for their unending intellectual support and deep friendship. I also want to thank Alexandra Santillan for seeing me through periods of craziness and reading my work. A special debt of gratitude goes out to Rita Sabat for being my cohort-mentor and teaching me how to read. Finally to Raju Parakkal, I want to thank him for pushing me to re-think and un-think some deeply rooted sometimes-unquestioned notions about India.

To my friends in Delhi, I have nothing but deep gratitude for going above and beyond their comfort zones to help me with my research. I especially want to thank Shikha Mishra for the numerous emails that she sent out to establish contacts for me and for ferrying me around in the madness that is Delhi. I want to thank Himanshu Verma for taking time out of his ever-busy schedule to help me set up interviews. I must thank the staff the library in Jagori for their patience as I sorted through hundreds of research texts.

As I finish my dissertation, I am aware that I have been very fortunate to be part of the supportive atmosphere in Florida International University. Whether financial support through graduate assistantships and the Dissertation Year Fellowship 2009-2010 or the open doors of professors, FIU has offered me a unique and inclusive academic experience.

None of this would have been possible without the love, support and complete belief of my family. My parents, Amit and Shila created a zone of comfort where I could question and challenge, without fear. Knowing that they are sheltering me with their love and prayers every minute of the day gives me the strength to plough on. My wonderful 
sister, Manisha, with her constant optimism and complete faith in my ability to write has pushed me to work harder and embrace the idea of finishing on time. I also want to thank my brother-in-law, Anant whose sense of humor and ability to listen without passing judgment has made him a wonderful friend and sounding board.

Finally for the two pillars of my life, my husband Sanjay and my three-year-old son Veer, I have such deep gratitude. I want to thank Sanjay for all his quiet unreserved support, from the morning cup of tea to sending me links to interesting academic works. I could not do this as easily without him. And, finally to Veer, who lets me work in peace and asks me if I felt better when I finish, yes I do!

As my family and friends support me through my academic career, I am filled with gratitude towards the media women, most of them strangers, who talked to me with no reservations, called me out on my preconceived notions, constantly challenged me with their knowledge and astounded me with their spirit to take on the dusty pillars of patriarchies.

And finally, for providing a canvas of swirling material, in the words of Alanis Morrisette, Thank you, India. 


\title{
ABSTRACT OF THE DISSERTATION \\ HINDUTVA MEETS GLOBALIZATION: \\ THE IMPACT ON HINDU URBAN MEDIA WOMEN
}

\author{
by \\ Monalisa Gangopadhyay \\ Florida International University, 2010 \\ Miami, Florida \\ Professor Gail Hollander, Major Professor
}

This study examines the impact of globalization and religious nationalism on the personal and professional lives of urban Hindu middle class media women. The research demonstrates how newly strengthened forces of globalization and Hindutva shape Indian womanhood. The research rests on various data that reveal how Indian women interpret and negotiate constructed identities. The study seeks to give voice to the objectified by scrutinizing and challenging the stereotypical modern faces of Indian womanhood seen in the narratives of globalization and Hindutva.

Feminist open-ended interviewing was conducted in English and Hindi in New Delhi, the capital of India, with 23 Hindu women, employed by electronic and print media corporations. Accumulated data were analyzed and interpreted using feminist critical discourse analysis. Findings from the study indicate that while the Indian middle class women have embraced professional opportunities presented by globalization, they remain circumscribed by mutating gender politics. The research also finds that as academic and professional progress empower the women within their homes, their public lives have become fraught with increasing gender violence and decreasing recourse to 
justice. Therefore, women accept the power stratification of their lives as being dependent on spatial and temporal distinctions, and have learnt to engage and strategize with the public environment for physical safety and personal-professional progress. While the media women see systemic masculine domination as being symbiotic with tenets of religious nationalism, they exhibit an unquestioned embracing of capitalism/globalization as the means of empowerment. My research also strongly indicates the importance of the media's role in shaping gender dynamics in a global context. In conclusion, my research shows the mediawomen's immense agency in pursuing academic and professional careers while being aware of deeply ingrained gender roles through their strong commitment towards their families.

The findings of this study contribute to the literature on Third World nationalism, urban globalization and understandings of reworked-renewed masculine domination. Finally, the study also engages with recent scholarship on the Indian middle class (See Nanda 2010; Shenoy 2009; Lukose 2005; and Radhakrishnan 2006) while simultaneously addressing the notions of privilege and disengagement levied at the middle class woman, a symbiosis of idealization and imprisonment. 


\section{TABLE OF CONTENTS}

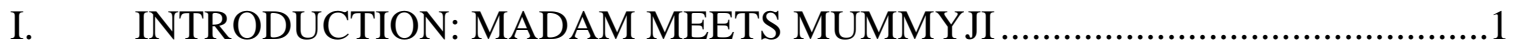

1. A Short Story: Hindutva and Globalization.......................................................

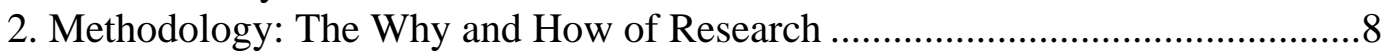

2.1. Theorizing Indian Women's Identity, Body and Space..........................9

2.2. Research Design and Methods.............................................................17

3. Related Texts: Connecting with Scholars ...........................................................27

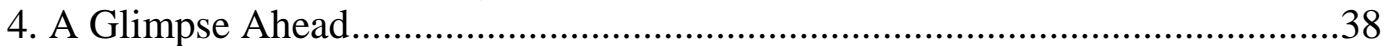

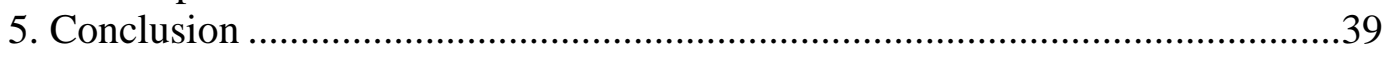

II. A BRIEF HISTORY OF GENDERED HIERARCHIES ........................................42

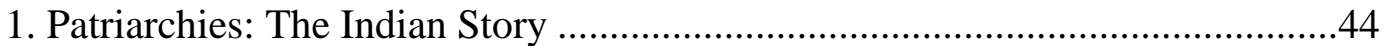

2. The Antiquities (1600 BCE-1200 CE) ……………......................................46

3. 'Outsiders' Reign I: The Delhi Sultanate and the Mughal Era

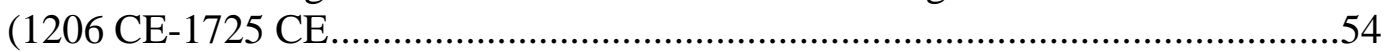

3.1. The Outliers Within ....................................................................56

4. 'Outsiders' Reign II: The Western Influence (1757 CE-Present) ......................58

4.1. The Outliers Within ...........................................................................65

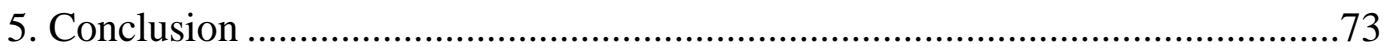

III. UNDERSTANDING IDENTITY:

THE THEORETICAL FRAMEWORK.................................... 77

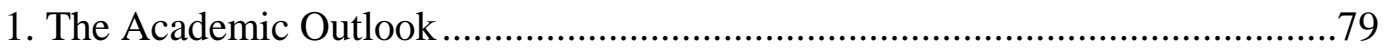

1.1. Embodying Indian Womanhood ........................................................... 85

1.2. Understanding Globalization .....................................................................91

1.3. Understanding Nationalism ......................................................................99

2. The Street Outlook on Indian Womanhood ..................................................108

3. Theorizing Security: Marking Space-Identity-Movement...................................114

3.1. Meaning of Security Within Public Space/Perception.................................115

3.2. Meaning of Security Within Domestic Space...............................................119

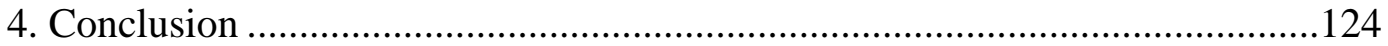

IV. FATHER, HUSBAND AND SON: THE GATEKEEPERS OF

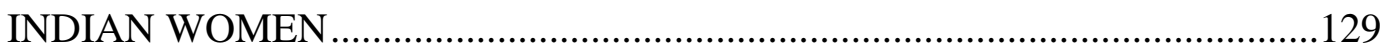

1. Multiple Personality Order: The Middle Class Woman .....................................130

2. The Schizophrenic Modern Home ..............................................................140

2.1. The Safe Woman.............................................................................141

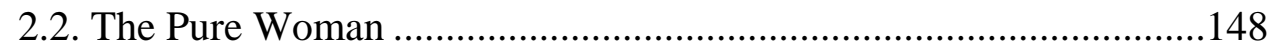

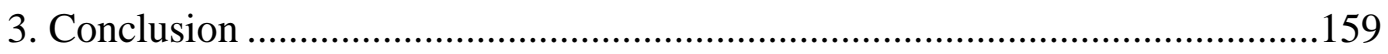


V. BOSS OR BITCH: STEPPING INTO THE WORKPLACE ................................161

1. Panic on the Street: Woman Sighted ................................................................162

2. Primped and Powdered: Carrying the Weight of Globalization .......................170

3. Carrying the Weight of Nationalism: The Good Hindustani

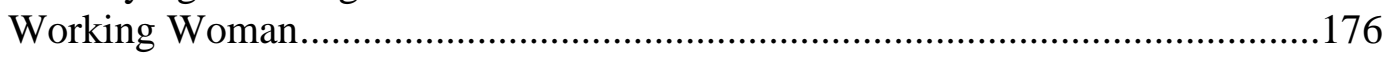

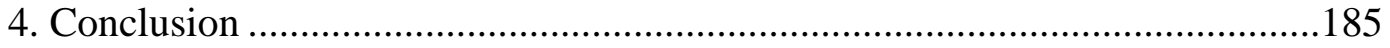

VI. ANSWERING WOMEN: THE WHAT, THE WHY AND THE WHO..................188

1. Answering Questions I: Data Generated..........................................................189

1.1. Gaze of the Researched..................................................................189

1.2. Gaze of Authority ..........................................................................215

1.3. Gaze of the Researcher ................................................................237

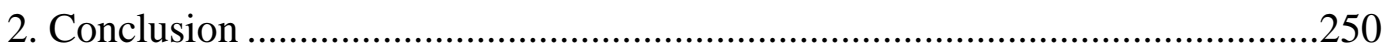

VII. SECURING INDIAN WOMEN: THE CARROT AND STICK METHOD...........253

1. Answering Questions II: Data Generated ............................................................254

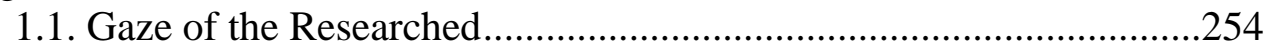

1.2. Gaze of Authority …………………………………......................268

1.3. Gaze of the Researcher ……………..............................................278

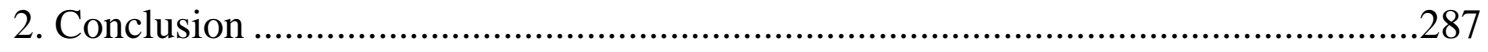

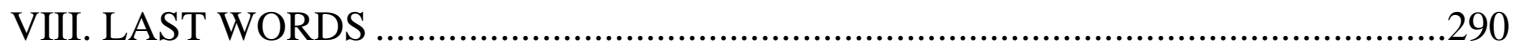

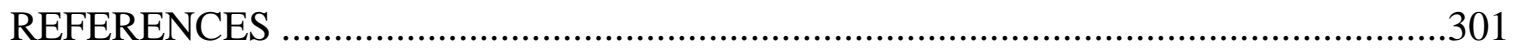

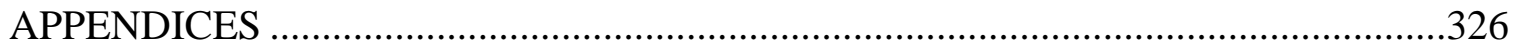

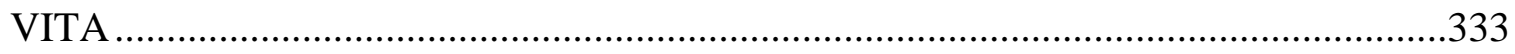




\section{LIST OF TABLES}

TABLE

PAGE

1. NCRB Pattern of Crimes Against Women (1991-2007) .................................218

2. Indian Penal Code for Crimes Against Women...............................................222

3. Gender Specific Employment Law under the Ministry of Labor, Government of India

4. Patterns of Differentiation Based on Gender ..................................................258

5. Safety Audit of a Delhi Neighborhood ......................................................280 


\section{CHAPTER I}

\section{Introduction: Madam Meets Mummyii}

On January $24^{\text {th }}$, 2009, a group of 40 activists of the Shri Ram Sene, a Hindu rightwing group, barged into a pub in Mangalore (a city in the state of Karnataka in South India), dragged out a group of young people and beat them up, claiming that the women were violating traditional Indian values by wearing Western clothes and drinking alcohol with their male friends. The video of the incident became fodder for national and international TV channels, newspapers and the Internet, establishing itself as a focal point for national condemnation and denouncement. While most Indian citizenry appeared angered and embarrassed by the message behind the violence, going as far as warning against Hindu Talibanization of India, many prominent politicians and even the National Commission for Women (NCW), condemned "the loosening of moral standards amongst young women” and called for controls on pub licenses and alcohol consumption in public (Mahajan 2009:134).

While the controversy raged, Shri Ram Sene chief Pramod Muthalik was unrepentant and vowed to disrupt all future Valentine’s Day and New Years celebrations in Karnataka, calling it an "international Christian conspiracy against our [Indian] culture” (Mackey 2009). He also threatened to force unmarried couples found together on Valentine's Day to get married unless they agreed to tie rakhis (threads) on their wrists signifying that they are brother and sister (Sen 2009).

As this moral policing was being thrust upon a largely outraged Indian citizenry, a group of women, largely activists-journalists going by the name, The Consortium of 
Pubgoing, Loose, and Forward Women started The Pink Chaddi Campaign (The Pink Underwear Campaign) to protest the acts of the Sene (Sen 2009). Kicked off on February $5^{\text {th }} 2009$, the campaign has become an iconic example of how a grassroots initiative coalesced into a successful mainstream collaboration through social media tools. Using Facebook and blogs, the group urged women to send in new or old pink underwear to Muthalik in order to shame him and the Sene. The group decided to use "chaddi" as the movement emblem because the khaki-shorts-wearing Hindu right wing cadres are often derisively called “chaddi wallahs” (underwear people) (Interview with Nisha Susan, Tehelka in New Delhi, one of the organizers of the Campaign).

As rhetoric from both groups filled the airwaves, the underlying angst stemmed from the question, "What is appropriate behavior for the ideal Indian woman of modern India?” My research project considers the implications of this loaded yet common question by examining how Hindu urban middle class media (HUMM) women experience and are impacted by the clash between two seemingly oppositional ideologies of conservative religious nationalism, specifically, Hindutva, and globalization. I examine the encounter of religious nationalism- which rests largely on the body of the middle class Indian woman - with neoliberal globalization, focusing on the geographic region of the national capital of India, New Delhi. I argue that these urban encounters, which are manifested in the lives of the HUMM women through particular anxieties and processes, lead to a continual reconfiguration of gender hierarchies within the globalizing modern Indian nation-state.

The Pink Chaddi clash between young, literate and technologically savvy India and traditional Bharat (the mythological name of India) perfectly exemplifies the 
juxtaposition of Indian culture, Indian womanhood and Indian citizenship within the teeming paradox of globalization and nationalism that is the central thrust, of this dissertation.

\section{A Short Story: Hindutva and Globalization}

The idea of Hindustan (The land of the Hindus) can be traced back to early eighteenth century texts of influential socio-religious reformers and nationalist leaders. But the popular term, Hindutva, was coined by freedom fighter Veer Savarkar in a pamphlet titled "Hindutva: Who is a Hindu?" where he defined an Akhand Bharat (United India) as a Hindu Rashtra (Hindu nation), whose true citizens thought of India as the Holy land as well as the Fatherland (Savarkar 1923). Given that this claim automatically excluded Muslims and Christians, Hindutva politics was concocted out of a territorial and rhetorical construction that actively saw and continues to see the Indian nation in cultural terms as being an organic and homogenous Hindu whole, which is threatened by the Occidental and Muslim Other. The core notion of the Hindu nation became strongly predicated on the purifying of the female body of the nation by removing the impure bodies/thoughts of the Outsiders (the West and Muslims). The responsibility of such removal rested on the disciplined bodies of the Hindu males, who would then, by extrapolation, protect the integrity of Bharat Mata (Mother India) (Corbridge and Harriss 2000). The Hindutva movement ${ }^{1}$, under the aegis of the Sangh

1. The foundation of present day Hindu nationalism was laid in the late 19th century, which saw a revival of Hinduism with the emergence of groups such as the reformist Arya Samaj and the Hindu Mahasabha. Even as there was a socially reformist posture on issues such as child marriage, caste, widow remarriage, there was a blatant assertion of Hindu superiority over other religious faiths. The ideological father of modern Hindu nationalism, Veer Savarkar raised the rallying cry that Indians should 'Hinduise all politics and militarise all Hindudom'. Savarkar codified the tenets of Hindutva, which was used as the basis for the formation of the Rashtriya Seva Sangh in 1925. The RSS is the founding organization of the present day 
Parivar (the Family of Associations), which is the main extoller of the Hindu polity/ideology and the umbrella organization of the Rashtriya Seva Sangh (the RSS: National Service Group), the Vishwa Hindu Parishad (the VHP: World Hindu Convention), the Shiv Sena (the militant Army of Lord Shiva, a political party in Maharashtra) and the Bharatiya Janata Party (the BJP: the national political Indian Citizen's Party) among other regional affiliates, remained largely marginalized through most of the twentieth century. Its emergence as a main player within Indian national consciousness began in the 1980s and led to the capture of the national elections in 1998 by a coalition led by the BJP (Swamy 2003).

As scholars like Castells (2004) explain, the rise of religious and ethnic fundamentalisms as well as identity politics can be linked to the prodigious entry of globalization. This rise is seen as resistance against a set of global processes that are perceived as endangering local-regional cultural identities and in turn, engendering economic and cultural insecurities. The rise of Hindutva therefore must be contextualized against the fall of the Indian developmental state and the simultaneous adoption of neoliberal economic policy in the early 1990s in the form of the IMF-World Bank structural adjustment plans. But globalization needs to be conceptualized as more than “....an inevitable leap into friction-free flows of commodities, capital, corporations, communication, and consumers all over the world...Eroding away fixed in-state places into fluid un-stated places now preoccupies the neo-liberal managers of globalizing enterprises” (Luke and Tuathail 1998:76). Various scholars have critically examined new

political Hindutva party, the Bharatiya Janata Party (BJP). Their strategy to attain a Hindu Rashtra (Hindu nation) professes political domination through cultural homogenization. 
structures and spaces of power; assertions about flexibility, borders, and fixities of globalization; shifting scales of governance; and the shifting terrains of geopolitics (Castells 2004; Giddens 2000; Luke and Tuathail 1998). For the purpose of this dissertation, I loosely recognize globalization as the global circulation of "commodities, people, capital, technologies, communications, images and knowledge” (Long 1996 in Channa 2004). In 1991, Indian Prime Minister Narasimha Rao, backed by Finance Minister Dr. Manmohan Singh, instituted a range of major economic reforms, supported by loans from the International Monetary Fund, the World Bank, and the Asian Development Bank (Atmavilas 2008). The Indian currency was devalued, tariffs reduced, and foreign investment restrictions lifted leading to a sustained growth in the economy. This economic rise resulted in the expansion of a consumer middle class with increasing number of households moving into higher income groups (Atmavilas 2008). As India tread on the path of global finance, branded goods and cable television, with an annual economy that currently boasts a steady growth rate of 5-6\% (Overdorf 2009), its sociocultural structure was and continues to undergo a rapid change, engendering anxieties as well as exuberance.

As India's billion plus population experiences globalization, its impact on the people is as varied as is the diversity of the nation. A majority of its 1.1 billion people continue to live in poverty; one-third of the population remains illiterate (Ali 2006 in Shenoy 2008) and yet its middle-class has quadrupled to almost 250 million (Das 2006 in Shenoy 2008) in the past two decades. And research shows that the Hindu Right's core support groups lies within the expanding middle and upper-middle classes, who are predominantly upper caste Hindus (Jaffrelot in Franckel, Francine et al. 2000). 
This group not only believes in the Hindutva ideology to a greater or lesser degree, but also embraces its clearly defined support for 'pure’ economic liberalization policies while opposing the evils of Western style socio-cultural changes (Jaffrelot in Franckel, Francine et al. 2000).

This rise of the Indian middle class within the strange symbiosis of globalization and Hindutva is a strong indicator of the paradoxes facing the Indian population. The parallel existence of upward mobility and stark poverty presents the real Indian landscape, beyond the multiplexes and multinationals. It evidences an India of dispossession and denial, of dysfunctional anarchy, and a land without justice (Shenoy 2008). Add to this picture of economic disparities, the social inequalities, especially gendered norms that emerge from the fogs of centuries past, and there emerges a picture of 'multi-chotomies' that define and influence the daily existence of all Indians.

Even as the tug-of-war impacts the lived realities of all individuals, I look specifically at the impact on the HUMM women, because they are constantly being presented as Indian ambassadors of globalization, the first run of beneficiaries of the processes of neo-liberal economic policies. Yet Shenoy finds that there is no solid basis for such claims since little is known about how globalization and the culture of aspirations have “affected women’s work lives across occupations, generations, and income levels” (Shenoy 2008:5).

While globalization opens certain doors for women, scholars like Pandey (2007) as well as Harriss and Corbridge (2000) find the body of the Indian woman continues to be naturally seen as the site for biological and cultural reproduction, which has to be shielded and protected from all outside eyes and influences. Honor of the woman is honor 
of the nation, which is particularly played out in the militaristic and highly masculinized concept of Hindutva. This militaristic form of Hindutva gives no agency to the woman, she is 'made' the nation but nationalism is the provenance of action, virility and violent masculinity (Harriss and Corbridge 2000). And her image rests in the articulation of a hegemonic middle class structure of defined culture (Sarkar and Sarkar 2008). The abstract figure of the ideal Indian woman is steeped in middle class morality to reflect piety and balance. All Indian women were expected to aspire to the position of middle class stature, where she could be an educated career woman but whose primary role remains that of a mother, wife and daughter (Sarkar and Sarkar 2008). Such construction leads me to Joan Scott, a feminist historian, who raised the question of who has the power to produce "social consensus about the meanings of truth" (Scott 1989:680). She asked, "By what process have men's actions [demands and expectations] come to be considered a norm, representative of human history, generally, and women's actions overlooked, or consigned to a less important, particularized arena?” (Scott 1993:242).

As I venture into an arena that is a space of overlapping physical, religious, socioeconomic and sexual identities, the enormity of this diversity is overwhelming. Yet the demand to understand the production and reproduction of a homogenized Indian womanhood through reinforcing values, attitudes and ethics of the enormously complex Indian society and the gendered hierarchy within requires me to focus on one particular group of women: the media professionals of media corporations in New Delhi, India. Even as this 'stereotyping' goes against the very grain of my Third World feminist understanding, I present strong reasons for my choice as I attempt to walk in the different 
shoes of media professionals as they negotiate with stories, salaries and sarees in their daily lives of struggles and achievements.

\section{Methodology: The Why and How of Research}

"I remain an independent and strong woman as long as I confine myself to a predetermined space. Who determines that space? My father, my husband and my politicians.”

- Suman, Camerawoman, Aaj Tak.

This quote provides the perfect backdrop for the teeming tensions that mark the complicated symbiotic relationship between globalization and nationalism that simultaneously thrusts and throttles the lives of women in India. The study investigates the public, professional and domestics lives of HUMM women who reside in Delhi (National Capital Region) and work in corporate media, both print and electronic.

Keeping a historical context as a constant background, I examine the lives of the HUMM women to understand the impact of the clash between two seemingly oppositional ideologies: of religious paternalistic nationalism, specifically, Hindutva, and globalization.

The findings of this study contribute to the literature on specific Third World nationalism, urban globalization, understandings of reworked-renewed gender hierarchies within different contexts and feminism. The research findings will contribute to existing debates in feminism about the “category of woman” (Puri 2003; Puri 1999 and, Butler 1990). Finally, the study also answers several recent engagements (See Nanda 2010; Shenoy 2009; Lukose 2005; and Radhakrishnan 2006) while simultaneously addressing 
the notions of privilege and disengagement levied at the middle class woman, a symbiosis of idealization and imprisonment.

\subsection{Theorizing Indian Women’s Identity, Body and Space}

Given my focus on specific markers that shape identity, I train feminist methodological lenses on religious nationalism and globalization as they act on 'securing' the female body, its functions and 'appropriate' roles in a straitjacket of paternalistic desires/demands. I use feminist theory to examine the processes of identityesteem formation of these 'privileged women', who are seen as being path-breaking modern women, the newly enhanced face of India Inc. In the following section I look at how womanhood and nation are co-created and controlled.

- $\quad$ Mapping the Nation

Post colonial feminist scholars like Parameswaran (2001), Ahmed-Ghosh (2003) and Oza (2006) have used a theoretical framework of masculine domination while examining the identity of the Indian woman as the site of contestation and inscription for the definition of citizenship, morality and nationalism. Feminist theory asserts that women’s bodies and sexuality became the “material and discursive sites where nation was performed, values were contested, and borders and boundaries were policed and controlled” (Oza 2006).

Feminist theory also tackles the issue of putative categorization of women into homogenous groups of actors that react, adopt and adapt to policies, identities and structures in a uniform manner. As globalization and nationalism clash, it is essentially referred to as a battle between tradition and modernity usually sited in a woman's body and it’s disciplining, where ideological notions are asserted and contested (Puri 1999). 
Feminists routinely borrow from Foucault's understanding of normalizing and discipline to understand how hegemonic codes within the post colonial state mark, regulate and constrain the woman's body, how social control is imposed through notions of normalcy and naturalness through codes of motherhood and wifehood ${ }^{2}$ (Foucault 1980). For instance, Sawicki (1988) has used Foucault’s understanding of power “...as exercised rather than possessed, as circulating throughout the social body rather than emanating from the top down, and as productive rather than repressive” (Sawicki 1988: 164). Similarly, Fraser notes that Foucault’s work gives renewed impetus to what is often referred to as 'the politics of everyday life' providing "the empirical and conceptual basis for treating phenomena such as sexuality, the school, psychiatry, medicine and social science as political phenomena” (Fraser 1989: 26). Following Foucault, Butler argues that the notion of a "...natural' sex formed before culture and socialization is implicated in the production and maintenance of gendered power relations because it naturalizes the regulatory idea of a supposedly natural heterosexuality and, thus, reinforces the reproductive constraints on sexuality” (Butler 1990:7).

Another important theoretical position of postcolonial scholarship that is central to my research is the concept of homogenization acts and processes that use socially constructed essentialized markers or qualities (skin color, class, caste etc.) to erase differences and create a uniform consistency, an un-nuanced group. Third World feminists have accused the feminist scholars of the West of essentializing the women of the South into a monolithic mass who are defined by their oppression (Mohanty 1988). A

2. Motherhood is seen as being the essence of womanhood and the body of a mother the site of reproduction, not only of future citizens but also for replication of nationalism. Marriage is the control mechanism through which the sexuality of the woman becomes respectable and her virtue safe, and hence the safety of the nation lies in the safeguarding of the women's bodies. 
liberal episteme calls for global sisterhood, an inclusive feminism premised on the centerperiphery model, with the Third World women, en masse, being the periphery in need of rescuing, leading to the replication-reiteration of the same power hierarchy that such epistemology is challenging (Jeffrey and Basu 1998). This is important for my scholarship since I seek to challenge the same homogenizing processes of globalization and religious nationalism that rest on essentializing women.

Previous scholarship has discussed the intertwined politics of identity, nation and masculine domination (See McClintock et al. 1997, Sangari 1998, Mohanty 1998, Parker et al. 1992 and Donaldson 1992). Their works provide guiding insights that I use to examine the notions of homogenized idealized Indian womanhood(s) manifest within the cultural discourse/rhetoric of the Hindutva brand of nationalism and in recent years, the consumer driven ideology of neoliberal cheerleaders. According to McClintock, “...theories of nationalism have tended to ignore gender as a category constitutive of nationalism itself... and yet nationalisms emerge through social contests that are ... always gendered.” (Schmidt 2005: 63). She proposes a feminist theory of nationalism that brings historical visibility to women's active cultural-political participation in national building (Schmidt 2005). Another important insight comes from the work of Parker et al. (1992) who suggest that integrating class, race and sexuality into the theory of nation building allows thicker understanding of the ideological apparatus that champions cultural revivalism and sexual/gendered affirmation or homogenized citizen-consumers.

According to Mohanty (1988) religious nationalism constructs women as entities to be worshipped from far, gazed upon by the sons of the soil. The woman, as nurturer, repository of Indian values, steeped in values of sacrifice, chastity and docility has to be 
disciplined into asexuality. Veer Savarkar, the founding father of the Hindu movement warned that woman as sexual are dangerous and impure, incapable of independent thought or action, they are emotional beings who need constant policing, in his myriad writings (Savarkar 1922). Along such 'wisdom’, Alexander and Mohanty (1992) find that the complexities of class, gender, ethnic and national identities of political female citizens prevent any simplified version of a mythical women's unified position. And yet certain women such as prostitutes, divorcees and lesbians are now being disciplined and written out of the nation's script; they have been invested with the power to corrupt otherwise loyal heterosexual citizens. Such women are positioned as being hostile to the procreative imperative of nation building (that rests within the body of the disciplined and ideal middle class woman), and, therefore invested with the ability and desire to destroy/corrupt her. Along such thinking lies the notion of 'correcting' all deviant women, whether middle class or otherwise, who confront and challenge set patterns of acceptable Bharatiya (traditional Indian) behavior.

In brief, feminist theory links women's bodies and sexualities to nationalism in two ways: centrality of women of various class, religions and races in the articulation of nationalism; and the emergence of nationalism in gendered, sexualized and racialized forms (Puri 1999). It is important to understand that the otherwise diverse Indian cultural system becomes a homogenous India when it comes to the disciplining of women, shaped by centuries-old gendered family structure. Yet these supposedly immutable structures of Indian-ness are being significantly eroded, specifically in the urban middle class strata by globalizing transnational cultural flows causing great anxiety and confusion within powerbrokers like the Hindutva brigade. 
Another important theoretical aspect that influences my research is borrowed from feminist geographers who have theorized about spatialization and its division into sexed and gendered societal constructs and realities (Massey 1994). It is important to remember that patriarchal society has deemed that women experience and negotiate space and spatial mobility differently. Following Foucaldian thinking that the control of mobility is central to discipline, Young (1990) finds that existing social structures and institutions create embodied female identity, which in turn limits spatial mobility. Hence feminine existence lives space as enclosed or confining. According to Massey (1994) and Grosz (2001), space and place are not just the outcome of societal practices; spatial organization informs these social practices such as job access, racialized suburbia etc. This knowledge of sexed spaces is important while choosing methods for research. This awareness is especially important in my research because Indian women while experiencing space as explained above also find the home, which in Western understanding is largely seen as the realm of the woman, as being the space of her incarceration (Rajan 1993) ${ }^{3}$.

\section{- Locating Globalization}

Given that this will be a study of the contrasting processes of globalization and nationalism acting on the body of the Indian woman, it is important to set a theoretical framework for understanding globalization. Applying Marxist philosopher Antonio Gramsci's understanding of cultural hegemony (the systems and values that reinforce the position of the powerful using discursive methods, education and the media to persuade

3. It is inherently important to note that even though the Western imagery as seen in popular media and popular understanding equates the domestic space with women's control, in reality this is a paradoxical zone, wherein it can be safe, or violent specific to time and circumstances. 
the masses to unquestioningly adapt certain values as common sense) to globalization, my research is aimed at examining and exposing this 'common sense' of globalization. Hegemony, a pivotal concept in Gramsci’s Prison Notebooks is the means of controlling society not just through violence and coercion but also through ideology, a hegemonic culture in which the values of the powerful become the commonsense values of all. Hegemony involves persuasion of the greater part of the population, particularly through the media, and the organization of social institutions to adhere to a social system in ways that appear natural, everyday occurrences (Connell and Messerschmidt 2005). The theory of hegemonic masculinity borrows from Gramsci’s notion of a culturally normative dominant form of malehood that subordinates other masculinities and femininities. It is important to be aware of hegemony since the structure of present day globalization negotiates and perpetuates the domination of a certain male class, the hegemonic masculinities (Connell and Messerschmidt 2005) that shape and define globalization. My interest in the impact of the global on the local identities of Indian women led me to Burawoy's (2000) attempt to ground the abstractions of globalization theory in the realities of local processes by applying historical and geographic context with a view to restructure existing theory. Burawoy focuses on reflexivity and the use of discretion and sensitivity as researchers deconstruct structures of power and gender domination (Burawoy 2000). Burawoy places the researcher on the same plane as the researched, explaining that self-reflexivity is an essential outcome of emancipatory research. I understand from Burawoy's work that treating women's lives as a scientific resource requires me, the researcher to remain constantly aware of the context, surroundings and history that are shaping the researched while being aware that my own subjective 
experience impacts the project researched.

Burawoy’s (2000) work exemplifies the need to confront the processes of power that dominate, silence, objectivize and normalize so as to understand and theorize about globalization, indeed to fill the lacunae in knowledge production that connects the local and the global. According to him, lack of such research will result in the wide acceptance that hegemonic global forces and processes are natural and hence immutable (to the detriment of the objectified and recessive subjects). Indeed as Margaret Thatcher famously said of neoliberalism, “There is no alternative”. (George 2004).

This idiosyncratic juxtaposition of globalization and nationalization while contrasting in their messages, ultimately seek processes of homogenization, of 'oneness' with no space for conflict or differences or presence of minorities. Just as Hindu nationalists linking space and ideology demand that indigenous ideas of female sexuality were never expressed, that all discourse on sexuality is foreign and outside the parameters of Indian culture, globalization enthusiasts encourage a homogeneity that encourages a carefully marked sexuality, a standardized Indian womanhood that is legitimated and disciplined by Western norms and standards. Having successfully performed Western disciplinary practices of feminism, Indian women and hence the nation, now have currency and are 'circulated' in global markets.

While both ideologies enthusiastically co-opt progressive ideas of equal status for women in Indian politics, economics or religion, ultimately the female body and female sexuality is still defined by historically immutable frameworks of subjugated femininity (See Oza 2006 and Parameswaran 2001). So the “ideal” Indian modernity for Indian women is distinct from "Westernization". Indian women become the barometer for 
Indian culture, used to define modernity by following "respectable public professions like medicine or the civil services, or engineering" but are prohibited from "Western practices" such as smoking and drinking. At the same time, globalization in its own flattening of difference pushes images that are ahistoric and acontextual so as to engender global patterns of consumption (Datta 2000).

\section{- $\underline{\text { Securing Insecure Identities }}$}

Focusing on the issue of security within the paradigmatic clash between globalization and religious nationalism, I examine the theoretical constructs of the notions of security. Traditional definitions of security have been questioned by feminist scholars as they argue that the realist position of domestic-international divide puts the political actors and citizens, largely Western men, in the arena of policy making and research while relegating women to the domestic space, outside politics (Grant 1991). This exclusion of women is largely attributed to essentialized gender roles that construct women to be the 'natural' keepers of hearth and home (though not finances) and bearersnurturers of children-future citizens (Yuval-Davis 1997).

Scholars like D’ Cruz (2005), Rao (2005) and Peterson (1992) argue against the public-private divide, wherein unregulated violence makes women "the objects of masculinist social control not only through direct violence but also through ideological constructs, such as ‘women’s work' and the cult of motherhood, that justify structural violence—inadequate health care, sexual harassment, and sex-segregated wages, rights and resources” (Peterson 1992:46). When women break the norms that are regularly used to define them, within their private as well as public domains, they are confronted by physical, emotional and psychological violence that aim to rein in the pace of their 
progress and keep them restricted to acceptable paths of movement, both physical and cultural.

In summary, women's security becomes dependent on how closely they toe the societal line. While security within the private is provided or withheld by the family, public safety is determined by general perceptions of piety/purity or lack thereof.

\subsection{Research Design and Methods}

Before elucidating on the 'in the trenches' section of my research, I am proud to have experienced and learnt from "feminist dilemmas in fieldwork" (Wolf 1996). As I grappled with power relations, preconceived notions and conscious attempts to be nonjudgmental, non-expressive and sometimes, poker-faced, I realized how all my scholarship: the reading, writing and listening are a product of my experiences. Words like epistemology and ontology took on more than just academic significance.

As I embarked on my research, I walked with the works of postcolonial scholars, including Mohanty (1988) and Chakravorty-Spivak (1985) among others who are reflective of how the personal background of the researcher matters and the politics of location matters. I now understand, first hand, the need for self-reflexivity, the need to recognize and guard against biases and assumptions. As feminist research treats women's lives as a scientific resource (Harding 1987), the reciprocal sharing of knowing between researcher and researched results in a project of collaboration.

Our life experiences shape our identity; therefore have political and theoretical implications with which we must engage. Hence following Mohanty's example, I would like to place experience, life stories at the heart of my scholarship and activism. My identity as a secular, educated woman in India is now marked with being a woman 
researcher of color in the United States, which constantly informs my scholarship and political inclinations.

Having briefly explained my theoretical framework, it is inherently important to explain my choice of postcolonial feminist methodology. Such methodology is ultimately a complete rejection of a positivist stance that places 'fact' over 'value'. The positivist stand prefers 'rationality’ and cultivates 'objectivity', which silences women by denying their presence and the presence of patriarchy (Monk and Hanson 1982). Post-colonial feminist methodology embraces the reality of women as 'products' of diverse experiences by committing to anti-essentialism of 'women' and 'cultures'. My research seeks to distinguish and extricate feminist projects that recognize differences among women as opposed to problematic essentialist colonial and postcolonial understandings of 'cultural difference’ between Western culture and its 'Others’ (Narayan 2000:80-100). In choosing a feminist methodology, my objective is to create new thresholds of enquiry (Jones et al. 1997) which are effectively attempting to destabilize the category of 'woman' while rejecting two claims of positivism: first, the claim to objectivity and second, the claim that a researcher can distance 'himself' from the research process and those researched. These notions are contradictory to the very foundation of feminist methodology that acknowledges the importance of experience, the legitimacy of subjectivity hence rejecting the levels-of-analysis approach used by realist thinkers (Blanchard 2003). For these reasons, I am drawn to scholars such as Jones III and Nast (1997) who make researchers aware of the partiality in knowledge production, of power relations that define 'facts'. This self-awareness is the concrete that holds together the building blocks of feminist methodology: openness to a diverse range of methods, the 
importance of situated knowledge and an emancipatory goal for research outcomes ${ }^{4}$ (Jones et al. 1997).

Even as theoretical stances and methodology are co-constituted, my biggest defense for choosing a feminist position is encapsulated in the pages of Thresholds in Feminist Geography: Difference, Methodology and Representation (Jones et al. 1997). Feminist methodology acknowledges that the world and theory are not exclusive and that this social world is gendered/sexed. Besides this, feminist methodology is flexible and allows a non-hierarchical method to break down power relations between researchers and researched hence empowering the subject. Therefore, knowledge gained is the product of the researcher and the researched.

- The Tools

As I negotiate my way through the halls, streets and minds of the HUMM women, I repeatedly borrow from the toolbox of feminist research. Using methods of enquiry that have been tried and tested, I also attempt to understand my basis for borrowing established research tools and thought processes.

Because personal experiences are central to my research, I realize that oral narratives as well as historical geographies are powerful methods in the feminist toolbox. The analysis of these narratives is an effective way of examining multiple juxtaposed social identities, their connectedness to social spaces and institutions (Nagar 2000) and deconstructing 'established' knowledge bases (Domosh 2005). Inserting oneself within existing patriarchal structures to question them is a powerful form of resistance to

4. Even as it is difficult to insert quantitative methods in feminist methodology, counting, classification, descriptive statistics and advanced methods of data analysis are too powerful to leave solely in the hands of the non-feminist. 
dominant ways of acquiring and codifying knowledge, of contesting essentializing categories of gender and race. Questions about identity or the identity approach are necessary to understand social action in the face of existing power structures (Somers 1999). Towards collecting such materials, I have used open-ended semi-structured interviews that ran from one hour to three hours. Interviewees were contacted using personal references via telephone and email. The interviews were conducted in my residence in New Delhi or within a space of their own choosing. In India, this choice is of utmost importance, since the home is not always a "safe space". The interviews were taped and if required, translated by the researcher.

I also use government data as well as data collected from Indian women's organizations to examine crimes against women statistics (rape, dowry deaths, domestic violence) and employment related statistics (number of women within organizations, number of women occupying senior positions, sexual harassment data) to observe trends or patterns, starting from 1991 (the year the structural adjustment plans were initiated in India) to the present.

I examined contemporary television program and print material to illuminate current patterns of understanding and expectations on gender and specifically, women's roles in society: both in domestic as well as professional spaces.

The next section gives extensive details about the women I interviewed, the participants who were the cynosure of my dissertation.

- The Group

In choosing my research project, I am strongly aware that one of the biggest challenges of researching Indian identity is the very diversity that defines the country. 
Therefore, the question of who to interview and why is of utmost importance. Borrowing from Inkson, Khapova, and Parker (2007), who argue that studying individual careers is flawed unless they are also understood from a wider perspective, I examine the HUMM women, not so much as a homogenized group (which they are not) but as a group that is socially constructed as homogenous, as part of a much larger nationalism and globalization agenda. As a feminist, I attempt to embed my analysis in an ontology where individuals are part of and are changed by social relations as opposed to state-centered 'traditionalists' who see actors as singular, independent and rational actors (Locher and Prügl 2001).

Middle class Hindu woman have been the site of ideal Indian womanhood (Sangari and Vaid 1989) encapsulating morality, boundaries and tradition. They have been historically constructed as guardians of (Hindu) tradition, transmitters of culture, and the reproducers of community who therefore needs to be pure, their bodies protected from the foreign (Ahmed-Ghosh 2003). It is upon this 'class', this constructed identity that most social phenomenon, whether nationalism or globalization, are enacted. It is this 'class' that the majority underclass of India's billion plus population aspires to reach. As the HUMM women see the maximum impact of globalization in terms of their socioeconomic identity, they are concurrently being buffeted by local sensibilities and guilt at losing their "Indian” identity (Pinches 1999. Also see Shenoy 1995).

Therefore I group them, not to homogenize their lived experiences but on the facts of demographics: religion, class, occupation and location. I am studying the lives, achievements, struggles and ultimately, social processes of the Hindu, middle class urban woman residing in Delhi, the national capital of India and working in corporate media 
houses that beam their messages into the living rooms and bedrooms and bathrooms of 134 million television owning households in the beginning of 2010, of which 103 million have cable (Sinha 2010).

Having lived in Delhi for twenty years, I am marked by and aware of, consciously and unconsciously, the strong tenets of politics and intense patriarchal codes that are almost unquestioningly associated with the city. It is after all considered the federal, political capital of India much like Mumbai is considered the financial capital of the country and Kolkata, the cultural capital. My reasons for choosing Delhi are multi-fold: one is my intimate knowledge of the city, familiarity with the local cultural nuances/body language; secondly, I am conversant in Hindi (the primary language in New Delhi) and English (the primary language of the HUMM women); and finally, Delhi is a city of migrants and reflects the diversity that is India's identity.

The interviewees were selected on inclusion criteria of being female, and belonging to a specific age bracket, religion, socio-economic bracket as well as urban location. The interviewees are urban Hindu women between the ages of 18 and 60, residing in middle and upper socio-economic conditions in New Delhi. They are employed in transnational corporate organizations, a space that makes them a part of the global economy. This will allow me to examine how such women adapt and "mutate" in their roles within their global professional arena and Indian household. Exclusion of certain religions, classes etc is premised on the inordinate complexities of the Indian population that makes research difficult since each group experiences the impact of these ideologies differently.

Academic institutions (colleges) previously attended by researcher as well as 
professional organizations, which previously employed the researcher were used as sources for potential interviewees. I explained to the interviewees that this is an academic research project that seeks to understand the impact of globalization and Hindu nationalism on their lives, identities and choices. They were told that the interviews would be taped, with their consent and their identities to be kept anonymous, if required. The sites for the interview were determined by the subjects and included private residences, offices as well as public spaces such as restaurants or parks. I used the following criteria while identifying an interview space: participant comfort, privacy and easy access.

\section{- The Structure}

My research method is triangular in its approach, using three methods, what I term, "a gaze triad". The first corner of this triad generated data collected in open-ended, semi-structured interviews that provided insights into HUMM women's perception(s) of their bodies as they experience disciplining and restrictions, which is "the gaze of the researched". The data collected from national archives, government bodies, Indian feminist research organizations and local literature have been used as indicators of how the state, the economy and the nation collaborate or compete as gendered powerbrokers, that is, "the gaze of authority". The third corner of this method triangle is the gaze of the researcher, as I extract patterns and trends from media materials and participant observation.

The data collected from the various sources will contribute towards understanding how women perceive their own bodies and their disciplining/restrictions/advantages, which ultimately shape their sense of self. I analyzed the interviews and other secondary 
sources (with a hopefully self aware and reflexive eye) to understand how the sexedfemale HUMM women's bodies are the pawns of the "new and improved" forms of various patriarchies.

\section{- The Stages}

As is required in most forms of research, my work was divided into planned stages. I began with data gathering in New Delhi, India (May-August 2008 and September-December 2009). Using personal as well as professional contacts (university affiliations, newspaper organizations etc), I scheduled semi structured; open-ended interviews with the HUMM women. The women were interviewed in locations of their own choice. Each interview lasted between one hour and three hours. Some of the interview locations allowed me participant observation of women's groups in media houses' cafeteria, newsrooms of television networks as well as office spaces of TV and print media houses.

During my stay, I also procured archival data from government archives/census bureau as well as statistics collected by New Delhi based women's group Jagori, the National Commission for Women and the Rashtriya Seva Sangh. I collected statistics related to crimes against women, numbers that are indicators of women's position within the corporate world as well as an overview of laws that 'protect' women. The archival work was done in the libraries of Jagori, Jawaharlal University and newspaper archives of The Times of India, Hindustan Times and Business Standard. I collected 'gray' papers, literature from the nationalist organizations as well as papers from Indian scholars who have not been published in the West. I also collected press releases about television shows (the equivalent of the ubiquitous soap opera) as well as copies of Indian (not 
imported and Indianized) magazines, Femina and Women's Era as well as the Indian Cosmopolitan, Elle and Good Housekeeping.

The second stage consisted of ongoing data collection and Analysis in Miami, United States. As I transcribed my interviews, I maintained correspondence with my interviewees via email and telephone calls to get further clarification on arising questions and socio-political events in India. I also continued archival data gathering via online resources such as newspaper archives (recent editions are available), academic Websites (Jawaharlal Nehru University) etc.

The recent availability of Indian channels via satellite television allowed me to watch and analyze episodes of Indian soap operas Balika Vadhu and Na Aana Is Desh Laado. Both are centered on female characters and it is my hypothesis that the structuring of these characters and the narratives are strong indicators of how women, their bodies, their identities and their space/place are being marked by insidious nationalistic and commercial forces.

The final stage consisted of continuing synthesis through analysis and the writing of the dissertation. I analyzed the text of the interviews to understand trends and identity markers such as notions about being Indian, being a woman/mother/wife etc. I juxtaposed the different gazes to understand the processes and motivations that demand the delineation of specific stereotypes as generated by the media.

Having collected data from different sources/sites, I engaged in a critical feminist discourse analysis of the material to engender patterns of consumption/rejection of globalization and Hindutva. Given that feminist discourse analysis is an approach that 
focuses on relationships between language, ideology, society and gender, I have used nuanced analyses to understand the workings of power and ideology structures that use Foucaldian discursive formation employing signs, language, multimedia among others to maintain hierarchically gendered social orders.

In feminist discourse analysis, gender is understood as a fluid and multiple variable, which is constantly being constructed into a range of femininities and masculinities, individually and socially. These identities are partly shaped by discourse and "interacts with other aspects of identity - such as ethnicity, age, class, sexual identity - and with power relations, thus gender is not discursively enacted in the same way for women and men everywhere.” (Lehtonen 2007:5). According to Lehtonen (2007), feminist critical discourse analysis focuses on empirical studies and the ways in which gender is actually constructed in authentic texts and situations against specific contexts.

As the Indian populace struggles with rapid changes within their lives, discourse analysis becomes very pertinent as it recognizes that operations of gender ideology and institutionalized power asymmetries are being sustained using particular ideas of gender appropriateness, safety, boundaries and identity. Therefore, focusing on this study of two ideologies, I used critical analysis to see how gendered identities are constructed in various texts and situations.

Further, I used the archival data to create a historical context to ground these patterns and discourses. The interviews, oral narratives and historical geographies were extensively sieved for content such as repetitive use of certain themes, which result in dis-empowering generalities/stereotyping of Indian women into groups such as "adarsh Bharatiya nari" (ideal Indian woman), "independent global citizen-consumer" etc. 


\section{Related Texts: Connecting with Scholars}

Nanda’s (2010) How Globalization is Making India More Hindu examines the impact of globalization on the religiosity of India. She finds a newly resurgent religiosity within the burgeoning and largely Hindu middle-classes, as is evident from a boom in pilgrimage and the invention of new, more ostentatious rituals ${ }^{5}$. According to her, the emerging state-temple-corporate complex, replacing the more secular public institutions of the Nehruvian era, is cultivating this Hindu religiosity. And this new religiosity, a virulent form of socio-political Hinduism is getting more deeply embedded in everyday life, both in the private and public spheres (Nanda 2010).

There is also a strong homogenization of the diverse rituals and practices within Hinduism resulting in unified images of 'national' hyper masculine Gods, a process called Rama-fication of Hinduism (Ram being the maryadapurushottam, the ideal man). This process of creating a centralized nationalist ideology that defines India's national pride and citizenship in uniform, monolithic language is being used in the game of “civilizational one-upsmanship” (Nanda 2010: 3). An outstanding example of this embracing can be seen in the group that is seen as the face of new India, the technologically savvy software professionals. According to Nanda, this group of globalization 'winners' seem particularly open to the ideas of Hindu nationalism such that the RSS organizes regular IT-Milans (information technology meet-ups), where right

\footnotetext{
5. According to Nanda (2010), in 2009 India had 2.5 million places of worship, but only 1.5 million schools and barely 75,000 hospitals. Religious pilgrimages now account for over 50 per cent of all package tours, while the bigger pilgrimage sites now vie with the Taj Mahal for the most visited sites: the Balaji Temple in Tirupati had 23 million visitors last year, while 17.25 million trekked to the mountain shrine of Vaishno Devi.
} 
wing technical professionals can "meet like-minded people and get a sense of participating in something bigger than just punching keyboards all day” (Nanda 2010:45).

Focusing on the Hinduism of ordinary Indians, especially those belonging to the new middle classes whose lifestyles, consumer tastes and aspirations are defined by the global consumer culture, Nanda (2010) finds that the hyper deification of Hindu Gods, rituals and sacred texts is resulting in a quiet albeit strong mobilization of religious majoritarianism. According to Nanda, "As the national history, culture and destiny of India gets to be told and ritually enacted — over and over again, everyday — through the medium of Hindu Gods, the line between the worship of God and the worship of the nation is getting fainter by the day. India is not only witnessing a resurgence of popular religiosity, this religiosity is becoming indistinct from national and even civilizational self-glorification” (Nanda 2010: 8).

Nanda (2010) argues that Hindu nationalism does not exist in the realm of ideas alone, but is embedded in the dominant political-economic institutions of India Inc. and is being aided by domestic neo-liberal policies and international corporate capital. She claims that as the state withdraws from various institutions under the newly adopted market reforms, the new public-private partnerships, which she calls the state-templecorporate complex, is taking over through the collaboration of the elected representatives of the people along with the machinery of the government; the corporate sector; the country's dominant religious sector, made up of a loose network of Hindu temples, their management committees with powerful government and business connections; and last but not the least, the representatives of political Hinduism, or Hindutva, who maintain 
fraternal relations with the Hindu establishment on the one hand and with the corporate players on the other (Nanda 2010).

As this collaboration brings in a socially conservative Hindu agenda into varied arenas, from private and government-aided institutions of higher learning to using public money for promoting pilgrimage to Hindu temples and other holy places, renovating and even directly subsidizing the building of new temples, ashrams and priest-training schools, the spillover is seen in the daily lives of Indian citizens ${ }^{6}$.

While the right-wing agenda creates homogenized, overlapping structures of nation and religion, urban Indians are also embracing their success in the global economy. According to Nanda (2010), the power players of the state-temple-corporate complex, along with influential opinion-makers in the media, are dispersing a new selfimage of Hinduized Indians, steeped in ancient civilization and spirituality and therefore, with a natural advantage of being intellectual and socio-econo-political leaders in today's globalizing world. In my conversations with the media women, there was repeated use of phrases such as “This is India’s time”, “This is called India’s century” and "No one can stop us now". This is indicative, as Nanda finds of the embracing of this idea by the public and leadership of the country. Even as Nanda's scholarship examines the juxtaposition of Hindu superiority against Semitic monotheistic civilizations and the prospects of secularism under the conditions of globalization, she finds that "new

6. According to Nanda (2010), with the withdrawal of the Indian state from its public sector obligations, the task of running schools, universities, hospitals, tourist facilities and other social services are being directed to the private sector and the Hindu establishment. As a result, public funds earmarked for creating public goods are being diverted into facilitating the work of these private charitable institutions, which bear a distinctly Hindu traditionalist bias. This, in turn, is helping to "modernize" Hinduism: many of the newly minted, English-speaking and computer-savvy priests, astrologers, vastu shastris and yoga teachers who service the middle-classes' insatiable appetite for religious ritual, are products of this nexus between the state, the corporate sector and the temples (Nanda 2010). 
technologies and institutional arrangements provide new opportunities for traditional religions to modernize themselves and penetrate deeper into the pores of the society” (Nanda 2010:33).

In "Examining the "'Global”' Indian Middle Class: Gender and Culture in the Silicon Valley/Bangalore Circuit”, Radhakrishnan (2008) focuses on the transnational class of information technology professionals, "who are actively engaged in constructing a notion of a new India that is global in scope, yet Indian in essence” (Radhakrishnan 2008:7). Examining the software hubs of Silicon Valley and Bangalore, India, she finds gendered discourses of belonging that emphasize "Indian family values” that are played out through the body of professional women, who are stringently required to balance an “Indian”' home life and a "global” professional life. She engages with the "symbolic and material ways in which an upwardly mobile diaspora interact with their professional counterparts in a globalizing India to construct an ideology of global Indianness” (Radhakrishnan 2008:8). This diasporic study examines how the machines of globalization intersect with 'tradition' to shape the proudly heralded new Indian woman, the symbol of "a nation rooted in an exotic, classical culture, that is still able to integrate seamlessly into a technology driven global political economy” (Radhakrishnan 2008:8).

Her research shows that the imagery of India Inc. rests on a foundation of fundamentally gendered presumptions that demands the continuation of the Hindu family structure from professional Indian women, both in India and the diaspora. She finds that within the upwardly mobile class of Indians, the concept of Indianness and Westernness are no longer oppositional with "a sense of “Indianness" set[ting] the moral and personal boundaries for the material successes available to the West” (Radhakrishnan 2008:9). The 
strong sense of Indian identity stems from a Hindu nationalist movement, which received significant financial and symbolic support from the diaspora ${ }^{7}$. In the project of recognition of India as a superpower, there is a strong push for the establishment of a pan-Indian identity that rests simultaneously on “... an exclusive cultural identification, a constructed set of “core values”, and a consumer-oriented lifestyle” (Radhakrishnan 2008:10). According to Radhakrishnan (2008), the expanding middle class of India embraces this peculiar juxtaposition of values, where the preoccupation with an "authentic”' culture makes affluent Indian Americans both liberal in the acquisition of consumer goods and conservative in matters of religion and family (Lal 2003; Mathew and Prashad 2000 in Radhakrishnan 2008:10).

India’s global face is recognized through mediated images of educated well paid IT professionals and 'east meets west' beauty queens with a suggestion that technology revolution is accompanied by a gender revolution. But Radhakrishnan's (2008) research reiterates that a gendered vision of “global Indianness” continues to circulate, indeed strengthen through IT professionals between Silicon Valley and Bangalore. Using "finding a balance” as a tool of operation, expressed through the language of sacrifice and progress, she demonstrates how women working in IT uphold and embody the cultural ideals of Indian family life, whether in India or as part of the diaspora.

7. Hindu nationalism must be understood as a sophisticated movement that has engaged with globalization in a sophisticated manner. The BJP government that came to power in 1998 actively promoted the information technology sector by providing strong incentives for foreign investment. For these reasons, the BJP has historically drawn from the strong support of the Indian middle classes. Hindu nationalism was also "global" in its success in mobilizing the Diaspora. Arvind Rajagopal and Peter van der Veer have separately noted the extent to which transnational Hindu organizations, such as the Vishwa Hindu Parishad (VHP), were funded in large part through the support of Indians living abroad, which in turn fuelled the rise of the BJP and a right-wing Hindutva agenda in India (In Radhakrishnan 2008). 
Yet, irrespective of location, Radhakrishnan (2008) finds that the interviewed women strongly believed, marked by gender, class and patriarchal familial expectations that "a decision to place their career before their family would be one that would violate a set of “'Indian”' values, and the benefits derived from working would become less desirable” (Radhakrishnan 2008:14). Much like the media women, the IT professionals find that the career of the woman, more so if she is a mother, is something that supplements a family life, but cannot overtake it. Like Radhakrishnan (2008), I found that implicit in this structure, "is the presumption of affluence, where a husband's income provides the basis for the well-bring of the family, and the wife, as the protector of the middle-class domestic realm, must continue to protect the sanctity of that space, echoing the gendered division of labour in the rhetoric of Indian nationalism during the colonial period” (Radhakrishnan 2008:15).

While previously existing ideals of domesticity and nationhood have fused with contemporary notions of a global Indian nation, professional IT women feel their educational credentials and professional achievements to be indicative of India's progress (Radhakrishnan 2008). While IT women are seen as symbols of respectable globalization, similar benefits are not necessarily extended to women in other global industries such as call center workers or media women. Within the urban middle class imagination, these women are seen as being "less educated, less family-oriented, and thus, unable to uphold the ideals of Indian middle-class womanhood” (Radhakrishnan 2008:16).

Therefore even as IT women are seen as the harbingers of women's emancipation and progress, Radhakrishnan's research shows the continuation of sophisticated ways in which "conventional values of womanhood and the Indian family underpin the decisions 
of professional women in the new global economy” (Radhakrishnan 2008:17). So while their middle-class status lends them the authority to legitimize large-scale cultural and economic changes, it continues to anchor them to the patriarchal constructs of the ideal Indian family.

In Making Miss India Miss World: Constructing Gender, Power and the Nation in Postliberalization India, Dewey provides a detailed analysis of the Miss India contest, a contentious stage that juxtaposes "beauty as an oppressive and hegemonic concept and beauty as empowering practice” (Dewey 2008:4). According to Dewey, the Miss India pageant is a site of "beauty, power, and class” (Dewey 2008:6) that provides a socially accepted space to urban middle and upper-class women to recreate their identities using their femininity as a cultural marker and capitalist wherewithal, while exercising their agency to achieve social mobility. She contends that given the popularity of Miss India, as “an urban cultural phenomenon”, this pageant is a uniquely Indian space that allows a broader understanding of what it means to be female in urban India as well as "the complex connections between femininity, beauty and power in India” (Dewey 2008:4).

According to Dewey's observations, it is apparent that while these privileged young women are touted a symbols of emancipation and 'beauty with a purpose', they are being molded to fit stringent physical-emotional criteria while being under constant scrutiny/surveillance and discipline, much like Foucault's concept of the Panopticon. She examines the various processes by which standards of beauty are created and reproduced to frame the bodies and minds of the prospective beauty queens to reflect "what a Miss India should be” (Dewey 2008:23). Therefore the women, who are largely educated, 
English speaking and self-described as being independent and modern, become a part of a “Foucauldian total institution” (Dewey 2008:99), wherein as “the embodied subjects for male consumption” (Dewey 2008:123), they are constantly under the observation, control, and supervision of their chaperones, toeing the line of specific gender rules.

These specific gender rules and spaces that encapsulate the Miss India pageant are a reinforcement of myriad patriarchal institutions that use the female body as a conduit of representation and discipline. Dewey (2008) finds that this space of performance, while commodifying of the woman's body also offers extraordinary opportunities for a narrow segment of usually urban middle-upper middle class women for upward social mobility and financial autonomy. It is also an outstanding example of women participating in patriarchal institutions to actively manipulate them for their personal advantage by "successfully transforming their bodies and selves into culture bound visions of beauty" (Dewey 2008:8). With the culture of celebrity becoming instrumental in determining lifestyles in urban India, the power of the gaze, especially with post-liberalization entry of myriad television channels, is actively sought after by the aspirational. Miss India is a direct path to stardom for these women, who are presented as being emblematic of "strishakti, which loosely translates from Hindi as "woman power”” (Dewey 2008:9).

As globalization allows the dispersal of ideas, commodities and aspirations as well as the creation of a significant transnational Indian class that is increasingly integrated in the global economy as consumers with deep pockets and high aspirations, the politics of consumption and beauty in the contest are played out through the bodies of urban Indian women. The beauty contestants are largely required to possess 'raw' 
characters that can then be polished to match Western hegemonic standards of beauty, which is easier to do when the 'raw material' has been exposed to global norms and expectations. Thus, the Miss India searches are restricted to specific largely urban centers to avoid the odd participant who has the "unfortunate accident" of being born and brought up in a small town or village (Dewey 2008:28). The urban participants are then groomed or "chiseled" to match a certain homogenized-Indianized beauty framework that coincidentally matches certain global standards (Dewey 2008:30).

Even as physical beauty is the primary consideration of any pageant, the creators and sponsors of the contest regularly use the notion of 'India Beautiful' or 'Beauty and Culture.' Dewey observes that 'this representation of national identity that being Miss India or Miss Universe provides is one that reinforces patriarchy while simultaneously situating women's performances of gender--approved behaviors in rhetoric of female achievement” (Dewey 2008:212-213). Dewey (2008) finds that the Miss India contest is seen as being a springboard for otherwise reticent Indian women into the media world, whether as models, cinema heroines or television stars.

While Dewey’s ethnographic work shows how a class of largely privileged women uses the performative nature of beauty as an instrument to construe and realize their agency within the patriarchal institutions, there is a distinct gap with respect to the role of the new middle class families and the dynamics within it (See Mitra 2009). In a scholarship that delves deeply into the institution of pageants, Dewey cursorily touched upon cultural and economic choices made available to the participants, as a function of birth into the newly globalizing, highly aspirational urban middle class families of India. 
In “Consuming Globalization: Youth and Gender in Kerala, India,” Lukose (2005) examines the impact of nationalist projects concerned with the place of women within the public/private and tradition/modernity dichotomies on new, globally-inflected patterns of consumption among youth in the state of Kerala, South India.

Placing consumption as an objectified field of practice, Lukose (2005) examines "a modem nationalist patriarchy which placed women in the private, but allowed them to traverse the public through the deployment of class-inflected gendered demeanors and feminine habitus, [thus] confronting the patriarchy of a globalizing capitalism through new forms of consumption” (Lukose 2005:917). He finds that the new imagery surrounding the globalized Indian consumer is fashioned in and through specific images of consumer agency. According to Lukose (2005), "a key figure in this articulation of global capital with specific sites of consumer agency is the young, westernized, female” (Lukose 2005:919).

Since this figure of Indian womanhood is seen as being disruptive to nationalist patriarchy that placed women within the inner sanctum, the spiritual residence of the nation, the body in public "was stabilized and rationalized through a construction of middle-class women who could traverse the nationalist public if they carried their "essential femininity” with them. This essential femininity, a gendered bodily habitus, variously identified as "respectability" and "modesty", involved the creation of appropriate dress, activity...” (Lukose 2005:919).

Examining the discourses surrounding a contested cultural politics of globalization and nationalism, Lukose (2205) focuses on youth of Kerala as a group. He focuses on specific youth slang words that encapsulate this contestation as well as 
Malayali cinema targeted to the youth. For instance, chethu, a Malayali word that refers most significantly to a kind of commodified masculinity that is seen as being "sharp" or "cutting edge”. While this desirable descriptor is used for a fashionable man, Lukose finds that this term is rarely applied to women. Instead, a fashionable, Westernized woman is said to "have gema, a term which connotes arrogance-something between being a "show-off” and being “stuck-up”” (Lukose 2005:925).

Similarly, the Malayalam feature, Pavithram (purity) is the story of the disruptions and displacements of the traditional upper caste Hindu household and lifestyle as it takes the viewer through the choices of a young woman. Her forays into the public urban space leads her to ruination, which is then reversed as she re-enters the fold of her benign traditional family and embraces its patriarchal mores. This clash is also replicated on the Malayali beauty pageant circuit wherein Lukose (2005) finds that World Malayalee Federation defines a hegemonic Kerala femininity in line with its upper-caste Nayar imagination that traverses over borders. The structure of a globalized middle class demands “ equivalence between the likes of a Miss Kerala from Kerala and a Miss Kerala from New York. The contest reveals starkly the production of locality on a global stage” (Lukose 2005:930). With specific requirements in terms of dress, the Federation homogenizes the diversity of the state to create a mold based on upper caste middle class 'respectability', which is then seen by the excluded, usually disempowered masses to aspire to.

Briefly, Lukose (2005) finds that any modern female body that is marked as being “incorrigibly modern” (Lukose 2005:929) is seen as being Western, dangerous and antithetical to the Indian nation-body unless situated 'correctly.' He finds that in the clash 
between nationalistic patriarchy ${ }^{8}$ and "the globally inflected spaces of public consumption which commodify women at the same time that they target them as consumers” (Lukose 2005:930), women's idea of fun (read sense of agency) has to be articulated carefully as she balances tradition and modernity to claim her place in the new consumer spaces of localized globalization.

What emerge from my review of the recent related scholarships are the following points of discussion. First, the quickly expanding Hindu middle class is actively embracing a new version of socio-political religiosity that is homogenizing the very diversity of Hinduism and therefore, of India. Secondly, there is a strong sense of civilizational exception of a new Hinduized modern India that rests on a foundation of unique traditional, spirituality and disciplined intellect. Thirdly, these ideas lean heavily on a strongly etched homogenized middle class female identity that insists on complementary balance between traditional homemaking and global professionalism. Fourthly, this idealized Indian womanhood is continuously being re-molded for patriarchal consumption: by nationalists reworking the borders/security of Bharat and by corporations trying to sell the skills-products of India. And finally, despite the progress made by middle class women in terms of personal-professional achievements, the security of their bodies continues to be defined in terms of their sexuality: the containedtraditional being safe while the exposed-aberrant risking violation.

\section{A Glimpse Ahead}

The dissertation is divided into six chapters, excluding the introduction and

8. Lukose (2005) describes 'Indian' patriarchy as the product of two divergent structures one rooted in the patriarchal family formed through India's colonial and the other through postcolonial, nationalist modernity (Lukose 2005). 
conclusion sections. Chapter Two is based on historical research as well as extensive secondary materials, which have been used to examine the role of patriarchy within globalization and Hindutva. Chapter Three will detail the theoretical framework that influences my examination of the identity making processes of performed on Indian women. I use feminist methodological lenses to deconstruct religious nationalism and globalization as they secure Indian women in roles, spaces and action that are deemed ‘womanly’ and therefore, appropriate.

Chapter Four examines the patrilineal-patrilocal structures that define Indian homes and the residents within. It will focus on the various roles that structure the life, choices and movements of women within the households. Chapter Five studies the permits-restrictions placed on women in public spaces, both within their professional zones as well as movement/gathering/waiting non-domestic zones of living.

Finally Chapters Six and Seven bring together empirical data, government statistics and my observations as a researcher to generate an understanding of the impact of globalization and nationalism on HUMM women.

\section{Conclusion:}

This research project is an attempt to understand how the contrasting processes of globalization and religious nationalism are constructing Indian womanhood and its impact on space, identity and choices of corporate-employed urban Hindu women. To this end, it employs a feminist theoretical perspective and methodology to examine how notwithstanding marked locational and cultural differences, Indian women whose bodies, sexualities and gender identities are sites where cultural notions of social respectability, nationalism and globalization are contested, are ‘made’ the same by strategies of social 
control that cut across ethnic, religious and regional affiliations. Hence one might hypothesize that the norms of patriarchal nationalism homogenize the identity of the Indian woman to produce a uniform narrative that informs the national identity of contemporary India. In the battle between nationalism and globalization, the Indian woman's body and identity is used to articulate discourses of modernity and development in post colonial India while also serving in parallel as the site where fears of loss of national traditional are articulated.

As I wrestle with structuring a non-invasive, maximally unbiased project, I am reenergized by recent occurrences that indicate the topicality of my work. A recent headline said, "In Madhya Pradesh [a central Indian state], Moral Police Against Lingerie Ads, Window Display” (The Times of India, January 14, 2010). Rightwing activists in the city of Bhopal were offended by an "obscene hoarding displaying the bare back of a woman” that was advertising a day spa near a women’s college as well as undergarment displays in window shops. According to the leader of the local manch (group), "Your mannequins should wear sarees, not underwear. From now on, keep all undergarments inside...[or] we will light a bonfire of the lingerie.” Similar protests against other 'invasions' include protests against Valentine’s Day as a “vulgar festival” of “western culture” from which, nationalists needed to "save the future generation from degeneration and the country from disintegration” (The Times of India, February 14, 2008).

The underlying message remains unchanged, wherein women, the reproducers of culture and future citizens have to be kept pure so as to secure the izzat (honor) of the nation. Add to this scenario the knowledge that women are traditionally excluded from the decision-making processes of global capital, which results in the gendered division of 
labor, the discounting of work in the home, the imposition of the dictates of structural adjustment programs, leading to the ravages of poverty and marginalization (Blanchard 2003). Therefore, there is a distinct need to counter the "hand-menservants" of masculine domination through theorizing that can then be used for future activism. 


\section{CHAPTER II}

\section{A Brief History of Gendered Hierarchies}

"Patriarchy cannot be dismantled. It’s like trying to undo evolution. It is here, it is ingrained and it is only going to mutate. For me, destroying patriarchy is a futile exercise. Instead I try to work with it, around it and sometimes, against it. The intent is to lessen my gender disadvantage and advance my individual advantage.”

- Alka, Consulting Editor, Zee News.

Sitting in the lounge of New Delhi Television’s (NDTV) office in a brightly colored sari with her hair in an elegant knot, 48-year-old Alka, Zee News is the image of a self-assured professional. Yet her matter-of-fact assumption that male dominance largely organizes economic activities, religious rituals and domestic lives is based on a history that indicates “.... produc[tion] of knowledge and perpetua[tion of] attitudes and value orientation favourable to male dominance” (Tandon and Mohanty, 2003). The well read woman repeatedly uses her knowledge of history, from the influence of the Aryan invasion to the imposition of Islamic conservatism under Mughal rule to the imbibing of Victorian mores under British colonialism so as to underscore what she calls "the futility of shoving against an edifice that has been in place for centuries and has grown deeper roots each day of the centuries.”

As I try to frame my research against the mutating structure of gendered hierarchies, evolving over centuries and its impact in the lives of present-day women, it becomes imperative to understand the historical a priori that grounds this knowledge and its discourses. A product of multiple invasions resulting in cross-cultural contact and diffusion of knowledge, the $21^{\text {st }}$ century nation-state of India is a canvas of immense 
socio-cultural, economic and political experimentation. Even as representative institutions of the country, from the gram panchayate (village councils) to the National Parliament, strive to achieve Article 15 of the Constitution of the Democratic Republic of India that prohibits any form of discrimination based on religion, race, caste, birthplace or sex, the hurdles the Indian populace face are formidable. With a population of over a billion people, a majority of who are forced to live a subsistence level existence, Indian policy makers and activists are faced with myriad problems, from "economic legacies of imperialism, periodic regional and religious sectarianism, increasing socioeconomic disparities... and the tenacious survival of caste and gender-based hierarchies...” (Duley in Duley and Edwards 1986: 128).

The current research is an attempt to understand how such gender-based hierarchies built around the spine of masculine domination, specifically in Northern India, have created a "terrible story of inequality and neglect" (Sen 1990). The historical examination is inherently important to this study about Indian womanhood because it presents a lesson in caution about the mutability of the power structures that are shaped by patriarchies. This chapter exemplifies how patriarchies borrows from and are borrowed by religion, politics, history and society to maintain status quo. It shows how in building the ideas of nation, various facets of masculine domination are extracted from history, indicating a dynamic, selective use of gendered hierarchies rather than a static, monolithic homogenous form. In the following sections, I have exhibited how gendered hierarchies have been used and moved from one era to another, from one region to another and from one institution to another by adapting, adopting, appropriating and coopting while keeping the reins of control in the hands of hegemonic actors. 


\section{Patriarchies: The Indian Story}

Masculine domination is the core concept that shapes 'Women's History' (borrowing Gerda Lerner’s term). While myriad scholars attempt to ascertain its roots, it is unlikely and indeed, unnecessary that there will emerge one universal origin (Smith 2005:11). According to Smith, the scholarship of archaeologists, anthropologists, and historians shows that most early civilizations “...with written records were more or less patriarchal” (Hughes and Hughes in Smith 2005:11). Tracing the history of nuanced gendered hierarchies is important because it allows us to examine how this particular ordering of society gained strength and the ways in which "it institutionalized the rights of men to control and appropriate the economic, sexual and reproductive services of women” (Anagol 2006:5). According to Anagol (2006), the dominance of the constitution and reconstitution of male dominance in Indian gender history has created and helped disperse extensive myths and expectations about the participation of women in society. The standard histories of ancient India largely neglect the role of women and the minimal commentary found in "formal religious texts and legal codes are the products of a priestly, literate class commenting upon women; the voices of women are excluded from The Great Tradition of the court and temple” (Duley in Duley and Edwards 1986:132). Over all the absence of women's voices is a strong indicator of masculinized norms that limited women's role in the public arena.

As I examined the tomes of scholarship that have been generated by social scientists in their examination and interpretation of Indian women's history over decades, it became apparent that perspective marked the production of knowledge. For instance, Scottish political theorist and philosopher James Mill wrote in The History of British 
India a singularly harsh judgment of ancient Hindu customs as a "backward culture notable for superstition, ignorance, and the mistreatment of women” (Mills 1818 in Smith 2005). Later Orientalist scholars such as Max Muller opposed this position by arguing that the Vedic period was the golden era of Indian history, especially for women (Hughes and Hughes in Smith 2005:25).

Reformers, almost exclusively male, up through the twentieth century have constantly claimed that women enjoyed basic rights in the Vedic 'Golden Age'. According to a paper written by S. K. Chattopadhyaya in 1929, "In the beautiful days of the Vedic period of India the glory of which still surrounds the country like a faint halo, women took part freely in the social and political life of the country, and, in the celebration of religious functions and rituals, they had a special place of importance assigned to them.... They were also earnest students of philosophy and took active part in subtle philosophical debates.... Such social disabilities as purdah and child marriage were entirely unknown.... Their rights of inheritance and succession were fully recognized, whether they were widows or daughters” (Gedge and Choksi 1929 in Moles 2000).

The articulation of the Indian woman's identity over the ages, as a citizen of the nation, is determined by the complicated relationship between gender, caste and kinship as set up in our socio-political arrangements. According to Geetha, “...women’s rights to equality are constantly undercut by perceptions of their femininity and sexuality... Household, kin and caste networks, rather than the spaces of the polity determine their life choices... The manner in which a democratic polity is underwritten by the logic of sexual and kinship contracts are particularly evident in the way crimes against women are understood and prosecuted. Rape or sexual assault is seldom viewed as a violation of 
woman's bodily being and integrity. Instead, it is consistently linked to her chastity, rather her virginal or non-virginal status, as the case may be...” (Geetha 2007: 147). Decades of masculine control over the role/place of women within the home and in the public/professional arena has created expectations and exclusions that continue to influence the lives of Indian women at all levels till today. The peculiarity of 'Indianized' patriarchies lies in the juxtaposition of masculine domination, strongly embedded caste lines, religious mores and regional peculiarities. Therefore feminist scholars and activists are confronted not just with strongly ingrained masculine domination structures but also the divisiveness of caste and religion.

As we look at historical records to understand the pathway marked by male domination and its impact on the Indian woman's life spaces and choices, two indicators become obvious. First, there is no linear progression to be mapped. And, second, the journey of male domination and gendered hierarchies have been examined by many and presented differently, depending on their perspectives. The following sections will look at specific eras and associated processes to understand the various layers that influence patriarchal constructs impacting present-day Indian women. My study of the meandering path and varying versions of patriarchies will begin with the Iron Age Vedic Period (1500 BCE-6th century BC) during which the Vedas, the oldest sacred texts of the Indo-Aryans were composed, continue to the Middle Kingdoms (1200 AD) and conclude with the Indian Independence movement and the entrance of globalization, focusing largely on Northern India.

\section{The Antiquities (1600 BCE-1200 CE)}

There is little knowledge of the status of women who lived in the Indian sub 
continent's oldest known civilization of Harappa and Mohenjodaro, which developed in the third millennium BCE along the Indus River. But scholars of women's history have found substantial material in the following eras, which began with the Aryan invasion of the Indian subcontinent in 1600 BCE and established the societies from which Hindu culture developed (Basham 1998). This era was defined by the constitution of the Vedas, which are seen as the scriptural authority of Hinduism. Composed in Vedic Sanskrit, the Vedas are the oldest scriptures of Hinduism (Flood 1996). Comprised of four canonical sections or Samhita (compilation), the Sanskrit word Veda means knowledge. Literary evidence shows that the Vedas were compiled between 1500 BCE and 500-400 BCE, popularly understood to be the Vedic Age (Flood 1996).

Even as Basham (1998) reiterates the patriarchal nature of the warring, pastoral Aryans, there is also strong evidence that early Vedic women had important roles within the economy as producers of milk, cloth and grain (See Sharma 1980). According to Flood, women in the early Aryan period were seen as scholars, teachers, religious sages and composers of Vedic hymns as late as the Upanishad writings (800-500 BC) (Flood 1996). This is reiterated in the works of scholars like Findley (1985) and Leslie (1983), who contend that Indian women participated in choosing their husbands and child marriages were rare.

The Rig Veda (RV), the earliest Samhita, is perhaps the only religious scripture wherein the Divine Truth is revealed to women sages as indicated by specific hymns that describe these revelations. There are over thirty rishikas (women sages) mentioned in the Rig Veda. The RV has specifically mentioned that women have the right to choose their husbands, the right to learn the Vedas, and the right to ritualistic worship (Flood 1996). 
- "The wife should do agnihotra (ritual), sandhya (worship) and all other daily religious rituals. If, for some reason, her husband is not present, the woman alone has full rights to do yagna.” (Rigveda Samhita, part 1, sukta 79, shloka 872).

- “O women! These mantras are given to you equally (as to men). May your thoughts, too, be harmonious. May your assemblies be open to all without discrimination. Your mind and consciousness should be harmonious. I (the sage) give you these mantras equally as to men and give you all and equal powers to absorb (the full powers) of these mantras." (Rigveda Samhita, part 10, sukta 191, shloka 3$)^{9}$.

It is interesting to note that while women are largely attributed the role of wife and mother in the RV, there also exist multiple other descriptors such as Dhruva (firm), Sarasvati (scholarly), Vishruta (learned) and Aditi (independent) among others (Kumar 1998). These descriptors emphasize characteristics that are independent of their gender and therefore are indicative of empowerment and independence.

But the latter Vedic years saw a tremendous deterioration of women's rights. As technology transformed the pastoral communities into agricultural sedentary ones, there were profound changes in societal structure. By $600 \mathrm{BCE}$, the caste system ${ }^{10}$ became clearly differentiated with an emergent powerful Brahman (priest) and Kshatriya

9. I was directed through the complexities of the Rig Veda by my grandmother, who is a scholar of Hindu texts.

10. Castes or jatis are constructed endogamous groups, which emerged in 600 B.C. and were fully articulated by 200 A.D. Arranged in a hierarchical manner, Jaat is determined by birth. The system is divided into four groups or varnas that define the occupation of the members and their status in society. The structure places Brahmins (priests) at the top, followed by Kshatriyas (warriors and ruling classes), Vaishyas (businessmen) and Shudras (farmers) in descending order. Outside this ordering system lie the Dalits or so-called Untouchables (sweepers, shoemakers etc.) and the Adivasis or tribal people. For further details, see Chandra and Mittra 2003, Ghurye 1996, Pandey 1986. 
(warrior) groups controlling the lives and processes of newly established towns and petty kingdoms (Misra 2008:157-166). The growth of surplus wealth and private property along with the corresponding desire to protect inheritance lines in the male controlled family led to increased restrictions on the position of women (Duley 1998). Yalman suggests that a core principle of Hindu social organization required a closed structure not only to preserves material inheritance but also regulate women and ritual quality (Yalman 1963 in Chakravarti 1993). He argues that "the three are structurally linked and it is impossible to maintain all three without stringently organising female sexuality...[which] forms the pivot of the entire structure” (Yalman 1963 in Chakravarti 1993:579).

As Brahmanical laws gained strength, the changes in women's position within Hindu society was marked by the fall of a bride's age from mid-teens in 400 BCE to prepuberty in $100 \mathrm{BCE}$, which in turn led to their exclusion from education and religious rituals (Smith 2005). According to Chakravarti (1993), the precipitous rise in child marriage was linked to the connection between men's honor/respectability and 'their' women. Therefore, the appearance of puberty was seen as a dangerous event that required ritualistic purification. In an attempt to keep the caste line pristine, early pre-pubescent marriages were recommended. The anxiety about polluting caste lines and blood lines through miscegeny (varnasamkara: mixing of castes), especially through the union of an upper caste woman and a lower caste man resulted in the highest order of condemnation and punishment, which includes the drowning of mother and child, excommunication and ritual death (Chakravarti 1993).

As women and honor got tightly enmeshed into one ritualistic entity, the Indian 
women lost their political rights of attending assemblies, freedom of movement, the very right to make individual choices. A daughter was described as a source of misery with the Atharva Veda (one of the four Vedic corpus) deploring the birth of daughters. This was because women were "regarded as gateways-literally points of entrance into the caste system...[their] upper caste purity ha[d to be] carefully guarded” (Chakravarti 1993:579).

The Brahmanas ${ }^{11}$, which are commentaries on the four Vedas and seminal in the establishment of Indian scholarship, societal structure and Hindu thought, reference women as properties with a status akin to Shudras (the lowest class) of the four-tier caste system (Flood 1996). Since women and property were bracketed together in several references in the epics, Smritis and Puranas, women could be given away or loaned (Flood 1996).

After the Vedic Age came the Mauryan dynasty (322-200 BCE), which was a vast bureaucracy with a standing army consisting of 400,000 to 600,000 men. This period produced the Arthshastra, a manual of statesmanship written by Chanakya, a chief minister of the kingdom, similar to Machiavelli's The Prince, which also provides an insight into the role of women in that era. While women were not equal to men, there appears to be development of female public status. According to Sanday, prolonged war and shortage of male labor led to female employment as basket weavers, textile workers, court attendants and courtesans (Sanday 1981). Even though women continued to be treated as male property subjective to protective seclusion, it is clear that women retained certain person right under the Mauryan legal code. The Arthashastra gave women

11. The Brahmanas date back to the Iron Age, between 9th century BC and 6th century BC (Basham 1998). 
absolute rights over their stridhan (means of subsistence and/or jewelry received from her family upon marriage or as subsequent gift from her husband) as well as the right to widows to remarry.

But these limited rights dissipated over the next few centuries. The post-Mauryan period saw an enormous change in societal structure. The landed gentry and the upper classes usurped enormous powers over the lower castes. From this era came the seminal book of the Hindu canon, "The Laws of Manu” (Manusmriti) or Manava Dharma Shastra, a revealed scripture comprising 2684 verses, divided into twelve chapters presenting the norms of domestic, social, and religious life in India (circa 200 BCE) under Brahmin influence ${ }^{12}$. A compilation of prescriptive texts, the Manusmriti is fundamental to the understanding of present day India since its definition of total legal dependence of the female upon the male, similar to that found in Confucian thought, Roman Law and the English Common Law's Doctrine of Coverture entrenches the patriarchal family (Buhler 1886 in Cohn and Singer 2007).

It is noted that the Laws of Manu is very contradictory in its position towards women. While certain verses glorify the position of women: "wife is the essence of the home”, "a man is incomplete without his wife" and " sons should respect a mother more than the father," others inherently treat women as beings of lesser intellect, moral character and virtue (Buhler 1886 in Cohn and Singer 2007). For example, Verse IX-15 states that "Through their passion for men, through their temper, through their natural heartlessness, wives become disloyal towards their husbands, however carefully they may

12. For complete translation, got to: http://www.bergen.edu/phr/121/ManuGC.pdf (Accessed February 10, 2010). 
be guarded in this world" while Verse II-24 "Women are able to lead astray in this world not only a fool, but even a wise man, and make him a slave of desire and anger”, both essentializing the 'nature' of women. Focusing on the rights of women, Verse V-28 dictates that "In childhood a female must be subject to her father, in youth to her husband, when her lord (husband) is dead to her sons; a woman must never be independent” while Verse VIII-416 claims that "A wife, a son and a slave, these three are declared to have no property; the wealth which they earn is acquired for him to whom they belong.” And finally, Verse V-15 clarifies the place of a man by stating "Though destitute of virtue, or seeking pleasure elsewhere, or devoid of good qualities, yet a husband must be constantly worshipped as a God by a faithful wife.”

According to anthropologist Sharma (1980), this extreme misogyny is rooted in the desire for "...limit[ing] the ways in which women can actually use whatever economic power they may derive from their role in production” (Sharma 1980:201). The continuing focus on the chastity of women's bodies and the control of their desires stemmed directly from the obsession for "pure inheritance lines, nervous male asceticism, and an anxiety that uncontrolled women might undermine caste distinctions” (Duley 1986). From these prescriptions, a family's honor and status became intimately connected to the chaste bodies of the women in the family.

Manu's Laws "authorized the patriarchal, patrilineal, patrilocal family structures associated with the Aryans” (Ramusack 2005 in Smith 2005:103). The structural foundations of many of the processes that have kept women in positions of disadvantage in modern India were laid during this era. According to Ramusack (2005), child marriage, marginalization of widows and prohibition of their re-marriage, self-immolation by a 
widow on her dead husband's pyre to demonstrate chastity (Sati) are some of the practices influenced, even sanctioned by Manu's Laws. While these tenets are widely criticized and declared abhorrent in the present times, these contradictory notions have led historian Romila Thapar to state, “The symbol of the woman in Indian culture had been a curious intermeshing of low legal status, ritual contempt, sophisticated sexual partnership, and deification” (Smith 2005: 157).

The symbolic Indian woman has been created using the notions of the "good Indian girl”, “docile Indian wife” and "sacrificing Indian mother”: all reincarnations of the "Adarsh Bhartiya Nari” (ideal Indian woman). Her sanctified place in Indian society has been spread from the literate elite to the illiterate masses during the Gupta period ${ }^{13}$ using the epic Brahmanical poems, the Mahabharat and the Ramayan. The epics are moral tales depicting cultural ideals, which are to be emulated the "watching" classes as the messages are sent out using song, dance, theater, arts and in the modern era, additionally through electronic media.

Both epics center on pivotal female characters. The Mahabharat is woven around the courageous and polyandrous Draupadi, queen and wife of the five Pandava brothers while the Ramayan advocates the mantra of the pativrata (chastity, wifely loyalty and

13. The Golden Age of India (3rd century CE-6th century CE) under the Gupta Dynasty saw enormous gains in the fields of science and technology, art and literature, mathematics, astronomy, religion and philosophy. The decimal system, chess and the concept of zero were invented during this period along with the proposal that the earth was round. The Gupta period produced scholars such as the poet Kalidasa, the mathematician Aryabhatta, writer of the anthropomorphic political treatise, Panchatantra, Vishnu Sharma and the creator of the Kama Sutra, Vatsyayana. Strong trade ties also made the region an important cultural center and set the region up as a base that would influence nearby kingdoms in Burma, Sri Lanka and the Indochine (Basham 1998). 
submission $)^{14}$ as exhibited by Sita, the wife of Ram, a reincarnation of the God Vishnu. Interestingly, it is not the ideal of a strong willed woman, Queen Draupadi that has been made into the cultural norm for Indian women to follow. Instead it is the uncomplaining Sita who is portrayed as the epitome of Indian wifehood and womanhood. It is telling that the 'ideal' woman Sita had to walk through fire to prove her chastity to her king husband and his subjects. Given that the Indian woman's identity is linked and defined by her roles within the family; these two epics have substantial impact on the lived experiences of women in India.

As different dynasties ruled over the lands that is today India, there were multiple upheavals within society that were reflected in law and religion but overall the status of women continued to be subordinate. The 'need to keep women in their place' was a necessary process of maintaining the status quo of male dominated power structures.

\section{3. 'Outsiders' Reign I: The Delhi Sultanate and the Mughal Era (1206 CE-1725 CE)}

Indian history saw the emergence of Arab and Turkish warriors-traders in the early $8^{\text {th }}$ century CE (Basham 1998). By the $13^{\text {th }}$ century CE, the Afghans and the Turks had started to establish their influence over the Indo-Gangetic Plain. This section examines certain aspects of the impact of Turko-Afghani invasion (1200 AD-1500 AD) and subsequent Perso-Arabic invasion (1500 AD-1725 AD) known as the Mughal Empire on India and the continuing evolution of gendered hierarchies (Basham 1998).

According to Basham (1998), the patrilineal and patrilocal Islamic communities

14. Patrivrata, or total devotion to the husband, set out by Hindu scriptures is the wifely ideal (Lebra et al.. 1984: 26-27). The ideal wife is one whose sole joy in life is to satisfy her husband. Her only concern is to perform properly any of the services demanded by her husband. Such a woman is attached to her husband even after he has died. 
accorded women more rights (of inheritance, widow remarriage, alimony etc.) as compared to native Aryan communities. And yet one of the strongest associations with the Mughal Empire today is the symbolism of the purdah, the art of seclusion. Even as Hindu nationalists ascribe the practice of secluding Hindu women to the impact of Islam and the desire of Hindu men to shield their women from Muslim invaders, there are ample references (as mentioned above) within Indian texts that required respectable women to have limited contact with unrelated men through veiling and traveling in closed conveyances (Ramusack 2005 in Smith 2005).

The purdah system essentially requires the veiling of a post pubescent woman's body and face as well as the segregation of women in an interior section of the residence known as the zenana (Ahmed 1992). According to Papanek (1982), purdah operated differently within Hinduism and Islam though the ultimate goal was the physical and social separation of men and women into exclusive spheres of activities. Under the Islamic system, women remained shuttered from unrelated males while under the Hindu system, women remained out of sight of elder male relatives as well as unrelated males. Yet Vatuk stresses that both Hindu and Muslim purdah practices were observed “...[to] protect the sexual modesty of women” (Vatuk in Papanek et al. 1982:69).

According to Papanek (1982), the separation of lived spaces marked more than physical spatiality. It manifested itself in a well-defined sexual division of labor, which were performed in sheltered spaces with the assumption that women are vulnerable in and to the outside world. Similar to Manusmriti's misogynistic prognostications, Islam assumed that women had strong sexual drives, which they had to be protected from while 
‘uncontrolled’ Hindu women were seen as temptresses (Papanek 1982).

Given that the purdah system was used to secure family honor, Sharma states that it was actively used "as a system of practices, which reinforce male control of productive resources” (Sharma 1980:201). Even though the system first originated within the upper classes ${ }^{15}$ so as to allow male control of inherited property as well as productive resources, the desire to emulate the powerful by the lower economic classes led to restriction of female participation in the workforce (Papanek 1982).

To counter such severe restrictions, many of the women utilized what Kandiyoti (1988) has called "patriarchal bargains" wherein some of the women within the harems despite very limited access to power or material resources, emerged as important political and social players. According to Misra (1967), these women were more than ciphers. She cites multiple examples of political machinations from behind the curtain such as the impact of Bibi Mubarika on Babur, the founder of the Mughal Dynasty as well as the maneuverings of Empress Nurjahan, the wife of Emperor Jehangir (Misra 1967). But these examples are few and are limited to royal women's attempts at furthering the claims of their male relatives under whose protection they lived.

\subsection{The Outliers Within}

There are a few outstanding women who ruled in their own right during this era, which includes Razia Sultan (ruled from 1236-1240 AD) and Rudrama Devi of the South

15. The Royal Harems of Mughal Emperors were central vehicles that institutionalized and legitimized the purdah system by lending it social acceptance within the upper classes. The Imperial Harems consisted of thousands of women: wives, concubines, female relatives and household staff, all housed in splendid zenana quarters in complete seclusion. Interestingly the need for sexual separation required the staff to be female civil servants and the guards be female warriors, skilled in defense arts. For detailed descriptions, see Soma Mukherjee's Royal Mughal Ladies and Their Contributions and Ruby Lal's Domesticity and Power in the Early Mughal World. 
Indian Kakatiya dynasty (ruled from 1261-1289 AD). They constructed a public male persona by adopting a masculine name and wearing male clothing (Talbot 2001). In other words, the inherent masculinity associated with the role of ruler/warrior required royal female rulers to reconstruct their persona. This separation of space and expectations between men and women set the foundation for future socialization of gender roles.

Smith (2005) finds that in spite of centuries of gendered disciplinary rituals, there are ample examples of women seeking to create enabling and empowering spaces. Besides the women mentioned above, another outstanding example of women's efforts for self-sustenance, is the Bhakti movement within Hinduism during Mughal rule. The forced exclusion of women by patriarchal Brahmanism and Sanskritized traditional demands led Hindu women to use bhakti or devotion to approach God. The message spread through the works of vernacular poetry (Smith 2005). One of the noted Bhakti personalities, poet-saint-princess Mirabai of Rajasthan (1498-1546) who transgressed societal and sexual-marital bounds to attain the divine, is seen as an early feminist and an embodiment of rejection of masculine demands. Mirabai enshrined the very basis of the Bhakti movement that rejected not only caste hierarchies but also domestic bonds. Belonging to the Rajput clan of Rajasthan, known for intense pride in their masculine warrior identity as well as inflexible rules for women (the origin of Sati is ascribed to the Rajput clan as well as the stringent use of the Hindu purdah system), Mirabai is seen as a powerful symbol of resistance within the Bhakti movement (Srinivasan 2007). According to Srinivasan, this movement carried "a liberating potential that went beyond the physical into a transcendental realm that allowed women to express themselves...to use the sexual metaphor without disapproval...” (Srinivasan 2007:56). 
Shakti (strength or power) embodies ultimate generative female power within Hindu understanding while Bhakti with its core of surrender and love of the divine are major components of female religiosity within Hinduism. Seen as the force of creation and destruction, Shakti informs all Hindu frameworks and influences social structuration (See Nandy 1983 and Srinivasan 2007). Feared and appeased, the concept of Shakti symbolizes “unsurpassable female power, unbridled female sexuality” (Srinivasan 2007:58). Various scholars such as Harish and Harishankar (2003) as well as Carr and Van Leeuwen (1996) have noted that societal norms have been shaped by the masculine fear of Shakti resulting in oppression and violence. Indeed, this need for “...social and moral structures to impose controls on women...” has been seen as being imperative because “...without such restraint, they would rule the human race; more significantly, they would possess the capacity to destroy human existence...” (Srinivasan 2007: 58).

Therefore, selective memory and 'his'tory are routinely used to demarcate acceptable behavior within society through the excoriation of anything that resembles female empowerment.

\section{Outsiders' Reign II: The Western Influence (1757 CE-Present)}

The general fascination displayed by the Indian masses and classes with Western mores can be attributed to the "brown sahib" mentality that took hold of the Indian imagination during the British reign and continues with the onset of trade liberalization in the early 1990s when the Indian government had to implement wide-ranging economic reforms in response to a massive balance of payments crisis. This economic crisis led to the opening up of the consumer market, which was flooded by so-called Western goods and ideas. While the Indian socio-political and financial elite attempted to sell India as a 
newly modernized democracy, deserving of foreign investment and a place in global institutions such as the United Nations Security Council, the Hindutva movement emerged as an oppositional force that continuously attempted to counter perceived foreign threats through the control of the body of its citizenry and organizational discipline as a whole. This form of masculinized Hindu nationalism insists that 'Indian' globalization must be limited to economic issues since modernity in India was not to be confused with Westernization and a loss of male-advantageous tradition.

Even as Hindutva activists rail against the intrusion of "lax Western morals” and take to the streets in their self-appointed role of guardians of Indian womanhood against corrupt modern western influences (International Business Times, April 18, 2007), the impact of the 'West' on the Indian subcontinent is far from recent. Globalization made its presence felt in the form of European colonization with the early sixteenth century establishment of a Portuguese trading company in Goa, which was followed by Dutch and most importantly British companies (Chakrabarti 2000).

The British trading companies became political encroachments when they usurped the right to tax the resource-rich province of Bengal in 1765. As the British East India Company began to extend their colonial endeavors, their position with regards to Indian women remained ambivalent. For instance, Sabin talks about the Suttee Myth, wherein "British colonial chivalry became less exclusively regal in its rescue missions and more structured to divide heroes from villains on racial lines...the foes were Hindu priests, brothers, fathers, sons and sometimes the woman victim herself” (Sabin 2002:72). At the same time, Mani (1989) finds that British officials first tolerated Sati, then legalized it if it was voluntary to finally prohibiting it in 1829 as opposed to the popular 
romantic British Suttee plot where "the Hindu widow is the touching female victim of enchantment; the British rescuer has the heart, if not always the power, of a chivalric hero” (Sabin 2002:72).

Within colonial discourse, the notions of civility and barbarism were the oftrepeated bricks in the foundation of British self-congratulation for 'owning' an advanced civilization. James Mill’s influential History of British India published in 1816 states that "one could judge the level of a civilization by the status of its women and concluded that India was at the bottom of the scale because of the position of [its] women” (Mill in Smith 2005:110). According to Ramusack (2005), the British colonists used the rationale of chivalry and moral obligation as a legitimate reason for the political and economic domination of India. Colonial globalization sought to “alleviate” the status of Indian women by legally opposing early marriage and the prohibition on widow remarriage while Indian nationalists and social reformers "felt compelled to explain these customs as aberrations from an earlier golden age for Hindu women during the Vedic period” (Ramusack in Smith 2005:111).

To foreshadow latter findings, we can draw parallels between the use of sociocultural differences by the British and the evidentiary use of socio-economic disadvantages in modern-day 'Third World’ India as a sub-plot of globalization, as one reason for their presence. Indeed, British colonists and globalization elites are known to congratulate themselves for alleviating the 'civilizational' differences and saving the nonWest from themselves (Corbridge and Harriss 2000).

Even as the colonists and nationalists distanced themselves from regressive/ repressive traditions imposed on Indian women by instituting legal reforms such as the 
[prevention of] Female Infanticide Act of 1870, the Age of Consent Act of 1891 that raised the age of sexual consent for girls from ten to twelve as well as the Child Marriage Restraint Act of 1929, the intent remained the recasting of Indian women into stereotypical roles. According to scholars like Sinha (1995), Sarkar (2001) and Anagol (2006) deployment of idealized femininity within colonial India in turn imposed codes of masculinity. Nandy's (1983) seminal work on the psychology of colonialism suggests that the entrenched masculine-feminine dichotomy of the post-Enlightenment West was seen in the hyper-masculinity of British imperial ideology that was manifested in the aggressive-yet-gentlemanly competition demonstrated by the Imperial British men. This behavior in turn was emulated by nineteenth-century Indian male elites who accepted British masculinity as being superior (Nandy 1983).

While the Indian male elite emulated the stiff upper lip and fashions of the British, Sarkar (2001) finds that revivalist Hindu male nationalists argued against British impositions of "civilizing laws" by stating that Hindu women were the symbol of the Indian nation and the embodiment of the spiritual superiority of Indian culture with respect to Western culture and British political dominance. Therefore, Indian women in the home, the domestic "Indian" space needed to be sheltered from British intrusion and domination (Sarkar 2001). The Hindutva Brigade today to confine Indian women in spaces deemed "safe” regularly uses the impact of this notion of protecting women from the male gaze of the Outsider.

An outstanding example of the clash between globalization and nationalism that stems from this notion of safe "Hindu-ised spaces" has been recently enacted on the Indian woman's body and expressed as the angst that surrounds beauty pageants. The 
extravagant spectacle surrounding the various Miss India performances on the global stage has resulted in widespread cultural backlash (Ahmed-Ghosh 2003). Invoking the connection between Indian womanhood, the notion of izzat (respectability) and the honor of the nation, the Chief Minister of Uttar Pradesh (a central Indian state) justifies his banning of beauty pageants by claiming, "Nudity and obscenity cannot be parameters for determining beauty. Indian girls should try to emulate Mother Teresa, Chand Bibi, Maharani Laxmi Bai and Sita. No religion allows its daughters to expose their bodies to win competitions” (Mishra 2001:9). His usage of historically eminent female figures is a common strategy of religious nationalists who define family-community respectability through women's bodies and behaviors. This enables masculine power structures to locate and define womanhood within the parameters of "decency" and "culture" that legitimates and perpetuates power differentials between the genders. According to Ahmed-Ghosh, “This logic confers a collective responsibility on men and women to ensure a Hindu nation in which women conform to a traditional status "of the golden era" as sacrificial, obedient, and devoted wives and mothers” (Ahmed-Ghosh 2003:213-4).

Even as this clash between 'East and West' can be rooted within British India, it is imperative to note that the colonizing officials consulted with and reinforced the authority of Brahman pandits and the Laws of Manu while ironically trying to institute legislation that sought to strengthen the position of women (Smith 2005). Ramusack (2005) finds that certain revisions of property law in the Northern states of Punjab and Haryana starkly impacted the status of Hindu widows by limiting economic and sexual options as well as increasing dowry demands (Ramusack in Smith 2005). Therein lies an outstanding example of the collusion between state and society, both controlled by 
hegemonic masculinities.

While the British Raj (rule) engaged in legal means to 'civilize’ the Indian masses, Indian reform groups such as the Brahmo Samaj in Bengal promoted education for women and set progressive agendas. These forward-looking emancipatory programs were tailored to produce “...emblems of modernity that prescribed reformed behavior for Indian women as daughters, wives and mothers...[especially] to mold women into companionate wives, combining Victorian virtues such as punctuality, cleanliness, and literacy with Hindu ones, especially self-sacrificing devotion to husbands...” (Ramusack 1990:112). But these reforms through their very intent continued to limit women’s access to resources and public spaces rather than truly emancipate them.

As Chatterjee (1989) argues, the end of the nineteenth century saw Indian men confining Indian women to the private-domestic sphere where women would preserve a superior Hindu culture from colonial contamination. At the same time, they further disciplined their behavior in the private space by calling on Indian women to be good mothers of sons who would fight to protect Mother India from foreign invasion (Chatterjee 1989). As the mother role gained ascendance, Indian women’s sexuality became a downplayed facet. The need for pure Indian women meant that even within marital spaces, their bodies were seen more as reproductive laborers, carriers of future male heirs rather than sexual beings (Chatterjee 1989).

The British rule did see the emergence of elite Indian women who were consistently critiquing and questioning male prescriptions for Indian womanhood. There are extensive examples of Hindu women working for journals like Antahpur in Bengali, Stree Darpan in Hindi, and the Indian Ladies Magazine in English as well as the 
establishment of women's associations such as the Women’s India Association (established in Madras in 1917), the National Council of Women in India (formed in 1925) among others (Ramusack 1990). These institutions advocated for women's education, lobbied for legal rights that included voting rights as well as discussed controversial topics like birth control. One of their notable victories was realized between 1923 and 1930 when all provincial legislatures (with majority Indian population) under British rule allowed women to vote and stand for electoral positions (Ramusack 1990). ${ }^{16}$ Ramusack (1990) notes that by the late 1930s, these elite progressive women found themselves opposed by women of religious minorities, lower-class urban women and rural women who questioned their right to set agendas for them without adequate representation (Smith 2005:114).

Another important institution that was established under the British rule in the early nineteenth century was a set of schools for girls. David Hare in Calcutta established the first in 1820 (Agnew 1979). Influenced by rationalist European philosophy and evangelical zeal, these schools paid little heed to the caste system and attracted girls from lower castes. Suspicious of the missionaries’ motives, the Hindu reformist groups like the Brahmo Samaj, Arya Samaj, among others responded by starting their own schools, the first of which called Bethune School, established in Calcutta in 1849.

By 1882, the Indian Education Commission reported the presence of 2697 women's education institutions (Mies 1980:131). According to Mies (1980), most of these schools operated at the primary level with 82 secondary schools, 15 teacher-training

16. The right to stand for candidacy required attaining set standards of education and the ability to pay taxes. Given that most women were not educated nor did they have any control over their family finances, this proviso was mere lip service rather than a real foot forward in the path of women's emancipation (Ramusack 1990). 
institutes and one college. Scholars such as Mies (1980) find that these institutions did not stray far from patriarchal expectations of women, albeit educated women. The curriculum was limited to further women's traditional roles of mother and housewife, with an "emphasis on home science, and simpler liberal arts-rather than the 'manly' subjects like mathematics, sciences or professional courses like law, engineering” (Mazumdar 1976:53). Thus, the challenges to gender stereotypes remained minimal, as did any challenges to symbols such as the purdah. In other words, the status quo remained in place, indeed was further strengthened under the guise of goals perceived as being emancipatory.

Indian male reformers working in Westernized professions and urban environs, sought educated women in their families. But this expectation was not universal as seen by statistics wherein by 1907 only 3.6 percent of school age girls were enrolled as compared to 23.1 percent of school age boys (Mazumdar 1976). Indeed Mazumdar states that "modern education and urbanization introduced a new barrier between men and women in many families” (Mazumdar 1976: 49). Even as elite women were exposed to increasing awareness of a world outside their domestic sphere, there was no radical redefinition of the female spheres or roles during the British Raj. But as seen in any structure of fixed roles, there are always exceptions to the rule as exhibited in the following section.

\subsection{The Outliers Within}

The nationalist movement of swaraj or self-rule, which later transformed into the independence struggle, saw a notable presence of women. While their activities ranged from peaceful protest to violent attempts at overthrow, it was the Indian National 
Congress (INC) and its most prominent member, Mohandas Karamchand Gandhi or Mahatma Gandhi who mobilized women into the march of independence (Sharma 1991). According to Sharma (1991), Gandhi saw female emancipation as an essential component of India’s nationalist regeneration (Sharma 1981).

At the same time, Gandhi invoked age-old Aryan stereotypes that mired Indian women in roles of self-sacrifice and forbearance that translated into non-violence. According to Gandhi, these ‘innate’ qualities made women ideal candidates for practicing satyagraha or peaceful resistance (Jain 1986). The "father of the nation" and other nationalist leaders asked Indian women to reshape their domestic realms by rethinking their modes of consumption. Gandhi asked them to buy swadeshi (Indian made products), to spin yarn for Indian handloom weavers and picket alcohol shops. These actions translated into economic pressure on the British rulers, which in turn was meant to weaken their political hold. Nationalist leaders’ roles in mobilizing women have garnered varied responses from women scholars.

Some feminist scholars like Mies (1980) insist that the expectations of nationalistic leaders like Gandhi was instrumental in hardening the divide between private and public spheres for middle-class women. Mies calls the support for limited women’s rights an exercise in cooptation that “made sure that the women's movement did not go beyond the basic structure of a patriarchal society; the patriarchal family and the caste system” (Mies 1980:120). Others like Sharma (1981) and Asthana (1974) write that his strategy drew women of various social classes into the political domain in ways that was 'permissible' to their conservative male relatives.

As the anointed Bapu (father) asked Indian women to engage in peaceful civil 
disobedience, there emerged groups of women who rejected his stance of nonviolent resistance. Bengal saw educated young women engage in violent resistance with "the goal of political freedom when changes in Indian society would encompass reforms for women” (Ramusack in Smith 2005: 115). Some outstanding and yet rarely mentioned examples are Santi Ghose and Suniti Choudhury who successfully assassinated the district magistrate in Cimilla in 1931 and Pritilata Waddedar who led a raid by fifteen men on the Chittagong Club in 1932 (Smith 2005) ${ }^{17}$ among others.

The presence of women in the freedom movement in various capacities and roles revealed their commitment to their vision of an independent nation. Yet a different form of struggle was coiled within the larger frame of Indian independence movement. Indian women’s sexuality and its control were central to this multi-layered struggle (Mies 1980). As Hindu men within reform groups like the Arya Samaj in the United Provinces policed women's sexuality and bodies, ostensibly to protect them while encouraging Hindu men to remarry Hindu widows so as to prevent them from marrying "Outsiders” (Muslims and British colonists) and containing their sexuality to the bounds of marriage, the core concern emerged from the Laws of Manu that validated male dominance of women’s sexuality so as to preserve caste and religious purity (Mukherjee 1978).

While India partially integrated with the world market system under the aegis of colonization, the obsessive concern over protecting Indian women's bodies and honor

17. In early 1930s, Pritilata joined Mastarda Surya Sen’s armed resistance movement. In 1932, they planned an attack on the Pahartali European Club, which bore the notorious sign 'Dogs and Indians not allowed'. He assigned Pritilata to lead a team of 10-12 men that would attack the Club on September 23, 1932. Members of the team were instructed to carry potassium cyanide with them so that in case they were caught by police they could swallow it before the arrest. Even as the raid was successful, Pritilata, dressed as a man was trapped. She committed suicide by swallowing the cyanide. For further information, see Smith 2005. 
restricted their movements and options at employment and self-sufficiency. As a general historical trend, lack of technical education, preference of industrialists for male workers who were seen as being mobile and cheaper to hire (without rarely instituted though legally required rights for women to access maternity leave and on-site childcare facilities) and mechanization kept women economically dependent and within the domestic sphere, where their bodies, motivations and desires, both sexual and occupational, could be easily controlled and disciplined. Additionally, the "protective" actions of the government through the enactment of legal undertakings such as the Factory Acts from 1881 to 1911 that limited women's hours of work so as to keep them safe at night and allow them to tend to their families, gave women workers limited opportunities of well paid employment (Sharma 2006).

While middle-class women remained largely indoors, behind metaphorical and real veils of modesty, the overwhelming majority of Indian women were peasants who carried the double burden of household labor-reproduction and childcare, household chores and eldercare-as well as agricultural work (Sharma 2006). These ‘lesser’ women led militant struggles so as to secure economic rights as well as human rights. For instance, Warli tribal women in Western India carried out a revolt between 1945 and 1947 to protest the degrading conditions of forced labor and sexual exploitation by landlords (Saldanah 1986). Yet these women continue to face sexually oppressive practices within their communities and families, who deny them the right to participate in the public sphere of politics. Similar experiences were noted in oral histories by women in the Tebhaga movement of Bengal in 1946 and the Telengana movement in Andhra Pradesh in the 1950s (Sen 1989). Much like other human rights struggles, women’s 
rights, especially those of marginalized classes and castes, become relegated to the pile of lesser importance, a further reiteration of gendered hierarchies.

With the adoption of a Constitution, India became a republic in 1950. The muchrevered Indian Constitution guarantees equal rights and status to Indian women. Among the guarantees present in the Constitution are equal protection under law (Article 14-1) and equal opportunities in employment (Article 16-1). But as feminist scholars' research indicates, not only were these sweeping changes not implemented but also the Aryan model of docile chaste Indian femininity continued to be invoked by post-colonial politicians as symbols of the Indian nation and her honor (Bose and Jalal 1997).

The notion of honor/dishonor of the Indian woman's body has been continually extrapolated to the honor/dishonor of the Indian nation. The motif of honor/dishonor is fundamental to the cement that holds together the foundation of independent India. The partition of the Indian sub-continent into a secular (though majority Hindu) India and Muslim Pakistan in 1947 saw the commission of inhuman violence and terror. Historical estimates put the number of refugees exchanged between the two new nations at approximately ten million while the number that succumbed to partition violence vary between five hundred thousand and two million (Bhasin and Menon 1998) ${ }^{18}$.

The depth of horror experienced by the survivors led to decades of silence and avoidance. The late 1980s saw historians attempt to piece together the picture of the Partition violence using individual experiences, much like a jigsaw puzzle. While the violence experienced by the refugees was horrific, there was a strong gendered

18. Chaotic conditions and traumatic experiences meant that there are few official accounts for the numbers cited. Eyewitness accounts that were recorded largely came from British colonists. Decades later, Indian and Pakistani survivors of the Partition came forward to record their experiences of survival and loss. 
component to these acts. The work of historians, largely on the basis of oral histories and limited government documents show that women were targeted by not only the 'oppositional' faction of men but also by their 'own' (Bhasin and Menon 1998). Some women were killed by their own male relatives to 'protect' them from rape and dishonor of their body/selves, which consequently would reflect on their family and by extension, the nation. Others were abducted, raped and/or killed by men of other religions as well as their own (Bhasin and Menon 1998).

Even as the ashes and dust of the partition upheaval settled down, the newly minted governments of India and Pakistan instituted programs to recover the abducted women of their respective nations. Indian feminists insist that these programs were largely set up to regain perceived lost national honor rather than concern for the physical and economic welfare or personal desire of the abducted women. This is indicated by the demand that any children conceived of the relationships in the 'enemy' territory had to be left behind as they indicated violation of the mothers' chastity (Bhasin and Menon 1998). There are many instances of social ostracization of these 'recovered' Indian women by their paternal families that viewed them as being tainted based on the assumption of sexual relations with Muslim men (Bhasin and Menon 1998).

In this time of upheaval, there emerged a small yet significant group of eminent women, largely from the upper classes and castes. Some notables are Vijayalakshmi Pandit (sister of Jawaharlal Nehru, India’s first Prime Minister) who went on to become an ambassador to the United States, the Soviet Union and the United Kingdom as well as president of the General Assembly of the United Nations; Rajkumari Amrit Kaur became India’s first Health Minister and president of the International Red Cross; Lakshmi 
Menon who became the Deputy Minister of External Affairs, India and later Chief of the UN Section on the Status of Women; and finally, Indira Gandhi (Jawarhal Lal Nehru's daughter) who in 1966 became India’s first woman prime minister (Manushi Website). Women entered the education and medical profession in large numbers. They made their presence felt in the bureaucracy and the social services. ${ }^{19}$ For the upper classes, a secular India fulfilled some of the nationalist promises and yet the publication of Towards Equality in 1974, ahead of the International Year of Women in 1975 removed the façade of perceived progress for Indian women (Sen 2000). It became evident that gendered and caste based hierarchies retained a strong hold on the structure of Indian society.

Comprising nine women and one man, this government appointed committee was created to assess the gains made by Indian women post-independence. After 27 years of independence, the committee found several alarming statistics, which included the declining sex ratio of the Indian nation (972 women to 1000 men in 1901 as opposed to 930 women to 1000 men in 1971) (Towards Equality, Chairman: Phulrenu Guha 1974 in Sen 2000). The committee found that abstract constitutional debate saw no dissent to the equality principle but when it was applied "to established preserves of traditional male privileges, such as the right to property and the unchallenged dominance of the husband in family life” there was a sharp divide (Guha 1974 in Sen 2000). Giving such rights to women was seen as being disruptive and antithetical to Indian customs and societal structure, which resulted in the chimera of progress.

The findings of this committee exposed the elite focus of the earlier women's

19. By 1998 Indian women held 7.1 percent of seats in the Parliament as opposed to 6.4 percent of women in the US Congress (Smith 2005). For more, read www.onlinewomeninpolitics.org/south/2003 wip_sa.doc (Retrieved on November 20, 2009) 
movements that overshadowed the lived reality of a majority of Indian women for whom real legal equality remained a distant goal. The dismal reality of the majority of Indian women’s lives galvanized educated women into feminist action. Elite women became involved in anti-dowry movements resulting in the later legislation of the Dowry Prohibition Act of 1986. Social change also came in the form of newly minted institutions like the Self Employed Women's Association ( $S E W A$ ), a self-help group that stared working with marginalized women in Amdavad in 1972. Beginning with securing low-cost credit and literacy training, SEWA diversified to organize women in the informal sector, the creation of a women's bank among other efforts (SEWA Website).

As these movements gained strength, the rooted institution of the Sangh Parivar ${ }^{20}$ was intensifying its efforts to dominate the political and cultural landscape of the Indian nation. The 1990s saw the emergence of the Hindutva brigade whose core motivator is the replacement of a secular India with a Hindu Bharat and their central emblem is the Hindu woman as the symbol and servant of a renewed and purified Hindu community. While the Sangh Parivar decries any accusations of control over women by 'parading' the Rashtriya Sevika Samiti (the women's wing of the Rashtriya Swayamsevak Sangh) as a symbol of women's empowerment, feminist scholars find that this organization of women are inculcated with the ideology of chastity and motherhood. With few discussions about daughters, the focus is on birthing "sons of the soil" and socializing them to accept the ideology of India as a Hindu nation (Sarkar et al. 1995).

20. Established in the late nineteenth century, a "family" of Hindu nationalist groups, the Sangh Parivar was led by a triad consisting of the Bharatiya Janta Party (an electoral political party); the Rashtriya Swayamsevak Sangh (the militant foot soldiers of the Hindutva movement) and the Vishwa Hindu Parishad (a Hindu global organization aimed at the Hindu diaspora). 


\section{Conclusion}

In looking at the history of masculine domination, this chapter attempts to bring together the homogenizing attempts of various invasions (political and economic) on Indian womanhood that continues unabated, constantly shaping the lives of women in India today. Whether it is the economic subjugation of women or the discipline of their bodies-movement, the tenets of 'seminal' historically rooted texts and traditions are constantly invoked. Indeed, the failure to meet these traditional Goddess-like attributes of chastity and honor regularly results in heinous crimes.

As Suman, camerawoman, Aaj Tak, one of only two camerawomen to work for the electronic news media in New Delhi, states, "I see crimes against women being perpetrated everyday, without fear, without compunction. All in the name of izzat (honor). Don’t forget the relatively recent alleged forced Sati of Roop Kanwar.” Suman is referring to the 1987 burning of 18-year-old Roop Kanwar in Deorala, Rajasthan on the pyre of her husband as an extreme expression of marital valor (Harlan 1994: 80).

Feminists see this as an indication of rising Hindu fundamentalism, intent of reviving the Golden Age of Hinduism. Such aspirations demand the subordination of women to male authority and make them the vessel of family honor, to be guarded and disciplined (Ramusack in Smith 2005:104). The ‘protection’ of family honor is seeing an alarming rise with fathers-brothers-uncles attacking 'aberrant girls' who marry men of their own choice, outside their community-caste-religion ${ }^{21}$. These modern day perpetrators regularly use historical references to Hindu texts like the Manusmriti and the iconography

21. http://www.telegraphindia.com/1040113/asp/nation/story_2780541.asp 
of Devi Sita as defense of their murderous actions.

But such 'protection' of centuries old institutionalized culture and tradition are not the sole reason behind the resilience of gender inequalities. This hierarchy of power continues through the additional support of the different phases of global 'capitalism' that work to colonize and re-colonize marginal subjects in complex manners.

Even as I engaged with vast publications that deal with gendered power structures within nationalism and globalization, I found that though there are elaborate tomes on the role of women within Hinduism and Hindutva, there is minimal research on Indian economic history with a gendered perspective (see Duley and Edwards 1986). Also while there is extensive research being done on the impact of globalization on the Indian economy and Indian women, a gendered perspective is sparse. Within the Indian context, globalization is largely seen, deciphered and interpreted as being an economic process of restructuring and liberalization, leaving out questions on social, political and cultural changes. There seems to be minimal insertion of the complexities of class, religion and caste while questioning the impact on globalization on women. The age-old dichotomy of oppressor-oppressed has to be problematized because globalization is not a simple replacement of patriarchal capitalism. Depending on socio-political and economic standing, the impact of globalization is varied and multiplicative.

While India has been shaped by various waves of globalization in the guise of multiple external rulers, whether the Aryans, the Mughals or the British, the seeds of 'modern' globalization were sown in the early 1990s, which saw the Indian government usher in the era of economic liberalization. The cheerleaders of globalization sought to 
secure a place in the global marketplace through increased productivity and cheap labor. With new global conglomerates making their way into the Indian economic landscape, myriad employment opportunities are being offered to the emerging middle class (Lakha 1999). As studies indicate that the impacts of global market reforms on women can be both empowering and constraining (Afshar and Barrientos 1999). While academic and professional opportunities abound for a certain segment of society, it is important to remember that the application of structural adjustment policies (SAPs) has resulted in the elimination of subsidies and continuous decrease in government assistance in the provision of schooling and health care. This has increased the risk and vulnerability of women and children in households exemplifying the variegated impact of globalization in India (Moghadam 1999).

At the same time, Hindutva has taken strong roots within the Indian imagination. Its impact varies depending on region and time period. While the RSS is seen as active 'on-the-street' political workers in Maharashtra, Gujarat and parts of South India, their grassroots level work in villages and small towns all across India has far-reaching impacts. This is especially so given the large-scale migration of largely male workers from rural to semi-urban areas to urban centers like New Delhi.

As educated-independent-empowered women routinely challenge generational gendered domination and entitlement in urban spaces like Delhi,, this clash between two ideologies constitutes the body of this research. The focus of this research is to seek answers with room for multiple constructions of gender and national identities.

It is inherently important to note here that the core of this research does not rest on simplistic assertions of masculine oppressors and female victims. Instead the intent is 
to examine a structure of power and influence that has historically been the preserve of hegemonic masculinities. This structure of power, shaped largely by masculine intents and desires, continuously adapts itself to the era, to the ideology and finally to specific circumstances. Powerful individuals, men and women to further their individual advancement use this construct but since the structure inherently favors the masculine, the lack of rigorous opposition and deconstruction means its continued and insidious strengthening. It is almost like a super weed, one that hardens and resists uprooting because the hands and trowels that can uproot it, use it to shelter them. This brief overview is intended to examine certain cultural determinants of subjectively selected historical epochs that I believe continue to influence gender relations in contemporary India through masculine dominations that are constantly reconstituted and reproduced. The following chapter will detail the theoretical positions that have shaped my research into the identity making processes of Indian women. Given my focus on specific markers that shape identity, I use feminist methodology to understand the impact of religious nationalism and globalization as they clash and concur in their project of controlling Indian nationhood and citizenry. This theoretical foundation-building process will be interspersed with a collage of snapshots that attempt to understand the positionality of Delhi-based media women with respect to framing the research. 


\section{CHAPTER III}

\section{Understanding Identity: The Theoretical Framework}

“We don’t want to be judgmental in our programming. I think you just do the story without bringing in feminism. It’s like being biased in our work.”

- Diya, Assistant News Editor (News and Current Affairs) Times Now.

As I prodded the 24-year-old woman to expand on the feminist-judgmental juxtaposition, Diya, Times Now shrugged her shoulders and said that she did not identify with "the bra-burning, men and women are equal brigade”. Elaborating on her stance, Diya, Times Now who lives with her parents, admits that she dislikes their “...hypocrisy” for having different rules for her and her brother. Yet she seems to understand their “concern for her safety...after all women are the ones who are attacked and raped...much more than men.” Other women interviewed for the research reiterated Diya’s, Times Now position about “feminism”.

This interpretation of feminism by women who are active in the public arena finds its roots in existing historical scholarship, as shown by Kumar (1993) who describes how Westernized women became "the focus of opprobrium from nationalists all over the country. Sarojini Naidu and Begum Shah Nawaz both declared that the Indian women's movement was not a "feminist” one like the Western movement; V. Ramakrishna Rao displayed an unequivocal distaste for the "sheer grasping suffragette”, bemoaning the loss of Sita and Savitri; and Cornelia Sorabjee linked the newfound assertiveness of many Indian women with "Western influence” (Kumar 1993:88). Given this historical thought process, it begs the question: In the present-day urban India of working women, 'modern' attire and 'equal' opportunities, what does feminism mean? How does one frame and 
understand the power relations that mark the processes of identity-creation? How do I, as a researcher in the field interpret the oppositional demands made on the lives of these 'women of substance' by globalization and religious nationalism? What does globalization and nationalism mean to these women?

Focusing on distinct markers that shape the identity of a specific segment of Indian womanhood, this chapter uses a feminist eye to construct a theoretical framework to understand how religious nationalism and globalization act on 'securing' the female body of the HUMM women; associating them with certain functions and 'appropriate' roles, a straitjacket of masculine desires/demands. From a feminist point of view, it is very important to focus on the constructions of masculinity and femininity, the gendered body since "the implications of gender extend from the most intimate to the most global social dynamics” (Peterson 1999:37).

At the same time, it is important to understand the mechanics of gendering/gendered bodies against a historic and social background that is formed by the intersection of geo-political, historical, class-based, racial, ethnic and religious units. This is important because it gives a geographically specific context to the stories of the media women as they negotiate, capitulate, compete and succeed in their continuous struggles to assert their rights to safety, security and opportunity. This is an engagement with the world around them that deems them progressive feminists. Towards that end, this chapter borrows heavily, not only from feminist theoretical scholarship, but also from the lived stories of the HUMM women, which also gave me an unexpected glimpse into their understanding of feminism. Briefly, the following sections construct a theoretical framework to understand nationalism and globalization, while keeping specific feminist 
positions in mind: "the recognition that gender is a focal point for all processes; a focus on power relations at various geographic scales; a suspicion of binaries or dualisms and a corollary preference for understanding connections and interdependencies, which feminists often refer to as relational analysis; a concern for justice; the need to comprehend the cultural construction of difference and boundaries; and a desire to build grounded, contextual understandings of global processes (Nagar et al. 2002:259)..

\section{The Academic Outlook on Indian Womanhood}

Feminist scholarship about post-colonial societies like India has centered on the 'woman question'. This body of research has sought to understand the place of women in the structuration of nation and nationalism (Jayawardena 1986; Moghadam 1994; Howland 1999) ${ }^{22}$. In the context of India, these studies have covered a range of efforts, from the social reform movements in colonial India to emancipate women from the practices of widow ex-communication, sati, and child marriage among other social ills (Chakravarti 1993; Sinha 1995; Bagchi 1995; Mani 1998; Sarkar 2001; Gupta 2002) to the prescriptions used by the independent Indian state to lift women from the domain of the traditional to the domain of 'careful' modernity. According to Das, the most recent focus has been to understand the impact of escalating tensions between religious nationalism and globalization, which has resulted in the "selective reinterpretation of the Hindu tradition” (Das 2004:1). As the Indian feminist scholarship-activism can

22. The appellation of the term Indian to nation-based women's movement is highly critiqued given its implication of social and political singularity that homogenizes the diversity and conflicts that assail them. The problem is not simply one of disunities but rather has to do with intractable conflicts involving the word "women" that derive from the central position of gender in postcolonial Indian culture and politics. Indeed, processes of gender - the construction of identities, roles, and relations based on sexual differences - played a key role in the historical formation of the Indian nation state (From Policy Research Report on Gender and Development, Working Paper Series 9, Samita Sen, 2000). 
"legitimately claim a rich, unique history" (John 1998), socio-cultural and economic upheavals caused by India’s liberalization and the re-emergence of Hindu-based nationalism demands a nuanced examination of the basic concepts of male dominance and gender hierarchies..

With this examination in mind, I turn to the concepts of patriarchies, a word that was often used during my interviews by the HUMM women to explain societal and institutional disadvantages they faced each day. They largely agreed that patriarchy was a multidimensional structure of power that privileged "everything male” (Alka, Zee News). Whether it was their labor, time, bodies or their skills, when compared to men, within patriarchal structures/circumstances, their value was lessened and the women largely experienced a distinct sense of gender-based disadvantage. While the HUMM women in particular and women in general experience, rebel and negotiate with gender-based differences, scholars have been grappling with the term patriarchy and it's various connotations, both enlightening and obscuring.

According to Kandiyoti, patriarchy is perhaps "the most overused and, in some respects, the most under theorized" (Kandiyoti 1988:274). Patriarchy, as a term with its monolithic, flattening binary definition structured around male domination and female oppression, has become problematic for feminist scholars. Since patriarchy, within families, societies and institutions takes on various forms depending on factors such as class, geography, religion, region among others, I find that it is necessary to contextualize the term otherwise, "it obfuscates rather than reveals the intimate inner workings of culturally and historically distinct arrangements between the genders” (Kandiyoti 1988:275). According to Mohanty (1991), a monolithic patriarchy, evenly present in and 
similarly effecting all places is a dangerous assumption. Not only does it erase the differences that exist among diverse female subjects, erasing history and agency, it also impacts development strategies and policies. Similarly Butler (1990) eschews the assumed universality of patriarchy. According to her, such application erases the particularity of gender bias and oppression in distinct times and places. Therefore it is extremely important to recognize that there are different forms of patriarchies, variations that operate using “systematic, comparative, empirical content” (Kandiyoti 1988:275) While agreeing with Mohanty (1991), Kandiyoti (1988) and Butler (1990), it is important to theorize gendered hierarchies and power structures that mark and control the lives of the HUMM women. Therefore I turn to Bourdieu's theories of gender construction and his analysis of the pervasive and insidious power of masculine domination, through which "the most intolerable conditions of existence can so often be perceived as acceptable and even natural” (Bourdieu 2001:1). According to Bourdieu, this domination is exercised through a form of "symbolic violence, a gentle violence, imperceptible and invisible even to its victims, exerted for the most part through the purely symbolic channels of communication and cognition, recognition, or even feeling (Bourdieu 2001:1-2). The language of masculine domination, when applied fully, act like "words [of] verdict...embedding social structures in bodies” (Bourdieu 2001:40, 70). This symbolic violence is a powerful weapon that creates the conditions of possibility for other immediate and explicit forms of violence, whether economic, sexual or physical.

Focusing on society and masculine domination, Bourdieu (1990), finds that social identities are acquired through the experiences and interactions of life. Calling the malefemale power dichotomy a naturalized condition, Bourdieu focuses on how "the division 
of the sexes" is not only present in "the objectified state...[but also]...in the embodied state - in the habitus of the agents, functioning as systems of schemes of perception, thought and action” (Bourdieu 2001:8).

While Bourdieu ${ }^{23}$ (2001) has been criticized for analyzing women’s apparent acquiescence, indeed complicity to masculine domination, rather than the structure itself (See Fowler 2003, Lovell 2002), I found certain shadows of this position, within specific situations/circumstances during my interviews. Whether talking about gender relations within the Kabyle society (a Mediterranean ethnic group) or Virginia Woolf's rendering of the Ramsay family dynamics, I also find resonance with Kandiyoti’s concept of “patriarchal bargains”, how “women strategize within a set of concrete constraints that reveal and define the patriarchal bargains of any given society, which may exhibit variations according to class, caste, and ethnicity” (Kandiyoti 1988:278). According to Kandiyoti , these patriarchal bargains have “...both the potential for and specific forms of women's active or passive resistance in the face of their oppression” (Kandiyoti 1988:278). Most importantly, these bargains are not written in stone but are susceptible to temporal and spatial influences. Therefore, a better understanding of these strategies employed by women in different social locations could provide “a corrective influence to ethnocentric or class-bound definitions of what constitutes a feminist consciousness” (Kandiyoti 1988:286).

In attempting to understand such consciousness within the HUMM women, I brought up the terms 'feminist' and 'feminism' during my interview and invoked strong

23. While Bourdieu's (2001) work has been soundly criticized for dismissing prominent feminist theorists, I find that I can use his definition of masculine domination that not only highlights the power, insidiousness and most importantly, mutability of the structure to theorize gender hierarchies. 
reactions from the interviewees that stretched from the imagery of sexually aggressive, anti-men heretics to the understanding of individuals who assert emancipation and equal rights/opportunities. This diversity of opinions is reflected in the extensive research that allows scholars to safely state that given varied historical eras, geography and sociopolitical factors that impact women's lives, there is a multitude of feminisms, multiple frames, rather than a single paradigm. Nowhere is this more applicable than a country like India. With it’s billion plus population divided by language, geography, urban-rural location, religion, caste-race and most importantly, the modern and the traditional, women's lives and experiences cannot be generalized in oppositional frames of empowerment and exploitation. Feminist intersectional approaches have been used to understand the processes of domination and inequalities inherent in social interactions on a micro as well as a macro level (Collins 2000; Glenn 2000; Sandoval 2000). These approaches have generated an impressive and critical body of works that cover the feminist nationalists of the Independence movement (See works of Jayawardena 1986; Minault 1982; Agnew 1979; Desai 2002) to Gandhian feminism (See Jain 1986), to ecofeminists (See Mies and Shiva 1993) to the 'new Indian woman' (See Dasgupta 2003 and Lau 2006), marginally co-opted and rejected by neo-liberals and Hindutva activists. The theoretically rich canvas of feminist theorizing and activism present a rich background for understanding and theorizing about new incarnations of globalization, nationalism, gendered roles among other socio-political and cultural phenomenon.

Before I embark on the path of theoretical framing for my research, I would like to briefly focus on certain tenets of Indian feminisms. This is important since my feminist theoretical framing of globalization and nationalism as well as the positions of the 
HUMM women has been strongly impacted by their inherent presence.

While categories of 'Indian’ feminisms exist and thrive, there seems conflicting information about the actual origins of these movements. The colonial period has been attributed as being particularly successful in the creation of a western educated elite and "female intelligentsia" within the Indian sub-continent (Pearson 1982: 136). It can be said that the rise of liberal feminism in India occurred because of a specific set of factors, which included "the presence of a colonial economy, the new web of modernizing impulses which interacted with contending circumstances and the criteria of sex, race, status, and class, caste and religion” (Anagol 2006:14). Understanding this juxtaposition is inherently important because it exemplifies power, "the place and mode of enunciation (who speaks and how) and that of its reception (how it is interpreted and why)" (Mani 1990:20). The politics of 'location' is also inherently important. As Mohanty argues, "the historical, geographic, cultural, psychic and imaginative boundaries, which provide the ground for political definition and self-definition” (Mohanty 1987:31) need to be seen not as fixed entities but as processes of knowledge production marked by "complex configurations of meaning and power” (Mohanty 1987:42). In other words, as tradition and modernity clash, irrespective of the era, society was defined by the voices and thoughts of those who wielded power. While a majority of such voices have been masculine, history has seen the emergence of feminine voices that have attempted to define and structure community and state.

But the images of such feminist Indian women constructed over the colonial and post-colonial periods continue to suffer from an elitist bias that is defined as being 
“western.” Most of the progressive women's forums, in colonial times, like the Bhagini Samaj started in Pune in 1916, the Prayag Mahila Samiti started by Rameshwari Nehru and the All India Women's Conference in 1926, were efforts of elite, upper class women (Bannerjee 1990). Mohanty has referred to these developments as the colonization of knowledge and the construction of "feminist interests as they have been articulated in the U.S. and Western Europe” (Mohanty 1991: 51). In other words, even as understandings of feminisms continually evolve in the Indian context, the roots of this multi-connotated ‘word-ideology’ appear to borrow heavily from Western progressive feminism.

But countering this position, Flavia finds that some Indian feminists have relied on "Hindu iconography and Sanskrit idioms denoting woman power, thus inadvertently strengthening the communal ideology that Indian, Hindu and Sanskrit are synonymous” (Flavia 1994:1124). This construction of Indian womanhood is further narrowed through the notions of class and caste. Locating the ideal of Indian womanhood within the Hindu middle class has been seen as a process of British colonial rule wherein feminist scholars such as Sangari and Vaid (Sangari and Vaid 1989:1-26) find that the consolidation of public and private spheres in the nineteenth century involved a systematic project of sexualization. Such idealization was achieved at the cost of loss of control over space, movement and the limiting of choices.

The following section examines the construction of idealized Indian womanhoods as defined by various interests.

\subsection{Embodying Indian Womanhood}

The body is a medium of culture, a surface on which regulations and hierarchies are inscribed and reinforced (Bordo and Jaggar 1989). It is not just a text or powerful 
metaphor for culture but also a practical, direct locus of social control (Foucault 1980). It is the location where through seemingly trivial processes; culture is "made body" (Bordo and Jaggar 1989:13).

According to Foucault (1980), organization and regulation of time, space and movements of daily life define, train and shape our bodies into prevailing categories of individuality, masculinity and femininity. For women, this disciplining and management of bodies has been channeled into a pursuit of a homogenizing, elusive desirable ideal. And this "pursuit without a terminus" serves the purpose of making female bodies into docile bodies whose purpose of being is decided by external regulation, gaze and subjection (Bordo and Jaggar 1989:24). Such processes of transformation are seen in the social reforms of the nineteenth century that required Indian middle class upper caste women to become the bearers of Indian culture against the West (John 1998). Women were subjectified as pious sites of nationalism that were solely responsible for shaping family ideals, maintaining conjugal relations and birthing future citizens of the nation. The domestic outlines of the middle class home and the family were strongly protected, refined and contested as the privileged sites of nationalist culture.

At the same time, the West educated Indian elite were creating their own version of 'docile bodies'. The creation of the Bhadralok (genteel folk) notion of middle class Indian womanhood was based on Victorian mores of chastity and homebound nature of women. Meanwhile, for Indian nationalists-activists, essentialist Indian womanhood was specifically constructed in opposition to both Western materialism and lower caste/class sexual norms (Mohanty 2003). Irrespective of the intention, whether colonization or liberation, the masculine cadres required the 'fixing' of Indian womanhood into a specific 
role-space. Borrowing from Narayan (2000), the fixing of Indian women into categories were projects of essentialism and such attempts at universalizing ideal Indian womanhood continue today.

According to Mehrotra’s (2001) research on women’s movements in Delhi, the liberties that middle class women continue to seek today are already available to marginal women and the socio-economic elite, who smoke, drink and lead far less sexually claustrophobic lives than idealized middle class/caste women in India. Mehrotra (2001) finds that women who have political and social clout such as Indira Gandhi, Medha Patkar and Gaura Devi, were portrayed and accepted by the Indian majority as goddesses in the traditional mould rather than feminist in the modern sense. Therefore strong public women personas have continuously been projected as asexual mother/daughter figures ${ }^{24}$.

These constructions can be theorized using Foucault's (1980) conception of power, a network of practices, institutions and technologies that sustain positions of dominance and subordination within a particular domain rather than those that rest on binary divisions of oppressor and oppressed. He finds that “..."Power,” insofar as it is permanent, repetitious, inert, and self-reproducing, is simply the over-all effect that emerges from all these mobilities...it is the name that one attributes to a complex strategical situation in a particular society” (Foucault 1980:92) According to Foucault (1980), power is exercised with the intention of producing behaviors and practices that

24. The overtly sexual woman within Indian consciousness is immediately associated with the cinema and other arts. Such 'laxity' is permitted for the artists since they are creating fodder for the largely male audiences. Recent cinema that portrays Indian women in empowered roles are targeted for the urban and overseas markets. But with few exceptions, known largely as art house movies, the defined roles for women remain traditional. 
would be different without such discipline. His analysis of power sees power seeking and building at the micro level of the local and individual rather than at the macro level of class or gender oppression. Power has to be understood through the patterns of practices and discourses, their interactions, not just as a general design or institutional crystallization but also as something more complex and insidious. Bordo (1989) finds that power's central mechanism is constitutive rather than repressive, "a power bent on generating forces, making them grow and ordering them, rather than one dedicated to impeding them...” (Foucault 1978:136 in Bordo and Jaggar 1989:15).

According to Foucault (1980) and I agree that power is an omnipresence that pervades the entire social body. One of the techniques/regulatory modes of power that Foucault(1980) cited was the Panopticon, an architectural design for carceral institutions such as prisons, asylums, schools and factories by Jeremy Bentham in the mid-19th century. Instead of employing violent methods as employed by the monarchial state to control its citizens, the new supposedly democratic state needed a different regulatory system. The Panopticon offered a powerful and sophisticated method of internalized coercion through the constant observation of prisoners, each separated from the other and allowed no interaction. The modern structure would allow guards to continually survey the prisoners from their vantage point in a high central tower, while remaining unseen by them. The consciousness of constant surveillance is internalized and creates a controlled pattern of behavior and self-discipline (Foucault 1980).

The Panopticon was used as a metaphor by Foucault to explore the relationship between systems of social control and people in disciplinary structures. Foucault states 
that the result of this surveillance is the largely unquestioned acceptance of regulations and docility, a normalization that was rooted in the threat of discipline. Acceptable behavior is achieved not through total surveillance, but by the assumption of its omnipotence that results in the internalization of such surveillance by entire populations.

For instance, these workings of power can be seen in the expectation of asexualized public persona of the Indian woman, which is rooted in the domain of mainstream Indian nationalist movement and regularly borrowed by globalization enthusiasts. It can be theorized that powerbrokers of both ideologies require the presence and support of women, while ordering them to remain in their control. Therefore they allow women public space and yoked power rather while constantly reiterating the codes of chastity. It is constantly reiterated that threatening and rejecting said codes would lead to the jeopardizing of their position and power, an omnipresent mechanism of control. According to scholars like Mohanty (2003) and Sangari (2001), male-led reform movements of the colonial and post colonial eras have been preoccupied with legislating and regulating the sexuality of middle class women while selectively encouraging their entry into the public sphere, by instituting modes of surveillance that in turn controlled women's place in the labor force and in politics.

A strong component of this surveillance of Indian women is strongly structured by the Lacanian concept of the gaze, where an autonomous subject sees the observation of himself in the mirror, which then shapes and influences individual human agency. The gaze is a powerful tool in the creation of "docile bodies" through constant observation that is characterized by an unequal gaze. According to Foucault (1977), such possibility 
of constant observation results in the internalization of disciplinary individuality and molding of bodies into correct forms.

Within feminist theory, the male gaze as coined by Mulvey (1975) was seen as a tool of power asymmetry and is seen as having ascendancy over the female gaze. She theorized that the male gaze denied women agency and relegated them to the status of objects, forced to experience all narratives through a male perspective. The male gaze commodifies women and her sexualized portrayal is for the pleasure of the heterosexual male viewer. The awareness of constant observation leads her "to survey everything she is and everything she does because how she appears to others, and ultimately how she appears to men, is of crucial importance for what is normally thought of as success in her life. Her own sense of being in herself is supplanted by a sense of being appreciated as herself by another...” (Mulvey 1975:43).

It is this awareness of the male gaze that sexualizes a woman's body that anchors the disciplining of women, their bodies and their movements. Indeed, as Kumar (2004) writes, it is fear of the male gaze that brought together feminist activists and Hindutva activists during the Ms. World contest held in Bangalore. While the feminist activists were protesting the commodification of the woman's body, the Saffron Brigade was against the 'un-Indianness’ of the contest. Yet both diametrically oppositional groups saw the power behind male gaze as omnipotent while reducing the women to inanimate objects with no will or agency. The uneasy alliance between the two groups is a strong indication that global realignments and entry of global capital has led to further consolidation and exacerbation of control over women and womanhood. 
The following section theorizes the various processes of globalization ebb and flow, integrating with local realities as they attempt to create a standardized ideal consumer.

\subsection{Understanding Globalization}

As noted in the previous chapter, globalization is not a new phenomenon. Political and economic relations at the global scale have long histories, rooted in colonialism, imperialism, and the discourses and practices of the development industry (Escobar 1995; Katz 2001). Mainstream understanding of globalization deems it to be a neutral phenomenon without any gendered power relations at play in its complex processes (Hawkesworth 2006). But denying such claims, feminist scholars have deployed gender as an analytical tool "to decode meaning and to illuminate how gender hierarchies are created, preserved, and changed through the complex interaction of norms, symbols, interpersonal relations, social practices and religious, economic and political institutions” (Hawkesworth 2006:10). They find that these systemic tools privilege malehood and masculinity while largely devaluing womanhood and femininity.

At the same time, it is important to beware of flat renderings of people within the framing of globalization since this homogenizes the multiple impacts, both oppressive and liberalizing on the lives of the subjects. As Nagar et al. (2002) find, analysis of gender and globalization frequently reduce all discussions of women as passive victims. Such construction of women as being universally exploited by global capital and neoliberal policies is opaque and “...obscures the ways in which gendered subjects in particular historically and geographically specific places engage in complex and 
contradictory experiences of, and in response to, global processes” (Nagar et al. 2002:269).

Globalization in India has been seen as a liberalization process that has influenced everyday life through powerful images created by television and print media, a reproduction of a new public culture which is "a continual interplay between a fetishization of hybridity and a politics of purity" (DeKoven 2001:149). Even as the viewing public is fed a staple diet of images that depict India's interaction with the world economy as being a productive hybrid relation, feminist scholars clearly delineate that emergent and fracturing configurations of power are displaced onto the territory of women’s sexuality (See Parekh 2001, Oza 2006, Das 2009). The notions of femininity and purity mark and maintain the borders of Indianness within hybridized interaction between the nation and the non-nation that is the result of globalization (Fernandes 2000). Indeed, the 'rules' are propagated through bodily discourse, through mediated images that insidiously teach women about a plethora of appropriateness, from body shape, facial expression to behavior and movement. At the same time, it is important to remember that such gendered expectations are also resulting in rebellion, indicating that it is important to conceptualize women as "people who are embedded in social relations of gender, class, race, and so on, as well as in multiple networks for coping with, reforming, or resisting global processes (including unions, feminist organizations, and environmental social movements)” (Nagar et al. 2002:269). Nagar et al.'s (2002) position on mediated imagery recalls Hall's work on hegemonic culture, power and institutions. According to Hall, culture is "a critical site of social action and intervention, where power relations are both established and potentially unsettled” and people are consumers and interactive 
producers of this culture (Proctor 2004:2). He states that the mass media are central to modern capitalist culture since they are a powerful, omnipresent resource for controlling and shaping of people’s beliefs and ‘common-sense’. Moreover, Hall (1973) “... argued that the practice of signification through language establishes maps of cultural meaning which promote the dominance of a ruling-class ideology, especially by establishing a hegemony. This involves containing subordinate classes within superstructures of meaning which frame all competing definitions of reality within the range of a single hegemonic view of things” (McQuail, 2000:307). At the same time, he also sees a field of ideological struggle. Therefore, the imageries of the urban Indian women, whether wrapped in ethnic ensemble or engaged in 'real' work is created, dispersed and interpreted through multiple stages or moments.

At the point of origin, the discourse is shaped by the "meaning structure of the mass media production organization and its main supports” or dominant ideology and creates a "preferred reading” (McQuail 2000: 57). This is followed by the dispersion of the message and its circulation within the viewing/reading audience followed by the decoding of the message by them. In his approach to texts, both verbal and visual, Hall (1980) focuses on the scope for negotiation and opposition on part of the audience. He finds that an audience is not a passive recipient of ideas and images. Instead depending on their own cultural background, the audience members will engage and negotiate the meaning of the text. Based on his model of 'encoding' (the institutional practices and organizational conditions of production of message) and decoding (the reception of the message) discourses, the meaning of a text lies somewhere between the producer and the reader. He calls this difference, this distortion, the margin of understanding (Hall 1973). 
This margin of understanding is dependent on three hypothetical interpretative codes or positions for the reader of a text: dominant or hegemonic reading (the reader fully shares the code of the text), negotiated reading (a part sharing and part resistant stance) and oppositional or counter-hegemonic reading (rejects the code based on alternative frame of reference (Hall et al. 1978).

Hall's research on how media messages are produced, dispersed and consumed also focuses on their common sense status through their repetitive performative nature. Repeated performances and reiteration create specific cultural interpretations of 'events' that attach values of plausibility and universality to them (Procter 2004). For instance, Hall et al.'s (1978) study of crime and the manipulating of crime statistics for economic and political purposes finds the media was used to create moral panics to both define and distort social problems so as to legitimize punitive measures and reiterate societal control in the hands of established authorities. The media amplified the perceived threat to the existing social order such that the viewing public embraced the 'common sense' of state and police control into their public spaces.

Extrapolating this study to the Indian urbanscape, one can theorize that the moral panic surrounding 'unfettered' women's bodies and therefore sexuality has been ignited in order to create public support for the need to police them. In other words, "the media tend to reproduce the definitions of the powerful” (Hall et al. 1978:57). They symbolically reproduce, the existing structure of power in today's dominant institutional order, whether it is nationalism or globalization.

The cultural politics of globalization in India demonstrate how globality and its influences are invented/nuanced through the deployment of dominant narratives. 
Fernandes (2000) finds that globalization in India has produced a form of reterritorialization, which is based on the politicization of gender and sexuality in the newly produced India Inc. Increasingly, both electronic and print media disperse images that support hegemonic political culture that encourages economic liberalization while largely discarding the remnants of a state-dominated planned economy. The imagery constantly visualizes a India that thrives on new patterns of commodious consumption by the urban middle classes. Such representations are the bridge between the global and the local, where the politics of economic liberalization are negotiated (Fernandes 2000).

According to Indian feminist activists, globalization has led to the destabilization of social codes, spaces and positions within the national boundaries. This has pushed established leaders of all ilk, largely male, to attempts of policing/disciplining the rapidly elasticizing boundaries of women's activities, expectations and voices. The tactics are mired in masculine panopticonism in which the emergence of Indian national identity rests on the preservation of a protected inner sphere of tradition that could confront and adapt to Western standards of progress and development (Chatterjee 1989).

Oza (2006) finds that the cartographic anxiety of postcolonial India has led to the equating of territorial national boundaries to the boundaries imposed on homogenized Indian womanhood. Therefore, protecting Indian women insures the protection of the nation's boundaries. Extrapolating this post colonial cartographic fears to globalizing India has impacted more than national territories and state power, the physical geographies of the country. It has impacted domains of everyday life by creating culturalpolitical-economic spaces that challenge traditional gendered identity. In other words, 
globalization is changing the narrative and geography of life and nation in India and feminist analysis of globalization needs to focus on how the abstract spaces, physical sites and scales are framed. It is important to frame and understand the impact of globalization from the ground up, focusing on the scales of the body, the household, community and workplace where relational processes bind spaces and scales. This challenges the masculinist understanding of globalized space and scale as being immutable and discrete (Hyndman 2001).

Since feminist scholars argue that globalization processes are embedded in community and household scales, focusing on these multi-scales has “...allow[ed] us to understand the nuanced ways in which neocolonial relations of power and political economic structures of domination and subordination combine to shape gendered politics of inequalities, difference, and resistance” in specific communities (Nagar et al. 2002: 685). My analysis of globalization recognizes the particularities of places, but also examines the impact of being deeply interconnected with processes of globalization, to reveal “a local that is constitutively global” (Katz 2001:1214).

These new threads that embroider new meaning into the fabric of the Indian nation emerge from semiotic spaces created by the media. Indeed, Appadurai (1996) states "the micro narratives of film, television, music...allow modernity to be rewritten more as vernacular globalization and less as a concession to large scale national and international politics”. Representations of commodities and the meaning associated with their usage led to the production of a national cultural standard associated with the urban middle and upper classes, a narrative of nationhood, modernity and development that 
defines the middle class and vice versa. This linking of middle class respectability and progress to commodity consumption is created through the reworking and reproduction of gendered social codes meant to delineate appropriate space-place and movementbehavior.

As Shikha, Associate Editor, Times of India states, "We are constantly cutting to commercials between our programming that send out messages that buying certain products will reiterate your status in society. But as I talk to you, I see that the basis of all the ads are the same...traditional family with a husband, wife and two children...usually a boy and a girl. Talk about subliminally sending out messages [about] what is ideal and what is happiness!” Shikha, Times of India is referring to the establishment of a sense of order, of common sense that is being used to quell the anxieties stemming from emergent cultural, social and economic restructuring associated with globalization. According to her, the widely dispersed images are always associated with scenes of idealized heterosexual domesticity, sanitized, traditional and implying controlled sexuality. Any deviation to this message can result in a plethora of crimes, of discriminations, of bodies being texted as deviant and/or disposable.

Melissa Wright’s (2006) work illustrates how another discourse of globalization, "the disposable women" has facilitated the success of maquiladora production in Ciudad Juarez, Mexico. Transnational firms employ women, who are constructed, through discourses of femininity, as being in the workforce only temporarily and as working for "lipstick”. Given such construction of temporary workers have allowed firms to not invest in educating, training, and promoting them. Their resultant low wages and dead- 
end jobs, justified through the gender ideologies that they are working only for their own amusement and will soon leave the workforce for family reasons, reinforce the notion that they are disposable women and, in the process, justify their low wages in the service of global capital accumulation (Nagar et al. 2002).

Using these various constructions of Indian womanhood, narratives of globalization has been created that is located within and borrows from/fed by nationalist imagination. The dominant imagery produced, dispersed and consumed by an avid audience sees an India structured by “contradictory and contested gendered politics...[wherein t]he trajectory of a globalizing India has produced images of "the new Indian woman," one who "must attend her national identity as well as her modernity; she is Indian as well as new..."the tough as nails career woman who finds it easy to indulge in the occasional superstition. Her outlook is global, but her values would make her grandma proud” (DeKoven 2001:156).

Therefore, I theorize that globalization in India has been accepted, indeed embraced by a burgeoning middle class in a mutated form resulting from a hybridization between global definitions of progress and a peculiar sense of respectability and sharam (shame). The principal shifts that mark this vernacular globalization are shaped, dispersed and injected into the imagination of the Indian population by mass media, not only as "direct sources of new images and scenarios for life possibilities but as semiotic diacritics of great power” (Appadurai 1996:53).

My feminist approach theorizes that globalizations are historically and culturally specific. Global capital and neoliberal policies engage and discipline peoples to create diverse and contradictory outcomes, spatial unevenness and sometimes, chaos. My work 
will reveal how globalization has re-organized class processes and transformed gender relations and identities in households, streets and workplaces.

\subsection{Understanding Nationalism:}

According to Peterson (1999), "nationalism is a particular - and particularly potent - manifestation of political identification...[that] is problematic from the vantage point of those within the nation who share least in élite privilege and political representation, especially those whose identity is at odds with the projected image of homogenous national identity” (Peterson 1999:35). Peterson (1999) theorizes that nationalism has three significant facets: "liberation (the positive association of nationalism with self-determination and democratization), exclusivity (the promotion of group homogeneity and 'difference' from 'others'), and domination (the negative effects of suppressing difference within the group and/or domination of 'outsiders' in the name of the group)” (Peterson 1999:36). Therefore, the nation whether imagined (Anderson 1991) or invented (Gellner 1983) rests on the promotion of uniformity within the group (Peterson 1999).

These three theoretical facets form the core of Hindutva ideology. In India, the intermeshing of the traditional and the modern rests in uneasy balance. As nationalist leaders interpret the unsettling of socio-cultural boundaries and the creation of hybrid spaces and individual expectations as indicating dangerous anti-norms and asabhyata (cultural indecency) that challenge the 'exclusivity' and 'self determination' of the Hindu nation, there has been an emergence of persuasive and coercive means to stamp out such rebellious notions. In an attempt to protect the 'core of the Indian nation', there has been 
a vigorous revival of gendered politics, of 'domination' that conflates the security of the nation with the protection of its women. This is done through the entrenchment of 'traditional gender roles' that inherently symbolize the Indian woman as the container of Hindu honor and therefore, vulnerable to outside contamination.

According to Hindutva rhetoric, “...every child of the Matribhoomi [Motherland] must daily bow before the Mother and renew his pledge to restore her to the ancient pinnacle of glory from which she has fallen.” (Swami Shraddhananda, emphasis in original in Gupta 1998). Even as Hindu iconography contains multiple versions of combative Goddess figures, the Hindu woman is constantly projected as a passive figure, as "Mother and nurturer, preserver of tradition, and property... [who is the] container, the repository of Indian tradition...” (Pandey 1991:2004). Her power lies in submission. Scholars have argued that the rise of Hindutva discourse in contemporary India is marked by the desire to further entrench Hindu male-defined traditions as well as a militant Hindu chauvinism (Das 2004:5). This is fundamental for group reproduction - both biological and social. An outstanding example of such politics is seen in the literature used by the BJP as it harnesses support within the Indian masses. Das quotes a leaflet entitled, "Hindu Bandhuon: Soncho Aur Sambhalo” (Hindu Friends: Think and Protect) that the BJP distributed in the district of Bhagalpur, India, 1989-1990 stating "The Hindu is being worsted everywhere in his own country... His women are being raped. The Hindus have been completely wiped out...their property have been looted. Their women have been raped” (Hindu Bandhuon: Soncho Aur Sambhlo, 1989-1990) (Das 2004:8). While Das (2004) uses the leaflet to explain the anti-Muslim core stance of the Hindutva brigade, I theorize that this "Othering” is now being used to engender fears of 
West-led globalization, which requires the rising of Hindu men to protect the Indian women, resources and nation from the marauding of the outsiders. These outsiders are ordered as threatening the Hindu order, the Hindu family that is seen as being prepolitical and natural. For instance, my conversation with Ram Madhav, the national spokesperson for the RSS that was held in his office in the older northern part of Delhi was a telling example of this motif. Dressed in a kurta-pyjama (Indian tunic and pants), the well-spoken public relations officer theorized that cultural globalization is a form of cancer that was eating away at the core of the Hindu nation. Regularly pointing to a portrait of Bharat Mata (See Appendix E) on the wall, he claimed that India should embrace only economic progress and demanded that the West keep "their sexual antics to themselves. Why should our Indian ladies copy that kind of wear or habits?” Closing his eyes and shaking his head, the voice of the RSS said, "We are Indians with centuries of tradition and culture. We are different from them, no matter how much they want to convert us.” In other words, the control over women and their bodies by masculinist Hindutva ideology is seen as being 'natural.' There is an aggressive and continuous process to text the woman's body for determining the limitations of gender and society.

The 'naturalness' of such constructions is based on a hierarchical dichotomy of gender that largely privileges the masculine over the feminine. This conceptual ordering is intrinsic to state making and constantly reproduced through masculinist discourse whether political theory, religious ideology or capitalist inclinations. With masculinity being constituted as reason, order, and control, masculine domination is reproduced through conceptual systems that privilege male entitlement - to authority, power, 
property, nature. Central to this ideology is male entitlement to women's sexuality, bodies, and labor (Butler 1990).

The 1990s saw the rapid incorporation of India into the global economy while on the domestic political scene, the election of the Swadeshi (our country) economics touting Bharatiya Janata Party heralded a new era. Even as they facilitated the continuation of economic reform, the nationalist party simultaneously implemented their traditional theory and cultural rhetoric with a focus on obscenity and censorship. Most of the censorship was targeted towards so-called sexualized representations of Indian womanhood, from the clothes of the female newscasters on Doordarshan (state television) to advertising that showed women in 'modern' attire. Scholars theorize that these policies are largely indicative of nationalistic resistance to globalization that veered from economic policy to gendered applications, the nationalist brigade focused on the supposed contamination of the purity of Indian culture embodied by the Indian woman, a politics of purity (Das 2004).

This conception of purity of the Hindu woman and by extension, the Hindu nation is largely constructed using Vedic literature and the misogynistic Manusmriti. In her study on gender politics and India's nuclearization, Das (2004) finds that "this traditional conception of Indian women (now identified by the BJP specifically as "Hindu” women) is being "re-furbished" by the party by "sharpening, standardizing, and generalizing" (Roy 1995:10) such identities along communal lines to construct a Hindu nuclear agenda” (Das 2004:14). She finds that a constant image of Hindu women in their "perennially threatened" conditions leads the Hindu nationalists to represent her as 
“Matribhumi, Bharatmata, and Woman writ large” (Das 2004:16). Resting in religious mythology, these constructions have deep roots within the Indian imagination.

And according to Barthes (1972), myth is a form of speech, a mode of particular signification that primarily functions to naturalize history, therefore suggesting that meanings are constructed through codes that make the images appear natural and obvious but in reality are 'man'-made. Myths are the hand-maidens of the dominant class that assist in mystifying and obscuring their origins and thus their political and social rights to lead and decide the path of the larger masses. Barthes states, “...myth hides nothing and flaunts nothing: it distorts; myth is neither a lie nor a confession: it is an inflexion” (Barthes 1972:129).

In his interrogation of specific cultural materials to determine the assertion of values through them, Barthes (1972) found semiotics useful. Using Saussure's model of signified (an object) and the signifier (a linguistic representation such as letters or sounds), he shows myths to be another sign, rooted in language that itself acts as a signifier. This action gives rise to a new meaning, which is the signified. He sees the use of signs to connotate specific meanings as a means of manipulation. For instance, in 'Le vin et le lait’ (Barthes: 1970:74-77 in Moriarty 1991) Barthes explores the significance of wine to the French. Wine is clearly an important symbol for the French that connotates conviviality, virility and national identity. Nothing could be more expressive of an 'essential Frenchness' than a ballon de rouge (McNeil 1999). But Barthes peels away the signification of wine as a French symbol of social equalizer that is refreshing and healthful by making explicit the connection between wine as a commodity-for-profit and wine-makers' exploitation of the Third World. He cites the example of Algeria, a poor 
Muslim country forced to use its land for the cultivation of a product, which they are forbidden to drink on religious grounds instead of using the same land for cultivating food crops (McNeil 1999). According to Barthes, exposing such connections as artificial constructs determined by history rather than nature or tradition allows the masses to confront existing power structures.

Barthes (1972) contended that myth is defined by intention rather than by its literal self. Myths lend ideology a natural and eternal justification. Ideologies based on myths do not ask for explanations instead ironically, they become statements of fact. This form of depoliticized speech that transforms history into nature helps explain how the male advantageous systems of nationalism, use images of Indian womanhood, as a homogenous entity based on the bodies of middle class Hindu women, as a reality that is pure, natural and eternal. In the structure of nationalism, the Hindu woman's body, the signified, is also the signifier (linguistic associations with chastity, docility, sacrifice among others), gives rise to the myth of the ideal Indian woman who must possess the above mentioned qualities as nature-given and therefore, unquestioned and unquestionable.

While this imagery for the masses, the Hindu woman as "cherished but remote icons” (Sarkar, 1995: 206-207) rests on her vulnerable images of the pativrata Sita and courageous Draupadi, the Hindu nationalists also use the imagery of militant Hindu Goddesses like Kali and Durga. These militant figures are used by the Hindutva brigade to put forth their progressive ideology for a modern nation, wherein these women are portrayed “... as sovereign embodiments of the state” (Agarwal 1995:30). Yet scholars will argue that Hindu nationalists might claim an emancipatory message within their 
ideology but their access to equal rights rests on their toeing the communal party line (Das 2004). The party line demands the purification of all spaces; physical-sexual, sociocultural and economic through the removal of all that is considered a threat to the IndianHindu nation (Oza 2007), whether it is the presence of a Muslim citizenry or the impact of Western mores on Indian life choices.

Borrowing from Foucault (1980), I theorize that this political construction of pure bodies is repeatedly used to create policies that target-limit the options for women. The body is more than just "a brutely biological or material entity" (Bordo 1989). It is a culturally mediated form that is open to interpretation and definition. The shift from the ideal of mythological characters to the practical dimension is not a turn to biology or nature but to another “register” (Foucault 1979:136). From the 'intelligible body’ that is created “...by scientific, philosophic, and aesthetic prepresentations of the body - our cultural conceptions” to “a socially adapted 'useful body' that through a set of practical rules and regulations is "trained, shaped,[to] obey, respond" (Bordo 1989:25-26), there emerges a new symbolic form of modern Indian femininity that is used to create and recreate societal discipline and state policies.

For instance, a 1948 Act that bars the employment of women in businesses before 6 AM and after 8:30 PM is regularly used by the morality brigade ${ }^{25}$ in the name of safeguarding the body and therefore honor of Indian women (Channa 2004). Feminist scholars such as Channa (2004) reiterate that the state's move to control the cultural lives

25. In 1996, the conservative Shiv Sena government in Maharashtra spearheaded a movement that revoked the licenses of all establishments that featured late night dance shows. According to the Cultural Affairs Ministry, these 'dance bars' were distorting Indian culture/morality and had to be shut down to protect Indian womanhood (Channa 2004). 
and spaces of its citizens require the deployment of gendered norms that are secured by a rationale, which rests on the protection and purification of women’s sexuality. Yet Channa (2004) finds variegations in the implementation of such rules. Therefore, the IT sector that defines the outsourcing revolution and the export oriented jewelry and electronic industries have successfully pushed through for modification of the Factories Act (prohibits the employment of women workers in factory night shifts) that now allow post dusk work for women while the bar dancers and waitresses of Mumbai continue to be included within such 'protection.' At the lived level, this creates divisions within women, sometimes through their own complicity and praxis.

I find such anomaly in legal application is based on Hindutva discourse that sees the new India as being modern rather than Western, creating a dichotomy through notions of cultural purity. In other words, women workers in factories are engaged in creating wealth for the nation through their underpaid labor and remain under the scrutiny of male managers. The constant vigilance of the female bodies even as those bodies are outside the confines of their homes maintains purity and respectability. On the other hand, dancers and waitresses are seen as being aberrant sexual bodies that are usually clad in skimpy Western outfits and therefore seen as being impure and dangerous to the sanctity of good Indian women and the nation. Therefore, they are restricted and left unprotected by the law (See Channa 2004). The subjective use of cultural purity to justify the implementation of laws of protection is regularly used by the media to create "stories of the specific,” such as the increased incidence of rape within women working in bars similar to Hall et al.'s (1978) research into the coverage of muggings in the UK by the 
national media. With their focus on the details of such horrific crimes, they create a timespace and place-space that are deemed dangerous for women. Therefore, depending on the context, the body is constituted as "a multidimensional and complex object of political struggle-a 'cultural battleground' on which a wide array of issues are fought out” (Hall et al. 1978:12).

Therefore paraphrasing Peterson (2003), I suggest that the following are conceptually and structurally joined in Hindutva ideology: a codification of homogenizing gender binaries as the foundational symbolic order, the production of oppositional gender identities to serve heterosexist reproduction and hierarchical relations, the conceptual and material creation of gendered spheres of social activity that structure hierarchical divisions of authority, power, labor, and resources.

In conclusion, I theorize that Hindutva-style Indian nationalism is predicated on keeping the core of the nation a pure Hindu homogenous structure. Gaining its strength from the immutable myths and traditions of ancient Hindu scriptures, Hindutva requires that the homogenized Indian Hindu woman be projected as the nation, as the repository of morals, values and citizenship. Her homogeneity rests in the essentialized qualities of docility, sacrifice and great forbearance. Hindutva ideology theorizes that all movements, spaces and behavior have a moral component and therefore, depending on how these elements are used and by whom, there are heterogeneous reactions.

Even as gender is deployed to understand the processes of nationalism and globalization, can we speak of a collective feminist understanding of the processes and markers of these discourses? Like any other lived process, the variations of the 
understanding of nationalism and globalization are unlimited. While the voices of women I interviewed rejected Hindutva as an embarrassing artifact while embracing globalization as their means of empowerment, post-colonial scholars like Spivak (1983) who use epochal terms like the "feminization of the proletariat," and the "NGO-ization of feminism" to describe globalization. Can the diametrically oppositional position be attributed to the divide between the ivory towers of academia (relatively empowered) and the battlefields of existence that working middle class women face every day?

During my fieldwork, my theoretical position that embraces the path breaking work of scholars like Mohanty (1987), Narayan (2000), and Oza (2006) was rigorously strengthened by the HUMM women who have taken admirable strides towards emancipation and attaining equal rights while battling against the imagery of being dangerous outliers who "outrageously buck traditions" and challenge the status quo of masculine domination. The following section seeks to place their insights into my theoretical understanding of globalization and nationalism, an analysis of power and identity "from below" (Foucault 1978:94).

\section{The Street Outlook on Indian Womanhood}

While this project is looking at the impact of mutating patriarchal ideologies on a specific class of women, it is very important to continuously reiterate that Indian womanhood cannot be defined as 'a' social category and marked by terms of "underdevelopment, oppressive traditions, high illiteracy, rural and urban poverty, religious fanaticism and overpopulation” (Mohanty 2003:47). When there is application of a cross-culturally singular, monolithic notion of patriarchy or male dominance, it leads to a reductive and homogeneous notion, what Mohanty calls the ““"Third World 
Difference"-a stable, ahistorical something that apparently oppresses most if not all the women in these countries” (Mohanty 2003:335). It is inherently important to state that I see patriarchy as a structure that is inescapably tied to ideas, images and expectations of the powerful male and is continuously evolving, non-inertial and largely defined by context. It is necessary to remember the theory of context, of background because without it, there is the danger of disregarding the chameleon like nature of patriarchy and deeming it a singular institution, a singular structure of oppression. Therefore, any form of essentialization that cuts a broad swathe and places ‘the' Indian woman in a hierarchy that sees the Western enunciation as being progressive/modern while 'she' is seen as being backward/traditional/oppressed by a unitary understanding of patriarchy and therefore frozen in "time, space and history" is insidiously limiting and denies appropriate prescriptions for emancipation and empowerment (Mohanty 2003:48).

Further layers were added in my conversations with my interviewees who dually rejected any connection with 'oppression' or Westernization. Instead they largely saw themselves as being modern progressives. According to Shikha, Associate Editor, Times of India, "I go to work at 10 in the night since the parties all start at that time...I make sure that the maid has cooked for my father and brother before leaving...that combination of activities means that I am modern and traditional at the same time...does that make me a feminist? I think so...because I am doing what I want to do...”

Feminist scholars such as Mohanty (1988), Puri (1999) and Rajan (1993) have repeatedly alerted us to the dangers of assuming that women are a coherent group upon which social, economic, or political processes act. Whether such groups are based on race, religion or nationality, the impact on the daily lives of women so defined is 
immense and usually destructive. According to Mohanty (1988), the homogenizing continues unabated not just because of the resilience of gender and racial inequalities but because of the ways in which the latest phase of global capitalism, or what she refers to as the military/prison/cyber/corporate complex, works to re-colonize marginalized subjects in complex ways and undermine gains fought for and achieved. At the same time, the cheerleaders of religious nationalism to further their agendas repeatedly use this homogenized assumed rootedness about identity and place. As Suman, Aaj Tak states, "We are the media wali (media women)...powerful when in our place.” Yet in spite of the awareness of attempts to fix their roles and lives, the media women concur that they follow the script and create texts that follow dominant ideology, what Hall (1978) calls "preferred reading."

An outstanding example of the media creating "preferred reading”, the ideologies of the dominant can be seen in the frighteningly pervasive programming that reflects and glorifies ‘traditional' roles and processes that are seen as being Indian but rural such as child marriage (Balika Badhu) and sexual dominance (Bairi Piya). The popularity of such drama series within its urban audience indicates a certain acceptance of the presence of legally banned traditions. While the makers of such series claim to highlight the presence of social evils within India, there is a continued reiteration of specific roles for Indian womanhood that is disempowering or draws power by being dependent/favored by the patriarch. In this form of homogenization, the HUMM women, most of who claimed to not watch the soap operas, relegated them to the pile of antiquity that operates in the rural spaces and marks the lives of the uneducated. Their positions denote the cleavage between the urban and the rural of India. As Mallica, a thirty-two-year-old ex-employee 
for Maxim 's, one of India's premier men's magazines, who is trying an alternative career as an alternative medicine practitioner, states, "I realize how privileged I am. Being born in the right family...it's like karma. I was born at the right time to avail the vast opportunities...booming media, technology and changing societal rules... at least for aspiring middle class families. But not so much for my kaam waali (maid).” Therefore, even though her household help lives in the urban, she is representative of the rural, the backward, the 'class' that makes the above-mentioned soap operas popular. Their reality is different from the HUMM women. They are "disposable women” (Wright 2006).

But for women like Mallica and the rest of my interviewees who are actively and continuously pigeon-holed by nationalists and globalists, globalization becomes equated to consumerism, where approximately 350 million middle-class Indians consciously aspire to become like "a Mercedes-driving, tie-wearing New Delhi-ite” (Appelbaum and Robinson 2005:180). According to Liechty, the middle class is defined by "cultures of consumption," which is used to create a socio-cultural identity in the globalizing world (Liechty 2003:7). And it is this culture of consumption that has allowed, indeed pushed women into the public space of professional work. While Mies (1986) has argued that capitalism requires the "housewifization" of women so as to avoid paying them living wages, the explosion of consumerist culture emphasizes the need for active consumers (Munshi 2001 in Appelbaum and Robinson 2005).

Thus, while globalization appears to engender further opportunities for women, the intent is to create disposable income that can be used to create an ideal pride-centered lifestyle. And towards this end, advertising in India addresses women as "active and vital consumers in their own right” (John 1998:379). Embracing the power of paid 
employment, Shikha, Times of India admits to "loving retail therapy. But I know that without having fifty expensive choices for cereals, it would be tougher for women to step out to work. It is rapidly rising cost of living rather than an Indian embracing of women's capabilities beyond making rotis that has led to women’s paid employment. Keeping up with the Guptas is getting maha-expensive (very).”

Such imageries find resonance with Althusser's (1971) understanding that society is constructed by ideology. In his essay, "Ideology and Ideological State Appartus," Althusser (1971) states that human beings' relation with the world around them is constructed through ideological frameworks and representation in popular culture, language and social institutions. According to him, "ideology acts or functions in such a way that it recruits subjects among the individuals or transforms the individuals into subjects” (Althusser 1971:172). This ideological construction undertakes the transmission of systems of signification that are based on class, perpetuating the existing relationship of class domination. And with a feminist perspective, the continuation of male advantageous ideologies through concrete steps that mark the daily existence of women, even ones that march under the banner of the empowered has strengthened the structure of masculine domination. In other words, even as women compete within public and professional spaces for their rightful place, they remain defined by their bodies/sex.

Applying the notion of co-optation of progressive ideas of equal status for women to Indian politics, whether of economics or religion, the female body and female sexuality is still defined by male dominance (See Oza 2006 and Parameswaran 2001). Indian women become the barometer for Indian culture, used to define modernity by following "respectable public professions like medicine or the civil services, or 
engineering” but are prohibited from "Western practices" such as smoking and drinking. After all, as Indian movies elaborately show, those were the activities of "vamps" (Dutta 2001). As Ram, RSS states, "Why should Indians, male or female, want to smoke or drink? They are terrible habits that Western society is shedding and Indians are picking up.” While Ram's position appears logical, I find that it overlooks the concept of choice. Simply said, males who smoke and drink in public are not viewed as aberrant though women are routinely deemed indecent and un-Indian. In other words, women are equated to children or non-adults who are unable to make adult choices, therefore directly made into lesser citizens-occupants of the state and their homes.

As noted in Chapter Two, the desire for the domesticated woman is rooted in Hindu texts such as the Manusmriti and the Ramayan, among others. The armed Hindu masculinity is juxtaposed against pure and chaste femininity. Indeed such emphasis on the chastity of Hindu women and the control of their sexual behavior in times of sociopolitical and cultural upheaval may be seen as a form of resistance to otherwise uncontrollable changes, an attempt to control the nation metaphorically (Dasgupta 2003 and Dutt 2001). This position is substantiated by my interviewees who cite various personal experiences from being coerced by family to give up news beats that demand too much time to clashing with senior male professionals.

And ironically, many of these otherwise empowered women are circumscribed by their status as middle class women. Feminist scholars find that irrespective of the particular process, whether the independence struggle against British colonization or the present-day infiltration of neoliberal economics, the Indian middle class woman's chastity is juxtaposed against the West's so-deemed crass materialism embodied by the 
apparent immodest behavior of the ‘scantily clad Western woman’ (Kumar 1993;

Chatterjee 1999). In the discourses addressing chaste femaleness representing India’s spiritual fortitude and superiority, the emphasis is on middle-class women. John and Niranjana (1999) find that a woman's right over her body and control over her sexuality is conflated with her virtue. So powerful does this characterization become that only the middle class woman has a right to purity. In other words, only "she is entitled to the name of 'woman’ in this society” (John and Niranjana 1999:584). And this idealized woman is placed on the pedestal, to be emulated by 'other' Indian women and worshipped by men until she steps off the pedestal. Then she is no longer an icon of the nation, an inscription for the definition of citizenship, morality, progress and nationalism..

Borrowing from Foucault's notion on docile bodies, nationalism needs women to sustain its cultural and political currency since their bodies are used to represent the nation (Banet-Weiser 1999) while globalization is seen as a contradiction, an emancipatory movement by middle class women and a cultural trespasser by Hindutva activists. Therefore, feminist theory asserts that women's bodies and sexuality becomes the "material and discursive sites where nation [is] performed, values [are]contested, and borders and boundaries [are] policed and controlled” (Oza 2006). As Ram, RSS states, “Aap Ghar ki Laksmi Ho” (You are the Goddess of Wealth). And such wealth needs to be secured and protected. Towards that understanding, the following section looks at the theory of security and its application.

\section{Theorizing Security: Marking Space-Identity-Movement}

This research is also an attempt to challenge and broaden the notion of security, of which definitions abound, mired in contestations and disciplinary ambiguity. Even as the 
traditional discourse of security sees a structure of war and peace in an international system of sovereign and self-interested nation-states wherein the state is responsible for protecting those 'citizens' that lie within it's borders from potential harm emanating from the outside and the outsiders, feminist scholars strongly disagree with this limited definition (Enloe 1989). To feminist scholars, security is the attrition of all forms of violence, including physical, sexual, structural and ecological (See Tickner 1992, Peterson 1992). With women being marginal to the power structures within the state and the household, the concept of women's security has to start at the individual and the community level. And this is important because women's safety is defined, regulated and mediated through their bodies.

Borrowing the term "structural violence" from Johann Galtung allows a deeper understanding of security/violence wherein an individual is made insecure when his/her "life expectancy is reduced, not by the direct violence of war but by domestic and international structures of political and economic oppression” (Tickner 1992). While the structures of violence/oppression are not (largely) life threatening for urban Indian women, it certainly requires a nuanced examination to understand the concepts of safety and security in the urbanscape. Therefore, while an Indian urban woman dressed in a business suit and striding in a corporate corridor will define herself as being "secure", the volume of her space of safety is limited as her "modern" attire-attitude is seen as deserving, indeed welcoming lewd gestures and disrespect when she steps into public space/transportation to go home.

\subsection{Meaning of Security Within Public Space/Perception}

While there is an expanding body of research within gender and the annals of 
Indian women’s history (See works of Ramusack 1990; Basu 1992; Chatterjee 1989; Sudhir Chandra 1998 among others), scholars like Anagol (2006) find that certain aspects of security have not been adequately addressed. According to Anagol, the improvements in the status of women, which secured them against regressive societal practices from the nineteenth century onwards are seen as, “... the product of a process of conscious assertion on the part of Indian women but through programmes of social reform devised and carried out by Indian men...” (Anagol 2006:3). Therefore, the Indian woman becomes a passive recipient of social and political processes, an oppressed and monolithic entity who is the beneficiary of the Renaissance experienced by Indian men within colonial India, who were exposed to Western tenets and mores (Anagol 2006). This use of Eurocentric models of progressive action created bodies of literature wherein even the most radical of Indian women are not described as being conscious agents of action (See Borthwick 1984).

But according to scholars such as Anagol (2006) and Mohanty (2003), this perception of "missing feminist consciousness" is misguided. According to them, rather than analyze the specific conditions of the Indian woman's existence to determine agency, such scholars predetermined its absence based on Western connotations of feminism. The notion of "stripped agency" under imperialism implies that there cannot be “any meaningful investigation into resistance or autonomy by Indian...women...with the result that the Indian woman was unable to answer back and therefore remains a historically muted subject” (Anagol 2006:7). She is seen as being dependent on her male counterparts and relatives, not only for her security but also for making political and 
social decisions that would assure her security. Indeed, it is telling that the women who had to be secured did not appear to contribute towards the notions of security.

Much like Anagol (2006) and Mohanty (2003), I understand that if Indian women are studied simply as 'sites' or 'shadows' of dominant processes, then their voices and stories are likely to be erased from history. The notion that power and discourse is possessed entirely by the colonizer or the patriarch severely limits the impact of women's participation and perspectives on social and legal processes that impacts their lives, movements and sense of safety. With my focus on the issue of security within the paradigmatic clash between globalization and religious nationalism, I have examined the theoretical constructs of the notions of security. The realist position centers on sovereign states seeking to maximize their military and economic resources to secure their citizens in an anarchic international system (See Blanchard 2003, Booth 1991, Waltz 1959). The masculinized world of high politics largely clings to the idea that theorizing about security needs to be a gender-neutral process (Fukuyama 1998). In realist understanding, a domestic/international divide premised on the private/public distinction is the supposed gender-neutral backdrop of all security related policymaking. Hence security is defined in the language of power and national interest with no murky 'moral responsibilities' (Tickner 1999). In a zero sum game, citizens are deemed secure within the boundaries of the state and insecure without.

It is important to note that the theme of public and private demarcation within the realist framework of security may be used selectively to create defense policies. An outstanding example of such encoding is the $B J P$ government rhetoric supporting the first Indian nuclear test in Pokhran (near the Pakistan border) rested on the notion of keeping 
Indian homes, women and children safe from the marauding eyes of outsiders. But the application of protective laws is subjective as is evidenced by the high rates of crimes against women. In domestic scenarios of violence, rape, child abuse etceteras, the state machinery and its trained personnel largely prefer that such 'incidents' be kept private.

Discounting this core position of realist thinkers, feminist scholars question the domestic-international divide that puts the political actors and citizens, largely Western men, in the arena of policy making and research while relegating women to the domestic space, outside politics (Grant and Newland 1991). This exclusion of women is largely attributed to essentialized gender roles that construct women to be the 'natural' keepers of hearth and home (though not finances) and bearers-nurturers of children-future citizens (Yuval-Davis 1997). I concur that while progressive movements under colonial rule within India were led by West educated men; these notions of idealized Indian womanhood were largely borrowed from a patriarchal Hindu lexicon. This fundamental framework has deep roots and continues to impact the homogenization of Indian women, irrespective of the ideological source.

Therefore, a gendered perspective has to be a central category of analysis within security studies (Butler 1990). Given that a woman's designated space is traditionally the domestic sphere, which lies outside the controlling realm of the state, feminists are suspicious of the capability of the state as a security provider. The tendency of the realist position to ignore or subsume women's perspectives under the umbrella of 'human' experiences results in what is defined as 'a universal rubric of 'human' that is in fact an expression of the masculine experience” (Bakker 1997). Thus, it is immensely important to recognize that the exclusion of women's experiences results in policy making that is 
violent in its gender blindness and the reiteration of masculine domination over women's ‘docile’ bodies through the sanction of the state. Peterson (1992) terms this hand-in-glove relationship between state and masculine dominated structures/institutions, a protection racket: a claim to protection from the state in direct exchange for subservience and acceptance of state discipline ${ }^{26}$.

Scholars like D’ Cruze and Rao (2005) and Peterson (1992) argue against the public-private divide, wherein unregulated domestic violence makes women "the objects of masculinist social control not only through direct violence but also through ideological constructs, such as ‘women's work' and the cult of motherhood, that justify structural violence—inadequate health care, sexual harassment, and sex-segregated wages, rights and resources” (Peterson 1992). In other words, it is extremely important not only to secure women at work but also within their domestic spaces. The following section looks at the theory surrounding security within the domestic sphere.

\subsection{Meaning of Security Within Domestic Space}

Griha meaning home is seen as a sacred and secure space, "both a thing and an idea”' (Ley 1981 in Holloway and Hubbard 2001:68). It evokes an image of safety and

\footnotetext{
26. In India, this collusion between state and patriarchy is strongly marked by religious vote banks. An outstanding example is the ironically titled Muslim Women's Protection of Rights and Divorce Bill, which was passed under Rajiv Gandhi's Hindu dominated Indian National Congress Party in 1987. In 1986, the Supreme Court of India ruled that Shah Bano, a divorced Muslim woman was eligible for maintenance money from her ex-husband (Jeffrey and Basu 1999). The law provided divorced Muslim women with the right to civil-judicial redress to seek life-long maintenance from their husbands. However, orthodox male Muslim leaders, who alleged that the court was interfering in their personal law, based on the Shariat, vociferously opposed the decision. The INC government, in an effort to garner Muslim minority support gave in to the demand of these leaders, and despite nationwide protests from women passed the Act, 'literally adopting the provisions of the Shariat into secular law" (Corbridge and Harriss 2004). The law curbs Muslim women's right to ask for maintenance from their divorced husbands (Jeffrey and Basu 1999). With this appeasement tactic, Rajiv Gandhi's government, in all manners, made Muslim women secondhand citizens.
} 
protection, “... with familiar and protective boundaries.... a haven in a heartless world” (McDowell 1997 in Meth 2003). Yet feminist scholars like Domosh and Seager (2001), Sunder Rajan (2004) and Rao (1996) recognize the home as a site of conflict, control and reciprocally, of rebellion and resistance. According to Sunder Rajan, there has be a nuanced understanding of the home as "differentiated, political, and marginalizing" (Rajan 2004:774). The home is defined more broadly as a political, economic and social entity besides being an income-earning commodity through rental and collateral functions (Meth 2003). Scholars like Domosh (1998) find that homes are seen as being a bounded, physical entity, which provides a private exclusive space where the residents are free to express their emotions, desires and rest their fears.

While theoretical definitions of home and its connotations abound (See Datta 1999, Mehta and Bondi 1999 and Chakravarti 1993), popular imagination deems it a place to safety and security. Yet statistical studies done by scholars like Mehta and Bondi (1999) indicates that violence against women happens largely in her private and semiprivate space. As Pain eloquently puts it, “An accurate map of urban rape would highlight far more bedrooms than alleyways and parks” (Pain 1997:233 in Meth 2003).

My work with domestic violence within the South Asian community in South Florida has shown that violence against women occurs in the home with “...aggressive forms of misogynous masculinity [that] are often exercised with impunity”' (Duncan 1996:131). Instead of being a protective space for its inhabitants, the home actually becomes a space of social and legal isolation since “...it is very often invisible and inaudible, [making home-based] violence...a privatised problem”' (Duncan 1996:132). 
This "privatized" problem remains largely uncontested because domestic masculine domination nests with not just masculine control of women's bodies, sexuality and labor but also on total male ownership of property, including the home space (Rajan 2004). This exclusion/deprivation of ownership/right to be present makes them vulnerable to violence and sometimes subject to forcible expulsion or forced departure. According to Rajan (2004), “...that women must exercise control over a space of dwelling - through their rights to as much as in the home - marks the most significant conceptual advance of feminist domestic violence legislation” (Rajan 2004:773).

According to Ram, RSS, "We need to have laws in place for crimes against women but we think that domestic issues should and can be sorted out within the community. We consider our women Goddesses and if she is abused, then the community needs to step in and control the situation.” Given the patrilocal nature of Hindu marriages, the notion of "I leave my husband's house as a dead body" and the inability/unwillingness of the maternal home to take in abandoned/abused victims, such women remain incarcerated in their assumed-to-be safe spaces.

Abandoned women (sometimes with the responsibility of dependent children) stare not only at lowered life standards, if not destitution but also the prospect of their disinheritance as a consequence of the matrimonial laws relating to property that prevail in India (Basu 1999). According to Agnes (2002), Hindu women’s right to matrimonial property has a convoluted history. Based on English law, Hindu personal law denied women the right to shelter or separate residence if the husband was cruel, even as simultaneously the Hindu Marriage Act 1995 provided for the divorce of the Hindu wife (Agnes 2002). With the male advantageous legal system wielding power in a way where 
marriage gives Hindu women "no right to matrimonial property; [nor] any legal record of or control over such property as they may bring to their marriage through dowry or stridhan" (Rajan 2003:774), abused married women were left with minimal alternatives and a complete lack of economic security and physical safety.

After years of lobbying, research and pressure by feminist scholars and lawyers, the Domestic Violence Act, enacted by the Indian government in 2006 included all women in domestic relations, giving them equal rights in a shared household regardless of the titleholder to the house and prevent any form of forced reconciliation or eviction. Furthermore, the Act, meant to work in conjunction with the existing laws, would allow more domestic violence cases to be tried as criminal $\operatorname{cases}^{27}$. This was a radical change in the formulation of property rights though as Rajan states that these initiatives under the DV Bill do not provide for an equitable distribution of the matrimonial property on the breakdown of a marriage (Rajan 2003).

While scholars attempt to dismantle the 'cuddly concept' of home, my research brought forth another interesting concept of the definition of the domestic space. This understanding rests on what makes a space private and safe. For instance, "Devika" (name withheld on request), a correspondent with the Aaj Tak network who is a single 34-year-old woman responded when asked about her domestic arrangement by laughingly stating, “Out of my bag! As a single woman, I carry a change of clothing with me as well as my essentials...sometimes, the office is where I sleep...especially if it gets too late for me to venture out.”

27. For details, go to: http://www.vakilno1.com/bareacts/Domestic-Violence/Domestic-Violence-Act2005.htm (Accessed on February 11, 2010). 
While in a different socio-economic class than those who live on the street, like them "Devika," Aaj Tak converts the public into the private. Her treatment of space is temporal rather than just spatial and she is able to feel safe within the 'outside', against prevailing wisdom. This 'aberration' brings to the fore the notion that like any other lived experience, the meaning of home and safety is dependent on gender, class and social circumstances. As “Devika” elaborates, "I never tell my mum that I stay at the office. She would freak out. My married colleagues or those that stay with their parents usually go home!”

The concept of being a respectable woman requires the returning of the female body to the patriarchal household by nightfall (Kumar 1998). Middle class households that are progressive and 'allow' the mothers/daughters/daughters-in-law to work outside the home expect a certain amount of dignity and decorum in the behavior of these women while expecting them to fulfill their domestic duties (Kumar 1998). As Shailaja, a 30year-old principal correspondent/chief sub-editor, Metro Plus, who is recently separated said, “It was fine if I worked late...but I had better have cooked and cleaned before leaving. Otherwise, my MIL [mother-in-law] did not let me hear the end of it...It never felt like home...[and therefore, emotionally unsafe]”

Indian feminist scholars like Rao (1996) and Rao (2003) who work on issues of domestic space, violence, safety and security demystify the 'domestic' as an ideological construct of the West and deem it, simply as a space of labor and incarceration, an alternative to destitution. It is necessary to remove the metaphysical barrier that separates spaces of violence under the guise of retaining social civility or keeping intact the notion of the "morally strong Indian family”. In the discourse surrounding home, safety and 
violence, the emphasis should be on engendering safety and exposing violence, rather than preserving the so-called sanctity of family and home. It is important to hear women's stories, to understand how "women resist patriarchy, construct their identities, assert their rights and contest the hierarchical arrangement of societal relationships between the sexes” (Anagol 2006: 7). Their stories of struggle as they seek the right to safety are the core of my research.

\section{Conclusion}

Resting on the strong foundation of feminism, the approach of this research is informed by the framework of female agency that is based on experiences and informed choices made by the urban Hindu media woman as they assert their rights, target socioeconomic injustices and adopt/reject 'Indian culture and tradition' within their lives. In doing so, the research uses Scott's (1998) notion of gender as the power relationship between sexes, which marks all political and social institutions and organizations. At the same time, underscoring the work of scholars like Oza (2007) and Rajan (2004), it is imperative to remember that in a country like India, where multiple discriminations reside based on more than just gender, various asymmetries and structures of privilege can prevent solidarities and definitely resist universal definitions and attempts at essentialism. Therein lies the theoretical heart of this research, which rests on the individual stories of the path-breaking HUMM women as they seek safe terrains as independent empowered physical-economic-sexual being.

I am examining the impact of nationalism and globalization on the body of the Indian woman, a body that may be defined as a field of discursivity, without a fixed center and a plethora of contradictory, competing meanings and signs. The body provides 
a physical and conceptual space in which recurring tensions and processes are reworked and reiterated. Whether theorized as Foucault's (1977 published in English), docile body, Wright’s (2006) disposable body, Bordo’s (1989) useful body, the Indian woman’s physical entity is the focus of control through regulatory institutions and self-disciplinary mechanisms. I also argue that while these embodied actors are partially socialized through a variety of interactions, relationships and the media, they are also active agents whose use their lived bodies to create spaces of transformation and struggle. My feminist research is rooted in understanding the relationship between women's bodies and society, the productive capabilities of the body.

All feminist struggles are incorporated at two interconnected, concurrent levels: "an ideological, discursive level that addresses questions of representation and a material, experiential, daily-life level that focuses on the micropolitics of work, home, family sexuality and so on” (Mohanty 2003:64). This engagement between the theoretical and the material is the backbone of my research. While denying gender oppression as the definitive and primary marker for masculine domination within the so-called Third World, my research implicates constantly mutating male-advantageous structures/policies as being major hurdles in the path of women's progress towards security and human rights. I use Bourdieu's (1990) theoretical construct of “masculine domination” to examine the various differences, discriminations and disadvantages faced by women in a gendered world as well as Kandiyoti’s (1988) term, "patriarchal bargains” to understand the various means, both obvious and insidious, which women use as they negotiate with ever mutating individuals, institutions and spaces littered with markers of male domination. 
This research also questions the assignment of womanhood to biology as was laboriously produced from the early nineteenth century in the West and then borrowed from and reworked by male dominated institutions within India, both colonized and independent (See Das 2004, Channa 1985). The continuous essentialization of Indian women so as to create an easily manageable and malleable homogenous idealized womanhood remains the core ideological process for both globalization and nationalism cheerleaders. Drawing from de Beauvoir’s (1973) much feted and critiqued statement, "one is not born a woman but becomes one," it is essential to deconstruct the sexualization of women's bodies, the domestication of the family, the confinement of pregnancy (de Beauvoir 1973:301). Without demystifying the connection between women-nature/destiny-biology, without questioning the naturalness of these orders, it is impossible to establish that the structures of gendered power are socially and culturally created structures that can be transformed.

Grounded in relations between class, gender and sexuality at a particular moment, this research hopes to contribute to feminist theory by recognizing that the insidious processes of stereotyping and image construction are tools of dominance that can be dismantled by redefining the notion of politics to include "struggles over socially constructed meanings and definitions and identities” (Hart 1991: 95). As Barthes (1972) contends, demystifying signifiers is the most efficient means of disempowering any dominant status quo. Whether the conceptions of home, work, entertainment and security within these concepts, myths and ideological definitions are constructed by those in power (almost exclusively male) and therefore require dismantling so as to make women more secure about their movement and choices. 
Given my examination of Indian media women and their world, I borrow from Hall (1973) to theorize that not only are they producing images for consumption or what Hall calls encoding using language borrowed from a framework of power, institutions and political-economic ideologies but they are also the decoding audience, each with their own specific backgrounds inserting specific margins of understanding. In my theoretical understanding mediated messages are never fixed, transparent or heard by a passive audience (Hall 1973 in Proctor 2004).

Using a feminist theoretical framework to deconstruct male-advantageous power structures, I am constantly reminded during my fieldwork that homogenization, whether of identity, culture (exhibiting power stratification along gender lines) or security are insidious and need constant vigilance. As Narayan states, "I believe that the development of a feminist perspective that is committed to anti-essentialism both about 'women' and about 'cultures' is an urgent and important task for a postcolonial feminist perspective" (Narayan 2000:87).

Such feminist research of globalization and nationalism will provide multilayered understanding of their impact on the lives of women by highlighting the ways in which gender-as a category that is part of the cocktail of race, class, religion, among others, is central to reworked forms of capitalism. A major strength of my work lies in its ability to make connections between overarching structural economic, political and sociocultural processes to contextual realities. This approach has allowed me examine "the intricacies of labor, identity, and agency and to explore the messy ways in which empowerment and disempowerment, production and reproduction, exploitation and pleasure remain thoroughly entangled with each other” (Nagar et al. 2002:277). This has 
allowed me to reject any simplistic generalizations that sees either of these processes as being totally emancipatory or frighteningly disempowering and instead has “... illuminated the subtle ways in which power relations, interdependencies, negotiated constructions of femininity and masculinity, and multilayered politics of difference constitute the everyday politics and realities of living” (Nagar et al. 2002:277).

While a range of scholars (as mentioned in the text above) informed my theoretical perspective, I also gained strong theoretical insights from the HUMM women, who drew their 'theories' from their unique life experiences, from their bargains and rebellions, from their present standpoint and their history.

With that evolving theoretical framework, the next chapter examines the patrilineal-patrilocal- structure of a majority of Indian households that define the roles of men and women within it. The focus of this chapter is on various global and national rhetoric/opinions/expectations marking the lives of urban Indian women that borrow extensively from his-story while cloaking the processes in images of progress and egalitarianism. 


\section{CHAPTER IV}

\section{Father, Husband and Son: The Gatekeepers of Indian Women}

“...at the end of the day, my domestic role trumps my professional role. Whether by guilt or by pressure...societal or by my family, I know that my professional commitments have to be set aside if my family needs me. My husband is wonderfully understanding but my instincts of motherhood and wifehood are difficult to ignore.” - Mridu, Special Investigations Reporter, CNN-IBN.

The young mother of one child, Mridu, $C N N-I B N$ has worked in electronic media in varying capacities, from field correspondent to newsreader and program presenter. She is expressing what she called "an unabated, self-directed sense of guilt" engendered by constant reiteration of specific gender roles that deem domestic responsibility as being the realm of the woman. As she says, "I live in a nuclear family with a husband, who is a true feminist...yet I suffer from enormous guilt because I am a mother and a news story should not take precedence over my child. My husband is a great father but he never seems to be afflicted by such deep rooted guilt.”

These gendered identity-behavior markers of good Indian women as being loving caregivers with a core of sacrifice, largely expressed through unpaid domestic labor is regularly and insidiously disseminated by the media as well as through oral tradition. Indeed, millions of television sets beam in the principles, practices and paraphernalia that are associated with the correct reproduction of a proper domestic household. Ironically, as globalization brings in technology and means that are used to produce specific messages of 'nationalistic traditionality', it also produces certain progressive ideas of individuality and equality, which has led to transformation and dislocation of gender 
identities, resulting in resistance to old school, 'obvious' masculine-advantageous constructions such as the heterosexist family. The following sections will examine the evolving role of Indian women in their households as globalization and nationalism clash over questions about their rights and duties.

\section{Multiple Personality 'Order': The Middle Class Indian Woman}

The norms of Indian womanhood that are largely prevalent today are the product of centuries of mutating masculine dominations, differing cultures and geographies. From the pages of Manusmriti, the courts of different dynasties, the demands of British colonialism to nationalism that emerged to strongly oppose it to the present day economic liberalization: every epoch created an amalgamated image of ideal womanhood.

While there cannot be 'one' womanhood in a country as diversely marked as India, middle class womanhood, marked by a set of bourgeois, European ideas that delineates the notions of home, hearth and family life, is strongly pushed as the model for ideal Indian womanhood. Naturalized in the nineteenth century as "a transnational, hegemonic discourse on domestic life...a global domesticity” (Walsh 2004:2), they shape today's Indian woman. The terms of this form of 'respectable' domesticity was fostered by capitalistic imperialism, which embraced indigenous patriarchal norms to reshape gender and domestic relations. According to Singh (2003), the ideal Indian womanhood "is the product of traditional elements drawn from inherited caste ideologies modified and then fused with Western education creating the newly emergent middle class urban elite woman.” These women who were held as the ideal for all 'good' Indian womanhood were created out of reflexive interactions between colony and metropole (Walsh 2004). 
The late $19^{\text {th }}$ century laid the foundation of global domestic standards through umpteen books that offered practical and theoretical direction to women about family life. Ranging from topics of hygiene and household management to kitchen duties, raising children and rules of conduct while dealing with extended family, these books written largely by reform-minded male authors had titles such as $A$ Husband's Advice to His Wife, The Laksmi of the Home and Conversations with the Wife (Walsh 2004).

It is interesting to follow how domestic power structures changed under the aegis of colonization. Where traditional Hindu domestic structure required women to remain uneducated and confined to the inner sanctum of the home (the antahpur, the ladies quarter), colonized Indian men rewrote a new order. Scholars like Chatterjee (1986) find that Indian men focused on creating domestic scenarios, which could compensate for their loss of power and position in public life (Chatterjee 1986). Chatterjee (1986) finds that reform-minded nationalists offered women participation in a new form of masculine power structure, which challenged the older form of masculine societal ordering by requiring that women be literate and allowed to move out of their domestic space into public space. At the same time, it maintained women in a dependent and subordinate status within the domestic space, which continued to be underscored as their priority, a space where a wife is required to remain under the tutelage and authority of her husband and his family (Walsh 2004). In this structure of power, , the new set of 'freedoms' allowed women more space in a horizontal axes but kept them pinned to their place/space of subordination in the vertical hierarchy of power.

This was based on the assumption that the natural order of 'healthy' human 
relations requires a male-led family structure, which can only be constructed through the gendered separation of spheres of activity (Davidoff and Hall 1987). Men inhabited the public space as the 'breadwinners' while women maintained the private space, which had to be ordered into a refuge where the husband sought comfort from the vagaries of the 'outside'. That notion continues to resonate in the present times with the "queen of domesticity”, Martha Stewart, who enjoys a dedicated readership in India and has spawned multi 'domestic goddess' imitators, maintaining that "Sweet dreams will come more readily when everything's in its place” (Potter 1998). Even though Stewart does not specify the gender of the one keeping order, it is telling that her 200-million-dollar media empire largely targets women (Roy 1998). After all the notion of "the ministering angel(s) of the house: guardians of order and organization in the household, superior moral forces in shaping the lives and characters of the children-and best friends, companions, soul mates and constant sources of solace and comfort for their husbands” in the heteronormative world, has to be a woman (Walsh 2004:12).

The following section looks at the shaping of the domestic role of middle class women by nationalists through different eras, each set of demands mutating with time yet essentially retaining control of society in the hands of the powerful elite, largely upper class males.

\section{- $\quad$ Demands of Nationalism}

Indian nationalism required middle and upper class women to be refashioned through education so as to become more suitable for their Western-educated husbands yet their essential feminine qualities had to be retained. Therefore, masculine control of 
women’s sexuality became an issue of concern because of women’s changing consciousness in response to modernity and their embracing of the accompanying freedoms. The anxiety produced in the national consciousness by modernization is manifested in the reconstruction of women's identities and played out in the 'gatekeeping' of their bodies.

In “The Nationalist Resolution of the Women’s Question”, Chatterjee (1986) focuses on the centrality of the figure of the Indian woman within a national culture defined by indigenous cultural elites (Chatterjee 1986). For instance, one of the three Brahmo Samaj founders, Kesabchandra Sen returned from a trip to England in 1871 committed to the idea of separate, special education for women, one that would focus on their unique biologically determined feminine nature. He argued that women need not learn "manly" subjects such as geometry or the sciences and should study domestic skills that would secure happiness in their futures as wives and mothers (Borthwick 1984:86$87)^{28}$. Even though his position was opposed by members within his own group who went on to fund a girls' school that provided equal education, which was then merged with the oldest women's secular school in Calcutta, the Bethune School to provide women education opportunities at primary and secondary level as well as university examination, the mindset of manly and womanly subjects continues to this day (Walsh 2004).

As Suman, Aaj Tak points out, "I am training my son to take care of himself...clean up, pick up, set up! But I am considered an aberration...because most of

28. Founded in 1828 in Bengal, the Brahmo Samaj was a reform Hindu religious association that opposed idolatory and was committed to a monotheistic principle. They opposed traditional Hindu religious and social rituals while being strong advocates of women's issues. They opposed child marriage, supported widow remarriage and the breaking of the purdah and the education of women. For more information, read Sarkar 1999, Munshi 1983). 
my friends and relatives with sons tell me that it's great but I don't see them doing anything along the same lines with their sons.” This dichotomy within most middle and upper-middle class with regards to treatment of sons and daughters within the household with respect to domestic education shows the marked preferential treatment of males.

"Just look at our technical staff. They are largely male. At home, my husband cooks and I am teaching my son to cook and take care of his [own] needs. But at the same time, my husband cooking is still seen as an anomaly. His friends tease him and call him joru ka ghulam (wife’s servant)," laughs Suman. “I think it’s easier for urban women to relegate their domestic chores because we have so much labor. But look at the domestic help...they are all women. I constantly hear from my maid that her husband gets suspicious if she is out too late. So even though she is contributing to the household budget, it matters little. I mean, we middle class women are relatively new to the workforce. Female domestic labor has always been out. The men need the money and yet resent the women and fear that they will lose control over their households if the women become too independent. And then these same men inhabit my public space and see me as being an easy available target” she concludes.

Traditional nationalists are continuously attempting to keep their masculine control by co-opting the messages of emancipation. Therefore, while they claim to encourage education and career options for women, traditionalists want "controlled education and positions of protected dignity within the family and the community...[so as to] enroll women as 'custodians of traditional cultural values' against the onslaught of Westernisation” (Kasturi and Mazumdar 1994:8). Under the orthodox framework for 
nation and nation-status, women's emancipation is required less to liberate women and give them equal civil rights but to promote the welfare of homes and families and to enhance the prospects of upwardly mobile men (Kasturi and Mazumdar 1994).

As Ram, $R S S$ states, “For a woman, her home and family are 'naturally’ more important. Of course, she should work...get educated but at the end of the day when a child gets hurt...he calls out “Oh Ma” and not “Oh Baba”, right?” The following section looks at how the entry of neoliberal policies has changed domestic roles and its impact on the lives of urban Indian women.

\section{- Demands of Globalization}

As globalization allows women, especially middle class urban women multiple opportunities, it also translates into a lack of control for men otherwise used to seeing their women (mothers and sisters) confined to domestic space and domestic work. To extrapolate Chatterjee’s (1993) and Sarkar’s (1987) research on Westernized Bengali men, it is precisely because men have yielded so much of their cultural autonomy to the structures and demands of colonization/globalization that they are desperate to have some notion of indigenous home and family life.

According to Chatterjee (1986), nationalism reconciled the oppositional pulls of tradition and modernity through its division of the spiritual and the material (Chatterjee in Singh 2003). With globalization changing societal structure, especially in the urbanscape, there emerged an understanding that 'The East' was subjugated because of the superiority of the material culture of the West, with its technological and economic institutions and 
its modern statecraft (Singh 2003). The colonized/globalized, therefore, had to learn those "superior techniques of organizing material life and incorporating them within their own cultures” (Chatterjee 1986:237). However, it was in the spiritual domain that the East believed itself to be far superior. Chatterjee argues that nationalism formulated an ideological framework to incorporate the technological superiority of the West while "retaining and strengthening the distinctive spiritual essence of the national culture" (Chatterjee 1986:238). Furthermore, according to Singh (2003), the discourse on nationalism juxtaposed the material/ spiritual distinction into analogous dichotomies of outer/inner, public/private, world/home, while the space from which the colonized resisted colonial domination was the feminized space of the home. The position as applied to colonization can be extrapolated to the resistance against globalization, specifically cultural globalization.

According to Chatterjee, "the home was the principal site for expressing the spiritual qualities of the national culture, and women must take e main responsibility for protecting and nurturing this quality” (Chatterjee 1986:243). While the men could be modernized in the public sphere and women could be selectively modernized, the latter “must not, in other words, become essentially westernized...” (Chatterjee 1986:243). The works of scholars like Chatterjee (1986), Butalia (1995) and Sarkar (2001) emphasize the steady transformations that insidiously locate the spiritual and cultural core of the nation in the home and the physical body of the woman, at the same time keeping the material reins of the state in the hands of men.

While scholars like Chakravarti (1999) and Rajagopal (2001) argue that economic 
liberalization has not live up to its promised empowerment of women, I found my interviewees embraced globalization as a positive set of processes that has enhanced their choices and opportunities. For instance, Shikha, Times of India, states, "I am speculating of course, but I strongly think...believe that I make a lot more money because of globalization...my choices have definitely increased.” Similarly, "Shipra” (requested anonymity), Senior Political Reporter and Anchor, $N D T V$ was emphatic when she said that "the skies have opened up...literally. When I started almost 25 years back, there was nothing...Doordarshan (Indian national broadcaster) is all there was. Now there is a lot of substandard crap out there but at least you can get your foot in though it's still pretty hard to get taken seriously...it just is easier if you want to do fashion and music.”

Such responses may be understood in the context of changing gender relations, as a result of “both women’s own changing perceptions as well as the postcolonial state's structural interventions in education and employment” (Ganguly-Scrase 2003:547). According to Ganguly-Scrase (2003) and Bannerjee (1999), the introduction of neoliberal policies into the Indian market has done little to challenge existing male advantageous institutions. Instead globalization has adopted and adapted such traditions to further its agenda of profit making and homogenization. Recent scholarship by Puri (1999) and Sunder Rajan (1993) on the discourses of modernity and female subjectivity in India find that women are encouraged to attain modernity, albeit in controlled measures that “reinforce rather than challenge hegemonic gender roles” (Ganguly-Scrase 2003:547). As the political and economic elite supporters of globalization gain strength in India, there has been an insidious equating of female employment with female 
emancipation, which is then taken to be an indicator of national progress. Such discourse of female empowerment through employment has become a part of standard state vocabulary (Ganguly-Scrase 2003). Ganguly-Scrase (2003) uses the term Global Intellectual Hegemony (GIH) coined by Gosovic (2002) to understand the disconnect between the 'real' impact of globalization and women's perception of it. The homogenizing impact of GIH is extremely effective since it disperses selective ideologies using modern technologies, particularly the global electronic media corporations, which are concentrated in the hands of a few individuals. According to Bagdikian (2000), "In 1983, fifty corporations dominated most of every mass medium and the biggest media merger in history was a $\$ 340$ million deal...[I]n 1987, the fifty companies had shrunk to twenty-nine...[I]n 1990, the twenty-nine had shrunk to twenty three... [I]n 1997, the biggest firms numbered ten and involved the $\$ 19$ billion Disney-ABC deal, at the time the biggest media merger ever...[In 2000] AOL Time Warner’s \$350 billion merged corporation [was] more than 1,000 times larger [than the 1983 deal]” (Bagdikian 2000:xx-xxi).

Since the Indian skies opened up in the early 1990s, international channels like CNN, BBC, Fox channels, NBC channels among others have been beaming their messages into the drawing rooms of Indian households. Add to this the local news and entertainment channels, and there is a formidable entity that sends out images and messages that declare globalization to be the new economic messiah, the tide that will lift all boats if one were to follow the 'common sense' of neoliberal policies.

According to Ganguly-Scrase (2003), GIH promotes homogenized consumerism and individualism while working against collective action that could be aimed at 
eradicating social inequalities. In an online interview, McChesney states, “Global conglomerates can at times have a progressive impact on culture, especially when they enter nations...that had significant state censorship over media (as in parts of Asia). The global commercial-media system is radical in that it will respect no tradition or custom, on balance, if it stands in the way of profits. But ultimately it is politically conservative, because the media giants are significant beneficiaries of the current social structure around the world, and any upheaval in property or social relations—-particularly to the extent that it reduces the power of business—is not in their interest” (McChesney 1999).

Thus neoliberal ideologies are constantly influencing perceptions but GIH is not involved in true emancipation. Instead they concentrate on “...bombarding audiences, targeting markets, capturing grosses, killing the competition, and winning, by which they mean making more money than the other guy” (Schechter 1998). As Ernest H. Drew, the C.E.O. of Westinghouse (CBS) succinctly states of this institution of globalization, "We are here to serve advertisers. That is our raison d'etre" (Drew 1997).

And advertisers demand that women become global citizens, aware of global goods/processes, which they are 'trained' to desire and consume. Modernity and emancipation become equated to consumerism and individualism (Oza 2001). But 'Indian modernity’ requires its women to be schooled into being laborers of love: good mothers, good wives, and good daughters/-in laws while working outside the home to add to the home kitty. But the public personas have to be constantly guarded against any possibilities of shameful actions, which ranged from smoking and drinking to clothing norms, sexual activity and even choice of professions. "Sometimes I want to get medication, laughed Mallica, Maxim, “...I mean, are you surprised? I feel like I have 
multiple personality disorder...good daughter, competent yet ice-queen writer, sexy girlfriend, docile going-to-be daughter-in-law!”

The following section looks at the shaping of domestic space and the varied impacts on the lives and choices of urban women.

\section{The Schizophrenic Modern Home}

When 'modern' globalization entered the physical and psychical space of India in the early 1990s, it faced a similar resistance to the "total modernization" of the Indian woman. As anti-colonial nationalism created a discursive space for the selective modernization of the domestic sphere and the liberalization of woman's place in it, religious nationalism appears to be engaged in a similar contest with the notions and norms of globalization. And this tussle has created “...craziness in families. Who is responsible for what in the house... whose needs are more important...sometimes I feel like I am having a mental breakdown...” (Shikha, Times of India)

And these ‘crazy-making' notions and norms of modern globalization are dispersed through the modern technologies of the media. The media persons are the filters through which varying ideologies are dispersed into the living rooms of India's viewing audience. According to Appadurai, “Mass media and traditional media ... transform the field of mass mediation because they offer new resources and new disciplines for the construction of imagined selves and imagined worlds” (Appadurai 1996:3). The projection of today’s multimedia-influenced world has led to a social order where "ordinary people who deploy their imaginations in the practice of everyday life" (Appadurai 1996:5). The deployment of such imaginations has resulted in an emergent 
social order that is herded along by mass-mediated imageries that transcends borders of class, caste and religion.

Borrowing from Appadurai (1996), the new urban society can be separated into the "diaspora of hope, diaspora of terror, and diaspora of despair" (Appadurai 1996:5). Indeed, the new Indian middle class women could well constitute this group. These women could well be termed 'diasporic', as they 'migrate' into new unexplored spaces to "create new mythographies for new social projects...Those who wish to move, those who have moved, those who wish to return, and those who choose to stay rarely formulate their plans outside the sphere of radio and television, cassettes and videos, newsprint and telephone. For migrants, both the politics of adaptation to new environments and the stimulus to move or return are deeply affected by a mass-mediated imaginary that frequently transcends national space...” (Appadurai 1996:6 in Singh 2003).

As these diasporic women travel through various hybridized urbanscapes that have been created by ideologies of nationalism and globalization and are in constant metamorphosis, there emerges the questions of safety: physical, emotional and economic.

\subsection{The Safe Woman}

“Can a woman who enters male-dominated public spaces at 'indecent' times for the purpose of work be considered virtuous? Or is she 'asking' for it, as regularly shown in Hindi cinema? You take a walk in the garden alone after dark and if you get attacked, you have no one to blame but yourself. Just because we are 'modern' and liberated, quite definitely does NOT mean that people...men who occupy these spaces are”, shrugs 
Suman, Aaj Tak. Her body tenses as she recalls her fear when her car stalled on the NOIDA Highway that links Delhi with Naveen (New in Hindi) Okhla Industrial Development Authority (NOIDA), a suburb of Delhi which acts as headquarters of multiple media houses. "My car just gave up on me. It was close to $2 \mathrm{am}$. I had just wrapped up a late night telecast and was coming home. Never have I been so thankful for having a cell phone. As I waited for my husband to pick me up, every car was like a platoon of rapists, muggers or both. Why should I feel like this? You can’t imagine how relieved I was when I saw my husband's car. I was sweating in an air-conditioned car. And then my husband said to me... why the hell are you working so late? Are you looking for trouble? I was so shocked. I know he was really scared too but it made me wonder how supportive he really is. But my point is...we can all be rah-rah about globalization and women's rights...but the core of the country is patriarchal and any woman seen outside the home, without a male companion, is fair game. This is more so when the jagah (time-space) is considered non-feminine...non-virtuous.”

Suman's experience supports the notion that the safest space for women appears to be the domestic even though violence within the walls of the Indian home has reached shocking levels, with as much as seventy percent of married women in between the ages of fifteen and forty-nine becoming victims of beating, rape or coerced sex, while every six hours, a young married Indian woman is burned alive, beaten to death, or driven to commit suicide (Capoor and Patel 2006). Therefore, irrespective of increasing opportunities and empowerment, it appears that at the level of the body, the HUMM women continue to be incarcerated. 
The media women interviewed repeatedly focused on the term, 'Indian of the $21^{\text {st }}$ century' folding themselves into this time-space as strong actors who are attempting to become their own agents by defining their subjectivities. Caught between two oppositional discursive ideological constructs, they are emerging as bearers of hybrid identities, formed by the clash between modernity and tradition. Extrapolating on Bhabha's (1990) concept of "space of the displaced", these media women are trying to create an empowered space which can produce counter-narratives of identity that challenge and displace the notion of fixed domestic spaces, the home as being the boundaries of safety and security (Bhabha 1990:300). According to Bhabha, a working woman's multi-positionality is ordered by an overlap of class, gender, and racial boundaries and it is impossible to ascertain "[w]hich of her identities is the one that determines her political [and personal] choices” (Bhabha 1994:29).

Whether they establish this indeterminate space of signification through their choice of profession or their challenge of domestic routine, the media professionals are fighting an uphill battle. And in this uphill battle, this newly formed space of enunciation is subversive to both nationalism and globalization, allowing neither ideologies discursive continuity (Bhabha 1994).

As nationalists engage with such 'aware' women, followers like Ram, $R S S$ reject the notion that Hindutva see women are reproducers “only”, calling such mindset, "backwards and incomplete.” The manifesto of the BJP presents a progressive agenda that does not require women to remain within domestic spaces or roles. Instead the Hindutva rhetoric uses the constant portrayal of the Outsider (traditionally Pakistan as a state and Muslims as a religious group and recently, Western socio-cultural globalization) 
as being sexually aggressive, violent and intent on religio-ideological conversion. It is for the safety of the honorable-vulnerable (read women, children and nation) that the Hindutva activists stand against trespassers, as rational actors, intent on protecting. Therefore they are "selectively progressive” (Ram, RSS).

With the state of India strategizing to further integrate the country into the global economy (thus mass-producing world citizens), there has been an upsurge in the desire to remain authentic and culturally unique within certain sections of society while being selectively progressive. This movement has gathered momentum under the aegis of the nationalistic brigade, which has deemed Indian authenticity as being 'Hindu'. This unequivocally masculinist ideology has energized an unexpected set of gatekeepers of women's lives. Numerous women's groups, women's wings of various parties comprising the 'brotherhood' such as the Rashtriya Swayamsevika Samiti of the RSS, the Durga Vahini of the VHP, Mahila Morcha of the BJP and the women's wing of the Shiv Sena have emerged from the shadows, as a safe space for Hindu women to participate in nation-building and thrive (Phalkey 1999). But such participation of women in Hindutva politics involves a re-enactment of traditional gendered social roles in the public and private sphere, wherein they are deemed safe as long as they follow the tenets set up by masculine understandings of space and place.

The women of the saffron brigade are not necessarily docile and submissive. Indeed Phalkey (1999) focuses on the elaborate preparations that the brigade women made before the attack on the Babri Masjid in Ayodhya. Food, flower garlands and ritualistic material was prepared, the women shielded the men from police crackdown but they did not scale the walls of the mosque during the demolition because it would be 
undignified for Hindu women to be seen climbing a mosque in their sarees (Phalkey 1999:42). The same women went door-to-door campaigns, coming in contact with housewives and other women in the households.

The engagement of women in acts that appear to give them a certain political agency and therefore, the Hindutva brigade a modern agenda, has contributed towards its popularity among the middle class Hindus. The Hindu Right has established an enormous network of grass roots level workers and organizations that spread the message of Hindutva, which includes normative roles for men and women (Phalkey 1999). While these groups operate largely in the rural and sub-urban areas, regular migration by such residents into cities translates into the transfer of Hindutva ethos into the public spaces of the cities. As male dominated notions mark these spaces, the questions about safety of women engender a standard response. "Women who know their boundaries will also remain safe. Certain behaviors and clothing can attract bad attention but the choice to not be like that is in the hand of the woman. In fact, why should Indian women not wear Indian clothes? Not only does it keep our culture alive but it keeps them safe” (Ram, $R S S$ ). This staunchly sexist ideology continues to drive the harassment of women and men in public spaces during so-called Westernized festivals such as Valentine’s Day, New Years celebration or as mentioned in the introductory chapter, in so-called womencorrupting spaces like the Mangalore pub.

Das (2004) situates the “women question” in contemporary India under the BJP by locating the "question" at the inter-sections of cultural nationalism, Hindu patriarchy, and certain forms of post-colonial (in)securities (supposedly faced by the Hindu rashtra), and a nuclear India. She uses a "semiotics of sexuality" (Agarwal 1995 in Das 2004) in a 
Hindu-Muslim/ India-Pakistan relationship to understand how certain images of Hindu women are being discursively utilized by the political party to support a "Pakistancentric/ communalized" version of Indian nuclearisation in defense of a Hindu rashtra. Given that male dominated political regimes have used women as markers of cultural identity to serve their nationalist projects, the masculinist Hindutva brigade is no different. It requires that the nation's safety, which is inherently tied to the woman's body be guaranteed by placing boundaries: real and metaphorical.

When any form of fundamentalism incorporates nationalistic ideology with political clout (the powerful presence of the $B J P$ on the Indian political stage), it impacts that daily lives and life-choices of the nation's citizens as seen through the regulation and disciplining of public and private spheres of everyday operations. In an expert paper presented on behalf of the Lawyers Collective (Women's Rights Initiative) of India to the UN Division for the Advancement of Women, Basu finds that judges reveal extensive biases against women and their use of the law, which is rooted in their understanding of women's roles in society (Basu 2005). She cites the example of Justice J. D. Kapoor (2002) of the Delhi High Court who in his book, "Laws and Flaws in Marriages: How to Stay Happily Married states "Women of superior intelligence are generally torn between their femininity and their intellectuality. They are obsessed with the development of their career to such an extent that they are forever absorbed with the self. It is mostly women who hold managerial or professional jobs who suffer from this syndrome, as they tend to lack the willingness to compromise. For them, even rearing children or raising a family is not a social obligation. A situation in which a woman considers herself intellectually superior is sometimes fraught with danger as there is always a likelihood of such a 
woman being fascinated by a person who is more capable than her husband. This can rend the marriage from cornice to foundation” (Kapoor 2002 in Basu 2005:5). Further, Basu states succinctly, "Interpretation is the heart of judicial decision making process, the creative element of decision making” (Basu 2005:6). Thus, when the interpreter, the very element that is supposed to protect and preserve human rights is tainted with sexist notions of Indian womanhood, it leads to the continued empowering of sexist expectations of behavior, control and guarding.

Similarly, Das (2004) uses Khattak’s (1996) detailed analysis of “gendered symbolisms" that shape a country's defense policies to show how a "complex web” of “religious and gendered” symbols was used to justify Pakistan’s nuclear policies vis-à-vis a Hindu India. The use of sexual metaphors and gendered symbols that blatantly juxtapose concepts like domestic/tradition/ mother/ sister/ protection versus the public/ national honor/state/masculinity/protector results in "projecting the nation-state as the mother/ a traditional entity in need of protection against the outside [Hindu] enemy...appeals not to maternal instincts but to a male macho psyche [the state] that is called upon for defense and survival.” (Khattak 1994 in Das 2004:349). These narratives of national security/insecurity written on the bodies of women transfer themselves from national borders to the confines of domestic space, the pure space.

This discourse of security and gender has been religiously used by the Saffron Brigade to define its position with respect to globalization. The BJP's utilization of Hindu women is two-fold. They are portrayed as traditional entities, "rooted in their past," with the staunch belief that tradition is immutable, which is then suggestive of an ancient Hindu Golden Age that can be revived through a Hindu rashtra (nation) (Roy 1995). At 
the same time, they are used in their more militant forms representing a modern India and therefore suggesting progressive emancipation. The resurrection of the Hindu woman as the standard bearer of Hindustan through "sharpening, standardizing, and generalizing” (Roy 1995:10) such identities along communal lines is being used as the basis for creating defense and national policies and agendas.

The era of surveillance is now not relegated to human eyes but is done using technology. As “Nandita” (name withheld on request), a 48-year-old political reporter, NDTV states, "I have colleagues whose in-laws constantly call, sometime on the hour, to check where they are. I mean...talk about a technological leash.” While strongly stating that she pays no heed to "such crap”, "Nandita”, NDTV has no qualms in clearly stating the overlap between Hindutva and globalization as far as women's roles are concerned. “Both movements see women as their 'soldiers'. As long, as we don’t make any demands or try to change established roles within the household. I mean...we are separated from men by our wombs. So if that is the basis of difference...the fact of reproduction.... as long as we become mothers and fulfill that role deemed ideal as a mother... of course becoming a wife before...God forbid otherwise!” she laughs.

As Indian women attempt to create a safe space that is 'mobile' and not tied to specific spaces, there emerges a strong directly proportional relationship between being ‘safe’ and being ‘pure'.

\subsection{The Pure Woman}

This concept of control rooted in biological metaphors is at the core of women's role within a Hindu India. As scholars like Chhacchi (1994), Derne (2000), Mayer (2000) 
among others find, the fixing of women's sexuality and bodies into predicated zones of acceptable behavior and acceptable physical spaces as emblems of resistance to assumed "decay of Indianhood" is situated in the notion that her body is the metaphor for the nation. And the control of this body becomes the locus of control of the nation, its borders - both physical and socio-cultural. Add to this notion the biological context of motherhood and the production of future Hindu-Indian citizens of the nation and the Hindutva understanding of women and their priorities become defined by the family and domestic space. Even as women within the Hindutva movement enter the national arena as citizen-warriors, the ideals of female virtue and the Hindu family "shunt aside a comprehensive critique of the multiplicity of women's lives, power relations and sexual aggression within families and the ideas of shame and sexual respectability that inhibit many Indian women’s freedom” (Banerjee 2005:17).

Sarkar argues that when the core values of society are embodied in the chaste and virtuous woman, the actual doors of the zenana (domestic space) may be unlocked (Sarkar 2001:2011). Ram, RSS agrees, though in less provocative terms. Shadowing Sarkar's (2001) findings, he states that Indian women are essentially feminine and virtuous, a revered figure who holds the family together in bonds of love, culture and tradition, who may be 're-constructed' to suit the need of a changing society. Therefore, traditional roles are being reproduced as being less coercive and more consensual while keeping the male as the head of societal structure.

As globalization strengthened its roots within middle-class Indian imaginations and lives, Banerjee (2005) finds that economic and political upheavals in the Indian 
landscape have created an oppositional context where Hindu nationalism resonates with a certain group of Hindus. In this understanding, armed masculinity that signifies action, strength and the willingness to protect one's own through acts of violence is a powerful cultural construct. In this construct, women continue to be portrayed as being pure chaste units who even as they march with their male counterparts, are also the focus of their protection. This emphasis on women's chastity and the disciplining of their sexuality during times of socio-economic upheaval, as being caused by globalization, may be interpre(sent)ed as a form of resistance to uncontrolled and uncontrollable mutations in the socio-cultural genealogy of India.

As Ram, RSS succinctly states, "Not all growth is desirable. A cancerous tumor is also an out-of-control growth of cells and that has to be cut out for the survival of the remaining body. Similarly, not all parts of globalization have to be accepted as being positive, especially when it is changing the inherent nature of Indianness.” When asked what he meant by "Indianness", his carefully constructed answer paraphrased Savarkar's concept of Hindu identity. Ram defined Indianness as “a sense of spirituality and belonging wherein your identity, your body and soul belongs to the land of Hindustan...where since we are talking about women...women are treated as Goddesses...worshipped and feted.” He borrows from the core of Hindutva rhetoric that rests in the notion that "every child of the Matribhoomi [Motherland] may daily bow before the Mother and renew his pledge to restore her to the ancient pinnacle of glory from which she has fallen” (Swami Shraddhananda, emphasis in original, 1924:141). In this understanding, every child who "renewed his pledge" to protect the nation’s glory 
were Hindu men, who constituted “...the Virat Purusha [the Hindu male larger-than-life ideal], the Almighty manifesting himself' (Golwalkar, 1980:48).

Therefore, even as Hindu women are urged to, indeed within the folds of the RSS are required to embrace hegemonic masculinity through martial prowess and physical hardiness to protect themselves and their daughters, there is a strong suspicion of women who step outside the confines of the family.

Conversely, in this traditional Hindutva discourse, a Hindu woman as "Mother and Nurturer, Preserver of Tradition, and Property” (Pandey, 1991: 3004) constitutes the foundational pillars of Hindustan. Her appearance as Mother Earth, Mother India, and the Hindu nation represents not only an emulation of the women's place as "begetter of the glorious sons of Aryavarta (the land of the Aryans) but under the Hindu nationalist discourses of Savarkar and Golwalkar also gets reframed as the "Container, or Vehicle, the repository of the Indian (Hindu) tradition, the essence, the 'inner' side, the spirituality, a greatness of Hindu civilization” (Pandey 1991:3004). These notions of male dominated demands regularly clash with urban women's expectation of civil rights, safety and self-expression.

This clash between globalization and nationalism, over controlling the Indian woman's body, has thrown up a new form of masculine domination. While this new form of domination still sees women as being 'essentially' different from men, it allows for women's reform through education and self education as long as this was done without jeopardizing her place within the home (Chatterjee 1993:128). The education of women focused on reinforcing 'feminine virtues,' "the typically bourgeois virtues characteristic 
of the new social norms of 'disciplining' - of orderliness, thrift, cleanliness, and a personal sense of responsibility, the practical skills of literacy, accounting, hygiene, and the ability to run the household according to the new physical and economic conditions set by the outside world” (Chatterjee 1993: 129-130).

In my interviews with the HUMM women, it appeared that they are struggling against an ingrained sense of womanhood, "an auto-pilot mode of behavior where I sometimes find myself reaching for a yellow jumpsuit, even though I hate the color...but my magazine tells me it's the season color...or an automatic backing down from asking for a story because an older male colleague is eyeing it” (Shikha, Associate Editor, Times of India). I find Walsh's (2004) deconstruction of Pierre Bourdieu's formulations of doxa, orthodoxy and heterodoxy can explain the struggle, the cultural and social conflicts seen in India, which are not just between traditional Hinduism and Western modernity (Walsh 2004). Indeed, these are the internal conflicts within Indian consciousness. The struggle becomes a matter of degree, the level of accommodation of Western ethos, ideologies and discourses. As every element of daily domestic life comes under scrutiny, those who are able and ready to embrace the greater (doxic) upheaval argue for heterodoxy while those who want to restore an older albeit reformed to a degree order of things become orthodoxy (Walsh 2004).

Even as globalization has problematized much of the doxic world of India's middle class family life, the new incarnation of masculine domination, as Chatterjee (1993) conceives it, is an effort that allows only so much of the habits of home and family into the disputed realm of orthodoxy and heterodoxy. Therefore, today struggle is about reforms going only so far and no further (Chatterjee 1993). This is what some of 
my interviewees called "the Lashman Rekha," referring to the line drawn in the sand by Lakshman, the brother of Ram to keep Sita, the wife of Ram, 'safe and therefore pure' in the epic Ramayan. When she stepped over the line, Sita was kidnapped by the demon king, Raven.

In praxis, the imposition and onus of "keeping the faith" rests or rather burdens women. As Pandey elaborates “...the body of woman...becomes the site for much of the punishment that is deemed necessary to expiate the sins of family, community, and nation: 'sins' which, all too often, involve men's deviations from prescribed moral, social, and political codes” (Pandey 1991:3004). As Shikha, Times of India says, "I was in a terrible marital relationship. When I went to my ex-husband's family for support, all I got to hear was how I needed to be a better wife and things will fall into place. How about him being a good...no decent husband in the first place!”

Such expectations from Indian traditionalists are hardly unusual. Whether the ideology is about defining women’s personal boundaries/roles or about defending the nation’s borders, the goal is to “...to recast India’s desired [Hindu] nationalist identity... in transnational arenas...especially in terms of re-thinking international hierarchies and inequalities" and points out that these policies also indirectly assert the party's patriarchal control over Indian women and the nation (Sangari 2002:12). This is a "new patriarchal" which "provide rationales for bringing together old and new forms of gender policing" of Indian women (Sangari 2001:14-15)

Therefore, the Hindutva Brigade draws strongly from an existing maleadvantageous quagmire of material and symbolic evidence involving Indian/Hindu women, to "repeatedly use and transport" the vulnerable images as Sites, Saviors, and 
Dhrupads $^{29}$ as understudies of a sexually violated Hindu nation, a mother who has borne the marauding of the Outsiders, whether the Mughals or the British or recently, Western mores/cultures through the invasion of Western corporations. This reinvention of the tortured Mother India has become the call for latent masculine Hindutva that incites, even worships the violence of the Saffron Brigade as it 'defends' the nation, whether that involves the public testing of India’s first nuclear device at Pokhran or the shocking violence of a marauding crowd that manhandles 'westernized' youth, largely women in a bar in Mangalore ${ }^{30}$.

Hindutva While women venture out into the world of competitive employment, engaging with male bastions of power and established 'club’ rules, there is an interesting dichotomy in the ideology of the Hindu Brigade. Traditional characteristics of femininity such as tolerance, sacrifice and Gandhian non-violence are being invoked as standards to be followed by working women (creating the lifestyle of double duty) while being

29. Sati Sita is the wife of Lord Ram, both protagonists of the Indian mega epic, the Ramayana. This tale of virtue and vice symbolizes and defines the perfect Man and Woman. And in this definition, the perfect wife, the ardhangini (the possessor of half the body of a marriage) is the shadow of her husband. When the perfect man doubts the purity of his wife based on the whispers of his washerman, the perfect woman proves her piety by entering a burning pyre and then is enveloped into the Earth.

Draupadi is the polyandrous queen of the Indian epic Mahabharat. While she is the wife of five brothers, the polyandry was not of choice but rather circumstance, which she accepts with little protest. In spite of being under the protection of five brothers, she is gambled away by them in a game of Chaucer (the antecedent of Chess) and had to bear the humiliation of being 'almost' disrobed in public, from which she is rescued by Lord Krishna, a male Hindu God.

Savitri is the wife of God Brahma (the creator within the Hindu Trinity). In Hindu mythology, Brahma and Savitri give birth to the human race. Another Hindu legend tells the story of a princess named Savitri who fell in love with Prince Satyavan, the son of a blind, exiled king. Although a holy man tells Savitri that the prince would die within a year, she marries him, nonetheless. After a year, Satyavan goes into the forest to cut firewood where he meets Yama, the God of Death. As Yama takes the soul of her husband, Savitri begins to recite learned texts about Yama. Touched by Savitri's knowledge and devotion to her husband, Yama grants her three wishes. She asks that Satyavan's father recover his sight and his kingdom. Then she asks that she might become the mother of 1,000 children. After Yama agrees, Savitri argues that she could not have children if her husband were dead. Impressed by the way Savitri had tricked him, Yama restores Satyavan to life.

30. See video of attack on Indian women in a bar in Mangalore.http://www.youtube.com/watch?v=17ygbdlmko 
"autonomous and animate symbols” (Agarwal 1995:30) that stand for an emancipated, globalized India. These progressive women of India have been assigned "autonomous cultural space” (Sarkar 1995:2007) wherein they are expected to carry out their roles are professional women symbolic of modern India and yet careful about overstepping their bounds as the moral bearers of the nation. The guardians of Hindustan reify these markers as feminine and to be worshipped in women while dismissing them as emasculating for the Indian state.

This juxtaposition of femininity and emasculation is largely interpreted as being antithetical to the might of the regenerating Hindu nation, wherein masculinity equates protection of self and Bharat Mata, her citizenry and her borders, both physical and cultural through violence. Therefore they demand that such characteristics be set aside by the Hindu state while raising high rhetoric about adopting "the Hindu bomb...[as] therapy for weak-spines, bad posture, and emasculation,” of the Indian state” (Sangari 2001:10). This juxtaposition of violence and masculinity are repeatedly manifested within domestic and public spaces as seen in the rising statistics that show rising crimes against women.

Lal (2007) finds that The National Crime Records Bureau (NCRB) reported a rise in the average number of women who faced domestic violence everyday from 125 women in 2000 to 160 in 2005. Also, more than 19 Indian women are killed for dowry everyday, 50 are raped and 480 subjected to molestation and abduction. The Bureau stated that 45 per cent of Indian women are slapped, kicked or beaten by their spouses with India also having the highest rate of violence against women during their pregnancies - nearly 50 per cent women were kicked while expecting babies with nearly 
seventy-five per cent of those beaten attempting to commit suicide (Lal 2007).

Responding to my questions about the increasing crimes against women and the nationalist brigade's response to it, Ram, $R S S$ invoked their strong militant female presence in the form of the Rashtriya Swayamsevika Sangh (National Self-help group for women) and BJP’s Mahila Morcha (Women’s Branch) and the presence of strong female leaders like Uma Bharati and Sadhvi Rithambara. According to Ram, RSS, these groups teach women self-defense and tactics to counter violence.

Yet Alka, Zee News shrugs off their notions of empowerment stating, "These women are powerbrokers and operate like any male leader of the group. The difference of course lies in the fact that men don't have to portray themselves as brothers or fathers to de-sexualize themselves.” This refers to what Bachetta (1993) calls the representation of powerful women possessing "split femininity" wherein modernity is present but subservient to the male preserve and therefore vulnerable to continuing violence.

As Ram, RSS says, without irony, "We want our women to be independent and work. After all they are individuals and have their desires. But everything has a moral boundary, for men and women. It is the responsibility of the individual to remain within their bounds.” What remains unsaid is the fact that women are expected to toe a longer and thicker line than men. The double standard is rooted in women's "relative deprivation” (Sangari 2001:10) and “entrapment” (Bachetta 1993:47) with respect to Hindu male power, where a "controlled self-objectification” are used by the party to “produce a visual self-image” that serves a national agenda. (Sangari 2001:11)

Even as this imaginary has been created, researchers question the acceptance of this self-objectification, which circumscribes Hindu women in male defined spaces 'for' 
femininity, both as nari (women) and narishakti (women power as militant), in the service of the Hindu glory. There is tacit acceptance of their responsibility to "maintain the purity, chastity, and honor of themselves. This naritya (traditional Hindu femininity) however is a tradition of our nation which we will continue...But as liberated and empowered women of India, we should also think about the security of our nation...” (Das 2004:24).

Indeed, the party's "Brahmanical/ cultural” male dominated structure appears to have an "impersonal contempt" (Agarwal 1995) over participant Hindu women, who accept the party's patriarchal clutches over themselves. The militancy/liberation of the participant female Hindu activists is regularly used by the Saffron Brigade as being emblematic of their support of a modern and a liberalizing India by involving these women “...often as sovereign embodiments of the state” (Agarwal 1995:30) and tokens of female emancipation. The understanding projected by the party's male leaders is that only if the Hindu women can remove any threat, either in the form of Islamic or Western influence from the Hindu soil, can they be physically and culturally secure, therefore allowing them safe spaces within and without their domestic spaces.

Using this logic, the Brigade uses women not only as an "unspecified reserve" (Roy 1995:27) for parties like the BJP to draw upon but also to "channel" and "contain" them along “appropriate lines” of behavior (Jeffrey and Basu 1998) according to the party’s male dominated communal perceptions.

Khattak (1996) examines nationalist discourse on defense policies, an arena where female opinion is minimal to find that the $B J P$ 's discourse on nuclear weapons is rife with blatant sexual metaphors. It relies on "heavily gendered" symbols to produce 
"nationalism and patriotism" such as the juxtaposition of Goddess Durga, as

Durgamohini (maternal instincts) and Durgavahini (militancy) (Khattak 1996: 348).

Basu (1995) finds that women's space, both domestic and militant (read public) is used by nationalist leaders to perform what she calls a "double-function” in supporting the party’s larger schema of maintaining a “communalized” agenda for India. Women in their "militants forms" are used by the party to perform the functions of "filial sons" (aggressive, militant, and modern) who "goad" the Hindu men/ community to action to support a Hindu agenda while women in their "traditional imaginaries" are also made to perform the duties of "dutiful daughters," who by maintaining their chastity, purity, and submissiveness to the Hindu nation and its male leaders re-affirm the "revival of a Golden Hindu Age” (Basu 1995:166).

Responding to the question of "double-functioning”, Ram, $R S S$ asks, "Why is [sic] there so many questions about our view of women? I mean we think Hindu women have so much power given that the purity, chastity, and honor of the nation rests on them. We want to protect them from physical and psychological harm.” Ram's position that sees modern Hindu women as "a complementary icon of traditionality and emancipation...[and the Hindu Brigade as wearing] a 'nationalist mantle' of a Hindu India...[brings forth] a domestic tightening in the social field of gender and religion, and the grouping of patriarchies, usually around female consumption, [which] provide rationales for bringing together old and new forms of gender policing” (Sangari 200:12).

But the $B J P$ appears to lose its toehold within the media women of upwardly mobile middle class but its stronghold within the cultural ethos of the larger middle class impacts the public and professional spaces of the Indian urban landscape. This is 
evidenced by the increasing crime rates against women. Therefore middle class families educate their daughters and expect them to become financially independent and successful citizens, yet the fear of cultural angst meted out by disenfranchised and disempowered male presence results in the policing of workingwomen, a refined form of paternalism. As Sangari states, "Patriarchies in fact are most ardently reformulated when new agential avenues open for women ...specific forms of agency while they (the agential avenues) also contain or curb them (women)” (Sangari 200:12, 14-15).

The constant reinvention of life-spaces for women within their space of citizenship, the boundaries of their nation-states that is based on fear and the need for physical/sexual/mental safety has resulted in the freezing of boundaries-- communal and national—in what Kristeva (1993) calls a form of "sexual, nationalist, and religious protectionism...” that circumscribes them in a space of dichotomous identity, empowered by their own acts but disempowered by male dominated expectations.

\section{Conclusion}

Feminist scholarship has shown that masculine dominated traditions in India legitimize male control over a woman’s mind and body. According to Kishwar (1997), the concept of individual rights that is the cornerstone of western feminism does not apply as easily to Indian womanhood given the centrality of the masculine controlled family. Within this domestic framework, the Indian woman's status remains linked to their performance in socially sanctioned roles of daughter, wife and mother. Therefore, even as women become economically independent individuals, marriage and motherhood continue as distinct markers with agency-limiting and agency-enhancing effects.

Even as the ideology of Hindutva is actively being disseminated as a discourse of 
empowerment, wherein Hindu women are being structured as bounded collectivities, as “stri-shakti” (women power), as the cultural guards against the Outsiders, they are still being strongly circumscribed by the parameters of decency as set up by traditional notions of the Hindu woman of the Golden Age. In the contemporary scenario, the Indian woman is a re-appropriated image that is empowered but bounded by limits that are set by the male-headed family structure. These imaginaries are central to the nationalist construction of India Inc., a landscape of layered progress, opportunities and insecurities.

I demonstrate how discursive and mediated strategies are used to develop cultural and economic demands from Indian women. The idiosyncratic juxtaposition of globalization and nationalization while contrasting in their messages, ultimately seek processes of homogenization. Just as Hindu nationalists linking space and ideology demand that ideas of female sexuality are foreign and outside the parameters of Indian culture, globalization enthusiasts encourage an assumption of homogeneity wherein Indian womanhood is legitimated and disciplined by Western norms and standards. Having successfully performed Western disciplinary practices of feminism, Indian women and hence the nation, now have currency and are 'circulated' in global markets.

The following chapter will focus on the identity markers placed on women in public spaces, both within their professional zones as well as movement/gathering waiting non-domestic zones of living. 


\section{CHAPTER V}

\section{Boss or Bitch: Stepping Into the Workplace}

"I know I have better opportunities than my mother...But I also know that I face more violence, whether it is eve-teasing or just taking on 'man's work'! Yet at the end of the day...marriage seems to be the goal."

- Diya, Times Now.

Sitting in the small lounge of the fifth floor office of Times Now located in busy Connaught Place, I converse with Diya, the 26-year-old assistant editor who sports a tattoo on her left arm and is clad in a salwar-kameez with an air of quiet confidence. Elaborating on her comment about work and opportunities, she states that irrespective of her confidence and ambition, there is a very conscious awareness that she has to work harder, stand her ground more forcefully and sometimes be passed over unfairly, for assignments and promotions.

As I ask the women to talk about their daily public experiences, whether in their professional capacity or as citizens using public space, I attempt to locate the respondents' understanding of women's work in general and their own work in the news media, specifically in a socio-historical framework. The respondents' answers are influenced by constant and competing debates about women's work in the public domain. The debates on public visibility of women, their participation in employment and the subsequent emancipation of women have occupied center stage in nationalism discourses and in globalization narratives. 


\section{Panic on the Street: Woman Sighted}

The presence of Indian women in the workplace has generated vigorous public debates and has centered on two demographic sets: menial, industrial and agricultural labor of poor women (deemed largely unskilled) and professional labor of educated and largely upper economic class women. Women’s menial work that includes maids, agricultural workers and street vendors is ‘encouraged and tolerated’ given society’s need for cheap, untrained labor. Upper class women in 'respectable professions' are encouraged as being progressive ideals of a modern nation. In traditional Indian discourse, female participation and presence in the public sphere is preconditioned on the notion of virtue, as "figures of heroic mother, chaste wife and celibate warrior" (Banerjee 2005:140).

\section{- $\underline{\text { The Economic Impact }}$}

Post independence national development agenda has touted empowerment through employment as a central goal for India. Feminist research has found that the neoliberal paradigm as well as the Hindutva movement has made women's empowerment and women's right to equitable employment/compensation a central component of their rhetoric (Bagchi 1999: 368-370, Ganguly-Scrase and Vandenbroek 2005). This change of gendered expectations wherein only financial necessity or elite 'entitlement' were deemed reasonable-respectable conditions for women's employment is based on evolving societal expectations. Indeed scholars like Channa (2001) and Desai (2002) find a huge overlap between state and corporate agendas and expectations resulting in the Indian state modifying pre-existing differentiation between home-time and work-time by relaxing legislation that historically restricted women's rights to work at night. But these changing 
work regimes have been accused of having the capacity "to erode national and cultural traditions” by traditionalists (Thompson, 1989: 197).

Indeed, scholars like Kantor (2003) and Measham (2004) have found that the empowering impact of economic independence is inconsistent and suggest that the ability to balance their economic role and their sanctioned domestic role is a key determinant of attaining agency and self-determination.

In urban India, for example, Kantor (2003) finds that financial autonomy, as an indicator does not imply increased female agency because social marital norms intervene in women's ability to convert resources into power. Also, economic empowerment creates zones of danger for women within their domestic space as the indication of such independence is seen as a challenge to the existing male-led power structures, resulting in domestic violence (Kishor and Johnson 200, Krishnan 2002 and Swaminathan 2004).

"My divorce is directly related to my profession... at least in retrospect. My husband's taunting and suspicion about my work hours...my ability to stand my ground, which largely stemmed from my ability to sustain myself economically...all of it contributed to my situation,” says Shikha, Times of India. Women working in corporate media where assignments regularly require them to work unorthodox hours experience certain tensions and hostility. The element of "glamour in the mediated professional space” also leads to tensions at a societal level.

As Diya, Times Now rings for tea during the research interview, she remarks that the juxtaposition of the modern woman who knows her mind and is independent with the 
notions of the traditional woman "makes life difficult." As the male peon ${ }^{31}$ brings in the tea, Diya wonders how he equates serving tea to a memsaab ${ }^{32}$ while his wife did the same for him in the morning. The relatively new presence of independent Indian womanhood constructed in opposition to narratives of traditional male dominated norms does challenge the gender ideologies in families and society at large.

The 'new' economy that has spawned the 'new' woman has brought up some critical questions about the notions of female dependency and feminine roles. The reconciliation between being the main financial provider within his household and being subservient to women in his workspace is challenging for males who operate in a largely masculine dominated system that provides a limited vision of Indian womanhood and specifically, middle class Indian womanhood. Puri’s work on middle class women leads her to state that, “...their lives are framed in terms of femininity and sexual responsibilities and their bodies, genders, and sexualities are social effects of a system that requires self-surveillance and internalization of responsibility” (Puri 2002:202). The centrality of heterosexual marriage and marital norms, vis-à-vis women are remarkably resistant to change, irrespective of the transformation of their public/professional roles. According to scholars like Puri (2002), this is strikingly true in the short term. After all, like any other hierarchy, the actors in control naturally attempt to maintain the status quo.

“Most Indian men I meet outside my familiar circles are pigs. The initial ‘exchange’ of greetings, eye contact or occupying the same space is fraught with a sense of sexing,” states Neha, anchor/principal correspondent, TV Today. The sense of outrage

31. In India, the term 'peon' is used for an office attendant or orderly that performs odd jobs.

32. Honorific title for a woman of higher status (economic or social). The term stems from colonial usage of the word madam-sahib (sir) or wife of sir. 
and unspoken fear expressed by the 28-year-old woman is the result of regular attempts to intimidate or demonstrate social power as experienced by women in New Delhi. "What makes it worse is that when I do get eve-teased ${ }^{33}$, I know that there is little that I can do. Go to the cops? That is laughable. After all I am putting myself out there and that is reason enough for the 'outrage of my modesty' (finger quotes)”, she continues.

And yet Neha, TV Today and the other women claim deep gratitude to the economic policies that allow 'women's advancement', expressed primarily in terms of entering the world of paid employment. The interviewed women are emphatic that their confidence and sense of self is boosted by the presence of financial autonomy and the ability to be consumers of modern society. Unprecedented career opportunities with competitive remuneration are augmented by increased opportunities for consumption as part of the wider trappings of consumer modernity. At the same time, the demands of the electronic news media, which is riding the crest of immediacy and “...operating in permanent panic mode, fearing the loss of breaking news” (Interview with Neha, $T V$ Today) requires long hours and unorthodox work shifts. These temporal shifts within workspaces are sharply impacting socio-cultural conditions relating to women's role is in the family and the workplace, both now and in the future.

The following section examines the social impact of globalization and nationalism changing the urban landscape where the HUMM women operate.

\section{- $\underline{\text { The Social Impact }}$}

The clash between traditional ethos and global capital has resulted in a strong

33. A term used in India to describe public sexual harassment that includes inappropriate touching, poking, lewd gestures and words as well as physical crowding. 
articulation of societal changes. As Sassen argues, “...these 'in between spaces’ or 'regulatory fractures' might represent opportunities for social actors to develop new combinations of local, national and global social relations” (Sassen 2000: 220). And in these spaces of interaction, obstacle and opportunities arise.

Ganguly-Scrase and Van den Broek (2005) place this transformation within the framework of expectations wherein "the cultural milieu of the colonial and post-colonial middle classes based on notions of gentility and respectability have been replaced by conspicuous consumption” (Ganguly-Scrase and Van den Broek 2005:4). The term “conspicuous consumption" has become a bone of contention between the ideologues of globalization and Hindutva. Even as middle class families are embracing the spaces created by globalization wherein public visibility of women and their relative freedom to pursue careers are seen as central to modernity, there remains a strong notion of 'respectability and appropriate behavior' that is expected from the working woman.

Suman, Aaj Tak one of two women camerapersons working with the media stations in New Delhi articulates her struggle with breaking societal norms, "Within our society, working such late hours is a social stigma. I have had people in my neighborhood look at me askance and I know they think that my work is not totally decent. I have been stopped by a male neighbor when I was returning home from a late assignment. His body language was aggressive and language disrespectful. Would you believe I had to call my husband to back my position? I was so angry and so afraid, all at the same time”.

In my research with the HUMM women, when the question of their 'sexed bodies' moving through public and professional spaces came up, there was a strong sense of anger and hostility towards Indian men and the state. According to Diya, Times Now, 
the terms, "sexual respectability”, "boundaries of decency”, "sexual freedom” among others are always applied to women. Any inappropriate attention that is received by the women, either on the roads or at work, is constructed as being the woman's fault for not following a "proper code of conduct...or wearing provocative clothing...or being 'too' friendly.” As Ramu (1987) notes, in a modernizing context, changing economic conditions is not immediately being accompanied by renegotiation of household power and broader diffusion of egalitarian values (Ramu 1987 in Ganesh 1997).

As I sat with Suman, Aaj Tak in her home, drinking tea and asking her questions, the largely Hindi-speaking 42-year-old woman exemplified just those shifting societal expectations. A maid swabbed the floor of her two-story house, her 13-year-old son repeatedly interrupted our conversation to seek help towards his homework while her husband, also a media professional, cooked lunch. In her articulate explanation of her domestic situation, the soft-spoken camerawoman states, "I am lucky. My husband is very supportive and he works in the same field so he understands the work pressure. But he is unusual. I have colleagues who fret at work about picking up their children from school and cooking dinner.” Asked about how often she encounters women who are not worn out by the "double shift" of "work-work" and "house-work", she admits that most women did "pull double-duty."

Suman's story is reflective of the story of liberalization. Indeed, studies have shown that the advantages of globalization have been monopolized only by a certain socially advantaged segment of society (Dreze and Sen 1995:154) while a majority of Indian women faced decline in terms of personal and professional gains. A reading through the week's newspapers would make clear that female infanticide, female feticide, 
rape and the burning of women for dowry are some of the ills against women's bodies that continue to be reported at an alarming rate (Anderson and Moore: 2000).

Abhilasha, reporter, Business Standard admits that much like the trickle down effect of neoliberal economics, the trickle down effect of cultural liberalization was slower than she had expected. "I live in a liberal household, where I am encouraged to be my best. I walk out of the house and immediately feel a sense of wariness till I reach my office, which feels much safer. It feels like I am straddling two worlds that exist in parallel dimensions”.

The interviews make it evident that one of the biggest contradictions in postliberalization India is that the ideals of Indian womanhood have not been transformed to include the modern woman. For a majority of Indian men, the ideal is still embodied in their mothers, who have been relegated to the domestic sphere and were essentially rooted characters in heterosexual families built to support the figure of a male head of the household. This is ideologically oppositional to the brigade of young, educated women who are financially independent and therefore better able to voice opinions and counter traditional demands.

“But no matter how liberated I am, culturally and financially...I still have to find a man who is willing to see these aspects of my personality as being immutable. Shaadi ke baad to ladki ko badalna hi padhta hai (a girl has to change after she gets married)...that cannot be part of the equation...” admits Diya, Times Now, who has been through the processes that form the custom of arranged marriages. Even as the concept of Western-style dating is on the rise within the urban youth, arranged marriages still abound. Largely based on religious and caste-based preferences, arranged marriages 
processes have also imbued 'modernity' by using Websites like www.shaadi.com (matrimony). Newspapers and Websites are regularly used for matrimonial advertising. Within most advertisements, the girls are imbued with qualities that reflect the "balanced blend of the East and the West”, which largely translates into images of fair, slim, educated women who are nurturing and submissive in terms of the welfare of the family unit (See matrimonial sections of any national newspaper such as The Times of India, The Indian Express among others).

While the middle and upper classes of urban India accept the liberated Indian woman as part of their lived landscape, the bodies of these liberated women still have to operate in spaces that are tied to male-advantageous norms.. The average Indian male who occupies the public and professional spaces when confronted by professionally employed, Western attired 'powerful' women are more likely be sexually aggressive towards them since ‘such women’ are diametrically opposite to the purified images of Indian womanhood that are routinely dispersed by the media, the Hindutva activists and the various self-proclaimed arbiters of morality.

The disconnect between mediated imagery and the reality of women's lived existence is regularly articulated in the rising physical and sexual crimes against them. The capital of modern India, New Delhi is frequently referred to as the rape capital of India, with rising incidences of rape, abduction and sexual harassment. In 2006, Delhi had the dubious distinction of recording the highest rate of crime against women at 27.6 per cent as against the national average of 14.1 per cent. The alarming data, part of a report by National Crime Records Bureau (NCRB), include crimes such as rape, dowry deaths, molestation and incest. Among the 35-mega cities in the country, those having a 
million populations and above, Delhi alone reported 33.2 per cent (562) of the total 1,693 rape cases. The report further added that out of total number of 2,409 cases of kidnapping and abduction of women, Delhi recorded 37.4 per cent or 900 cases (www.ncrb.nic.in).

The crime figures and the interviews strongly indicate that even as globalization celebrates the entry of women into the workplace and Hindutva embraces the new Indian woman as an extension of empowered devis (Goddesses), public presence of women continues to attract unwanted attention and rests the 'blame' of violence on these out-ofplace female bodies.

\section{Primped and Powdered: Carrying the Weight of Globalization}

In India, the rhetoric of globalization has a constant hypnotic murmur that places women's advancement, especially in the work place as being the cornerstone of progress.. Neha, TV Today whose deceased father was a renowned journalist remembers how her father took pride in her academic prowess and expected her to excel in her profession. "I know that we constantly talk about how our lives are ruled by ideologies of consumerism and 'keeping up with the Batras' but for me, it is about economic independence. Money means power to me...not in the sense of power-power but more about being able to take care of myself without having a man...any man...take care of my needs. No one can tell me what to do or not...except my mother!” she smiles.

Elaborating further, she states, "I know that my mother worries for me. I travel at odd hours. The news is constantly focusing on crimes against women...that gets us the eyeballs... and so she stays up waiting sometimes. But that is the downside of working in the media. There is little demarcation between works hours and home hours.” These changes in centuries-old normative societal behavior are the result of strong economic 
impulses. As Sassen (2000) writes, “...nation states are not containers that invite global processes to fill them, global economies have to be actively implemented, reproduced, serviced and financed” (Sassen 2000: 217).

The following section examines the impact of globalization-led changing societal mores on the bodies and spaces of Indian women.

\section{- $\underline{\text { Body Politics }}$}

As a certain class of urban women has gained substantially under the regime of neoliberalism embraced by the Indian state, they have also felt the impact of newly mediated messages defining their symbolic identity and personal worth. These markers include superficial qualities such as skin color, slim figures and shining hair as the ultimate goals of womanhood while simultaneously stereotyping 'good' and 'bad' gender behavior. This research tacitly finds that this imagery is the product of neoliberal ideology and "the new cult of consumerism forced on every part of the world by the dominant culture of capitalism", which insidiously borrows from local cultural gender norms, specifically those embraced and dispersed within the ideology of Hindutva (Ganguly-Scrase 2005: 15).

Diya, Times Now and the other respondents admit that globalization has added another "burden" to their daily lives: keeping up with the beauty standards of the West. These media generated standards of esteem that are measured in terms of skin color, slim figures and fashion-ability are constantly and insidiously building on colonial and postcolonial expectations to set newly amalgamated goals of perfection, of desirability. As Menon asserts this tension is a product of a historical moment, where a developing nation like India is caught in the complexities of globalization and internal politics (Menon 
2004:101). A manifestation of this tension is seen in the marketing done by West-based producers of beauty products that use the technology of communication to beam into the living rooms of millions of Indian household, the insidious messages about women's' bodies and how to 'repair' or 'improve' them with the goal of acquiring a good husband or a good job. These regressive messages used by the cheerleaders of liberalization fall back on using imagery that seeks to make the woman's body and in some cases, the man's body, into currency that can buy or be 'sold' as the perfect package.

It can be safely stated that mediated products belonging to the electronic media, the Internet and paper publications play a substantial role in promoting and disseminating information about idealized life styles, socialized roles, socio-cultural expectations, political ideologies, religious norms, workplace participation as well as global patterns of consumption that 'should' be emulated. And among the various mass communication sources, the electronic media rules the roost. With the choice of over 500 channels (Hindi, regional languages and English), of which about 50 being news channels, the television is literally the 'eye on the world' of the Indian family that sits in their home and absorbs multiple ideas and notions about self and others.

While the electronic media has expanded at an admirable rate, as has the number of women employed by them, researchers find that there is an alarming trend of depicting women as victims and largely sexualized beings (Bahuguna 1999). In advertising, there is an increasing commodification of women's bodies. Even as new images of independent women appear to be oppositional narratives from traditional patriarchal norms, there continues certain thread of women as mothers and wives and daughters as well as workers. According to Bahuguna (1999), irrespective of claims of progressiveness, the 
desire to keep the woman's body circumscribed in specific roles of subservience continues unabated.

As Alka, Zee News indicates, there is immense upheaval in material and social relations of women media professionals. Unprecedented job opportunities that pay comparatively good wages are augmented by increased opportunities for consumption as part of the wider trappings of consumer modernity. However along the way traditional family relations are being challenged. As Bhabha states, "Terms of cultural engagement, whether antagonistic or affiliative, are produced performatively. The representation of difference must not be hastily read as the reflection of pre-given ethnic or cultural traits set in the fixed tablet of tradition. The social articulation of difference, from the minority perspective, is a complex, on-going negotiation that seeks to authorize cultural hybridities that emerge in moments of historical transformation” (Bhabha 1994:2).

As Indian urban spaces/lives mutate and regenerate rapidly in the era of globalization, therefore clashing with traditional expectations from its citizens, the media has become the central player in both producing and reproducing 'moulds of behavior' through tools of focusing/popularizing/denigrating attitudes, mores and values. And the ideologies of the burgeoning media channels are reflected in the style, choice and presentation of their programming that deems women's bodies and behaviors follow a tightly scripted role. The attempt to 'fix' women's places and roles that are advantageous to the corporate and religious worlds while simultaneously encouraging their liberation has led to a minefield of confrontation. The following section examines how such constructions of roles impact the psyche of the HUMM women. 


\section{- $\underline{\text { Mind Politics }}$}

Focusing on the processes adopted by corporations, especially the much-touted offshore call centers that are seen as India Inc.'s mascot of progress, which regularly host company sponsored 'family days' and offer social activities within the confines of the call centers including dance classes, pool rooms, canteens, games rooms and gymnasiums among others that are looked on favorably by those who work there and appeal particularly to the parents of 'respectable' women entering the industry (Ganguly-Scrase 2005), the media women appeared largely amused.

According to them, the 'night-shift' is a new concept for these companies while media persons have always scouted for stories '24-7-365'. As Alka, Zee News states, “the playing field in call centers is much more even. The women are in safe spaces and don't have to venture out into the big bad world to get their work done. We are constantly outside...especially as correspondents or camera people...that is why sometimes women media professionals just prefer to be the face of the channels rather than the backbone. It can get tough and dangerous sometimes. I remember traveling to the interiors of a ...[northern] state where a Dalit woman ${ }^{34}$ had been marched naked through the village

34. Derived from the Portuguese word, casta, meaning breed, race or kind, the Indian caste system is divided into four major groups, membership in which is achieved by birth. According to the sacred texts of the Rig Veda, that date back to oral traditions of more than 3,000 years ago, progenitors of the four ranked varna groups sprang from various parts of the body of the primordial man, which God Brahma created from clay. Each group had a function in sustaining the life of society--the social body. Brahmans, or priests, were created from the mouth. They were to provide for the intellectual and spiritual needs of the community. Kshatriyas, warriors and rulers, were derived from the arms. Their role was to rule and to protect others. Vaishyas--landowners and merchants--sprang from the thighs, and were entrusted with the care of commerce and agriculture. Shudras--artisans and servants--came from the feet. Their task was to perform all manual labor. A latter category, “untouchables” (called Scheduled Castes in legal and legislative parlance) or Harijans (coined by Gandhi meaning "Children of God” was created to group together a mixed population of castes. The term Dalit is a self-designated Hindi word that means oppressed or downtrodden (Basham 1998). 
square to punish her son, who had been seen with a woman of a higher caste. Even as I talked to the other Dalit women, a group of higher caste men surrounded me and my cameraman. They pushed me and used awful language, threatened to break the camera...they accused me of inciting the women. Aurat ban ke raho (behave like a woman). At the end, we had to use local police to get my story. But I did get it. It was just tougher than if I had been a man. At the same time, I think I got a lot more information from the women because I have breasts and no facial hair. So there are pros and cons.”

At the same time, the respondents admit that with the widespread trend of large number of women working in call centers, there is a slow reworking of societal norms with respect to women and odd working hours. More importantly, women see themselves differently in terms of their own decisions and spaces. Globalized work expectations and globalized work hours, which are being institutionalized by the state into a modern work regime appears to have the capacity to erode national and cultural traditions (Thompson, 1989: 197). This was patently obvious in the conversation with the media women who articulated such erosions or remaking of social and gender relations. This is exemplified by the acceptance of live-in relationships and 'love' marriages within the women. At the same time, the right to walk out on a bad marriage, once seen as being cause for social ostracism is more accepted.

It is evident that the entry of global capital and neoliberal ideology into the borders of nation-states to influence social and economic institutions has met resistance 
and accommodation of varying degrees, “depending on the social (and economic) resilience or thickness of nation states” (Ganguly-Scrase 2005). Scholars like Sassen (2000) and Bhabha (1994) have focused on these 'spaces of confusion'. Particularly, one could extrapolate Bhabha’s (1994) notion on nationhood - as "narrative” constructions that arise from the "hybrid" interaction of contending national and cultural constituencies wherein "[i]t is in the emergence of the interstices-the overlap and displacement of domains of difference-that the intersubjective and collective experiences of nationness, community interest, or cultural value are negotiated...” (Bhabha 1994:2) to complex ongoing local processes that shape these interactions through resistance and embrace.

The next section examines the different expectations made of Indian women as icons of Hindustan.

\section{Carrying the Weight of Nationalism: The Good Hindustani Working Woman}

As stated earlier, globalization has mutated the playing field of work in India, with women being allowed steady entry into the workforce. Yet the essence of a 'good' Indian woman lies in 'good behavior', which is determined by her ability to adhere to the rules of the normative male-led Hindu family. This adherence to rules allows the family to 'give her away' to a good husband.

In feudal times, it was essential for families that their bahu (daughter-in-law) possess excellent qualities, measured in terms of social and moral character. In the urban landscape of today, the meanings of these terms have metamorphosed. Even as families 


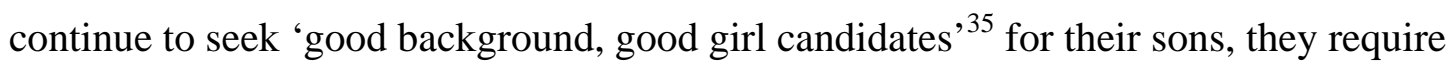
well-educated girls who are "pleasing to the eye" (Interview with Shikha, Times of India). While producing children of virtue and high ability remains the focus of marriages (the deeply entrenched male dominance of Indian society is exemplified by the preference given to male children because of matrilineality and patrilocality), there is an additional expectation of urban women, the ability to work outside the home and add to the household income.

- $\quad$ Impact of Working on the Personal Lives of Women

Even as globalization has expanded professional and academic opportunities for women, Kapadia (1995) finds that education does not always serve women well within a traditional framework. For instance, among the urban middle class, traditional values of dowry are being grafted on to contemporary social situations. Societal norms dictate that a highly educated woman needs to marry a man who is preferably more educated than she. According to Kapadia, a highly educated man’s parents would demand a higher dowry since "it is the wife who is to get benefit of his salary" (Kapadia 1995: 59). This exemplifies the intersection of traditional notions of male social superiority within a marriage with the modern calculative vision of upward economic mobility that is marked by global consumerism.

Scholars like Dube (1997) have found that dowry in the times of supposed liberalization of women under the globalizing economy has seen as escalation in all

35. Economic factors have become much-researched factors given the rise of dowry and dowry related deaths in India. For more information, see Sen 1990; Thakur 1998; Bhat and Halli 1999; and Dalmia and Lawrence, 2005. 
regions of India. From the concept of woman as merely a womb to produce and nurture children, the framework of globalization now views her as a consumable body, a source of Lakshmi (Goddess of Wealth). And like any other repository of economic value, she can be replaced or removed ${ }^{36}$.

"I would never give up my work. It is my identity and my strength. I know that tomorrow if I want to walk out of my marriage, I can” says Alka, Zee News, “Given my clashes with my mother-in-law, who does NOT stay with me, there are times it feels like a possibility.” This inter-generational clash is not a new phenomenon. The relationship between a mother-in-law and daughter-in-law has always been perceived as being largely fractious. This is rooted in the structure of the joint male-led family, wherein the worth of a woman was measured by her contribution to the household economy in terms of her home-making skills and in lower-caste households, her skills in the family's occupation.

Traditionally, women were the repositories of knowledge, especially in the arena of the kitchen and household healing, including mid-wifery and women's ailments. Since the only means most women had of gaining this knowledge was through the tutelage of older women within the family, a much-entrenched hierarchy was formed. The older women, who guarded the components of their skills, which garnered them respect and power within the otherwise male dominated family structure, imparted such knowledge to

36. The Statesman (February 10th 2003) described the sale of female infants as young as 10 days by a poor and marginalized community in the Salem district (Andhra Pradesh). It was mentioned that the police had cracked down severely on this very community some time back for their practice of female infanticide. Desperate parents, not wishing to be burdened with daughters, for whom heavy dowries must be paid, were now resorting to the sale of baby girls for amounts as paltry as 2500 rupees (approximately $\$ 60$ ). Andhra Pradesh happens to be the most high technology and "progressive" state in India, chosen by Bill Gates for expansion of his Microsoft city (Channa 2004). 
their daughter-in-laws, only after years of 'respectful' behavior. This made the younger and newly-entered women totally dependent and indeed, at the mercy of the older women within the household, which created divides and kept the women engaged in petty household power struggles rather than engaged in challenging the masculine dominated system that otherwise kept them subdued and disempowered.

While this structure continues to hold sway over large portions of the country, especially in rural and semi-urban India, a majority of urban families today are nuclear in nature, with both partners employed in 'outside' occupations. As the younger women garner respect and power through education and their ability to earn, the need to learn 'womanly skills' from the older women in the family has decreased. With modernity dictating life choices today, there is decreasing demands for mid-wifery or complicated kitchen activities. As older women and traditional women see the trivialization of their knowledge and skills by Westernized education and modern technology, the tussle for power has become more complex.

"Not only am I carrying the tensions of work but I used to dread coming home...knowing my mother-in-law would be there...silent but oh so silently evocative...” says Shailaja, Metro Plus. As the roles of husband and wife have slowly evolved in the globalized world, extensive studies have shown a rise in domestic violence. In a study conducted by RTI International's Women's Global Health Imperative, University of California-Berkeley, Indian Institute of Management-Bangalore, and 
International Center for Research on Women ${ }^{37}$, it was found that “despite bringing empowerment and financial stability to Indian women, jobs also make them more vulnerable to being hit, kicked or beaten by their husbands.”(Bhowmick 2009)

This study examined the association between spousal employment status and physical domestic violence in Bangalore. The results showed the rising tension and violence faced by women within their private space after they stepped out into the public space of paid work. According to Suneeta Krishnan, an epidemiologist in RTI's Women's Global Health Imperative, “Our study is consistent with evidence that rapid changes in gender roles and relations can lead to backlash, including violence against women” (Bhowmick 2009).

While 57 percent of the women interviewed have experienced different degrees of domestic violence, the study showed that women who were unemployed at the time of the first interview but had gained employment by the second interview had an 80 percent higher chance of experiencing domestic violence than did the women who remained unemployed (Bhowmick 2009). The research also noted that women whose husbands had sporadic periods of employment or no employment were more than twice as likely to experience domestic violence.

37. The research was funded by a grant from the United States Eunice Kennedy Shriver National Institute of Child Health and Human Development. The study took into account the testimonies of almost 750 married women between the ages of 16 and 25 from working class neighborhoods in 2005-2006. The women were interviewed three times during a two-year period. 
The RTI research underscores the complexities that today's working women face as clearly demarcated duties-positions between the husband and wife blur giving rise to a power struggle wherein they compete for time-space-power. The observation was supported by my research. For instance, Shailaja, Metro Plus said, “At work, I was so used to interacting with my colleagues, male or female, in terms of their position. But when I went home, I was faced with a MIL, who demanded that I do housework and toe her line...and then my husband would never support me in these wars over territory. I finally walked out when I realized that things were not going to change no matter how well I did at work...it would always be about me not being a stay at home bahu (daughter-in-law) and biwi (wife)...”

The conflict that Shailaja, Metro Plus faced in her marital homes rests in the contest between the Indian man's loyalty to his mother and the newly emergent notion of coexistence with his wife as a socio-economic partner. Even as the urban middle class nuclear household needs a wife-mother who is schooled enough to tutor the children, modern enough to accompany the husband to social occasions, there is still the almost unquestioned assumption of the traditional that requires the wife to be subservient, as noted by Mukul Kesavan, author of The Ugliness Of The Indian Male And Other Propositions, “The Indian male's bullet-proof unselfconsciousness comes from a sense of entitlement that's hard-wired into every male child in an Indian household.” The notion of entitlement is encouraged through "a prolonged infantilism - a hatchery protected by doting mothers, fathers, sisters, girlfriends, and society itself” (Susan 2009). While my 
conversations with the women did show some change in the operations of modern households, the women still contend that society as a whole has a long way to go.

When the natural assumption of superiority is challenged by events and processes beyond his control, men are threatened by a sense of emasculation, which results in acts of violence, both physical and otherwise, in an attempt to reassert their sense of malehood in the new urban domestic space that is marked with contestations and competing loyalties-egos. According to Kapadia, “.... deep contradiction exists between the ideal self-image....and reality. They like to see themselves as authoritative and in control, but in fact, they have to regularly depend on their wives' incomes. This may contribute to their depression and frequent drunkenness” (Kapadia 1995:210).

The following section examines how women negotiate with public and professional spaces during their daily routines.

- Impact of Working on the Public Lives of Women

While women face the conflicts at home when they step out into the working space, the contradictions of idealized Indian womanhood strongly marks their nondomestic experiences with fear, violence and gendered competition.. For a majority of Indian men, the ideal is still their mother, devoted to family and confined to the household. Therefore, working women are faced by a large number of men in their public and professional space, who are not averse to making sexually violent overtures to the 'non-domesticated female body' present in their midst. As Abhilasha, a 30-year-old writer for Business Standard says, "I work in a male dominated magazine but it isn't 
overtly sexualized. But I hear men talk and it amazes me as to how little they seem to have progressed in terms of gender equality. They don't use words like 'loose' or 'slut' but the mindset is very present.” The media reiterates these images, wherein the unmarried heroine is a Westernized outsider, who immediately embraces her traditional role when she plays the married counterpart of the hero and submits to 'Indian' values.

These ‘values’ are omnipresent irrespective of the diversity of India. According to Abhilasha, Business Standard, the increase of crime against women in New Delhi can be traced back to the rising movement of boys-men from the surrounding states of Haryana, Punjab and Uttar Pradesh, a violently patriarchal belt. According to Channa (2004), "While on a field trip with my students to Haryana, a strongly patriarchal and conservative belt of Northern India, some young men told me quite frankly that they could not think of the jeans clad, semi-western looking girl students who had accompanied me as their mothers or sisters to be treated with respect. The rising numbers of rape and sexual molestation are often reported from urban slums that house recent migrants to the city from rural areas” (Channa 2004:12). Channa (2004) finds that these men, often young boys displaced from their homes in rural, remote areas where women commanding respect look-dress-speak differently from the ones they encounter on urban streetscapes, commit acts of sexual violence against women in public spaces (Channa 2004). This can be directly connected to highly sexualized images of 'modern’ women who are characterized as being morally corrupt and therefore, promiscuous that litter movies, television series, newspapers and magazines. 
These mediated images that combine with unschooled notions of male superiority to create unsafe spaces for women in the public spaces also add another burden on working women. Even as contradictory values are demanded of them (highly educated working women with traditional home-based values), the globalizing woman is bombarded by global values of western style femininity and beauty. The constant bombardment from the media of global aesthetic and cultural images have led to the construction of imagined ideals of both masculinity and femininities that men and women find hard to realize, especially as such imaginary constructions are a blend of the old and the new (Channa 2004).

The recently divorced Shikha, Times of India, returned to New Delhi after living in the United States and Dubai and is starting to date is amazed at the expectations of Indian men and workplaces. "Svelte and sexy seem to be givens. And then they want smart educated women who can hold their own...in English! And they don't always seek a woman who can cook but at the end of the day...keeping of house is still not shared...that is a 15 second advertisement...not reality.”

That advertisement showing the metrosexual 'Westernized' man is rare but the standards of beauty have rapidly tilted toward western models projected by global advertisements: smart, sexy and always slim. But these images are created without contextualizing the dangers faced by women, physically and emotionally, in a nationstate strongly marked by patriarchal notions, a specific form of patriarchy that is rooted in controlling the so-called dangerous sexuality of women's bodies traversing public spaces. 
This has caused tremendous conflict, especially within elite women, with respect to appropriate body language and cover.

Therefore, we have urban women attempting to compete in a global economy by emulating standards that are regressive, irrespective of their origin. As Menon (2004) asserts, ...”this tension is a product of a historical moment, where a third world country like India is caught in the complexities of globalization and internal politics” (Menon 2004:101).

\section{Conclusion}

The research of various scholars seems to underscore the idea that "society absorbs values in a selective manner, grafting on the new to the old in a hybrid culture” (Channa 2004). The Indian urbanscape appears to have encouraged women's education and emancipation while contrarily clinging to ideas of male superiority, as exemplified by skewed sex ratios, increased abortion of female fetuses within upper class pregnancies and rising crime against women. The battle between traditional and modern values continues. Long calls this process “relocalization," wherein certain processes become meaningful only in the context of "existing experiences and cultural understanding” (Long 1996:50). And as globalization and nationalism engage with each other at various levels, the process of relocalization will mutate and reshape. As the nation's political, economic and social elites continue building the India Inc. project predicated upon technological progress and all round emancipation, there will emerge multiple traditional 
thought processes that will clash with this agenda so as to keep in place age-old power structures led by hegemonic masculinities.

As the new model of empowerment requires the entering of women into economically meaningful work without deconstructing the framework of insistent maleled power structures, there is a steady rise of gender degradation/discrimination and uneven empowerment. While a certain class of women, including the HUMM women have made substantial professional gains, most of the new technologies/policies are making poor, already marginalized women totally redundant to the workforce,. These new measures are seen as having a devastating impact on the survival of poor families. This destruction of family and societal structures in turn has enormous detrimental impact on public spaces-perceptions. The ever-increasing chasm between the rich and the poor, the confusion about femininity-masculinity, and the discrepancy between empowerment as "all about being vocal, having a right to "voice”" (Cheater 1999 in Channa 2004) and actual material returns is resulting in a resurgence of fundamental reactions and a call to return to the traditional. Even as elite women conference around the globe and call for the formation of "transnational feminist solidarities," the impact on the disenfranchised who form a majority-majority has been far from positive (Desai 2002: 15). The poor who have not 'inherited the earth' and yet occupy majority portions of it due to sheer number are increasingly being pushed in underpaid jobs in the informal sectors, are losing their access to natural resources as states increasingly “....appropriated [land] for global production, land for cultivation and local sustenance decreases” (Desai 2002: 15). 
As the global 'few' increasingly concentrate their economic, military and humanrights power, the local 'many-ies' are reacting to this rapid negative change and loss of power in their own identity by movements of subversiveness. The regression of women is often a means of achieving the goal of cultural preservation and identity. As UnnithanKumar (1997: 20) has pointed out, women serve as boundary markers. And even as the numerically small numbers of middle class women appear to be making gains in their road to empowerment, there needs to be a strong understanding of how the progress they are making through their access to technology is limiting and in some cases, literally killing girls and women. By emulating the Western understanding of emancipation without attempting to construct a hybridized 'alternation', as Channa eloquently states, "[Indian] women have not been redefined, only reinterpreted and left unfinished as a result of modernization” (Channa 2004:18).

The following chapter brings together empirical data, government statistics and my observations as a researcher to generate an understanding of the impact of globalization and nationalism on HUMM women. 


\section{CHAPTER VI}

\section{Answering Women: The What, The Why and the Who}

"Why are you doing this research? What is the point of questioning me about feminism?... I don't understand the need to critique globalization and really...Hindutva matters little to me. Globalization has worked for us and...[it] helps me confront patriarchy and other male dominated issues. And like any other process, there are always adjustments to be made.”

- Alka, Consulting Editor, Zee News.

I was sitting with Alka in the meeting room of Zee News' main office in Noida, a satellite town of New Delhi that is the hub of the electronic news media outlets when she questioned the reason for my research. Surrounded by the hum of people talking, flat screen televisions beaming out Zee News, and phones jangling, I listed the questions that I was attempting to answer with my research, to generate an understanding of the impact of globalization and nationalism on HUMM women. Those questions are as follows:

1. How do HUMM women employed by transnational corporations, define Indian womanhood?

2. How are these homogenizing images of Indian womanhood interpreted, accepted and deflected by HUMM women?

3. What does "security" mean to HUMM women who are actively a part of the global economy? How do they measure security?

4. How do HUMM women negotiate space: domestic, professional and public as sexed bodies? Have these bargaining tactics changed over time? 


\section{Answering Questions I: Data Generated}

As I attempted to answer these questions, I met and interviewed generous, successful, highly articulate media women who told me why India and Indian women could no longer be seen as an "oriental diversion” (Purie 2006:7). While these urban educated media women grapple with professional issues such as stress, discrimination in hiring practices, barriers against upward mobility in management, and inequity in reward and pay structures (See Channa 2004; Gupta and Sharma 2003; Kaila 2004), they also challenge the existing structures of masculine dominated expectations within their homes and outside.

As stated in the introductory chapter, I have analyzed my primary and secondary data using feminist critical discourse analysis, using three different gazes. The following sections present analyses of the gaze of their own selves, the gaze of authority institutions and the researcher's gaze as they grapple with questions about globalization and nationalism.

\subsection{Gaze of the Researched}

As I juxtaposed the questions about the impact of globalization and religious nationalism, specifically Hindutva, I focused on the fact that the HUMM women work in “... the field of mass mediation [by offering] new resources and new disciplines for the construction of imagined selves and imagined worlds” (Appadurai 1996: 3). The salience and power of the profession, if in the hand of the truly empowered and informed would allow the women to break away from the norms of gendered power structures entrenched and constantly generated in their lives. As Hall's (1977) work on British television shows, mass media has a crucial role in defining the problems of society, Indeed, he calls 
them the most powerful channel of public conversation and debate in segregated society. My research will show, that while the path towards justice and equity is lightly marked and difficult to navigate, the path has been set.

Focusing on contemporary forms of globalization, which I asked the HUMM women to consider as more than just a monolithic neo-liberal paradigm and as a cultural force that is producing modernities through changed cultural, political, and economic conditions (Nagar et al. 2002), the intrinsic reaction was one of unfettered acceptance.

According to Diya, assistant editor (News/Current Affairs) for Times Now, an English News Channel, “....it is a positive move for India...especially us women. I see so many more women working now. My news floor has more women than men. I am more aware of my options and I have more opportunities.” Similarly, Shikha, associate editor, The Times of India, said, “...of course! For someone like me...it’s a Godsend. I am independent, aware of my rights and fully cognizant of the advantages I have over my mother's generation.”

According to Shruti, consulting researcher, Outlook magazine, "I think of it as being a catalyst. I mean women are always working...but with globalization, the work outside the house becomes important because now women can say...I work and get paid too...so why should I shoulder all the burden?” When I asked if that impacted and equalized household dynamics in terms of domestic duties, she said wryly, “...not everywhere and not equally. But there are changes...my husband is less demanding than my father was and more helpful around the house.”

Abhilasha, writer for Business Standard, was emphatic as she saw globalization, “...not only as an economic springboard but also a cultural do-gooder! When I got 
divorced, I wasn't totally ostracized. I am now remarried. I think this broadened understanding is a direct impact of globalization.” As Ojha talked about her divorce, she admitted that the preponderant reason for the clashes centered around her long work hours and her total disconnect with her husband with regards to the demands of her job and her lack of time for domestic work.

The various responses of the women targeting a variety of issues, from professional gains to personal dynamics bring forth Bordo’s and Jaggar's (1989) idea of the useful female body, a body that has been shaped by dominant ideologies of globalization. The liberalizing message of globalization has found significant allies in the HUMM women. With their relatively privileged backgrounds that accords them access to education and professional careers, these women have assumed the position of dominant readers, fully sharing the preferred text of the globalization discourse (Hall 1980). Having embraced such text, they are in the powerful position of replicating the message, becoming encoders, 'being made' into champions of globalization. In other words, the HUMM women are not just the audience but they also become the message and the messenger.

As I further interrogated the women about the dynamics of globalization and consumption and its impact on their work-home balance, I find that their conditions are profoundly marked by dichotomous categories such as "tradition/modernity" and "public/private”, which structure and dictate how these women negotiate new homebodyworkbody-consumer identities, politics and spaces.

Anoothi, assistant editor, Times of India Crest Edition, was eloquent in her discourse about this balance. She said, "It varies from family to family. But largely if 
your family is liberal enough to let you work in the media...that requires long hours, sudden travel and constant interaction with the opposite sex...then they are usually chilled about the whole domestic role. But at the end of the day, as a woman, I worry about my home and child... as much as my husband would deny it...more than he does. So even at work...I have to prioritize my schedule according to my domestic demands.”

Anoothi's guilt was reflected in varying degrees amongst the other women, with those who are mothers and wives being more anxious than the single women. Theoretically, this stems from being socialized in an urban societal space that continues to be strongly marked by naturalized roles of woman as homemaker and constantly reiterated by the media as queen of domestic space. Ironically, even as globalization is opening up various avenues for women, gendered expectations have mutated to accept women working outside the home and yet, society and women themselves continue to borrow from gendered texts that claim roots in tradition, where the myth of Sita (from the Ramayan) becomes an icon for domestic roles.

As the women unilaterally supported globalization, all of them agreed that they were a privileged “class”, economically middle/upper class, raised in "liberal families" that supported their academic and professional goals and urban residents who had access to "global facilities and demands". All of them took pride in their work identities and their corporate employers. As I questioned them about their organizations, their descriptions showed hierarchical structures with few women in corporate leadership or on editorial boards.

According to Devraj (2010), more than 50 percent of the staff in India’s major English-language newspapers and television channels is female but not one of India’s 
major dailies or channels has a female editor-in-chief. Like the women I interviewed, Pamela Philipose, former senior editor with the influential and multi-edition newspaper Indian Express observes, “... a definite trend toward feminization of journalism, but this is happening at the lower levels.” According to her, while this trend will continue, “structural problems” will prevent most women journalists from attaining top editorial positions for some time to come (Devraj 2010).

According to the women I interviewed, such hurdles, or "structural problems" include masculine dominated set-ups where corporate leadership is more comfortable with male editors, lack of "schmoozing opportunities” (interview with Shikha, Times of India), domestic expectations, the demands of marriage and reproduction and finally, a certain amount of lack of self-worth/confidence. As Suman, a forty-two year old camerawoman with Aaj Tak says, "It is easy for the girls today to get caught up with the glamour aspect of media. Sit in front of the teleprompter looking pretty and then get recognized on the streets. Why give that up to push and be pushed as you search for stories?” Agreeing with Suman, Aaj Tak, Aarti, a senior political correspondent for the same organization, shakes her head in disappointment as she talks about a junior journalist who "gave up the grit to embrace the glamour."

While Philipose finds that women journalists have distinct advantages starting with an ability to document the lives of people and events better than their male counterparts since "Women are able to build contacts, cultivate sources and persist with their stories...however... after a certain level it is not merit alone that will take you higher up in the organization” (Devraj 2010). Adding to this conversation, Joseph (2005) finds that while certain situations such as investigating gender crimes allow women more 
access, they are handicapped while dealing with largely male led institutions such as security, politics and at a lesser level, financial entities.

Suman, a camerawoman for Aaj Tak illustrates just such a hurdle with an example from her working life. Sitting back in her home, she recalls an assignment where she accompanied a woman journalist as her camerawoman to a village skirting Delhi. The village had been confronting large-scale caste-based violence. One of the upper caste leaders had arranged a meeting that could turn into a field of confrontation between the two groups. As the two women reported from the site, the situation deteriorated rapidly and the police lost control of the crowds. Along with the other journalists (all male), Suman, Aaj Tak and her colleague were asked to leave. The two women decided to stay while the others left. As they continued filming the mayhem, the crowd noticed the two women and surged towards them wherein the two women rushed into their satellite truck for protection. As the crowd rocked the vehicle, the driver managed to dislodge the attacking men and drove away from there. According to Suman, Aaj Tak "We got about five minutes of film only but that was more than anybody else in the field. But you know what we got to hear the next day from our male colleagues... 'if one of the male journalists had gone, we would have gotten the entire story'... and the editor agreed so from then on if there was a female journalist, only a male cameraman was allowed to go while I can only go with male colleagues.” As we talked in depth about the event, it appears that the organization made policy changes that directly impacts women professionals detrimentally. "I miss out on some great assignments because the principal correspondent is female. As it is there are only a couple of female camerawomen...add to it these conditions and you are dissuading women from entering this male dominated 
section of the media" she concludes. This automatic gendered response by the media corporation is exactly what feminist scholars like Nagar et al. (2002) and Mohanty (1991, 2003) continuously warn against, a response that is based on discursively reducing all women into passive victims in need of protection. Ironically, the media world, the encoders of globalization as empowerment quickly embrace the Hindutva stance where the Indian woman's body is inscribed with regulations and containment as a means of being 'made' safe (Bordo and Jaggar 1989).

Given this example of knee-jerk installation of policies as well as the lack of other clearly defined gender-related policies such as maternal leave, sexual harassment etc., I asked my interviewees about their experience with dealing with management and the human resources department. Though most of the women denied having to face any sexual harassment, they did affirm that maternity related affairs were dealt with in varied fashions, from a few weeks unpaid leave to working from home. Childcare facilities and maternity leave are still not a right in most media organizations (NCW Report 2004).

According to my respondents, it is laughable that becoming a mother would make one less reliable or less professional. But they did admit that most media houses have an unspoken bias against working mothers “...though things are getting better and is also largely dependent on the boss” (Indrani, senior features writer, Times of India). So while the women had stories about colleagues being pushed into less prestigious and less challenging jobs, Indrani, who is undergoing a high-risk pregnancy, says, "My woman boss was nothing less than stupendous. She told me to get off my feet and work from 
home when possible while she dealt with the higher-ups.” But this show of support appears to be the exception rather than the norm.

Commenting on the impact of maternity issues on women's careers, renowned journalist Mrinal Pande has said, “Women’s [best] productive years are also their reproductive years.” While India has seen a literal explosion of television news channels leading to a tremendous increase in job opportunities for women, “...very little is known about the employment patterns, pay structures, conditions of work, job assignments. Anecdotal evidence suggests that both pay scales and working conditions are not what they should be” (Joseph 2005).

According to Devraj (2010), a recent survey conducted in India, Pakistan and Bangladesh for the global report on women in news media to be brought out later this year by the U.S.-based International Women's Media Foundation revealed that it is very difficult to get information about human resources management policies and practices from media houses in this region. This was reiterated by Atul Thakur, a correspondent with the Hindustan Times, who works on issues of human resource policies within various Indian industries. According to him, the Indian media is too nascent for quantifiable data to become available. A lack of transparency within the corporate media houses vis-à-vis pay and promotion along with the unacknowledged presence of old-boys networks makes women's move up the media hierarchy tenuous and difficult. According to Amulya, op-ed page editor, Hindustan Times, who joined the paper after getting a degree in communications from the Massachusetts Institute of Technology, “...it is about networking and knowing the right people at the right time. And to know the higher-ups, 
almost exclusively male, you have to have access into certain social spaces that are usually exclusively male...like the proverbial cigar-rooms.”

While women continue to make their presence felt in the public mindscape, The "Status of Women Journalists in India” report of 2004, commissioned by the National Commission for Women (NCW), presents a disturbing picture of women journalists. Prepared by the Press Institute of India (PII), this report is the first such attempt in India to examine the lived reality of women media professionals. The PII's National Study Group (NSG), consisting of media representatives from across the country, approached 3,500 women journalists working for 141 newspapers and publications (including several regional language dailies and magazines) for the preparation of this report. However, only 410 women responded indicating an insidious fear of reporting personal information or thoughts. The report says many women journalists (even from established newspapers) work as daily wage labor, without an appointment letter, signing a muster roll at the end of the month to get Rs. $1,500-3000(\$ 33.33-\$ 66.66){ }^{38}$ The possibility of such blatant discrimination rests in the deeply entrenched notion that women's 'productive' work (outside her home) is secondary to her reproductive work. According to Dewan (2009), traditional social structures that forbid girls’ families from using their income resulting in parents not undertaking the expenses of a higher education, is at the root of this double standard.

38. In the states of Madhya Pradesh (MP) and Chhattisgarh (where media giants like Dainik Bhaskar and Nai Duniya flourish), there is no woman journalist who has a permanent job. The 'lucky' ones are those on contract for two-three years. In the conflict-ridden northeastern part of the country, only 35 women work as print journalists in the seven states. Only 35 per cent of these are full-time employees; 40 per cent say they have never been promoted (PII National Study Group 2004). 
At the same time, Dewan (2009) finds that trends identified in 2001 indicate an increase in women taking on professional courses, especially in the Indian middle classes in India. She attributes it to the middle class structure seeing it as an investment in their social status as well as an additional criterion for marriage. According to Radhakrishnan (2008), women with professional technical qualifications in urban India have are becoming "highly valued in the marriage market, as a rising cost of living makes dual income households the norm” (Radhakrishnan 2008:4). While the post-liberalization phase demanded a specific kind of professional education, Dewan's research shows that while women wield professional degrees but most of these jobs are short term and contractual and suit the social role expectations of women (Dewan 2009). As demonstrated by studies mentioned above, these trends are eminently visible in the field of journalism wherein there is a distinct feminization of the media houses.

Theoretically, these women are what Wright (2006) calls 'disposable women', who are seen as working for 'pin money' as they either wait to get married or become a mother. These stories of devaluation simultaneously create capital for the media corporations. The responses of the women also underscored what Wright (2006) calls the normalization of such disposal, wherein for instance, there is an acceptance of lower wages or reduced work because of maternity reasons. While the discursive mechanism that scrutinize and control the corporeal movements to produce the embodiment of the HUMM women is not as invasive as those used on the factory workers who are the core of Wright's (2006) work, these processes still maufacture a laboring body that can be set aside or yoked in place based simply on gender. 
Yet the women continue to see themselves as empowered and leading emancipated lives. This distortion in analysis of the same body is a study in perspectives and location. The HUMM women do lead lives of choice when compared to other groups of women, variously defined by caste, class, religion and profession. At the same time, when their options, means to legal recourse etc are placed in a wider, more abstract construction of gender justice and human rights, the picture is marred.

According to the NSW Report, large numbers of women journalists across the country are rarely promoted; sometimes for decades. Where women have been promoted, they have faced trouble and rebellion from male colleagues. As Shailaja, principal correspondent and chief sub-editor for Metro Plus smiles, “This power play as a woman is a double-edged sword. So I can't bond in a bar with a male colleague because I am a married woman. At the same time, when I do get recognition, its because ... what do they call it in America... affirmative action...exploiting my gender. We are heading towards modernity but globalization is a new process and we have a long way to go.”

According to the NSW Report, women journalists in the urban landscape are better situated than their semi-urban and rural counterparts. And within the urban landscape, the English dailies and channels are more progressive in their operating procedures. As Neha, an anchor and principal correspondent for TV Today, who had previously worked for a Hindi network Aaj Tak admits, "It was tougher in the Hindi channels. My colleagues were less urban and urbane! I think the fact that I am young also played against me. It is a lot better now. I continue to handle 'soft' material...film, fashion, horoscope stuff but I do get to do some hard hitting stories too.” 
Though the HUMM women embraced globalization, there was some hesitation when I asked them about the visual and aural markers of globalization on their professional lives. In my observation of Indian television channels, I have noticed a distinct preference for Western style power suits for women anchors as they handle 'real news' while the anchors fronting shows about fashion, entertainment etceteras are clad in 'sparse clothing'. As I questioned them about the message sent out by the image of scantily clad women who seem to distract from the material, about a third of the interviewees saw it as a part of uniform. Parul, a reporter-producer for $C N N-I B N$, shrugged and said, “We can’t claim to be progressive and then play Sati-Savitri (pious mythological characters)." When asked about the overwhelming objectification of the female body to sell the program content, she denied being a “...pawn of patriarchy. I am choosing to wear it. Nobody is forcing me. I am confident so I do it.”

Some of the women were less enthusiastic about the clothing norms. Diya, Times Now, "Nandita", $N D T V$ and Mridu, $C N N-I B N$ were emphatic in their position that they wore both Indian and Western clothing. Abhilasha, a writer for Business Standard emphasized that she understood the bias towards the Western formal clothing. According to her, “...there is an almost unconscious expectation of professionalism and ability associated with a power suit. It is seen as being intimidating. A saree or a salwar-kameez are beautiful but harder to wear when you are running from one story to another. But a well-draped saree can be as admirable in a board room but that is my opinion.” In an interesting aside, Alka, Zee News states, "We are a globalizing nation and the opportunities within media corporations for women, especially urban women who are 
educated and speak 'good' English ${ }^{39}$ are many. But if we want to be more than pretty faces on the screen, we women have to take some initiative. Lot of the younger women I meet see themselves as being liberated by exhibiting Western cultural awareness and mores. But wearing spaghetti straps and speaking with a videshi (foreign) accent does not make a good journalist.”

Shifting focus to the domestic realm, I found that most of the women agreed that home spaces are still marked by strong notions of tradition and gendered roles. The women carried the majority load of domesticity/parenthood yet saw globalization as being the great equalizer. This is indicative of how globalization operates as much through the production of difference as sameness. So even as globalization pushes through the notions of citizen worker-consumer for women by providing them with ‘equal opportunities', such 'naturalness' of equal rights camouflages/homogenizes the need for such corporations and consumer created societies to deconstruct unfair gendered norms-demands. After all as globalized female bodies collide with the age-old structures of male dominance, there needs to be a systematic change in the depth of male control over space/gaze/violence.

Because if there is not the dismantling of those elements, then the purported gender blind gaze of globalization colludes with the local/regional hegemonic forms of patriarchal nationalism, in this case, Hindutva in strengthening trends of dominationmarginalization. The women interviewed while embracing globalization were succinctly critical if not dismissive of traditional conservative Hindu nationalism or Hindutva. This is in direct contrast to the findings of Nanda (2010) who argues that the newly emergent

39. Public school English. 
middle class was not only becoming more religious but was helping turn largely secular public institutions 'more' Hindu. According to her, this has resulted in homogenized expectations of its Hinduized citizenry that is sometimes expressed in violent oppressive manners (Nanda 2010). This distortion of understanding is rooted in what Hall calls the interpretive position of the reader of the text (1973). Given that this interpretation is dependent on socio-economic and political background, the oppositional reading of the Hindutva text rests strongly in the HUMM women's embracing of the secular aspects of the globalization text. Additionally, the globalization text has been produced as one empowering all humans "who are willing to work hard, irrespective of whether they have a vagina or a penis” (Shikha, Times of India).

For instance, Shobita, a thirty-year-old features writer for Outlook, a national newspaper frowned when asked about the Hindu Brigade. "They are an embarrassment. I think they are a racist bunch of thugs who emerge to create drama and violence during Valentine’s Day or about sensitive films like Water and then disappear," she said.

Similarly, thirty-year-old Nisha, who is a correspondent for the investigative magazine Tehelka, was dismissive of their presence, saying "They are much more active in Mumbai and further South physically...you know...marches, physical intimidation. The problem with groups like these is that they keep awake notions of nation, women, citizenship that are disempowering for women and minorities." Nisha is one of the organizers of The Pink Chaddi Campaign (The Pink Underwear Campaign) — organized on Valentines Day by The Consortium of Pubgoing, Loose, and Forward Women to protest against the right wing Hindu group Sri Ram Sene. Even as the campaign was successful in stopping the Sene from harassing citizens, Nisha admits that while the 
condemnation of the Sene was validating, "The number of people who disapproved of women in pubs...copying Western mores as opposed to Indianness...was eye-opening.”

Many of the women interviewed as well as Ram, RSS, echoed Nisha's observation. According to Ram, "There is nothing wrong with Indian women wanting to get educated, get jobs, join in globalization. But what does smoking, drinking or being provocative in attire have to do with being modern?” When asked about the right to make that choice, as adult women, Ram responded, "If some cells in your body become cancerous...do you say...oh it is part of my body and has the equal right to grow? No...you treat the part or cut it off.” The violent biological imagery is an insight into how the Hindu Brigade operates in their mission to protect the body of the Indian nation.

The Hindutva brigade largely positions itself with respect to Indian women as gatekeepers, as moral police. Drawing parallels with Foucault’s (1977) theorizing on surveillance, the project of Hindutva's disciplinary technique rests on constant surveillance. Such surveillance, which is initially directed toward disciplining the body, takes hold of the mind as well to induce a psychological state of "conscious and permanent visibility” (Foucault 1977: 201). According to Ram, RSS, such discipline is required in the face of cultural conversion of the Indian masses by the neocolonialism of globalization.

When asked about such imagery, the interviewed women were initially dismissive, calling them "regressive”, "out-of-tune” and "archaic.” According to Shikha, Times of India, "That BJP-RSS-Bajrang Dal people can no longer take on the urbanization of Indian minds. Women are out there...working...partying...spending. If all our [women’s] work can help the country progress...no gang of goons can stop it.” 
While it appears that narrow cultural spaces are opening up within the Indian middle class that allows women certain 'liberties' to plan and execute their own lives, deviations from the norm are still seen, if not by the HUMM women but certainly by middle class society, as being deleterious. For instance, according to Alka, Zee News, unmarried women living on their own or divorced/widowed women continue to be seen as being "too free." According to her, the unsaid assumption is that any woman who does not physically reside within a family's bounds (determined largely by a male relative) is capable on wreaking havoc on monogamous relations as well as professional ethics. The suspicions range from the sex-starved husband hunter to the "casting couch" related professional climber. Therefore her identity becomes defined by her singlehood, a largely un-Indian status for a women past a certain age.

Radhakrishnan's (2008) work on gendering of Indian IT workers finds that the media has been an active agent with established Indian magazines such as Outlook and Business World as well as international magazines like Business Week and The New York Times in regularly heralding the arrival of a new India and 'the' new Indian woman. With women's ability to earn and access to an increasing market niche for products and services, the new Indian woman is touted as having "utterly changed the balance of power between the sexes” (Menon 2004 in Radhakrishnan 2008:5). And yet Radhakrishnan (2008) finds that the “images of this 'new' woman is almost always unmistakably Indian. Marked with distinctly Indian clothing, makeup, mehndi, and bindi, the images of these "new" Indian women help to project India as a progressive nation still tied to a sacred cultural past” where divorce, premarital sex and children out of wedlock lead to ostracism and violence (Radhakrishnan 2008:6). 
When asked about such messages of advertising and mediated offerings such as older soap operas (Kyunki Saas Bhi Kabhi Bahu Thi and Kahani Ghar Ghar Ki among others) that use women as arbiters of good and bad, wherein 'good' women stay at home as nurturing sacrificing daughters/wives/sisters while 'bad' women worked outside the home, wear western clothing and are portrayed as being conniving and promiscuous, the media women largely called them anachronisms watched by housewives and retired people. Yet the length of their run and high urban TRPs suggest a connection with the viewing public, a sense of identification with the characters and the social processes.

Focusing on the new wave of soap operas, Mridu, reporter for rural and development sector, $C N N-I B N$ states, “The new soaps focus on women’s issues like child marriage, widow remarriage and other such social evils but the background is rural. I think the message is that social evils that target women are not modern issues. They live in villages and away from the arc lights of the city.” The latest offerings like Ballika Vadhu (Child Bride) and Na Aana Iss Desh Lado (Don’t Come to this Country, Beloved Girl) showcase issues of child marriage, marital rape, widow seclusion, and forced marriages. While the serial makers claim that their creative work highlights the evils that women and children face, critics like Puja Marwaha, of the children's charity Child Rights and You (CRY) state that the driving force behind child marriage is poverty and the soap operas rarely bring forth this crippling situation where the girls are largely illiterate, malnourished and considered a burden on her family and therefore married off to assume an adult role and responsibilities. She is 
adamant as she states that their lives bear no resemblance to the glossy images seen on TV and decries the glamorization of these gendered societal processes.

While the women claim no connection with the soaps, Juhi, an environmental reporter for $C N N-I B N$ admitted that her family did watch the soap together. She appears a little embarrassed as she states, “It’s my guilty pleasure. It irritates me and yet draws me. I know it has an effect on people because I have friends whose mothers in law have these unreal expectations from them. Whether it stems from these soaps or not, it is hard to tell.” But scholars like Gokulsing (2004) have found that "The traditional idea that women should be more accommodating than their men folk in the interest of the family still had currency...” (Gokulsing 2004:72). These ideas of traditionality and Indianness are the core of religious nationalism. The insidious insertion of such ideas into the homes of a third of India's billion strong population (Gokulsing 2004) using modern technology and finding resonance indicates that the modernity the HUMM women aspire to is constantly under attack.

I find that there is a strong component of moral panic behind the popularity of such rural or semi-based soap operas. Increasingly Indian urban centers are being seen as “westernized” spaces, a global-within-local, that allow behaviors, both masculine and feminine, which are considered un-Indian while semi-urban and rural spaces continue to be scripted as Indian, traditional and conservative. As global capital and norms infiltrate the nation space, slowly un-fixing naturalized roles for families, men and women, there is a sharp sense of unease about what is being perceived as a loss of traditional status quo as Nanda’s (2010) work amply demonstrates. As the Hindu 
middle class increasingly embraces Hindutva, the media houses have gauged a systemic need to create scripts that fulfill the nostalgic needs of the urban viewing public that wants to sigh over eras bygone. Ironically, the same media corporations and professionals who are creating an alternative script for the public to read claim moral repugnance of the same content.

Unlike the media women I interviewed, the women IT professionals interviewed by Radhakrishnan (2008) saw "Indian” values and morals as being part of the global, complementary rather than being antithetical to each other. She finds that the cultural ideology of Indianness and globalness "are fused in a manner that presumes affluence, transnational mobility and a nuclear, heterosexual family” (Radhakrishnan 2008:12).

Radhakrishnan (2008) finds that the women see the individual self, as being global while Indianness is associated with collectivism and family solidarity. When in conflict, the limited individuality is circumscribed by the family. This understanding of 'Indian within global' was seen as being more constrictive by the women interviewed when working in India as opposed to their lived experiences in the US.

As Shobita, features editor for Outlook says, "I wonder why the outside has not become safer even though so many women work now. I mean that I feel safe at home, at work but when it comes to traveling alone at night or just sometimes walking on the streets...I feel tense...waiting for a hand to swipe my bum...and it happens sometimes. I think what is worse is that I no longer feel as angry as I did before. Now its like part of the package. I would rather be out and about and gaped at than be at 
home, safe.” Most of the respondents agreed that they never felt totally safe and "perhaps that is a feature of city living...but I feel more exposed sexually in Delhi. So I don't fear getting mugged as much as I fear the high possibility of sexual violence” says Shikha, Times of India who has lived in Washington DC, San Francisco and Dubai before moving back to New Delhi.

She also finds that while more women work outside the home, sometimes earning more than their partners, the domestic space continues to be their responsibility. "I don’t know whether it is social training...my brother never bothers and we were not really forced to do housework...but I care more about whether my father has eaten... whether there are groceries in the house and the state of hygiene in the house.” she laughs. Shailaja Tripathy of Metro Plus agrees, “This need to be in control is self-imposed. It's the classic 'I excel at all' mentality. You think men care whether they have cleaned the kitchen before going to sleep. At the end of the day, women have to take care of the home. It’s not about being Indian...it's about being a woman.”

This expectation of being house-proud and family-proud borrows heavily from specific constructions of society wherein the home space belongs to the woman (though not the physical ownership). These processes of gendered pride plays beautifully into the hands of consumer culture. Rather than see consumption as merely the site of gendered domination and the sexualization-commodification of female bodies, in my opinion the combined impact of globalization and nationalism has created a consumer culture that is a complex site of female participation and constraint.. In other words, as Mallica, who 
was employed at an Indian men’s magazine Maxim states, “As an Indian girl, I think of the home as my space. It's empowering for me. And I want to live a certain lifestyle that I want to support. So I work...I mean I enjoy my work but it is also about a paycheck. As I talk about it with you...I see the impact. As a good girl, I have to keep the house a certain way. At the same time, I get the message that I need to go out and play with the boys in the work space."

Such self-imposition certainly implies certain complicity with existing structures of masculine domination. In other words, even as globalization induced consumer culture requires women workers who are largely underpaid and mostly discriminated against, yet there is an embracing of just that structure by the HUMM women. I borrow from Kandiyoti's (1988) concept of patriarchal bargains as an explanation. The women embrace the "rules of the game" because globalization has presented them with optimum options for active and passive resistance against varying levels of oppression. Whether it is providing a space for a divorced woman to work and seek another mate, or provide a salary that allows a single woman to live independently or allow a married woman to stay out nights for work, globalization has allowed the HUMM women a professional vehicle that with all its missing parts and various breakdowns, still allows them to travel out of restricted controlled spaces.

Now this disruptive figure of a woman who is not only out in public but as a professional media woman is inquisitive and aggressively seeks information has been stabilized and rationalized through the construction of middle-class women who could traverse public spaces if they carried their "essential femininity” with them (Lukose 
2005). In her work on consumption and gender in the state of Kerala, India, Lukose (2005) finds that this essentialized femininity, “a gendered bodily habitus, variously identified as "respectability" and "modesty", involved the creation of appropriate dress, activity, and a set of exclusions that constructed working-class/low-caste women as coarse, vulgar, and crude” (Lukose 2005:928). But this class-specific, gendered habitus that is seen in the public remains problematic given "the constant threat of sexualization [which,] makes the woman in public an unstable and volatile presence" (Lukose 2005:930).

In my interviews with the HUMM women, I brought up questions about their work content. I was focusing on imagery, socio-political context and sheer control on material produced. The majority of the younger women produce content that may be defined as entertainment as opposed to news. When asked about the lack of equal presence in fields of politics, security, criminal investigations and finance (though financial news channels do boast a higher presence of women anchors), the women largely talked about lack of access, youth, lack of interest, safety issues and family demands. On further problematizing the question, Shailaja of Metro Plus said, “It’s just tougher to break into those fields. The people you interact with...the police, the politicians are difficult to handle. Sometimes you get the feeling that they are being paternalistic and condescending...sometimes they are lecherous... and honestly, a lot of my friends just got tired of the fight and moved into PR or fluff Page Three kind of work. It's more glamorous and less taxing. The hours are odd but the work is easy.” 
It is interesting that the journalistic sphere that has weight, respect and validation remains a largely exclusive male bastion even as the number of women media professionals has increased exponentially, especially in large metropolitan areas. According to Anoothi, assistant editor, Crest, Times of India, "This is changing but not fast enough. We have such entrenched notions not so much about doubting women's capacities but about appropriateness...when it comes to issues of covering say, caste based tensions or religious rioting...there is no doubt about whether a capable woman journo can go out and do the job...but it's the patriarchy of the editorial mind set that questions whether a woman can get the same access as men... whether she will be safe or not... and that impacts careers all the time...of course pregnancy and family duties.”

Along with such control of women's careers, Wright's (2001) research on advertising and cultural identity in India finds that "the parameters of the new Indian woman consumer is limited to more or less traditional ideas about Indian femininity that had been purveyed by nationalist agendas” (Wright 2001:48-49). According to her, the woman's role might be changing in terms of her ability to work and earn but her place remains squarely in the family. For instance, an IBM ad she deconstructs shows that a child sees his mother as a "Goddess” because of her phenomenal ability to multi-task (Wright 2001:196). Therefore, the discourses about women, women's role and patriarchal family structure remain fundamental to ‘the’ Indian value system, which is built around hegemonic Hinduized Indian culture. In other words, the media floors, even as they get 'womanized ${ }^{40}$ continue to sell Indian values without being questioned and

40. I use 'womanized' to indicate the rising number of women working in the media rather than the sense of 'feminized'. 
problematized, by recasting them in new contexts. When I questioned them about the production of such homogenized material, the HUMM women demonstrated what Hall (1973) called a "margin of understanding." All of the women who produced or worked in creating entertainment products indicated an oppositional reading of the text that wrote women's bodies as vessels of chastity. Pointing to TRPs and advertising rupees as reasons for their creation, the women distanced themselves from the material. And yet when asked about why there was no opposition to such violent scripting, the women largely pointed to a masculine dominated corporate head office. At the same time, some of the senior professionals also cited examples where they used their connections to the male dominated corporate structure in an effort to make changes within the workplace and in the mediated products.

Another topic that the respondents elaborated upon was the notion of beauty and lifestyle. While the women were dismissive of religious nationalism, there was a certain pride taken in "being Indian" as far as ethnic identity was concerned. So even as they grappled with the overflow of western ideas of beauty (slimness, hair coloring and styling among others), there was the constant mention of how the world was embracing Indian motifs such as yoga, ayurveda, Indian foods, henna and other Indian products. When I pointed out the commercialization of these inherently Indian 'products' and the racialized politics of beauty related companies that has resulted in "the recent upsurge in winners from Third World countries such as India and Botswana that have many pointing to the development of new markets for multinational cosmetics companies such 
as Avon and Proctor and Gamble” (Lukose 2005:927) was causing a certain homogenization of 'beauty expectations', the women had varied responses.

While most of them claimed to follow their own regimes, almost all of them admitted to gym memberships and regular salon visits for hair care. Tina, an associate editor for a line of lifestyle magazines that catered to the niche of the super-rich (read private planes, golf tournaments in the middle east over the weekend and shopping trips to Milan) said, “I see a lot of rich people in my line of work. Most times you can't tell where they are from. All you can tell is that they are rich! They all look like clones...same beauty treatments, same designers, same 'lifestyles of the rich and famous'....and it is the same with us middle class women. It's aspirational and in my case, largely instinctive. I don’t ...what did you call it...problematize my choices!”

According to Mridu of $C N N-I B N$, there is a growing obsession with looking good. "What that 'good' is, is dictated by magazines and movies...it is completely commercialized and confusing! There are issues of self-confidence and self-worth that come into play when it comes to making a choice to conform... and the market messages that impose these stereotypes of beauty are as oppressive, insulting, depressing and annoying to me...I mean seriously...how many Indian women can aspire to be 5'8” and $50 \mathrm{kgs}$ [110 lbs]...this is a country where average women are barely 5' tall...and are very well rounded!’ However such ‘icons of beauty’ are churned out yearly via Miss India pageants and other such emulative clone contests.

Dewey (2008) finds that young participants are consciously creating beautiful bodies that emphasize a specific cultural performance of beauty and gender identity that 
conforms to international standards and established gendered identity within India. Their grueling month-long training program in Mumbai within five-star confines, require them to "master fluent, British-accented English, a superficial espousing of feminist causes while simultaneously affirming specific gender roles...[attain] a great deal of cultural knowledge about the United States and Western Europe” (Dewey 2008:2).

In my conversations about beauty regimes and fashion styling, the women told me that they had mixed wardrobes, though they chose to wear Indian clothing during festival seasons. "What should please the traditionalists is that I actually think most Indian clothing and especially Indian cloth...batik...tie-dye...woven silks are much better than the mechanized crap we get from China” says Parul, $C N N-I B N$. There was an air of validation when the women talked about using herbal remedies and cosmetic products. The women's pride in India's progress was palpable and carried a sense of inevitability. Like the IT women studied by Radhakrishnan (2008), the HUMM women saw themselves as being active players in the progress of India.

It is ironic that the new self image of competitive excelling professionals who repeatedly used phrases such as "India rising" and "leaders of the new century" appear to rest their abilities and work ethos on civilizational advantages. And yet in the contested space between globalization and religious nationalism, there seems to be a larger embracing of 'all things Indian' that seems to have come about primarily because of its commercialization by global corporations supported by the Indian state. The widespread dispersal of 'boxed' beauty and body standards/products underscores Hall's (1973) understanding of the media as a omnipotent homogenizing vehicle of culture 
creation. The following section examines the various channels of control exerted by authority figures within the lives of HUMM women and the impact such interaction has on the lives of the media women.

\subsection{Gaze of Authority}

In July 1991, the Indian government set aside it’s post-independence developmental strategy and replaced it with the New Economic Plan (NEP). Based on the directives of the International Monetary Fund, the NEP embraced the neo-liberal paradigm of open markets; minimal bureaucracy and limited government sponsored social safety nets.

While India was being re-imagined as India Inc., the marginal twentieth century ideology of Hindutva had begun to appeal to the masses and was becoming a legitimate presence in the Indian political scenario. The fluttering of the 1980s took on a resonance that ushered in a coalition led by the Bhartiya Janata Party (or the BJP), a Hindu rightwing political party into national majority in 1998.

Study done by Kumari and Kidwai (1998) that focuses on the inner workings of the Hindutva movement with respect to women, finds that “...the BJP and its historical forbearers subscribe to provide very little space to women to move away from traditional role definitions. The strong links of cultural nationalism, familial affiliations, and affinity to traditions have all resulted in binding women to an ideology which prevents any real emancipation” (Kumari and Kidwai 1998:99). This lack of total emancipation is underlined by the fact that all the office bearers in the women's wing of the BJP are nominated by male leaders who are in total control of the organizational agenda and day- 
to-day functioning (Kumari and Kidwai 1998). These practices that compress and condense to create an absolute homology of meaning are anxiously repeated so as to ensure “... [the] effect of probabilistic truth and predictability which, for the stereotype, must always be in excess of what can be empirically proved or logically construed" (Hall in Bhabha 1994:370).

An indication of the Hindutva brigade's position on women is articulated by the stance it took over the Roop Kanwar Sati in 1987, which was openly supported by the party leadership as being emblematic of Indian womanhood. Ironically its 1996 political manifesto now reads like a progressive wish list:

1. An end to discrimination against women and an impetus to gender sensitivity.

2. Reservation of 33 percent seats in all elected bodies.

3. Promotion of legal and economic rights for women.

4. Uniform Civil Code to endure property rights and women's right to guarantee guardianship rights.

5. Removal of discriminatory clauses in divorce laws and an end to polygamy; and end to sexual harassment.

6. Focus on the non-reproductive health needs of women.

7. Support to single and working mothers.

8. An end to discrimination against the girl child.

But Kumari and Kidwai (1998) find that these commitments did not convert to fielding women candidates in their elections. Indeed the token national level women politicians also toe the party ideology of female emancipation within the boundaries of Indian tradition. In other words, women "were to have rights and freedom but within a 
strictly defined role” (Kumari and Kidwai 1998:106). My reading of this nationalism discourse suggests that there is a deliberate creation of text loaded with meanings and signs that is not necessarily a part of their core narrative yet is essential as symbolic gestures that appeal to the middle class voters and activists.

An outstanding example of Hindu tradition shaping state policies can be demonstrated through the actions of Sushma Swaraj, the Union Cabinet Minister for Information and Broadcasting in the BJP governments of 1996 and 1998. She is known to have remarked that "the female newsreaders on Doordarshan (State television) wear semi-transparent clothes and need to dress more circumspectly” besides stating that Indian media should not ape the West and forget Indian traditions (Kumari and Kidwai 1998:106, 107). According to this high ranking member of the BJP, while a woman is allowed the freedom to dress as she pleases, as long as she has the sanction of her husband, she has to follow protocol in public (Kumari and Kidwai 1998). When political and legal institutions perpetuate the idea that certain behaviors are sacrosanct and challenging them can engender dangerous responses, it restrains women from "bucking the system through fear and lack of justice options” says Shikha, Times of India. This form of surveillance that appropriates, dominates and directs women's bodies is based on the gendered gaze, the male gaze that determines the subject position of the women on television and then by extension to all women. As Mulvey (1975) has suggested, the position of the spectator or audience is “...blatantly one of repression of their exhibitionism and projection of the repressed desire onto the performer" (Hall et al. 1978:382). 
The state's role in censorship, whether of the media or life-choices of women always centers on demands on women to return to culture and tradition. This cultural nationalism "enslaves women to be the perpetuators, custodians and practitioners of their own oppression” (Kumari and Kidwai 1998:108). This form of ideology is "syncretic fundamentalism" that refers to such fundamentalist movements, which are inspired less by strictly religious considerations, and that reach for religious justifications, tactics and organizational patterns to redress social or political grievances (Appleby et al. 2003:110).

While it would be easy to relegate all the ills against women to this syncretic fundamentalism, the politics of India has rested in the hands of the liberal progressive Congress Party for a majority of its independent history. Yet recent statistics have revealed shocking sex ratio statistics. Studies have revealed that there are only 927 girls for every 1000 boys. The states that have much to explain over the significant drop in the number of girls are Punjab (793), Haryana (820), Uttar Pradesh (898) and Himachal Pradesh (897), all states in North India. The 2001 census figures show a sex ratio of 821 girls for 1000 boys in Delhi (Immigration \& Nationality Directorate, India Bulletin 2005).

Similarly crime statistics across the country show disturbing trends.

Table 1: NCRB Pattern of Crimes Against Women (1991-2007)

\begin{tabular}{|l|c|c|c|c|}
\hline & $\begin{array}{c}\text { Crimes Against } \\
\text { Women }\end{array}$ & 1991 & 2007 & $\begin{array}{c}\% \\
\text { Change }\end{array}$ \\
\hline 1. & Rape & 10,410 & 20,737 & $+50.2 \%$ \\
\hline 2. & Dowry Death & 4648 & 8093 & +42.56 \\
\hline
\end{tabular}




\begin{tabular}{|l|c|c|c|c|}
\hline 3. & Molestation & 26856 & 38734 & +30.6 \\
\hline 4. & Sexual Harassment & 4689 & 10950 & +57.17 \\
\hline
\end{tabular}

The National Crime Records Bureau of the Ministry of Home Affairs finds that the proportion of Indian Penal Code crimes committed against women has increased during last 5 years from $7.6 \%$ in 2003 to $8.8 \%$ during 2007. But the rate of this increase has been more pronounced in the latter year comparison wherein the incidence rate of crimes against women in the country has increased from 1,64,765 in 2006 or 14.7 percent of total crimes to 1,85,312 in 2007 or 16.3 percent.

Among 35 mega cities, Delhi city reported 29.5\% (524 out of 1,775) of total rape cases, $31.8 \%$ cases $(1,021$ out of 3,207) of kidnapping $\&$ abduction of women, $15.6 \%$ cases (111 out of 711 ) of dowry deaths, $14.2 \%$ cases $(1,711$ out of 12,031$)$ of cruelty by husband and relatives and $21.5 \%$ cases $(744$ out of 3,463$)$ of molestation.

If one were to extrapolate the data about the highest declining sex ratios being present in the North Indian states that surround the National Capital Region (NCR) of Delhi, it gives an indication as to why the capital of the largest democracy in the world treats its women citizens with such rates of violence. There is an inherent presence of deep gender discrimination within these surrounding states that sends migrant workers to Delhi. And according to the HUMM women, this has radically impacted the sociocultural ethos of the city. As the Economic Survey of Delhi 2001-2002 finds there has 
been a decennial growth of $46.31 \%$ in Delhi's population between $1991-2001^{41}$.

According to the survey, the ratio between natural addition through birth and migration is $1: 1.24$.

The percentage of migrants divided by state is as follows:

1. Uttar Pradesh $49.61 \%$

2. Haryana $11.82 \%$

3. Bihar $10.99 \%$

4. Rajasthan $6.17 \%$

5. Punjab $5.43 \%$

6. West Bengal 2.79\%

7. Madhya Pradesh $2.71 \%$

8. Other States $10.48 \%$

Comparing the sex ratio of these states, their migration rates, the crime statistics and my interviews gives an indication of the transfer of cultural values that infiltrate the streets, public transportation and the institutions of Delhi. In Dewan's (2009) work on globalization, higher education and the changing status of women, she finds a distinct pattern of socio-cultural practices and negative attitudes of parents towards the higher education of their daughters in North India. She attributes the lower number of women professionals in the North to the practice of female seclusion and strongly etched domestic roles. Add to this, “different standards- roles for boys and girls, competing demands on the girls' time, economic reasons like -lack of resources, distance from school, lack of facilities in schools for girls, lack of female teachers, lack of security both

41. http://delhiplanning.nic.in/Economic\%20Survey/Ecosur2001-02/PDF/chapter3.pdf 
in and outside the school, curriculum not relevant and flexible, gender stereotyping in curriculum, gender unfriendly classroom environment, early marriage and child bearing, absence of women role models, fear of deterioration of social structure” and you have a plethora of reasons for keeping girls inside, 'protected' and dependent (Singh 2008:4).

This form of structural discrimination against educating women and emancipating them is also dependent on producing narratives that insidiously train society to see educated working women as a threat to their identity, marriages and family structures. For instance, the sexualized bodies of the so-called uncontrolled HUMM women, who are seen in public, unescorted at night, are deemed as deviant beings that have the capacity to attract the male gaze. Consequently, 'homebound' women are pitted against working women in a power struggle. Radhakrishnan finds similar trends in her study of diasporic IT women, who struggle within their family structure to find a balance between "Indianness and globalness” (Radhakrishnan 2008:67). According to her, the IT women find their work life circumscribed by their family and other domestic responsibility. Similarly, the HUMM women regularly find themselves battling the gendered stereotypes that demonize their bodies as being disorderly and degenerate. It is this discourse of being out-of-place that creates a sense of 'otherness', of abnormality that enables transgressions against their bodies, identities and choices.

Given the rise in crimes against women, it is imperative to examine the legal system and the protection it provides its' women citizens under the Indian Penal Code $(\mathrm{IPC})^{\frac{42}{2}}$.

42. http://www.netlawman.co.in/acts/indian-penal-code-1860.php 
$\underline{\text { Table 2: Indian Penal Code for Crimes Against Women }}$

\begin{tabular}{|c|c|}
\hline $\begin{array}{l}\text { Molestation of Women } \\
\text { IPC } 354\end{array}$ & $\begin{array}{l}\text { This is also known as indecent assault. Age } \\
\text { of the woman is immaterial, young or old, } \\
\text { intelligent or imbecile, awake or sleeping, a } \\
\text { woman possesses modesty capable of being } \\
\text { outraged. The reaction of the woman is } \\
\text { very relevant but its absence is not decisive }\end{array}$ \\
\hline $\begin{array}{l}\text { Eve-Teasing } \\
\text { IPC } 509\end{array}$ & $\begin{array}{l}\text { Whenever a person utters any word, makes } \\
\text { any sound or gesture or exhibits an object } \\
\text { or intrudes upon the privacy of a woman } \\
\text { with intent to insult the modesty of such } \\
\text { woman, an offence is committed. }\end{array}$ \\
\hline $\begin{array}{l}\text { Dowry Death } \\
\text { IPC304B }\end{array}$ & $\begin{array}{l}\text { Likewise under Section 304B IPC, which } \\
\text { provides for punishment for dowry deaths, } \\
\text { where the death of a woman is caused by } \\
\text { burns or bodily injury or occurs otherwise } \\
\text { than under normal circumstances within } 7 \\
\text { years of her marriage and it is shown that } \\
\text { soon before her death she was subjected to } \\
\text { cruelty or harassment for dowry, the } \\
\text { presumption is that the husband or his } \\
\text { relatives caused the death. The punishment } \\
\text { for the offence is imprisonment for not less } \\
\text { than } 7 \text { years extendable to life. }\end{array}$ \\
\hline $\begin{array}{l}\text { Cruelty by In-Laws } \\
\text { IPC 498A }\end{array}$ & $\begin{array}{l}\text { Cruelty has been defined as any willful } \\
\text { conduct which drives the woman to } \\
\text { commit suicide or grave mental or physical } \\
\text { injury to her, or harassment of the woman } \\
\text { with a view to coerce her for dowry. } \\
\text { According to law if a woman commits } \\
\text { suicide within seven years of her marriage } \\
\text { and there is evidence of cruelty, the court } \\
\text { may presume, having regarded other } \\
\text { circumstances of the case, that the husband } \\
\text { or his relatives have abetted the suicide. } \\
\text { Section 498A of the IPC says "whoever } \\
\text { being the husband or relative of the } \\
\text { husband of a woman subjects such woman } \\
\text { to cruelty shall be punished with } \\
\text { imprisonment for a term which may extend } \\
\text { to three years and shall be liable to fine" }\end{array}$ \\
\hline Prevention of Domestic Violence Act 2005 & $\begin{array}{l}\text { The Act seeks to cover those women who } \\
\text { are or have been in a relationship with the } \\
\text { abuser where both parties have lived }\end{array}$ \\
\hline
\end{tabular}




\begin{tabular}{|l|l|}
\hline together in a shared household and are \\
related by consanguinity, marriage or a \\
relationship in the nature of marriage, or \\
adoption; in addition relationship with \\
family members living together as a joint \\
family are also included. Even those \\
women who are sisters, widows, mothers, \\
single women, or living with the abuser are \\
entitled to get legal protection under the \\
proposed Act. \\
One of the most important features of the \\
Act is the woman's right to secure housing. \\
The Act provides for the woman's right to \\
reside in the matrimonial or shared \\
household, whether or not she has any title \\
or rights in the household. This right is \\
secured by a residence order, which is \\
passed by a court. These residence orders \\
cannot be passed against anyone who is a \\
woman. \\
The other relief envisaged under the Act is \\
that of the power of the court to pass \\
protection orders that prevent the abuser \\
from aiding or committing an act of \\
domestic violence or any other specified \\
act, entering a workplace or any other place \\
frequented by the abused, attempting to \\
communicate with the abused, isolating \\
any assets used by both the parties and \\
causing violence to the abused, her \\
relatives and others who provide her \\
assistance from the domestic violence. \\
The Act provides for breach of protection \\
order or interim protection order by the \\
respondent as a cognizable and non- \\
bailable offence punishable with \\
imprisonment for a term which may extend \\
to one year or with fine which may extend \\
to twenty thousand rupees or with both. \\
Similarly, non-compliance or discharge of \\
duties by the Protection Officer is also \\
sought to be made an offence under the Act \\
with similar punishment. \\
\\
\hline
\end{tabular}


The Indecent Representation of Women (Prohibition) Act
Prohibits indecent representation of women through advertisements or in publications, writings, paintings, figures or in any other manner.

It is important to note here that the table above is a limited presentation of laws that protect women. The intent of this inclusion is to show that there are extensive legal measures on the books that protect women against private and public crimes. And yet crimes against women continue to escalate not just in number but also sheer violence and virulence. In my interviews, a hundred percent of the HUMM women said that they had been eve-teased ${ }^{43}$. None of them had approached the police and had instead reacted in varying manners depending on the circumstances, from ignoring the behavior to screaming to physical actions such as slapping and knees to groins. Asked at the lack of involving the police, the women appeared amused or wry. Abhilasha of Business Standard said, "It's more of a hassle. I have spoken to many young women...college students for instance that have approached PCOs (Police Communication Officer) for help...sometimes they try but the perpetrators always get away.” Other women spoke of circumstances of the offense. "Sometimes it is dangerous to engage with the assholes. I have been followed by jerks in a car at night, making obscene gestures. All I wanted to do was get home,” said “Devika”, Aaj Tak.

The women separately repeated that they "had heard stories of women being disbelieved or blamed for the incident” (Mallica, Maxim). This stance is justified by a study conducted in 1996 by Sakshi, a feminist legal resource group that interviewed 109 judges to assess their attitudes towards violence against women, and found a disturbing

43. Eve-teased is the Indian word for sexual harassment in a public space. 
prevalence of stereotyped assumptions. (UN Report available at http://www.un.org.in/gender/images/VIOLENCEAGAINSTWOMEN.pdf and Kapur 2001).

- $48 \%$ believed that there were certain occasions when it was justifiable for a husband to slap his wife.

- $74 \%$ believed that the preservation of the family should be the woman's primary concern, even if she faces violence.

- $50 \%$ believed that child sexual abuse is not common.

- $68 \%$ believed that "provocative" clothes are an invitation to sexual assault.

- $34 \%$ believed that dowry has an inherent cultural value.

- $55 \%$ believed that the moral character of a woman is relevant in cases of sexual abuse.

- $9 \%$ believed that a woman who says "no" to sexual intercourse often means, “yes”.

And the violence is not limited to the streets. Shailaja, Metro Plus who is undergoing a contentious divorce talks hesitantly about being "tortured mentally by her in-laws. It was always about work times... and whom I met...and why was I late. It got so bad that I left but I never invoked any of the laws available. I think it’s just easier to deal with it quietly. I mean I am in the media and sometimes that can be detrimental to my options. I don't want it to become news, for instance...'Media woman takes on cruel saas (mother-in-law)' or 'Reel life becomes real life.'

Sexual harassment is also prevalent and largely dealt with personally within professional spaces.. It inherently walks in with the male staff and colleagues of the 
women or is encountered as they travel on beats. "It is much easier to ward off that kind of attention, especially if it is an equal. With a senior, it is a little harder. Humor comes handy,” says Shikha, Times of India, who had caught the eye of an editor-in-chief, “...I used to laugh his advances away... and he got the message.” While there are legal provisions for women employees, it is apparent from my interviews that their implementation is uneven and even absent.

One of the landmark cases that took a strong stance against sexual harassment of women in the workplace occurred in the Supreme Court of India in 1997. Sexual harassment was held to be violative of women's rights under Articles 14,15, 19(1)(g) and 21 of the Constitution, and the Court recognized the primary responsibility of the State in ensuring a "safe" working environment for women. The Court also laid down detailed guidelines for prevention and redressal of grievances. The National Commission for Women subsequently elaborated these guidelines into a Code of Conduct for employers (http://www.un.org.in/gender/images/VIOLENCEAGAINSTWOMEN.pdf) ${ }^{44}$.

\footnotetext{
44. A survey conducted for the National Commission for Women in July 1998, covering over 1200 women in both the organized and the unorganized sectors, found that nearly $50 \%$ had experienced gender discrimination or physical and mental harassment at work. Yet, $85 \%$ of them had never heard of the SC ruling. Only $11 \%$ of them were aware that they could seek legal redressal in cases of sexual harassment, and that sexual harassment was an offence punishable by law. Apart from sexual harassment, $32 \%$ of the women covered in the survey also reported discrimination in salaries, leave, promotions, work distribution and working hours.

A separate study of women in the civil services found that women civil servants were not protected from harassment by their "officer" status, any more than their sisters in the unorganized sector. More than a fifth of the women officers surveyed reported that they had faced harassment at some stage of their careers. Women officers who resisted unwelcome sexual advances from their bosses were penalized in several ways - by adverse remarks in their confidential reports, transfers to undesirable posts, or by spreading slanderous gossip about them. Women officers were reluctant to report instances of harassment - the "KPS Gill syndrome”, or the fear of their complaints being ridiculed and trivialized, was often cited as a reason for remaining silent. Apart from the fact that the perpetrators are usually senior in the hierarchy, a strong "old boys network" results in the unwillingness of colleagues to judge a case on its merits - the assumption that "it must be the woman's fault" is easily accepted. In the few cases where action has been taken on a complaint of sexual harassment, the person concerned has gone to court for "justice". The case of a senior officer, who was dismissed by his organization on the charge of sexually harassing a junior clerk, is
} 
The Supreme Court order makes it mandatory for every organization to set up a mechanism for prevention and redressal of sexual harassment cases. Yet there are few of these present. Even national trades unions have ignored the issue in their negotiations with employers (http://www.un.org.in/gender/images/VIOLENCEAGAINSTWOMEN.pdf).

Besides these recent strictures from the Supreme Court, the following legal provisions are part of employment law to protect women employees.

Table 3: Gender Specific Employment Law under the Ministry of Labor, Government of India

\begin{tabular}{|l|l|}
\hline Name of the Enactment & Protective Provisions \\
\hline $\begin{array}{l}\text { 1. Industrial Employment (Standing } \\
\text { Orders) Act, 1946 }\end{array}$ & $\begin{array}{l}\text { Provision regarding safeguards against } \\
\text { sexual harassment of women workers at } \\
\text { their work places. }\end{array}$ \\
\hline 2. Factories Act, 1948 & $\begin{array}{l}\text { Provision of crèches in every factory } \\
\text { wherein more than thirty women } \\
\text { workers are ordinarily employed. } \\
\text { Employment of women in factory is } \\
\text { prohibited except between the hours of } \\
\text { 6.00 A.M. to 7.00 P.M. However, in } \\
\text { exceptional circumstances, employment } \\
\text { of women is permitted up to 10.00 P.M. } \\
\text { Employment of women is also } \\
\text { prohibited in certain factories involving } \\
\text { dangerous manufacturing process or } \\
\text { operations } \\
\text { - Claim for maternity benefit becomes } \\
\text { due on the date medical certificate is } \\
\text { issued for miscarriage, sickness arising }\end{array}$ \\
\hline
\end{tabular}

illustrative - he presented himself before the Delhi High Court as a "victim", and was able to get himself reinstated. The Court held that his dismissal was not justified because, although he had tried to molest the woman, he had not succeeded! It took another Supreme Court intervention to overturn this judgment and reiterate the principles of gender justice (NCW Report 2004). 


\begin{tabular}{|c|c|}
\hline & $\begin{array}{l}\text { out of pregnancy, confinement or } \\
\text { premature birth of child. } \\
\text { Claim for maternity benefit becomes } \\
\text { due on (General Regulation 1950) the } \\
\text { date medical certificate issued for } \\
\text { miscarriage, sickness arising out of } \\
\text { pregnancy, confinement or premature } \\
\text { birth of child. }\end{array}$ \\
\hline 4. Maternity Benefit Act, 1961 & 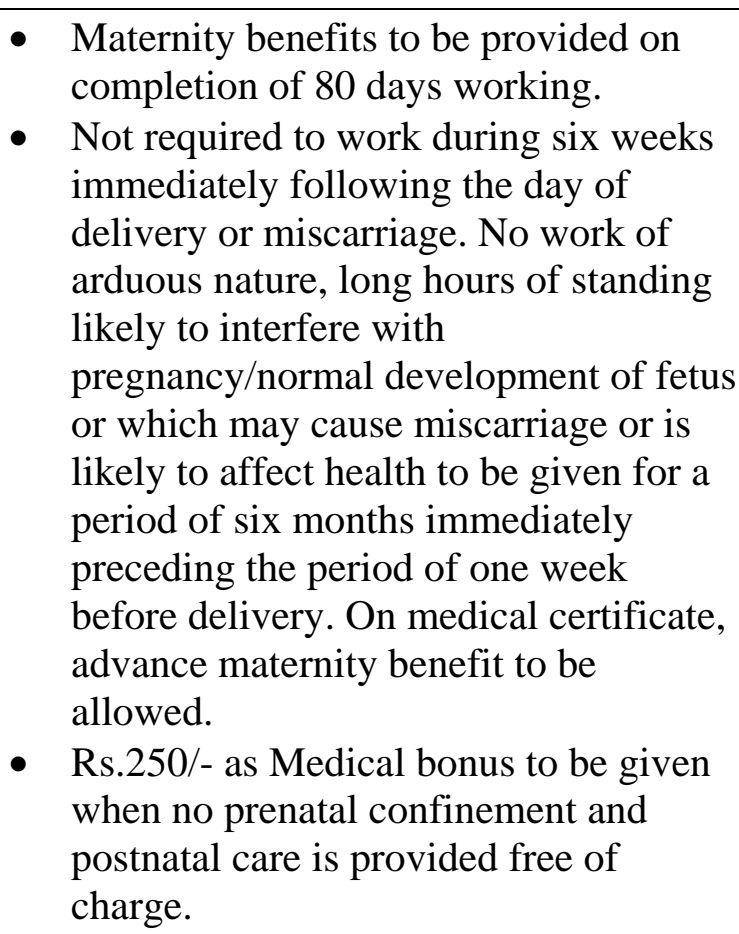 \\
\hline $\begin{array}{l}\text { 5. The Contract Labour (Regulation \& } \\
\text { Abolition) Act, } 1970\end{array}$ & $\begin{array}{l}\text { - Provision of crèches where twenty or } \\
\text { more women are ordinarily employed } \\
\text { as contract labour. } \\
\text { Female contract labour to be employed } \\
\text { by any contractor between } 6.00 \text { AM to } \\
\text { \& } 7.00 \text { PM with the exception of } \\
\text { midwives and nurses. }\end{array}$ \\
\hline 6. Equal Remuneration Act, 1976 & $\begin{array}{l}\text { - Payment of equal remuneration to men } \\
\text { and women workers for same or similar } \\
\text { nature of work protected under the Act. } \\
\text { - No discrimination is permissible in } \\
\text { recruitment/service conditions except } \\
\text { where employment of women is } \\
\text { prohibited or restricted by law. }\end{array}$ \\
\hline
\end{tabular}


As I examined the various Acts that protect women workers, it became obvious that the laws have been in place for a lengthy period of time but are minimally implemented because of multiple reasons, from unashamed gender discrimination to lack of knowledge. Besides the mutating presence of masculine domination, this lethargic application of the law also rests in the lack of its invocation. Further this lack of invocation can be located in a certain training and regulation that has created what Foucault calls, “the docile body” (Foucault 1977). While the HUMM women hardly reflect the imagery of the docile women, the hesitation behind approaching a large masculine dominated and designed legal system is certainly indicative of specific discipline that limits their options in terms of legal recourse.

In another study commissioned in 2004 by the National Commission for Women (NCW), the focus was on women journalists in the Indian print media. Attempting to examine the position of women in this burgeoning field with respect to the matters protected under the legal system, the principal investigator Pamela Bhagat points out a low response rate of 11.5 percent as an indication of institutional ennui and lack of legalemployee information. Women cited myriad reasons, from lack of time to invasiveness of the questions., When I asked my respondents if they would contribute to such an exercise, only 40 percent of them agreed. The remaining sixty percent were wary of who would have access to the information and issues of identity. As Mridu of $C N N-I B N$ said, "It is a small world. I am an outspoken and courageous person but sabka time aur jagah hota hai (Everything has a time and place). You can’t rock the boat too much. And 
Mona, you have Big Brother in America [Uncle Sam]...we have it here too.” This implication of surveillance regularly emerged as reason for various responses, especially when it came to invoking laws against harassment or professional discrimination. Being a part of the media appeared to make them aware of the power of the institution and those who controlled it.

For instance, the NCW Report showed that 21.2 percent of the respondents refused to comment on gender-based promotion discrimination while 45.5 percent stated that they felt discriminated against while 8.4 percent admitted to leaving a media organization as a result of the lack of organizational recognition. When I showed my respondents the numbers, fifty percent of them understood and related to the numbers (nearly matching the NCW trend). When I asked about the reason for such blatant oversight, the responses varied. Some of the respondents cited youth and lack of experience while others pointed to institutional prejudices that "simply don't want women to be outspoken or aggressive with suggestions or being in the spotlight...just advance this much and no more" (Interview with a well-placed electronic media journalist who asked not to be named.)

The rate of advancement within media organizations is also hampered by the reproductive role of the female professionals. The NCW Report found that 29.2 per cent of all respondents were sure that having children affects promotion and 37.8 per cent felt that this was because of the perception that having children affects women's ability to put in late hours. Among my respondents, 65 percent agreed that motherhood would hamper one's progress within the organization. As Suman, camerawoman for Aaj Tak and mother 
of a thirteen-year-old son said, "Family comes first. I am lucky to have a supportive husband but things were hard. I had to give up plum assignments, which is fine. I could not be there. But that can't be taken as an indication of evaporation of talent and intent. I just had more to do...my ability to handle the camera did not deteriorate because I had a child!”

This association of motherhood and decreased professionalism is reflected in the NCW study, which showed that while most of the respondents had not deferred marriage or pregnancy because of to job insecurity, only 56.7 per cent of those with children had availed of maternity leave and a further 10.6 per cent had availed of unpaid or part maternity leave. An astonishing 17.5 per cent were not aware of any such facility in their organization and of those without children, 54.2 per cent said that they would avail of maternity benefits in the future if such a provision existed (NCW Report).

When I asked my respondents about the Maternity Benefits Act of 1961 that provided them with twelve weeks of maternity leave, medical bonus and certain other prescriptions, most admitted not knowing about it. As Shikha, Times of India says, "It’s a piece of paper. Media organizations of course, give leave but that Act cannot guarantee that it will protect you after in terms of what stories you will get... whether you will remain on your beat. And who has the time to take on the giants?”

Similarly, when it came to issues of sexual harassment in the workplace, ninety percent of the women said that they had encountered "being hit on" several times but called it "part of the game” and did not find it overtly threatening. The NCW Report (2004) found that 22.7 percent of the respondents had put up with sexist remarks/gestures 
while 8 per cent said they were 'not sure' while the remaining denied or refused to comment. Further, of those who had experienced sexual harassment, 31.5 per cent said it had "seriously" undermined their confidence and affected their work, 24 per cent said it had "mildly" but an alarming 41.3 per cent said it had had "no affect". Only 15.2 per cent of women who experienced sexual harassment had made a formal complaint.

When I asked the HUMM women about organizational policy with respect to sexual harassment at work and the legal consequences against such actions, all the women admitted that they had not been apprised of any policy when they had joined their respective organizations. Also all of them said that such "unpleasant interactions” (Parul, $C N N-I B N$ ) was best dealt with quietly. As she says, "Once you get to be known as a 'trouble maker', no one will touch you. So in the long term, most women either talk it out with their supervisors or get a transfer to a different desk or just leave.” All the women had anecdotal evidence of women who had been harassed and yet had not sought restitution. "Usually the woman just leaves or gets a promotion with the promise of gagging herself. And then these lead to stories of sleeping your way up the ladder. There is no winning for the woman in this situation," Parul continues.

The NCW Report found that the overwhelming majority of women (76.2 per cent) believe their working conditions are similar to their male colleagues and 10.8 per cent said they were better. Perhaps what is shocking is that an astonishing 87.6 percent are not aware of any superannuating scheme, 31 per cent were not aware if any equal employment policy existed in their organization and 19.5 per cent did not know whether 
formal appeal procedures or mechanisms for handling grievances existed. An overwhelming 50.7 per cent were sure of no such facility.

Among the women I interviewed, all of them were aware at varying levels of their benefits and terms of their contracts but seemed unsure of employment and safety policies within their organizations. "I go to HR when I need any questions answered. But you know how things are here...nothing is written in stone and legal-shegal is too much to take on unless it's like...too much," said Neha of TV Today.

Alka, Zee News was dismissive of organizational policies. "They are like any law. It's one thing to be created and another to be applied. I have a friend who was involved with her married boss. It was mutual...there was no harassment but when the wife found out and there was going to be a major scandal because all three individuals were high profile public figures...guess who had to leave the job? The woman, of course. She went to another organization...the man is now on the editorial board of one of the most powerful TV news channels and she is doing quite well too. The point is...she is the one who had to bear the brunt of the scandal...even though she came out of the ugly situation not as badly scarred as she could have been...perhaps things are getting better!”

As much as Alka, Zee News was being facetious about "things...getting better," the women participating in the NCW focused on a set of issues that required improvements:

1. Positions advertised and proper selection and interview procedures introduced; 
2. Provision of training about equal employment opportunity and gender issues for their male colleagues;

3. Transparency in terms and conditions of contract system of employment;

4. Childcare facilities and maternity leave;

5. Insurance; and

6. An elected (not nominated) body for redressal of grievances.

Not surprisingly, the NCW Report found childcare at work place and insurance cover emerged as the most required facilities. 54.4 per cent thought that there had been no development (permanent part-time, flexibility of working hours, special leave, childcare facilities, study leave etc.) at their workplace in the interest of women generally. Only 29.4 per cent of the respondents felt that their corporate employers were responsible for changes that had taken place while the remaining perceived that individual cases were dealt with depending on personal relationships.

Speaking to Indrani, Times Life who had just learnt that she was in a high-risk pregnancy, I found a similar story. "When I found out that I had to be on bed rest for at least three months, I was sure that was the end of my job. I had no idea what maternity provisions are in place but my boss who is a woman couldn't have been more supportive. She told me to put my feet up and that she would figure things out. So I can work from home... of course my work profile will change but I am grateful to have retained the job,” she said in a telephone interview. When I asked her if the benefits extended to her were 
not the norm, she said, “No way...not when I can’t get to work at all. I mean it would be unfair to expect them to retain a job I can’t do.” She was hesitant to comment on the protection extended to her under law. “I don’t know about it so I won’t comment but I am grateful to my boss... because I am better off than a lot of other women in the same condition,” she ended. Time Life employee, Indrani’s position reiterates the 2004 NCW Report findings and gives empirical truth to Wright's (2006) of disposable women, “...women whose disposability is naturally and culturally scripted” (Wright 2006:1). While Wright's construction of disposability scripts “a living state of worthlessness...a wasting process [where]...within a relatively short period of time and at a young age, \{there is loss of] physical and mental faculties” (Wright 2006:2) as a central trope, the HUMM women face disposability largely due to reasons of reproduction: both biological and social. In other words, HUMM women are not “... a form of industrial waste...[to be] discarded and replaced” (Wright 2006:2) but there is certainly an understanding, for instance, that pregnancy merited replacement or reduced hours.

This “better position” of women media persons was reflected in the conversations with all my respondents. All of them were vociferous in their position that globalization had allowed them, as media women access to job opportunities though roughly half felt that there was a tendency to typecast them into certain beats. The NCW Report findings reflect that 24.7 per cent feel that they do not have access to all areas of work and that lifestyle, arts, gender, fashion and education are traditional areas reserved for women.

About a third of my respondents, largely in the forties (with a minimum of 15 years work experience in the media field) felt that the trend in the typecasting had 
changed. "When I started out, the options were fewer and there were few women in the field. So I had to fight my way into political reporting...act like a man! But now I find the younger generation see news differently...it is more about entertainment. And they seem to prefer being faces rather than the bodies in the field. It is a little disappointing to see some of my colleagues turning down field work to sit in front of the teleprompter", said Aarti, Aaj Tak. Alka, Zee News and Nisha, Tehelka shadowed this position. "You can't always blame discrimination or the system. I mean the bad policies are there to be taken down but not if you sit on your pretty butt and fall in line because it's glamorous and ego-boosting,” said Alka, Zee News.

When I asked my younger interviewees (between 24-35 years) about this position. About forty-five percent agreed, saying that easier beats meant more regulated time, safety and of course, glamour. "My issue is with this dichotomy. Why should fashion, music, movies be considered less than politics or rioting or whatever. I mean these 'entertainment' stuff generate crores of rupees in revenue...they are major elements of our economy. So why call it fluff stuff...plus we entertain people. Life is hard as it is...if coming home and hearing about beautiful things helps...why not?” says Shikha, Times of India with complete agreement from Mallica, Maxim.

The difference in understanding of the text of globalization, jobs and gendering within the HUMM women brings forth the idea of different readings of the same text, Hall's theorizing of variations in audience reaction. While the more experienced HUMM women were critical of the gendering of beats and stories, the younger women distanced themselves from such characterization or division of news into gendered categories. In 
other words, a general "why are women given so-called womanly beats” question was juxtaposed against “why should any beat be called womanly?” question. And perhaps the answer lies in one's experience with masculine dominated corporate, political and legal structures and the degree of patriarchal bargains each individual HUMM woman had struck with the system. It appears that the longer the women had dealt with the system, the higher the likelihood of them defining certain beats as being masculinized and therefore, more desirable and powerful.

The scepter of authority, whether the police, the state, the head of the household or the corporation that influence these women's lives is either sheathed in an attractive, seemingly innocuous glove or operates by generating fear. Much like an extendable leash, it allows women only so much freedom before reining them in, "always for their own good” (Ram, RSS).

In the next section, I use my own position as the researcher and 'by-stander' to put forth my observations and analysis in the following section. I attempted to remain 'poker-faced' in my interaction while trying to pinpoint my own biases and background influences as I journeyed through my fieldwork.

\subsection{Gaze of the Researcher}

My first interview of my fieldwork was with Diya, Times Now in the conference room of her office, located in Lutyen's Delhi ${ }^{45}$ Clad in a salwar-kameez, wearing a

45. Lutyens' Delhi is named after the leading British architect Edwin Lutyens, who was responsible for much of the architectural design and building of the central administrative area of the city when India was part of the British Empire. The core of the design is the Rashtrapati Bhavan, formerly known as the 
glittering nose pin and sporting an abstract tattoo, the twenty-six-year-old came across as being self-aware, confident and articulate. She imbued the essence of new India. In my eyes, her embracing of the Indian clothing and re-worked traditional jewelry (nose pins are worn more commonly by the rural and urban poor women but the urban middle class women wear it as a badge of retro-chic) while taking pride in her imagery of rebellion through the tattoo, was a perfect picture of the mind-clash between the presumed new and the presumed old.

When I asked her to deconstruct her 'look', her first self-descriptor was “individualistic". She was quick to place herself within a space that I came to see as India Inc. $^{46}$-space with a self-image of nationalized pride that not only drew on India's historical achievements but also strongly rested on the rapid economic progress seen in the urban zones under the circus tent of globalization. And in this space, while there was an acknowledgment of gendered biases, it was made peripheral, ancient and "dealable” (“Devika”, Aaj Tak).

All the respondents saw themselves as being the fortunate recipients of India Inc.’s offerings, calling the political-economic move of 1991, “a huge step forward” (Shikha, Times of India), “much needed in our battle for equality” (Alka, Zee News) and “an obvious blessing” (Mallica, Maxim). Associating globalization as an imperialist form of capitalist oppression or a process of homogenization was met with raised eyebrows and in some cases, with outrage. As Amulya, Hindustan Times said, “This is India’s time.

Viceroy's House. The Rajpath, also known as King's Way, connects India Gate to Rashtrapati Bhawan, while Janpath which crosses it at right angle connects South end road with Connaught Place, which is now called Indira Chowk, after Indira Gandhi, the first woman Prime Minister of India.

46. The term, India Inc. was coined by the Indian media to refer to the corporate sector of the nation. 
Of course, globalization has created a lot of problematic issues for the marginalized...poor women...low ‘caste’ population. But for women like me...fortunate women like me...its been awesome. Let’s not confuse issues...”

In line with Shenoy's (2008) research that looks at women and work at different economic levels, I find that within the HUMM women, the role of caste is minimal. Instead "it is social mobility, a rising standard of living, and an embracing of consumerist values and lifestyles that distinguish people from one another" (Nijman 2006 in Shenoy 2008:4). "I have no idea what gotra ${ }^{47}$ I have...I mean who cares? I don't think I have ever been asked what caste I am. I think within the educated middle class, it is politically incorrect to ask that," said Shikha, Times of India.

Statistics and anecdotal evidence appears to support the idea of progress for the HUMM women. The newsrooms were teeming with vibrant, strongly confident women who appeared excited about being at work and play. Sitting in a cubicle in the beautifully appointed $C N N-I B N$ office in Noida (a satellite township of New Delhi and a corporate media hub) talking to media women employed in different capacities, I saw a structure of professional and personal aspirations that simultaneously generated anxieties about selfimage and national image. Parul, $C N N-I B N$ kept stressing that Indian women, especially urban women were no longer a subjugated class. She cited multiple examples of women in power within the media world, “...Barkha Dutt, Mrinal Pande, Shireen Bhan and I can carry on and on.” When asked why in twenty years of globalization and sixty-three years of independence, the corporate media was missing women at the pinnacle, she shrugged,

47. Gotra is the lineage or clan assigned to a Hindu at birth, which is usually taken from the father. 
"It takes time to break the glass ceiling and it will happen soon. Also, I suppose women sometimes just choose to get out of the race to have children and families...but that hardly means they are not capable.”

Radhakrishnan (2008) finds similar gendered presumptions that demand the placement of family before professional career. Indeed the reverse of this would not only be considered un-Indian but also unwomanly (Radhakrishana 2008). I find that the fundamental expectation from women of the middle class Indian families centers not so much on domestic drudgery but on reproductive labor. With the availability of extensive and cheap labor, middle class Indian women's role within the domestic are largely that of being home-managers who relegate physical domestic labor to a plethora of maids, nannies etc. Therefore, their success as mothers, daughters and wives are largely scrutinized through the appearance and achievements of their husbands and children. Any deviation from the path of success is directly blamed on the women and their choices.

This sentiment of 'softly' blaming personal choices such as the choice to marry or have children that force them to de-prioritize professional advancement was prevalent through my interviews.. I found that single women as well as those without children appeared less cognizant of the impact of reproductive labor. But without fail, they all said that corporate media offices should "spend money on opening in-house crèches rather than gyms!” (Parul, $C N N-I B N$ ). Also there certainly seemed a lot of appreciation for women bosses among the women I interviewed with high marks given for understanding home issues or health issues. "Even though the HR is gray about these issues, my boss...woman boss is very supportive of my need to tend to emergency home 
situations...I mean the policies are in place....and I think implementation is starting to happen...one drop at a time,” said Shruti, Outlook, “...[we are] no longer expected to be barefoot and pregnant.”

And yet the media, whether entertainment or news continue to push the same gendered programming. The women largely allocated corporate earnings and TRP ratings as path markers. The conversations around media products strongly indicated that the creation and dispersion of certain materials rested on 'being professional' and following editorial guidelines. While all the women were disdainful of gendered and gendering material, they continue to operate in these zones of power and resistance, domination and dependence. In my analysis, this has resulted in an ambivalence about their identity and a sense of separation from the 'women's bodies' they construct in and by their work.

This sense of separation rests heavily on the HUMM women's utter rejection of traditional Hindu expectations of idealized Indian womanhood and enthused immersion in the processes of urban globalization. I am troubled by what I see as the almost unquestioned embracing of globalization as being the bridge to empowerment, to individual choices. . Equating India’s modernity to Indian women’s emancipation through globalization, a set of processes rooted in a reproductive petridish containing the genetic material of unfettered gender blind capitalism and gendered productive bodies swimming in a soup of ever-morphing gendered expectations is troubling.

My disquiet bears fruit when it comes to discussions surrounding more sensitive personal issues such as workplace harassment or maternity benefits or other gendered issues, where the women seemed less willing to take on the authorities. Amazingly, a 
third of the women stated that they held back because they were in the media. Asked to elaborate, the reporter from $A a j$ Tak, who requested anonymity said, "I was attacked by a senior reporter in the car while we were going for a story last year. I pepper sprayed the bastard and got away. I went to work the next day, spoke to my boss and told her about the attack. She told me to think before reporting it because in her experience, I would come off badly. So I stayed away from him. And I know he got a private reprimand. But I had these images floating in my head...of being followed by my colleagues for comment, as my private hell became public fodder. It still makes me nauseous that the bastard got away with it.”

The media women were very cognizant of the intrusiveness of their jobs and the excruciatingly gendered coverage given to certain issues such as entertainment, crimes against women, and women achievers among others. And there seemed an unspoken horror of being talked about. "We are a very small world. Unlike most other professions, media people are very incestuous in their professional and personal relationships. And news is our business... and there is a thin line between professional news-seeking and personal gossip mongering," shrugged Shikha, Times of India.

The horror of becoming gossip fodder amplifies the power of the corporate structure, its ability to 'see', an exercise of control over the bodies of its labor. While the women seem largely comfortable in their interactions with their male colleagues, I gauge an underlying omnipresent sense of awareness of the male gaze. Whether it is moving through their bodily space, shaping program content or establishing personal connections, each aspect is shaped by masculine authority and approval. As Mulvey’s (1975) 
extensive work indicates, the male gaze is used as a barometer for how normal women should ideally look, act and be treated. In other words, the male gaze serves as a disciplinary device that is used to shape and then patrol the contours of that normativity.

When I asked about why globalization, the harbinger of modernity in India, was not outlining change in gender relationships more rapidly, I was repeatedly asked about how things were in the western world I had chosen to live. The questions indicted how a postcolonial location apprehends globalizing capital, the seemingly defensive position indicative of simultaneous rejection of my criticism of India’s largely gender-blind adoption of globalization (See Menon 2004, Mirchandani 2004, Vishwanath 2007) and embracing the perceived empowerment associated with their understanding of the same processes. The dichotomy can be framed in Barthes' notion of codes, complex patterns of association learned in a culture. In this case, an aspiring urbanized middle class culture that repeatedly sees neo-liberal economic policies as a means to achieve Westernized ideas of progress, a global standing as equal citizens who no longer need to explain away snake charmers, elephants on the roads or poverty.

The same code of identity reared its head when I spoke to the women about Hindu nationalism. The self-described modern, liberal, westernized women were physically expressive (shoulder shrugs, grimaces, clenched fists) when I asked them about Hindutva. The terms "thugs", "goons”, “out-of-step idiots”, "embarrassment to the country”, "archaic” and "irrelevant” were used generously. The Delhi-based women did not see it as a "personal issue” (Nisha, Tehelka). The activists and politicians were seen as being more active in Maharashtra, Gujarat, Karnataka and Uttar Pradesh. But when I 
asked them about the shakhas (branches) of the Sangh Parivar active at the grassroots, spreading their message of nationalism, largely riding on the bodies of Hindu women, some of the women were skeptical about the impact it would have on their lives. "All that crap works in the villages... who is going to listen to an uneducated individual who claims that pure women require protection and therefore should stay at home?” laughed Neha, Aaj Tak. When I asked about the increasing rates of crime and the general perception of lack of security, the women largely pointed to the inundation of migrants from the surrounding highly masculine dominated states like Uttar Pradesh, Haryana etc. Juhi, $C N N-I B N$ said, "It is a strange city, Delhi. There is high conservatism...tradition is used to mask gender oppression and patriarchy.”

About a third of the women said that Delhi had always been conservative in nature and all of them agreed that Delhi is known for crimes against women. But with the entry of globalization, the HUMM women made a connection between conservative disapproval of changing societal structures and crimes against women.

In my conversations with the women and some members of the Hindu Right, I came away with the opinion that under this Hinduized understanding of womanhood, the identity is seen as a privatized tradition that must be defended against the corruption of Western materialism. The commodification of the woman's body is associated with an invasive, alien, foreign culture. This stems from “...urban Brahmanical philosophy [that is] played out on the body of women to contain and control public media space” (Kumari and Kidwai 1998:108). Extrapolating on Barthes' (1972) work, such expectations are mere fragments of a more general syntagm, wherein the unity of the message is realized 
at a higher level of philosophy. Such denoted images, such the Hinduized Indian woman naturalizes the symbolic message, a natural being there-being like that of subjectivity.

And the methodology to attain such control became obvious when I spoke to the RSS national spokesperson Ram, a man of calm intellect and eloquence who talked about the influence of his group. Displaying political expediency and sharp skills, the RSS has instituted over 80, 000 grassroots level Shakhas (branches) all over India that give ideological instruction to families through training camps and seminars. The outlines of such programs are decided through yearly plans of action that are shaped by a joint initiative of the BJP, RSS and other participating Sangh Parivar members. According to Ram, RSS “These shakhas don’t do only religious work...we are a seva sansthan (a service organization).”

As Kumari and Kidwai (1998) find that while all the Sangh Parivar groups operate as separate entities, they share similar goals and principles. And their agenda is to spread their version of political education among all sections of India's women population. In the $B J P$ office, ironically located in a colonial compound in the center of Lutyens’ Delhi, I was very aware of the total absence of women. I saw male workers and politicians who looked at me with curiosity and question. As I interviewed Bala, a public relations officer, Bharatiya Janata Party, I noticed multiple calendars of Bharat Mata (See Appendix E) adorning the walls. An articulate man, Bala's position on Indian women appears surprisingly progressive. He talked about his fourteen year old daughter, who he "allowed to wear jeans and travel by bus." Asked if he was comfortable with the idea of her interacting with male friends, he was hesitant but said, “...it's part of the 
culture now. But I always tell her to be careful.” When asked about what, he smiled and said, "What madam...you know!" This boundary of sharam (shame) is what is being decimated by Western culture, according to the Hindutva brand of nationalism. While Bala, speaking for this brigade was totally supportive of progress, of multinational capital forging into the domestic consumer market; he was adamant that Indian womanhood and culture had to be protected from the "effluence of this capital flow". In their attempt to "remain Indian", the conservative brigade is constantly producing, reformatting and circulating spacio-temporal grids that locate Hindustan on the Indian woman's body.

Interestingly, Bala's conversation with respect to urban women seems to indicate that the nationalists have adopted some aspects of Althusserian philosophy wherein the ideology is not imposed and instead is done through reiterating “...unconscious categories through which conditions are represented and experienced" (Curran, Gurevitch and Woollacott 1982:24). Therefore we see the antipathy towards Western cultural systems that directly targets women, whether it is the attempt to impose dress codes on newscasters or the lack of female leadership within their own cadres. An outstanding example of gender-based political-cultural machination is the ouster of the term Jai Siya Ram (Long live Sita and Ram) to be replaced by Jai Shri Ram (Long live Ram). Kumari and Kidwai (1998) reason that the Hindutva cadre, in their militant nuclear testing mode saw the inclusion of Sita in their signature battle cry as “...preaching pacifism” (Kumari and Kidwai 1998:87). Recent research done by Nanda (2010) finds similar homogenization of Hinduism and by extension, the identity of India, as a nation through subtle but constant reiteration. According to her, this flattening of icons, rituals and 
citizenship is being insidiously conducted so as to create a centralized national identity that further shores up the powers of the religious-political-economic elite while making it easier to disperse the idea of a singular India within the masses (Nanda 2010).

While the saffron brigade decries cultural 'modernization', their political requirement has led to a tremendous rise in the number of militantly communal Hindu women. According to scholars like Oza (2006), rural women as well as upper middle class women have become visible entities in scenes of rioting, whether in Ayodhya ${ }^{48}$ in 1992 or Gujarat in 2003. According to Kumari and Kidwai (1998), 20,000 kar sevikas (woman who performs service as part of her religious obligation) courted arrest on January 4, 1992 in Ayodhya. Tanika Sarkar finds in her interview with Sangh Parivar female activists that they were confident, self-aware women who sincerely believed that the establishment of the Hindu Rashtra would end all evils against women (Basu, Datta, Sarkar, Sarkar and Sen 1993).

Bala, $B J P$ brings up the active role of women in the BJP cadres, saying that they supported the Reservation Bill for Women that sought 33 percent reservation for women in government at all levels (that has yet to be passed). Offering me a cup of tea (he poured it out in an elaborate process indicating that he was happy to do 'women's work), he said, "Come on Mona, you are a Hindu. You know how much we bow to our mother (sic)...how we protect our sisters and daughters...how the wives control the homes and children's future. So where is the question of us controlling women?” Such nostalgia for

48. On December 6, 1992, members of the Sangh Parivar demolished the structure of Babri Masjid (mosque) in Ayodhya, claiming it be to be built over a temple consecrating Lord Ram. It led to widespread rioting and gave voice to several women like Sadhvi Rithambara and Uma Bharati, who were loud voices of communal rhetoric. 
"tradition" is largely cast in masculine desires and therefore the anxiety of its loss is also masculinized with gendered erasure of memory, conveniently forgetting the lack of women's rights and restriction of space/choice/sexuality under such structures of masculine control.

Bala's, $B J P$ reiteration of the Hindu woman's revered position is steeped in Barthes' conception of myth, the use of signs to denote meanings rooted in tradition, in nature, in order. Much like Barthes' analyses of the semiotics of red wine or the front cover of Paris Match (See Barthes 1957), my analysis of the Hindutva rhetoric surrounding the Indian woman's body exemplifies how such images of reverence and power obfuscate the transgressions on their bodies, rights and spaces. As the HUMM women endanger the fixed 'pure' images of Indian womanhood, they automatically are seen as deviant women, threatening women who need to be put under surveillance.

My observation stems not only from my awareness of the absence of female presence on the $B J P$ campus or $R S S$ office but also from scholarly analyses of general role of women within these groups and specifically, their role during the planning of the Babri Masjid destruction and it's actual perpetration, the event that defined and rooted the Hindutva movement. Scholars like Oza (2006) and Sarkar (1993) find that the activists, who were regular members of Durga Vahini (a sister organization that trains women in martial arts and is named after Durga, a militant Goddess of the Hindu pantheon.) were brought to Ayodhya to run the community kitchens, sing devotional songs and act as reminders to the male members as to what they had to protect. Post-demolition, the women went back to their traditional roles, of working within the family and community, to spread the message of the Hindu nation. The aim is to expand the Hindutva network 
into new kin groups rather than new social groups. Interestingly, even this ‘job’ is limited in scope as the Sangh Parivar does not allow them to actually be involved in village welfare or tribal mobilization work (Kumari and Kidwai 1998). The assumption is that it takes them away from their primary role within their family. But in reality, the fear is stemmed in power hierarchies since development and mobilization work not only exposes 'their' women to outside influences but also makes way for the women to gain power and control.

Mridu, $C N N-I B N$, Aarti, Aaj Tak and Suman, Aaj Tak agreed with my hypothesis, saying that they regularly ran into problems of condescension with the $B J P$. According to Aarti, “I don’t think they even realize it sometimes. I have been told once that I could not meet Advani (leader of the $B J P$ ) because he was busy and then my male colleague was escorted in. When I made a noise about it, I was told that the issue being discussed was complicated! I finally got in but this is hardly unusual. I get it in police stations with officers trying to 'protect' me from the hoary stuff...” While the women laughed about the hurdles, it was obvious that they were not toeing the line of authority when it came to their work but they would not rock the boat when it came to their own rights.

Perhaps this self-consciousness about their private roles that demands obedience, an unaware sub-conscious knowing of being tradition commodified, a body inscribed and consumed by a male gaze, keeps them from challenging existing discriminating structures. In de Beauvoir’s (1974) terms, she is a sex object, defined by the male gaze, construct and desire (de Beauvoir 1974). Further questioning led to a legion of reasons for not challenging certain status quo. They ranged from "not upsetting the bosses" 
(Neha, Aaj Tak), “upsetting my family” (Tina, Lifestyle) to “losing job/beat/plum assignments" (multiple respondents) to "not my personality" (Shruti, Outlook).

To my understanding, this dichotomy is indicative of the oppositional pull of two structures of masculine domination. One is rooted in the male-headed family formed through India's historical epochs while the other is the gendered structure of capitalism in the shape of "emergent, globally inflected spaces of public consumption, which commodify women at the same time that they target them as consumers” (Lukose 2005:931). Therefore, most of these women are ready to become global consumers and producers yet unlike their male counterparts, the burden of idealized expectations continues to hover over their lives, albeit with lesser weight.

\section{$\underline{\text { 2. Conclusion }}$}

In the hours I spent talking to the HUMM women, I learned how they internalize, negotiate and codify their emerging spaces of professional and personal engagement. My analysis of HUMM women and their stories reveals that globalization has created a symbiotic relationship with masculine controlled and designed post-colonial preoccupations about tradition and modernity while religious nationalism has attempted to co-opt and modify feminist agendas. These varied tugs-of-war have created new citizen-consumer identities. The media woman is a work in progress as she reinvents herself within the parameters of the respectable, middle-class woman who is antithetically a successful professional: 'shamelessly’ sexual, personally confident and out in public. My work finds that these women, each with their different experiences, expectations, strengths and limitations, generated certain 'fuzzy’ zones of overlap. These zones are: 
1. The women defined themselves as being individuals yet strongly see their role as being a part of the family structure, as daughters, mothers, sisters and wives. They continuously resisted typecasting, not a whore yet not just a mother.

2. Masculine domination is seen as having a permanent place in their lives but they see such gendering as being an offshoot of nationalism, a traditional problem.

3. The presence of Hindutva and its impact on societal norms that structure the lives of the interviewed women is seen as being peripheral.

4. Globalization is seen as being the antidote for gender discrimination. There is a strong embracing of the tenets of globalization and all it entails. "Westernization" and "Modernity” are sought after as selfdescriptive adjectives. Patriarchy within the corporate structures was attributed to old patriarchal India rather than the gendered globalization.

5. The confronting of gender-based issues were a personal 'interaction' rather than an institutional confrontation. Being a media woman was seen as being a hurdle in such 'inflammatory matters'.

6. There is a strong sense of professionalism but the HUMM women regularly face automatic assumptions about their roles within media networks. As stated above, entertainment and 'soft' news becomes women's premise. 
7. The women identify themselves as global Indians, embracing a civilizational advantage and yet distancing themselves from patriarchal demands that stem from that very structure of Indianness.

The following chapter will examine the meaning of gender, safety, feminism and empowerment in the lives of the responding media women. 


\section{CHAPTER VII}

\section{Securing Indian Women: The Carrot and Stick Method}

“Fathers, uncles, cousins, kings...you remember this? We used to chant this not knowing that it stood for F@\#\$. And we are...constantly by the men in our midst... whether it is for not doing enough at home...being out at night or wearing something semi-transparent. At the end of the day, it's about our bodies...we are judged by our bodies, we are attacked because of our bodies, we are told to protect our bodies...it never ends...”

- Shikha, Times of India.

An attractive and self-aware woman, Shikha, Times of India met me several times to talk about what she called “...something I never thought about [but] faced every day of my life in Delhi”. Sitting in a restaurant, she came up with the title of this chapter. "The carrot and stick method is how I see it. So you show me the advantages of working and making money but hamesha (always in Hindi) threaten me with violence, losing home, losing izzat (honor) and on and on.”

As I listened to the confident thirty-two-year-old woman, Einhorn’s and Yeo’s (1995) research came to mind that globalization can be both "empowering and constraining” (Einhorn and Yeo 1995 in Ganguly-Scrase 2003:546). Add to this the gendered demands of "Indianness” and you have a potent combination for women, “...somewhat schizophrenic state of living”, says Shikha, Times of India. 
Continuing from the last chapter, this section focuses specifically on issues of gender, safety-security, feminism and empowerment as understood, embraced, repelled and deconstructed by the HUMM women.

\section{Answering Questions II: Data Generated}

Sitting in the restaurants, living rooms, and offices and, in one case, a car of the HUMM women, my conversations made real Mohanty's "feminism without borders" (Mohanty 2003:2). Each of these women dance with and around visible as well as invisible boundaries, “that suggest both containment and safety” (Mohanty 2003:3). As I waded through statistics, Indian feminist research, and interviews with media women and others, a picture of modern India was etched out wherein women's place in the frame of modernity and progress reinforces instead of challenging hegemonic traditional gender roles. (Das 1994; Puri 1999; Sunder Rajan 1993, 1999, 5-8). And yet, I met a bastion of women who are engaged in a quiet duel with gendered expectations, and appear to be slowly shifting paradigms of gendered hegemony, if not "shattering them to smithereens" (Diya, Times Now).

\subsection{Gaze of the Researched}

As I talked to the HUMM women, who variously defined themselves as being “empowered”, “independent”, “modern” and "feminist”, I saw a pattern emerge in this juxtaposition of "old versus new" (Parul, $C N N-I B N$ ). The women tackled questions about gender, feminism and safety by identifying with what Mohanty called the "implicit selfrepresentation of the Western woman as educated, as modern, as having control over 
their own bodies and sexualities and the freedom to make their own decisions” as opposed to being “...third world...sexually constrained... ignorant...tradition bound, domestic...victimized...” (Mohanty 2003:22). According to Suman, Aaj Tak, “That group is present in India, right here in my house too...my maid but that is not us. We are educated, working women and we are struggling, no doubt but we are not pao ki jooti (foot slippers in Hindi, implying trod upon)”.

While the data in the previous chapter indicated that women in their place of work are reticent about addressing uncomfortable issues such as sexual harassment or equal pay head on, they claim to be more assertive within their domestic structures. Interestingly, all the women claim to belong to "largely" progressive families, given that they were 'allowed' to work in a profession that demands unusual hours, travel and interaction with the opposite sex. "Can you imagine what it would be like if my father was truly conservative?” asked Juhi, $C N N-I B N$. Amulya, Hindustan Times echoed the same sentiment saying, "My dad was ultra supportive of my ambitions. I went to MIT with their trust.” When I asked them if there was any strain of conservatism in their relationship, Juhi said, "He is my father so of course, he is going to be protective..." Amulya was dismissive of any conservatism. "He is cool with my mum and I working or keeping late hours. It is a woman's household and my dad and brother see little difference between men and women when it comes to work or play.” Nisha, Tehelka laughs when I ask about gendered expectation within middle class urban families. She talks about an article she wrote for her magazine, "Why Indian Men are Still Boys?"49 In a witty, tongue in cheek piece, she talks about the state of Indian malehood, post globalization.

49. http://www.tehelka.com/story_main42.asp?filename=Ne010809coverstory.asp 
According to her, "There is a thin sliver of the upper middle class where there are some changes. People use the term 'more and more' but really there are no ways to tabulate actual figures.” According to her, “...this new trend is largely media generated....and its wishful thinking. I want to believe that our men are sensitive, supportive and progressive but as I write in my article, the urban Indian male hasn't really changed. He is cocooned as he has always been in a sort of prolonged infantilism - a hatchery protected by doting mothers, fathers, sisters, girlfriends, and society itself” (Nisha 2009).

This is reflected as I talk about households and hierarchies within it. The response varies from head-shaking indulgence to a certain acceptance that domestic space is fraught with gendered connotations Borrowing from Althusserian thought, it appears that Indian middle class values, desires and preferences are inculcated within the structure of the home/office through ideological practice. And therefore, centuries of gendered structures while constantly mutating, retain their potency under the rule of what Susan, Tehelka calls the "The Innocuous Man”.

According to Nisha, Tehelka, "The innocuous man never makes the news because what he does is not news. He leverages power so casually it seems to be his by natural right. It is legitimate for him to exert measured but highly effective violence to protect his way of life. He is the man who is impeccably well behaved everywhere but at home, he throws plates if meals are late. This is the man who hates that his girlfriend earns more or that his promotion was sidelined by a woman who slept her way up the ladder, who assumes his teenage sister-in-law does not mind his copping a feel as long as she stays under his roof, who never introduces his wife using her name or the one who tells his much loved and high-powered daughter that if she comes home later than $7 \mathrm{pm}$ after 
work, she is without morals or the one who wears designer clothes, drinks in designer bars but does not flinch from casually slapping his designer wife in spaghetti straps. The hushed whisper families maintain around the tyrant of the house is uncannily similar to the ones that surround a colicky baby” (Nisha 2009).

When presented with this narrative, the HUMM women were in "shrug mode". There is vehement denial of any continuing violence in their lives though about fifty percent of the women admitted to having been in violent relationships in the past. One of the respondents who requested anonymity said, "It's everywhere...this violence. I used to think that I am being cynical but I see it in my colleagues’ homes...not all of course, but in many...perhaps seventy percent. Not physical always...but soul killing tension.” Suman, Aaj Tak says, "Security within the home is so important in our work. It is an unconventional job if you want to be a real journalist. So if family is stupid then I tell young women...either you live alone or don’t come.”

Radhakrishnan's (2008) finds similar trends of intersection between tradition and modernity within the gendered discourses of identity. The deep-rooted tenets that bind together the demands of globalization and religious nationalism expect IT professional women to produce economic and reproductive labor (Radhakrishnan 2008). Reproductive duties always trump professional aspirations. Some of Radhakrishnan's interviewees expose the intense tension that simmers within diasporic families that might be separated by career demands. As she finds, unquestioned assumptions from prevailing family structures requires women to sacrifice their career goals. Any other choice invariably results in stressful home lives, threats of divorce and separation from children as well as varied levels of domestic violence. Such violence is rooted in moral panic, an ideological 
tool used for societal control (Hall et al. 1978). Therefore the threat to masculine dominated social order, interests and values regularly brings out the moral police or “moral entrepreneurs” (See Cohen 1973).

I found that such continuation of male led family structures is partially the result of repetitious patterns of upbringing. There was a cognizance of differences in their understanding of male-female 'training' in their homes. Eighty percent of the women interviewed agreed that there were differences in the way their parents interacted with the children of the family, based on gender. There was no claim of gendering when it came to education, healthcare or employment but there are patterns of differentiation when it came to issues of marriage, travel, sexuality and safety.

$\underline{\text { Table 4: Patterns of Differentiation Based on Gender }}$

\begin{tabular}{|l|l|l|l|}
\hline & Issues & Response\%: Positive & Response\%: Negative \\
\hline 1. & Education & $0 \%$ & $100 \%$ \\
\hline 2. & Healthcare & $0 \%$ & $100 \%$ \\
\hline 3 & Employment & $0 \%$ & $100 \%$ \\
\hline 4. & Marriage & $80 \%$ & $20 \%$ \\
\hline 5. & Travel & $90 \%$ & $10 \%$ \\
\hline 6. & Sexuality & $98 \%$ & $2 \%$ \\
\hline 7. & Safety & $100 \%$ & $0 \%$ \\
\hline
\end{tabular}

As I attempt to understand this pattern of differentiation, I began to see "everyday forms of struggles” (Scott 1988:6) against the omnipresent structures of gendering within nationalism and globalization that shapes the lives of the HUMM women. These 
struggles are simultaneously conditioned by such structures of domination and yet have profound impact on them. This constant interaction of conditioning, enabling and rebelling has created an entangled web, wherein the HUMM women have created strategic identities. The women, especially ones in the twenties see themselves as being 'products' of global consequence. Their empowerment and enrichment rest deeply on the processes of globalization while the elements hindering further stratospheric rise is blamed on traditional expectations.

According to Dewey (2008), the ideal of modern Indian womanhood, which is shaped through the machinations of the Miss India pageant, is constructed to match transnational qualities of beauty and feminine desirability. Therefore, the public face of Miss India is global and embraces 'Western-style' modernity but the private body is literally guarded to keep her from "indiscreet and inappropriate behavior" (Dewey 2008:214). Dewey finds that such supervision is necessary to keep the 'Miss' India contestants from overstepping the bounds of unique Indian traditions and culture. In other words, the globalized pageant stage which claims female empowerment by catapulting a narrow spectrum of women to immense fame and possible wealth, quietly reinforces the same notions of gendered discipline that define religious nationalism (Dewey 2008). The construction of such 'docile' and 'useful' bodies is foundational to the processes of globalization (See Foucault 1977, Dewey 2008, Ahmed-Ghosh 2003, Banet-Weiser 1999). The HUMM women recognized the stereotyping and scripting that occurred in extraordinary grooming of the contestants into Ms. India. A majority of them agreed that the images generated by such contests were hardly realistic leading to increased spending on a plethora of products, from weight loss to plastic surgery. Yet they saw the potential 
of the contest and pointed out that as controlled as the stage was by multinationals, it still provided a space for women to showcase themselves, a relative act of empowerment.

Further discussion of empowerment brought forth a different dimension to what can be called an uncoordinated individualized women's movement against gendered differences and "dependency relations” (Lindsay 1983) within Indian urban centers. Even as the HUMM women, given the nature of their globalized profession are in continual engagement with Western influences, ideas and positions, there was a definitive separation between the idea of empowerment and feminism. "I would not call myself a feminist” was the response from seventy percent of the women to the direct question, “Would you call yourself a feminist?”

The knee-jerk spontaneous reaction from seventy percent of the women interviewed was eye opening. It is especially so since research on women's resistance movements in India shows that women have used different feminist tactics to resist the structures of political, ideological, and economic power/domination embodied in the state of post-colonial India (Kumar 1993; Basu1995; Purushottam 1995; Desai 2002). Among these movements are those including but not limited to anti-alcohol, anti-dowry, and antiprice-rise movements (1950s); movements against the sexual division of labor, unequal wages to women; sex-selective abortion, etc.-- that made such violence public issues and led to legal and social changes (1960s/ 1970s); and the Chipko/ environmentalist movements (1980s/1990s) among others (Das 2005). According to Das, the Indian feminist resistance movements focused on issues which were regarded as "women's concerns" but did not challenge areas of male control or domination over women, did not demand women's parity or equality with men in their families, nor struggled against the 
sex-based definitions of the "roles" of men and women, or the codification of biological difference between men and women as embodied by the state in its policies. (Das 2005:7). But these above-mentioned demands are found in the taxonomy of feminist theory usually deployed in the West within categories of liberal, Marxist, socialist and black feminisms.

Further discussion reveals an understanding of feminism that is clothed in the much-mediated stereotype of the male-bashing, unattractive, aggressive, bra-burning heretic. "I am proud to be a woman. It carries its burdens but I have huge advantages too, especially nowadays. I can work and play like a man but I don’t want to be a man” (Mallica, Maxim). There is a strong sense among the women denying feminist ideology that it is unattractive, unwomanly, that 'demanding' emancipation was "sterilizing and un-sexing” (Burton 1994:18). This strong rejection of feminist as a self-descriptor can be extrapolated to the findings of Lukose's research wherein she finds that there is an open disdain for women who are "too Western...too emancipated” (Lukose 2005:931). Her observation of the Miss Kerala pageant and interaction with the contestants exposed the rooted demand for pure upper class femininity that rejects feminine self-expression as being harmful to self and nation (Lukose 2005).

Ironically, the Hindutva movement strongly rejects the very same progressive movement. As Ram, RSS said, "We have plenty of strong images in our myths and history. Why seek Western ideas to structure our families? This feminist movement is a bad idea. Indian women are already empowered. See our computer engineers, our doctors, our politicians. Does America have any woman prime minister? We have Indira Gandhi...Sarojini Naidu...Sushma Swaraj...so many more.” The strategy of tokenism, 
whether by nationalists using the names of privileged women like Gandhi or the HUMM women pointing to handful women in positions of seniority, is regularly used.

For instance, Indira Gandhi, India’s first and only woman prime minister is regularly touted as an ideological symbol, for modernity and femininity. In an interview, Gandhi said, "I do not regard myself as a woman. I am a person with a job to do" (The Asian Student, 23 November 1974 in Kapadia 2002:514). While she tried to portray herself as an a-sexed equal with the right to leadership in the largest democracy in the world, she was shown as Goddess Durga in the cover of a special Independence cover of a popular magazine for modern women, accompanied by the words, “...to be a womana wife, a mother, an individual— in India means many things. It means that you are the store-house of tradition and culture and, in contrast, a volcano of seething energy, of strength and power that can motivate a whole generation to change its values, its aspirations, its very concept of civilised life” (Femina August 1973:14 in Kapadia 2002:514).

This ambiguity from sources such as Femina, which portrays itself as the handbook for modern women and is the main sponsor of the Miss India contest, does seem to influence the notions of liberated womanhood. In other words, while the HUMM women strongly embrace globalization and credit its processes for their empowerment, they reject the notion of feminism as being the ideological tool that is attempting to expose and disassemble the structures of gendered institutions. According to Shailaja, Metro Plus, “All this talk of women’s lib is shit. When I was going through my divorce, I called a couple of these women's groups and they did nothing to help me. I never understood it before and after my experience with these so-called feminists, I am glad I 
don’t.” She continues, “I thank God that I had my paternal family to fall back on...otherwise it would have been difficult and dangerous.”

Shailaja’s sentiments are strongly echoed by Shobita, Outlook who says, "This nonsense is very distracting. We are different, period. And I have progressed fine without being a feminist.” When asked about concepts of equality before law, employment rights and assurance of security, she says, "Those are human issues. Not feminist. They place all people as equal...all religions, all individuals." She elaborates, "I dislike this loud need for demanding equality. There is the glass ceiling and there are restrictions on movement...correct. But it is better to engage and make changes rather than scream and shout about it.”

The HUMM women who distanced themselves from feminism repeatedly talked about engaging with the system and negotiating with it as strategies as opposed to directtargeted confrontation. Kandiyoti (1988) finds similar strategies in his studies of different groups of women, totally unrelated, which he calls patriarchal bargains. While the actual strategies vary, the foundational idea is to maximize security and personal gains through interpersonal relations with masculine power.

The women who strongly claimed the title of feminist have a broader understanding of the history of feminism. As Nisha, Tehelka said, "What kind of feminist would be a better question! Environmental, liberal, which wave etceteras. My position is non-categorized...I know that there are multiple laws in place to assure justice. I want them implemented before there are more laws promising the earth to women. So my idea of feminism rests in individual justice. Only then can a society have justice.” Similarly "Devika”, Aaj Tak and Mridu, $C N N-I B N$ had no qualms about embracing the tile of 
feminist. According to them, equality and justice was a no-brainer and that was the core of their understanding of feminism. As "Devika”, Aaj Tak says, "I want to be safe...in my home and at my work. Safe to travel...safe to ask for a hard-worked for promotion...safe to date and so on. This is not just about physical safety...to me it's about mental security too”.

The common thread through all the interviews was the concept of security. The women constantly talked about security, in terms of their bodies, their jobs and their place in society. As a narrative, their life stories are reflective as well as constitutive of their experiences with safety. Again there was an interesting dichotomy to their understanding of safety and security. Given that a majority of the women claimed to be in ‘safe’ domestic spaces (living with parents or partners), their engagement with 'nonsecurity’ surfaced in public and professional zones. In this understanding, the spatial has to be contextualized on the scale of time-place and as an articulation of social interrelations (Massey 1994) as does safety within that space. As women traverse through spaces, the reactions generated to their presence indicates how “...the identities of place are always unfixed, contested and multiple” (Massey 1994:5).

The first national survey on Indian women and issues of security, a CNN-IBNIndian Express-CSDS report ${ }^{50}$ showed some shocking statistics. The 2008 "State of the Nation Survey- An Exclusive Survey of Indian Women” was designed and analyzed by the Centre for the Study of Developing Societies, Delhi. The findings presented were based a sample of 3998 women respondents in 160 locations in 13 metropolitan or 'million plus' cities, 17 big cities with population over a hundred thousand, 11 small

50. http://ibnlive.in.com/news/living-with-fear-india-unsafe-say-women/57236-3-p0.html 
towns with population less than a hundred thousand and 68 rural locations. Urban women comprised 56 per cent of the sample, although only 28 per cent of the country’s women stay in urban areas. Despite this limitation, the social profile of the achieved sample was fairly representative: 75 percent Hindus, 12 percent Muslims, 14 percent Dalits and 10 percent scheduled tribes.

Extrapolating the figures that have implications on my research on HUMM women, I find the numbers supporting my findings.

- Forty-four percent of Indian women confess to feeling insecure the moment they step out of their homes. Fifty-three percent of these are women living in metropolitan cities.

- Sixty percent of single, working women fear for their safety outside their domestic space. Women feel particularly vulnerable in public places.

- Twenty-eight percent of workingwomen have been teased or molested at least once.

- Nearly fifty percent of the surveyed were hesitant about going to the police if attacked.

- While seventeen percent say they are beaten by their husbands, six per cent face the same from their in laws. The number goes up to twenty-three percent when the women are working. Twelve percent of respondents were beaten by their father at least once in the past year.

- Fifty-nine percent of the respondents from the metros had experienced either physical or verbal harassment in the last one year; 37 percent had faced physical violation. 
Even as the statistical data corroborates the experience of the HUMM women, specifically in the public and professional spaces, the reasons for the disturbing numbers demand answers. When asked why the urban workingwomen were more prone to violence, Anoothi, Times of India, said, "It’s all that Indian conservatism. We are supposed to follow certain rules and those rules sometimes demand time...you know...cook for the family and all that. If you belong to a family that sees nonfulfillment of your 'duty' because of work...you will get beaten. And there are many families like that. But try doing a story on it and it will be shot down faster than a Pakistani missile.”

Similarly "Veda”, Headlines Today says, "Patriarchy has deep roots. And families have operated on women's labor for so long. If the home falls apart ...it becomes the woman's fault. You step outside the house and you make yourself 'available' to all the perverts. Globalization can give you opportunities but it can't wipe out generations of double standards.” The HUMM women claim security within their own circles, especially personal. "My friends, male and female, come from educated backgrounds. There is a sense of acceptance as individuals...so we have the pretty one...and the handsome one....and the one who never works...but never is there a categorization based on gender," says Shruti, Outlook. She continues, "That kind of sexual harassment or physical threat comes from people who are uneducated and come from the villages. You know that with new opportunities, these idiots come here but don't know how to behave. If the girl is outside unaccompanied...she is fodder.”

In other words, the processes of globalization that gave them opportunities of empowerment at the same time brought out the "uneducated rural masses", which are 
responsible for their endangerment in public and professional spaces. Even as globalization has made a significant dent in the number of women who work professionally outside the home, the numbers are still too small to be statistically significant in a macro-enquiry (Kapadia 2003). The lack of 'real' empowerment is reinforced by the increasing violence against women, whether for dowry or in the matter of gender based selective abortion.

Similarly, my research found that while these women are significantly empowered relative to 'regular' Indian women, given the power of the press, the majority do not see themselves as vessels of change, of harnessing their ability to make an impact through their programming. "We are not here to judge. We are here to provide news and entertainment," said Diya, Times Now. There is a strong sense within a majority of the women that harnessing the existing system for their individual progress and empowerment is more strategic than any outright confrontation. There is a sense of impatience about any strategy that asks for aggressive engagement. Instead there is an understanding that individual emancipation will lead to a wider empowerment of women.

Some of the HUMM women described attempts to try and get sanction to generate programming that recognized the feminist gaze but gave a generic reason for failure to produce the material. For instance, “Shipra”, $N D T V$ focuses on a specific story that dealt with the murder of a flight attendant. She wanted to use that story to talk about the dangers faced by workingwomen and the laws that were in place yet not implemented. She said that she was told “...the viewers will not be interested. Unless there is a sex-angle. Every time a woman in 'such' fields...media, hotel, airlines is hurt...there is an immediate swing towards sexualization...[the victim is portrayed] as 
being promiscuous...loose...so she deserved it...she made her lifestyle choices and therefore...she paid for it. It is disgraceful...disgraceful.” Such mediated images are the product of social control, the implements of appropriateness (Nagar et al. 2002).

According to my research, this largely self-confident set of women sees themselves as being empowered but in shades. Therefore, while all of them claim domestic equality, their experiences in public and professional zones are "middling" (Shikha, Times of India) and could be alleviated only if "this Sita-Draupadi comparisons were dropped” (Mridu, $C N N-I B N$ ).

The following section examines the gaze of authority with respect to issues of feminism, security and space.

\subsection{Gaze of Authority}

The comparisons of Indian women to Goddess figures are so entrenched that they have become a part of the vocabulary. Ghar ki Lakshmi (The home's Goddess of Wealth), Shut putravati bhav (May you be the mother of hundred sons like Draupadi) are some examples. The expectation of piety is deeply influenced chronologically by conservative Brahmanical impositions, Islamic interpretation of religious texts and finally by Victorian mores that were inculcated in the Indian middle and upper classes during British domination. In each of these eras, capital colluded with existing gendered institutions to create an order that would protect the status quo. As more wealth was amassed, the wealthy put their women behind the purda (curtain). The purda was seen by the masses as a sign of the classes. More than the sign of oppression, it became a sign of wealth, implying that these women were pampered, did not have to work in the fields or 
the home and were served by maids. So the purda became a symbol of enriched masculinity, a masculinity that provided and therefore wielded power.

Even as the purda holds little meaning to the women I interviewed, the historical memory of authority is far from receding. According to the younger unmarried women (below 30) in the group, they have no restrictions on their movements, coming and going as they please but “...it did not start that way and even now, I have to let my parents know where I am...if I am late,” says Amulya, Hindustan Times. She continues, “I know my parents worry more about me than my brother...as I worry more about my mother being out late at work than I would my father. I think it’s so ingrained in us that it is automatic." Further Juhi, $C N N-I B N$ says, "I think my father who is truly the patriarch of the family is worried about my marriage. So he constantly says...'you can do what you want once you get married because this won't work in my house'...because when I am married off, I am no longer his responsibility." Similarly, Diya, Times Now tells me about her "completely equal household where her father and mother work in partnership" but where “...there is a natural concern for her physical safety than her brother.”

Theoretically, such concern for physical safety lies in the scripting of the woman's body as being sexually desirable to the male gaze while simultaneously being vulnerable, aberrant or deserving of violence, depending on the situation. As Wolf has argued about women and modernity, “...the flaneuse [a woman stroller in public] was an impossibility. In part this is so because 'respectable' women simply could not wander around the streets and parks alone...[those who did] could be effectively restricted by the threat of male violence” (Wolf 1985 in Massey 1994:234). 
The expectation of such male violence is the basis for social construction of spatial and temporal propriety, which translate into silvery threads of control and the deeply engrained fear of the outside spaces that were assumed to be inhabited by the Other, in this case the predatory males, the uneducated masses, the migrant rural and semi-urban transplants that brought with them, “...the burden of sexual frustration, lack of cultural progression and really...a certain lawlessness,” according to Alka, Zee News.

The women citizens as is demonstrated in the CNN-IBN-Indian Express-CSDS report survey included in the earlier section keenly feel the lawlessness of urban geography. In the survey, one out of every two women claimed that they would be hesitant about going to the law in case of a physical attack. As Diya, Times Now states, "The average police constable is a less educated rural chap who most likely thinks that women who venture out of the house deserve everything they get...I mean we do stories that deal with police brutality regularly and I have seen how they treat women...”

The palpable disgust that came through in my interviews with the women with respect to seeking assistance from the police or the courts was disconcerting given that India has an "extensive range of pro-woman legislation” (Sen 2000:43). But as Agnes points out, "If oppression could be tackled by passing laws, then this decade would have be adjudged a golden period for Indian women...Almost every single campaign against violence on women resulted in new legislation” (Agnes 1992 in Sen 2000:43). As Dr. Poornima Advani, Chairperson of NCW, said that despite a Supreme Court order, several media organizations have still not set up the committee required to look into cases of sexual harassment. The report claims that some women have learnt to "manage” sexual harassment instead of seeking redress (NCW Report 2004). 
The presence of women-friendly laws means that women fare quite well within the legal process - especially women who have sufficient financial assets to take on court battles. But to invoke law is to invoke the state and law alone cannot effect changes in cultural practices without widespread state intervention (Basu 1999). And the state, “...it ain’t gonna do it” says “Devika”, Aaj Tak, “...look at the hoopla over the women’s reservation bill. The idiot politicians are coming out of the woodwork expressing 'worry and fear' about how it would effect the structure of state politics." According to Anoothi, Times of India, women's rights and laws to protect them are not cohesive. She says, "The legal system is not gender neutral. You have all these judges sitting on the bench who read out these insane judgments...allow a rapist to marry the victim...allowing murderers to go free because the woman they murdered was a bartender (assumed to be morally deficient)...” A report mentioned in Chapter 6 that examined the attitudes of high court judges all over India lends credence to Alka's Zee News, words (UN Report available at http://www.un.org.in/gender/images/VIOLENCEAGAINSTWOMEN.pdf and Kapur 2001).

Add to this the minimal representation of women in the legislature and India Inc. is not quite as attractive for women as portrayed by the cover of Time magazine ${ }^{51}$. According to Aarti, a political correspondent for Aaj Tak, "The fears of the male politicians over women's reservation would be comical but it is such a window into how males in power operate. Some of them are complaining that it will usher in 'elite' women and propped candidates. Elite women?...meaning women without criminal backgrounds

51. http://www.time.com/time/covers/0,16641,20060626,00.html 
and a university degree? And of course, the ever-present caste/religion question. It's nothing but excuses from giving women power.”

According to the Inter-parliamentary Union (IPU) Report, created on the basis of information given by national parliaments on January 31, 2010, India (the largest democracy in the world, with the second largest population of 1.2 billion) ranks $99^{\text {th }}$ in the world out of 187 countries, for its presence of women in parliament. After the election in April, 2009, women held 59 seats out of 545 seats or 10.8 percent in the lower house or the Lok Sabha while the July 2008 elections saw 21 women in 233 seats or 9 percent in the upper house or the Rajya Sabha (IPU Report 2010 52). According to Aarti, Aaj Tak, "Sab number game hai (It's all a number game). I have forgotten and now given up trying to convince my producers to sketch out programming that deals with issues of women and children...not sexy ones but for women out on the roads everyday. But no no...no one wants to see them.” Further conversations with the different women, all working in capacities ranging from junior correspondent to senior editorial consultant, appear to buy into the numbers game. As women move up the ladder and become producers of news programming, implying substantial power in shaping content, especially within the English language press, the innate status quo of the system seems to persist. The 2004 NCW report on the media shows that while English language press get a better deal in terms of salaries, job security, facilities and choice of assignments ${ }^{53}$ as opposed to the regional press, sexual harassment remains rampant in both. About 22

\section{2. http://www.ipu.org/wmn-e/classif.htm}

53. This differential treatment is apparent even when the same management brings out both the English and local language daily (NCW Report 2004). 
percent of the 410 respondents said they had been sexually harassed but only 15 percent made a formal complaint. A significant 40 percent said they did not complain because the issue is not taken seriously or that they would be seen as over-reacting to a situation (NCW Report 2004).

Given this mindset of 'not rocking the boat', it is hardly surprising that the content and meaning of programming, whether news or entertainment rarely appears path breaking. After all, as Hall (1978) indicates, the mass media is a powerful tool of controlling dominant ideologies. Such homogenizing machines whose primary purpose is to generate profit rather than societal change is hardly going to allow alternate mindsets that are detrimental to the core of globalization. The structure of gendered power within the media houses persists with women being complicit, consciously or sub-consciously. As Shikha, Times of India says, "The few women who rise to the top...get absorbed in the system. If you want to play with the boys...you have to become one of them. And the boys network demands that you protect the structure...the inner secrets otherwise out you go.” In other words, the women largely operated within the power structures with the awareness that the system was lopsided in favor of certain hegemonic masculinities. Yet they were moving up the professional ladder not just on the basis of their skill set and experiences but also by negotiating, embracing and disarming the gendered structures of power. The HUMM women's interaction with gendered structures, whether at work, within public spaces where they seek stories or private spaces where they seek rest are marked by individual stories of engagement and distancing. They see the disassembling of discriminating institutions resting in chipping away at individual levels rather than through organized mass movements against “the boy’s club” (Shikha, Times of India). 
One exception to gendered media organizations that I was given access to is the magazine, Tehelka. Walking into their congested first floor office in the middle of a posh neighborhood, I found the shabbiness of the interiors strikingly different from the uber modern steel and glass media floors of the other media offices I had visited. The lack of interior decoration 'fashion-forwardness' indicated, indeed screamed individuality. According to Nisha, Tehelka, "The structure here is much less hierarchical and the open door policy means that we can walk in with our ideas and as long as we can execute them...we are good to go. One of our first requirements is to go out into the field. There is no armchair reporting...no gender basis for assignments. You come up with the idea and you go...to the tribal areas...to riot torn zones...no restrictions.” A look at the Tehelka staff tells an interesting story wherein there is no strict gendering of beats or stories published.

The Tehelka case is an anomaly. The statistics show that women in the media, as much as they outnumber the men, continue to largely remain out of positions of decisionmaking power. The system has its "tokens" and "queen bees", who "want to retain their exclusive positions and sometimes are just plain mean” says Neha, $T V$ Today, “...The frustration of women in such a system often results in [horizontal] violence, with women attacking each other. They need to be more supportive and less seeking of male approval.” When asked if there is a difference in perception between male competitiveness and female competitiveness, she says, "There has to be. I mean men are competing in a system that allows them certain equality. Women are not. We are in a laden situation and should assist each other.” 
The question of collective empowerment ran through the HUMM women. When I brought this up with a renowned television journalist, who sought anonymity, she laughed, “That's the problem. Men don't help each other. It's a competitive business and the women who get into the media, especially the English media are already privileged. Work, fight like the men do... why the tears? I think the issue of empowerment is about producing profits. And news is business now, Mona. Make them the profit or show them how and you will move up....at least to a certain degree. No holding hands and group support is going to work." So what should women who face the glass ceiling do? She smiled and shook her head, "You tell me...I am facing it right now. The excuses for not letting me get to top dog position are many...no place right now to its too limiting for you...to a few more years. Its all political...its all capital.”

Focusing on media corporate structure, she says, "This is where I am seeking change. More child friendly offices...flexible schedules...stringent anti-discrimination policies and most importantly, creative production...I constantly tell my younger colleagues that [pure] feminist projects will not fly...so dress it up...the medium matters little...the message has to go out. And seriously, as old as that makes me...some of the neophytes are here for the wrong reasons... and perhaps that is indicative of what the news business has become today. When I started out...news was down and dirty...today it's all polished and pretty.” Her sentiments are strongly supported by other senior news professionals. Alka, Zee News says, "When I started out, I was one of very few. Look around today and there are more women than men. But structurally, women still drop out or slow down...children, families, sometimes sheer laziness. Glamour is very enticing.” 
The feminist historian, Joan Scott (1998) alluded to "the politics of knowledge production" (Scott 1998:236). So even as globalization allows powerful media houses to enter the air space, mind space and home space of India, it continues to produce gendered “social consensus about the meanings of truth” (Scott 1998:680). It appears that glamour is seen as being the goal, the cornerstone of success. The powerful sensation of being recognized as a celebrity, the concept of ' 15 minutes of fame' has overtaken the news brigade, according to the more experienced HUMM women. While women journalists make great strides, there is a consensus within the women interviewed that serious newsgathering is still dominated by men.

This social consensus largely continues to see men's action (in this case, as aggressive news gathering about 'important' issues) as norm, “representative of human history”, while women's actions (in this case, news gathering seen as 'fluff stuff') is overlooked, or consigned to a less important, particularized arena” (Scott 1998, 242). As Aarti, Aaj Tak, says "Sometimes the minute a minister or political persona sees me asking a question, its almost as if the issue is minimized. I mean a woman asking a question about the serious business of politics is seen as lessening the issue.”

The characterization falls squarely in the paradigm of the Hindu activists. Even as the media women constantly scoff at the impact of religious figures of authority, they are still caught in the quagmires of masculinist nationalist ideology that operated through the fiction of equal citizenship and the right to justice. The space of the Indian nation often acts as "an extension of family, caste, and community structures and defines women as belonging in the same way as their structures” (Sen 2000:3). Ram, RSS and Asha, a member of the RSS is singularly persistent on their idea that women within Hindu 
households are seen as Goddesses. If they acted as Goddesses, then they would be revered, protected and worshipped. "Hum isiliye to beti ko devi maante hai (That's why we consider a daughter the incarnate of a Goddess)" says Asha. And if they fall out of such constructs, then she deserves and is asking for every form of discrimination and violence therefore needs to be guarded "for her own good" (Asha, $R S S$ ).

An outstanding example of this securitization centered around the 1996 Miss World pageant in Bangalore, which saw the mobilization over a two-month period of 12,500 police and paramilitary personnel from city, state, and central security forces, the largest use of state power to help what was essentially a multinational, private, commercial venture to fend off widespread protests from a diverse array of political organizations (Lukose 2005). Right wing Hindutva women’s groups protested the importation of a decadent Western culture that would undermine the tenets of Hindustan. In the words of Premila Nesargi, a lawyer and member of the right wing political party, the $B J P$, "There is only one common culture of Indians, irrespective of caste, creed, and sex. Our culture cannot be taken away by others. In India women are not meant to be sold. Women are not treated as a commodity available for sale in the bazaar. If she sells herself, either her flesh, or body or beauty, she is offending every law in India. Commodifying a woman is wrong” (Lukose 2005:922).

And yet women's bodies are regularly commodified by a majority of social institutions, as bearers of culture, as bearers of modernity. Ironically, they are regularly reduced to token currency for the furtherance of ideologies. And usually such currency operates on the notion of normative versus deviant because most institutions, whether familial or corporate actively divide women, on the basis of caste, class, looks and skin 
color so as to prevent the formation of any primary collective that could potentially challenge the existing status quo. Isolation of women from each other allows masculinist organizations to speak and make decisions for women's lives. "Nandita", NDTV remembers a few attempts that were made to create media women's support groups that cut across electronic and paper media but was told to "not stir the waters because it was being seen as an effort to unionize. That was the end of it.”

The figures of authority: whether the male head of the household, the hypermasculinized men on the roads or the camouflaged co-worker in the workplace, constantly adjust their reins of control to suit the purpose of capital and national identity. Even as India Inc. becomes the default imagery setting for globalizing India, the statistics of crime, education and employment, the feminist studies of the legal and political systems and my own research shows that gendered power structures are sheathed in a satin glove adorned with feminized beading but the core of it still demands that women "be less, be quiet, be a part or be dead" (“Nandita”, NDTV).

\subsection{Gaze of the Researcher}

"Nandita's" words of "be less, be quiet..." echoed in my head as I sat in my car at a traffic crossing in Delhi, instructing my driver to keep his calm. A man in another car, who appeared to be his 30s, well groomed and seemingly educated had attempted to cut through the red light and had been blocked by my car. As he yelled at my driver, I told him to “...relax...the light's going to turn in about a minute. No point killing yourself or someone else.” To this he responded by saying, "You are a whore.” As I sat there speechless at the response, I saw a piece of life that Amulya, Hindustan Times, had called “daily encounters”. While the stranger’s words were shocking, what struck me was the 
ease, impunity and loudness with which they were said. As the words echoed on the dusty road, people in other vehicles, either looked away or laughed. Collecting my thoughts, I responded to the slur, attempting to put the man in his place. This resulted in him following me to my home. As I related the conversation to my friends, their response shocked me further. While their words were couched in concern, the message reflected “Nandita's” words, "be less, be quiet, be a part or be dead” (“Nandita”, NDTV).

Jagori (Women, wake up), a Delhi-based women’s organization launched a 'Safe Delhi' drive in response to increasing harassment of women on the roads of the city. In their report, Safe in the City, they found that over 80 percent of the 500 women interviewed had faced harassment in public transportation while 62 percent had been harassed on the roadside (http://jagori.org/wp-content/uploads/2009/02/is-this-ourcity.pdf). They ran safety audits based on a method established in Toronto in the 1980s that surveyed urban landscapes to determine zones of safety-danger for women as they went about their daily public life. They examined the state of the built environment (streetlights, pavements, bus stops, availability and condition of public toilets, maintenance of parks, obstructions caused by overgrown trees and bushes, parking lots among others); the location of police booths, shops, public telephones and roadside vendors; and the demarcation of space based on temporal-gender lines (spaces around cigarette, liquor and auto vendors was masculinized as were parks after dark while grocery stores, vegetable vendors etceteras were more women-friendly spaces) (Jagori Report found on their Website www.jagori.org). Creating maps of different areas of Delhi, they found that little thought has been given to planning a gender-safe city. This reiterates the idea that women often think of themselves as being illegitimate users of 
public space, which is seen as belonging symbolically and physically to men (Andrew in Miranne and Young 2000).

Taking a cue from the Jagori safety audit ${ }^{54}$, I did a walk around with Shikha, Times of India in the privileged South Delhi neighborhood of Greater Kailash I (GK I) at $10 \mathrm{am}$ and then again, at $10 \mathrm{pm}$, for a period of half-hour. The differences were undeniable. Briefly, GK I is a mixed use upper middle class colony that houses two major upscale markets. The houses vary in size and largely share common boundary walls. With the exception of the main road, the neighborhood roads are narrow and require skilled driving especially since it is home to multiple street vendors who use thela gadis (push carts) to hawk their products. The population is reflective of the city, with a majority Hindu-Punjabi population residing in largely nuclear families or in joint families that reside on different floors within the same house.

Walking through the streets with Shikha, I measured the following factors:

Table 5: Safety Audit of a South Delhi Neighborhood

\begin{tabular}{|l|l|l|l|}
\hline & Elements & $10 \mathrm{am}$ & $10 \mathrm{pm}$ \\
\hline 1. & Urban environment & Multiple & Few pedestrians and \\
\hline
\end{tabular}

54. The Jagori Report found that the following factors made Delhi unsafe:

- Poor urban environment - dark or badly lighted streets, derelict parks and empty lots, badly maintained public spaces, inadequate signage, lack of public toilets.

- Empty streets at night because of early closing of shops and businesses or lack of a tradition of street life.

- $\quad$ Poor public transport and rude/unhelpful/abusive behavior of bus drivers and conductors.

- Insufficient presence and unresponsive/aggressive attitudes of police and civic authorities.

- Isolation from neighbors and lack of community life.

- Traditional notions of privacy and refusal of police/police to intervene in situations of domestic violence.

- Ideas and beliefs about appropriate behavior, leading to reluctance to protest in cases of public violence.

- A ‘macho' culture and a lack of respect for women and women's rights, leading to cases of violence being ignored or trivialised by the general public as well as those in positions of authority. 


\begin{tabular}{|c|c|c|c|}
\hline & & $\begin{array}{l}\text { pedestrians, cars, } \\
\text { open stores, } \\
\text { vendors setting up, } \\
\text { semi-full car parks }\end{array}$ & $\begin{array}{l}\text { cars (a few cars } \\
\text { slowed down as we } \\
\text { walked on the } \\
\text { pavement, creating } \\
\text { anxiety), closed stores } \\
\text { and few vendors } \\
\text { (cigarette vendor, ice } \\
\text { cream push cart), } \\
\text { largely empty car } \\
\text { parks }\end{array}$ \\
\hline 2. & $\begin{array}{l}\text { Signage (Indicating directions, } \\
\text { name of streets etceteras) }\end{array}$ & $\begin{array}{l}\text { Confusing signage } \\
\text { for a non-resident } \\
\text { but presence of } \\
\text { people made it easy } \\
\text { to find addresses. }\end{array}$ & $\begin{array}{l}\text { Lack of pedestrians } \\
\text { made it difficult to } \\
\text { find addresses, which } \\
\text { was further } \\
\text { exacerbated because } \\
\text { of poor lighting }\end{array}$ \\
\hline 3. & Police presence & $\begin{array}{l}\text { Four police vans } \\
\text { sighted along with } \\
\text { police presence in } \\
\text { booths near the } \\
\text { market. }\end{array}$ & $\begin{array}{l}\text { One police van } \\
\text { sighted and the police } \\
\text { booth was empty. }\end{array}$ \\
\hline 4. & Access to neighbors & $\begin{array}{l}\text { Immediate and } \\
\text { constant. }\end{array}$ & $\begin{array}{l}\text { Difficult because of } \\
\text { lack of regular } \\
\text { interaction/community } \\
\text { life. }\end{array}$ \\
\hline 5. & $\begin{array}{l}\text { Public transportation (Not used } \\
\text { but observed from the street) }\end{array}$ & $\begin{array}{l}\text { Packed to excess } \\
\text { with men hanging } \\
\text { from the doors. }\end{array}$ & $\begin{array}{l}\text { Largely empty with a } \\
\text { few travelers, the } \\
\text { driver and conductor }\end{array}$ \\
\hline 6. & $\begin{array}{l}\text { Attitude from other } \\
\text { pedestrians/drivers occupying the } \\
\text { same public space }\end{array}$ & Balanced & $\begin{array}{l}\text { There was staring, } \\
\text { slowing down of cars, } \\
\text { some measure of } \\
\text { increased aggression } \\
\text { as men walked past. }\end{array}$ \\
\hline 7. & Gender presence & $\begin{array}{l}\text { Men and women } \\
\text { present in equal } \\
\text { numbers. }\end{array}$ & $\begin{array}{l}90 \text { percent of } \\
\text { pedestrians } \\
\text { encountered were } \\
\text { men. }\end{array}$ \\
\hline
\end{tabular}

My safety audit helped me better analyze my primary data collected through my conversations with the media women, especially in the issues of safety and security. In my conversations, there was a certain degree of normalization of daily violence, a 
numbing of anger along with a sense of separation from the issue based on class. Most of the women drove their own cars or had chauffeurs. Working late or traveling late did not require them to depend on public transportation. At worst, they would take auto rickshaws or taxis. Answering questions about dealing with harassment on the roads or being followed in their cars, the women largely claimed one of two responses: ignore the perpetrators or confront them. "I slip into my crispest English,” said Diya, Times Now, “... it seems to work. The colonial hangover of being addressed by a 'memsaab', I guess.” Not one of them had ever sought intervention from the police. With each woman claiming a minimum of two events a week of physical harassment (touching, leaning or obscene gestures) even within relatively safe spaces, the lack of police reportage indicates a high degree of distrust of the authorities as well as a sense of non-conscious ennui. My research supports the findings of scholars who concur that crime statistics are not reliable sources for reality especially when it comes to forming policies given the under-reportage of gender-based crime (Vishwanath and Mehrotra 2007 and Femmes et Villes International Reports).

Similarly, the statistics on workplace harassment indicates the under-reportage. According to a Times of India report in 2008, the National Commission for Women registered sixty cases of harassment over three years in New Delhi (October 21, 2008, Times of India). "That is laughable” says Shikha, Times of India, "I think they are many multiples of that. I can tell you now that you will find no numbers within the media business. Yet I hear so many stories. Some women lose out and others make out to go up." Similarly, Shobita, Outlook says, "I hear stories all the time. The thing is that sex is no longer taboo...there are a dozen extramarital relationships going on that I know of. 
But they are mutual. And the ones that are not...either the woman moves...or she gets slandered. Gossip is rampant but there are no actual figures.”

This normalization of violence in non-war environments appears to have numbed the 'media nose'. When I asked them about featuring stories/programming that highlight the problem of violence, especially public, there was a sense of 'been there, done that'. As Neha, Aaj Tak says, “I have done stories on women’s safety but they usually follow a heinous crime story and then the issue fades away in public memory so we move on to something else.” When I push further to ask why there is little analysis or follow up, Neha says, "There are many problems. We are competing for eyeballs so in-depth can sometimes become 'boring'. Also there are deadline pressures so sometimes the bare facts without any background are presented. We are much more about the event rather than the process."

As Parekh (2001) finds that there are certain news subjects like domestic violence, rape, dowry deaths, laws on inheritance, divorce and maintenance, sexual harassment, sexual abuse, lack of access to education and health services, police cruelty, and reproductive rights, rarely do well unless it is sensational and high profile (Parekh 2001).

I was also interested in the understanding of what constitutes "women's issues" within the media women's understanding. Interestingly, while all of them denied the categorization, the women largely talked about fashion, home, health, education, entertainment and gender-based crimes. Much like Parekh (2001), I found that the media focuses on sensation while ignoring non-celebrity/non high-profile but socioeconomically important stories completely or at best relegating them to obscure 
pages/blink and it's gone sections of the news. The media tend to focus on women only when it comes to the above mentioned "women's issues," while "forgetting that women also have an equal stake in so-called "male concerns" such as the budget, economy, globalization, agriculture and conflict resolution” (Parekh 2001 for Nieman Foundation for Journalism at Harvard University ${ }^{55}$.

The questions about gendering, empowerment and content-generation brought an interesting insight from Amulya, Hindustan Times. Sitting in an upscale chocolatethemed restaurant, Amulya was critical of my question. She asked me if I would have the same question for a male journalist. I told her I would, give they are part of the same corporate-fourth estate structure that she belonged to. I added that given the present trend, the possibility is a male writer progressing faster within the profession is more likely though not a certainty. The twenty-seven year old op-ed editor continued to be skeptical and said, “Should we continue the trend of women’s news and men’s news? I mean would it not be better to write news as a gender-neutral entity?” When I asked her what gender-neutral meant, she said, “News that is important for the readers-listeners.” A fresh perspective is required to understand the impact of news structure and presentation. My interviews generated responses that I wanted to deny because there seemed an unquestioned embracing of certain tenets of capitalism/globalization while the inherent nature of systemic gendering was reduced to being an element of the past, attempting to be resurrected through the tenets of nationalism. As Parekh (2001) finds, women journalists, especially those in the upper echelons or aspiring to be, have become conditioned (both socially and through the competitiveness of this profession) to adopt

55. http://www.nieman.harvard.edu/reportsitem.aspx?id=101614 
masculine attitudes and global values (Parekh 2001). They embrace the core norms of globalization and produce stories that are deemed appropriate for a mass audience that has to be trained to be 'correct' consumer-citizens. Therefore, given the inherent structure of globalization, she finds that most "mainstream" stories have a masculinist perspective, which is not surprising since majority of the experts on news panels are male.

Even as the media landscape is marked by female staff reporters and sub-editors, senior editors (including political and financial editors), chief reporters, chiefs of bureaus, special and foreign correspondents, business journalists, sports reporters and columnists as well as sports journalists and camerawomen, not a single mainstream newspaper or news channel has a women chief editor. The two women who are at the top - Shobhana Bhartia (managing editor of The Hindustan Times) and Malini Parthasarathy (executive editor of The Hindu)—both belong to the families that own the newspapers. As Parekh states while they are both extraordinary professionals, it seems improbable that they would have risen to the position without their family connections. The fact that both women do not have brothers is also telling (Parekh 2001).

Focusing on questions of gendering within the corporate structures, a few of my respondents defended the lack of women at the top saying that women joined the profession much later than men since the first batch of women entered the profession in the 1960s—and took to covering politics even later. Yet I found that a substantial number of men at the top of the ladder, the chief editors are younger than many well-established, well-respected senior women journalists.

The older respondents (above 40) who have confronted or are presently confronting the glass ceiling more closely scoffed at the "thinning of the glass ceiling" 
(Amulya, Hindustan Times). Alka, Zee News said, "Long long way to go. And I think the problem is not just with men wanting to lose power...it is the system that demands constant gratification in terms of returns. Most women have too much on their plate to focus on one aspect and that is what is needed to get to the top and then remain there. I stepped down when the responsibilities got too much. I could not get home in time to my daughter who was getting to the age where she needed her mother. So I became a consultant...my terms...better pay...more flexibility. Lesser power but then I made the choice and then structured my contract. I think that is power.”

At the same time, there appears to be distinct empowerment in terms of personal choices. For instance, Shikha, Times of India reveled in her ability to walk out of her marriage when it started to fall apart. "I think knowing people in the industry, many of whom have gone through divorces made it easier for me. I knew the judging would not be constant and debilitating....at least not as much as in my marriage. And I think that has to do with women becoming more able to take care of themselves without a man...being able to walk out...well in groups anyway...to a bar...own a home...work late.”

The notion of independence, irrespective of gender, was a continuing thread in my conversations with the women. Each one of the women said that they had complete control over their finances. They invested on their own and spent without seeking permission from the oldest male in the family, be it father, husband or father-in-law. They saw themselves, as being empowered though not necessarily feminists. Feminism as a personal ideology was repeatedly disclaimed with it being defined variously as “dangerous”, "mere words” and "inapplicable in the Indian scenario.” The women were 
constantly battling with gendered power structures and adapting to them so as to create spaces of empowerment, progress and fulfillment for themselves and their families.

As I spoke to the women and their "patriarchal bargains” (Kandiyoti 1988), it made me realize that each of these women were aware of the gendering that marked their lives and yet even as they are being constantly circumscribed by various mechanisms of control, old and new, they are drawing a larger circle around themselves, sometimes over-writing the existing boundaries.

\section{Conclusion}

Irrespective of the different interview sites, whether a living room, a restaurant, an office or a car, I noted two common variables of behavior. First, the need for privacy while remaining within a crowded (therefore, safe) space; and second, certain wariness about being the interviewee instead of the interviewer. Gracious without exception, the HUMM women did not shed their professional role through the interview, asking me questions about my beliefs and understanding. As I closely observed the HUMM women, I noticed that there was a strong awareness of the surroundings, a constant sweeping of the eyes and cocking of heads. As I analyzed their words and their varied body language, I saw emerging patterns of behavior/actions that are impacted by the need for security and empowerment.

Collating the summaries from each point of the gaze triad, my research delineated the following trends:

1. There is a constant reiteration of varied versions of masculine control over women's bodies and its relation with security. Whether globalization has presented opportunities for women to work or the Hindutva Brigade projects a 
progressive demeanor towards incorporating women in the public, the safetysecurity of the woman remains tied to toeing invisible lines of acceptable 'Indian' behavior.

2. There is a strong majority antipathy to the concept of feminism and the title of a feminist within the HUMM women. While they embrace the tenets of globalization, simultaneously they reject feminism as being abrasive, homogenizing and foreign.

3. Even as they reject Hindu nationalism and the specific form of masculine domination associated with it, there is little effort to actually problematize and even tackle this form of masculine domination by this group of privileged, empowered women with the tools to reach the vast Indian populace. The confrontation with masculine control is largely seen as being individual projects of contestations and negotiations.

4. Similarly, safety-security issues are tackled at the individual level through careful planning of movements and disciplined timing.

5. The HUMM women attributed their professionalism to a mixed ball of globalization standards and civilizational advantages. While the women showed great tenacity in establishing their credentials and professional abilities there appears little agency when the women are discriminated against in 'personal' issues of maternity leave, pay rise etc.

6. Finally, there is a distinct sense of class separation awareness, especially when it came to the impact of globalization. The HUMM women acknowledged they had 
reaped enormous advantages from its processes and that globalization had emphasized class barriers.

Briefly, nationalistic expectations create the message of good women while globalization 'allows' them to venture into the public albeit demanding strongly gendered demeanors and behaviors. Such expectations have been made largely of the middle class Hindu women because they as a group feel the maximum impact of any socio-economic institution or process such as globalization and nationalism. While the very rich and the very poor are not directly impacted in terms of social behavior, the middle class are constantly in fear of losing their moral standing and their socio-economic progress. Add to that the nature of media work, which requires long unorthodox hours, constant interaction with the opposite sex as well as traveling and it makes a potent combination for disciplining and constraining the HUMM women. In short, while the ideologies of globalization and Hindu nationalism appears to publicly confront each other, privately both structure require the constant homogenizing of Indian womanhood, especially the HUMM women, to sustain the global face of India Shining. 


\section{CHAPTER VIII}

\section{$\underline{\text { Last Words }}$}

“The media [is] a major cultural and ideological force, standing in a dominant position with respect to the way in which social relations and political problems [are] defined and the production and transformation of popular ideologies in the audiences addressed.”

- Stuart Hall (1996:117)

In my project that examines globalization and nationalism as they play out their ideologies on the bodies and minds of India's diverse population, I specifically chose to focus on the Hindu urban middle class media women primarily because of the crucial cultural-political role the media plays in building the idea of nation. As communication technology swiftly innovates and creates means of widespread message dispersal that has a maximal impact on societal discourse, it is extremely important to examine the role of the HUMM women who are members of the fourth estate, the guards for India's billion plus population. After all, the HUMM women are the producers and consumers of news. And according to Hall, “...the media plays a central role in the circulation and securing of dominant ideological definitions and representations” (Hall 1996:118).

My dissertation is an attempt to understand the 'street-level' reality of gendering, empowerment and change/difference that is continuously occurring within the urban spaces of India, a space that is marked by diversity of populations, ideas and cultures. I sought out this group of media women because they are unquestioningly assumed to be located in privilege, embodying empowerment and modernity. They are seen as members 
of a normative group, middle class Hindu women who define the face of India and Bharat. They are deemed the norm, the ideal.

My chosen subjects, the HUMM women and their bodies are the stage where the question, "What is appropriate behavior for the ideal Indian woman of modern India?" are played out. The analyses of the stories of this group of women help understand the mutating chameleon-like nature of masculine domination in "their cultural, class-specific, and temporal concreteness... [while] reveal[ing] how men and women resist, accommodate, adapt, and conflict with each other over resources, rights and responsibilities” (Kandiyoti 1988:285).

While using the media women’s “narrative identities” (Somers and Gibson, 1995) to understand the structures of power that influence the ways in which women construct their identities, I have tried to avoid the "a relation of structural domination, and a supression—often violent—of the heterogeneity of the subject(s) in question” (Mohanty 1988:61). Instead I find that masculine domination and gendered hierarchies impose symbolic violence (Bourdieu 2001) as well as latent violence not by remain rooted universal structures but rather by mutating and camouflaging. As the women tell their stories, there is an inherent presence of gendered hierarchies that rests on specific and selective use of different forms and degrees of masculine domination. And what I found within these narratives are stories of exception, scripts imbued with contradictions, individuals who variously challenge hegemonic constructions of an ideal Indian womanhood that resides within specific parameters of modernity and respectability while continuing to strategize "in the context of identifiable patriarchal bargains that act as 
implicit scripts that define, limit, and inflect their market and domestic options” (Kandiyoti 1988:285).

The ideal Hindu middle class woman's identity is regularly defined in terms of “cherished but remote icons” (Sarkar, 1995: 206-207) that are "simple, home-loving and compromising” (Puri 2003:22). In a country that is marked with diversities, the "traditional characteristics" as well as "feminine characteristics" that are used to define Indian womanhood, not only constrict women but these imaginaries are also used to homogenize their private and public personas. At the same times, these constructs are used to further national, political and defense policies. As Das finds such "imageries" guided by the religious/cultural lenses of Hindutva enables the Hindu right to justify a nuclear agenda by extending Hindu women’s insecurities from the "familial to extra/nonfamilial” sphere (Das 2002:80). In such homogenization lies the suppression of alternative femininities so as to maintain the hegemony of conventional forms of femininity (Cheng 1999). And conventional forms of femininity that center on subordination to specific threads of masculine domination is an "emphasized femininity, a kind of gender performance that accommodates hegemonic masculine interests and desires while preventing other femininities from gaining cultural articulation” (Connell 1987:183 in Cheng 1999).

But my research finds that such conventional forms of femininities are not accepted or rejected in their entirety by the HUMM women. While Nanda’s (2010) work finds a burgeoning acceptance of religiosity within the Hindu middle class who she claims are embracing homogenized Hindu religious signs, symbols and traditional social order, the HUMM women actively distance themselves from such 'traditional' ideology 
as being archaic and out-of-step. The HUMM women invoke Althusser's understanding of society and ideology as they blamed age-old rooted notions of Hindustan and Bharatiya Nari (traditional Indian woman) for the continuation of male domination and male advantageous structures.

At the same time, the extremely confident and outspoken HUMM women are very aware of deeply rooted gendered constructs of the political-judicial system. They see the implications of traditional expectations within their globalized workspace and are constantly negotiating with, absorbing from and rejecting such gendered hierarchies. My research indicated that the degree of the fallout from challenging the system influences how the women negotiate with hurdles within their lived spaces. For instance, sexual harassment within the office, home or public space was dealt with in a 'hushed' manner. Institutional authority, whether the police or anti-harassment work policies, are rarely activated, invoking images of “docile women” (Foucault 1980). Instead the women chose to bargain at individual levels, gaining strength from their personal alliances with the hierarchy (Kandiyoti 1988).

Radhakrishnan’s (2008) work on women IT workers in Bangalore, India and Silicon Valley, USA as well as Lukose’s (2005) work on globalization, youth and gender in Kerala, India finds similar gendered discourses that stringently enforce traditional family values/piety/respectability while encouraging ideas of global Indianness, that rested on largely on education, technology and innovation.

But while Radhakrishnan (2008) finds that the IT women, specially in the diaspora have embraced their 'global' Indian identity derived from the ideology of 
Hindutva, which is strongly supported financially and symbolically by non-resident Indians, the HUMM women have rejected the same markers. I found that the women saw religious nationalism as being the backbone that supports structures of masculine domination within their homes, offices and public space, where specific roles and responsibilities are pre-determined because it was unquestionably 'natural.' Instead the HUMM women identify Indianness with modernity and progressiveness that are tools to slowly and strategically dismantle structures of male domination. As a group, the women showed an unfettered acceptance of globalization, both economic and cultural claiming that India's entrance into the global economy had expanded their personal and professional choices.

At the same time, I found within the HUMM women, an embracing of selective markers, what Nanda calls "civilizational advantage” that was coded in terms of spirituality, history and antiquity (Nanda 2010:34). With claims of "India Rising”, “India Shining”, the HUMM women were categorical that India's rise as an economic and political power was inevitable and their own supportive roles in this emergence.

It was also very evident that the absolute embracing of class-specific globalization led to enormous reluctance about deconstructing those institutions that are inherently gendered in nature, whether media corporations, the justice system or the transportation department, especially when it concerned what they considered personal issues (sexual harassment, maternity benefits, promotions, pay raise, domestic violence). This ingrained desire to avoid confrontation has created what Wright (2006) has called the "disposable woman,” who can be easily denied her rights and in some cases, dismissed. And the 
causes for dismissal such as difficult pregnancies, as Radhakrishnan (2008) also finds, are rarely challenged. This can be explained by rooted beliefs that most women of the middle class work to "indulge themselves... and therefore, the money earned is supplemental to the family income” (Radhakrishnan 2008:44). Yet many of them took great pride in telling me stories where they had confronted discriminatory attitudes while attempting to get stories or leads. "Professional” and "strong work ethics” were often used as selfdescriptors.

I find that the different approaches towards personal and professional confrontations within the HUMM women lies in how ideological messages have shaped “...their gendered subjectivity, since they permeate the context of their early socialization, as well as their adult cultural milieu” (Kandiyoti 1988: 285). At the 'personal' level, there remains an ingrained sense of passivity and fear of repercussions while at the professional level, the HUMM women interpret and use the text of globalization that has provided them with career opportunities in terms of empowerment and agency. The respondents largely agreed that application of the policies varied at an individual level and was dependent on the relationship with the boss.

My analysis also found a marked difference in perceptions about gendered institutions within the interviewed group, with the older women being more aware and willing to accept such presence within their work and home spaces/choices. The younger women, while acceding to such presence and its impact on their lives were less willing to give gendering as much import, placing it as individual encounters and circumstances rather than a structural inherent presence. Irrespective of depth of acceptance, it is 
obvious that such lack of transparency and equal application makes the HUMM women vulnerable to harassment and unfair practices.

These different forms of negotiating and strategizing with gendered hierarchies, what Kandiyoti (1988) calls "patriarchal bargains” were largely embraced by the HUMM women as being more effective as tools of balance as opposed to direct confrontation. According to Lukose (2005), there is a similar form of negotiation within the Malayali (Kerala state) beauty contest where young women contestants are given the opportunity to make great individual strides as long as they embrace a hegemonic Kerala femininity that is structured by upper-caste middle class imagination.

Similarly, Dewey (2008) finds that the participants of the Miss India contest, who are largely urban, English speaking women have to fit certain physical and cultural standards as the object of desire for masculine spectators (Mulvey 1975). In return for such objectification that occurs under stringent surveillance, she becomes a disciplined useful body that is a symbol of emancipated India, much like the HUMM women.

The same male gaze that shapes programming whether on stage, on television or on newspaper pages also becomes the source of moral panic for traditionalists in India. Shielding and protecting objectified women's bodies from an aberrant male gaze has incited laws and policies that are discriminatory and largely unquestioned. This moral panic defined as “.... a threat to societal values and interests, which is characterized by stylized and stereotypical representation by the mass media, and a tendency for those in power (politicians, bishops, editors etc.) to man moral barricades and pronounce judgment” (Hall et al. 1978:58). Authority figures and institutions, irrespective of 
ideology continue to reiterate the message that a body that is sexed female is vulnerable to physical and sexual violence. The correlation between violence and the female body is consistent in such rhetoric, irrespective of education, employment and class.

The pervasiveness of gendered violence and the minimal expectation of repercussions against such rights abuse are demonstrated by the tired acceptance of daily violence encountered by women. The normalization of regularly encountered violence by this relatively privileged group that largely travels in personal cars and rarely in public or semi-public transportation (auto rickshaws and taxis) and a strong pattern of underreporting of workplace harassment within the media strongly indicates that being safe is seen as an individual endeavor. Becoming a victim of violence is seen as a personal weakness, bad planning or bad timing rather than a failure of the state-society structure.

And such messages are constantly reiterated by the mass media. Whether it is through the imitation of Indian soap opera themes and characterization or the general presentation of news and news professionals, the preoccupation is with the construction and dispersal of common sense knowledge that privilege and normalizes specific representations of gender, womanhood and malehood (Hall 1996). With the media pushing certain dominant ideologies, "a representation of the imaginary relationships of individuals to their real conditions of existence” (Heck in Hall 1998:122), the delivery of idealized womanhood strengthens gendered expectations within the viewing population.

The media professionals were strongly aware of the gendered content and presentation of both news programming as well entertainment products. Yet they sharply distanced themselves from any homogenized rendering of 'woman as victim', 'woman as 
servile' or 'woman as less', even if they were complicit in its production. They strongly demonstrated Hall's (1973) margin of understanding wherein the HUMM women squarely rested the production of homogenized women-unfriendly material as inherently separate from their own location as empowered women. Instead, they saw it as being professional and following orders from largely male editorial boards who were chasing TRPs and advertising money. Having embraced the text of globalization, they are in the powerful position of replicating the message, becoming encoders, 'being made' into champions of the global media. They see themselves as empowered women who seeks high TRPs, advertising revenues and delivering breaking news at any cost.

There was also a strong sense of distinction within the group where they recognized that they were culturally and economically privileged urban women, separate from other women who inhabited their physical space but whose lives were marked by different, perhaps more violent and definitely more rigid structures of gendered hierarchies. And it was for this majoritarian group who kept the TRPs high for anachronistic programming that the HUMM women were creating media products.

Even as they distanced themselves from traditional roles and language, the HUMM women continue to face extensive gendering within their workspace, with news beats being defined in terms of masculine and feminine. I found an interesting juxtaposition within this group of women, wherein the largely more experienced group of professionals saw certain newsbeats as being masculine and wielding higher power and prestige while the women with relatively lesser experience questioned the division of news beats based on gender. In my observation of programming as well as the physical space of the news corporations, I saw a distinct divide. The political, crime, sports, 
security and disaster/violence beats, the editorial boards and the technical staff (editors, camerapersons) were largely male whereas what is called the infotainment section (Bollywood, music, fashion, social events), women’s issues, finance and environment had a larger presence of women. While this divide does not demand gendering, it does raise questions about promotions, raises and general prestige. With most editorial board members emerging from 'hard' news beats, the division of beats could essentially be the reason behind the low percentage of women in positions of seniority.

And according to the HUMM women, the women professionals in the position of seniority were to be admired because they had used the system to enhance their careers. But the HUMM women acceded that there is distinct tokenism within male dominated institutions wherein political, religious and financial organizations use a handful of women as iconic female presence. Yet such women rarely stray from the delineated path of power brokering while creating hurdles for progress of all women. Whether it is mothers-in-law who remained uneducated because of societal demands or women politicians who herald motherhood as the ultimate feminine identity or powerful media women, who maintain the status quo to retain their own position, such authority figures that use patriarchal bargains become the perfect peons of existing gendered hierarchies.

As I analyzed the different narratives, there emerged a collage that represented the HUMM women in a confusing, distracting hodge-podge of identities. The women saw themselves largely as empowered individuals who portrayed themselves as being conduits of news and entertainment dispersal and not as vessels of change or deconstruction of structural discrimination and in-security. Whether they are managing 
their homes, instructing their children, drinking a margarita in a smoky bar, driving home at night or stalking a newsworthy individual for a story, the HUMM women continue to operate against a backdrop of heterosexist male-led family structure that rests firmly on keeping women, their bodies/wombs and labor circumscribed. Even as small groups of Indian women build admirable careers, control their bank accounts, and become owners of their lives, it is apparent that mutating structures of domination will not be dismantled without constant and sometimes, violent confrontation.

In conclusion, the stories of the HUMM women appear counter-narrative to the norms of default 'Indian femininity' as they embrace the tenets of modernity in their technology, dress and worldview. Yet the strong roots of gendered hierarchies continue to anchor their lives as they maneuver through public and private domains. While this juxtaposition of modernity versus tradition is hardly a new theory, what is most interesting is the perception of these women who are aspiring to new frontiers of professional and personal achievements, who see the shackles of masculine domination resting solely in tradition while the key to empowerment rests on embracing globalization, Indian-style. Therefore gendered spaces are being transformed by globalization and these changes are being actively countered by the ideologies of Hindu nationalism. And the HUMM women who not only occupy these gendered spaces but also work within the media institution that largely operate to disperse such dominant representations are engaged in daily exercises of negotiation/creating and countering these ideologies. 


\section{REFERENCES}

\section{Books}

Afshar, H and Barrientos, S. (Eds). (1999). Women, Globalization and Fragmentation in the Developing World. London: Macmillan.

Agarwal, Purushottam. (1995). "Surat, Savarkar, and Draupadi: Legitimizing Rape as a Political Weapon”. In Women and the Hindu Right: A Collection of Essays. Sarkar, Tanika and Butalia, Urvashi. Eds. New Delhi: Kali. pp: 29-57.

Agnew, Vijay. (1979). Elite Women in Indian Politics. New Delhi: Vikas Publication House.

Ahmed-Ghosh, Huma. (2003). "Writing the Nation on the Beauty Queen's Body Implications for a ‘Hindu’ Nation”. Meridians: feminism, race, transnationalism. pp. 205-227.

Ahmed, Leila. (1992). Women and Gender in Islam: Historical Roots of a Modern Debate. New Haven, C.T.: Yale University Pres.

Altekar, A.S. (1963). The Position of Women in Hindu Civilization: From Prehistoric Times to the Present Day. $3^{\text {rd }}$ Edition. Delhi: Motilal Banarsidass.

Althusser, L. (1970). “Ideology and Ideological State Apparatuses”. In Lenin and Philosophy and other Essays. Monthly Review Press.

Anagol, Padma. (2006). The Emergence of Feminism in India, 1850-1920. Ashgate Publishing.

Anderson, Benedict. 1991. Imagined Communities: Reflections on the Origin and Spread of Nationalism. London: Verseo.

Anderson, John Ward, and Molly Moore. (2000). “The Burden of Womanhood”. In Social Problems of the Modern World: A Reader. Moulder, Frances. Editor. Belmont, CA: Wordsworth. Pp. 92-96.

Andrew. 2000. “Resisting Boundaries?”. In Miranne, K and Young, A (ed.). Gendering the City: Women, Boundaries and Visions of Urban Life. Rowman and Littlefield.

Appadurai, Arjun. (2006). Fear of Small Numbers: An Essay in the Geography of Anger, Durham, NC: Duke University Press.

Appadurai, Arjun. (1996). Modernity at Large: Cultural Dimensions of Globalization. Minneapolis and London: University of Minnesota Press. 
Appelbaum, Richard and Robinson, William, I. (2005). Critical Globalization Studies. Routledge.

Appleby, R. Scott. Almond, Gabriel A. and Sivan, Emmanuel. (2003). Strong Religion: The Rise of Fundamentalisms around the World, Chicago and London: University of Chicago.

Asthana, Pratima. (1974). Women's Movement in India. New Delhi: Vikas Publishing House.

Bagchi, J. (1999). “Women’s Empowerment: Paradigms and Paradoxes”, in Sangari, Kumkum and Chakravarti, Uma. Eds. From Myths to markets: Essays on Gender. New Delhi: Manohar.

Bagchi, Jasodhara. (1995). Indian Women, Myth, and Reality. Hyderabad: Sangam Books.

Bagdikian, Ben H. (2000). The Media Monopoly. Beacon Press.

Bakker, Isabella. (1997). The Strategic Silence: Gender and Economic Policy. Zed Books Limited.

Banerjee, Partha. (1998). In the Belly of the Beast: The Hindu Supremacist RSS and the BJP in India: An Insider's Story. New Delhi: Ajanta Books International.

Banerjee, Sikata. (2005). Make Me a Man!: Masculinity, Hinduism, and Nationalism in India. SUNY Press.

Bannerjee, Sumanta. (1990). "Marginalization of Women's Popular Culture in Nineteenth Century Bengal”. In Recasting Women: Essays in India's Colonial History. Sangari, Kumkum and Vaid, Sudesh. Eds. New Brunswick, NJ: Rutgers University Press, pp. 127-179.

Banet-Weiser, Sarah. (1999). The Most Beautiful Girl in the World: Beauty Pageants and National Identity. University of California Press.

Barthes, Roland. (1972). Mythologies. Trans. Annette Lavers. New York: Noonday Press.

Basham, A.L. (1998). A Cultural History of India. Oxford University Press.

Basu, Srimati. (1999). “Cutting to Size: Property and Gendered Identity in Indian High Courts”. In Signposts: Gender Issues in Post-Independence India. Rajan, Rajeshwari Sunder. Editor. New Delhi: Kali for Women. pp. 277-81. 
Basu, Tapan. Datta, Pradip. Sarkar, Sumit. Sarkar, Tanika. Sen, Sambuddha. (1993). Khaki Shorts and Saffron Flags. Orient Longman.

Basu, Aparna. (1992). “Women’s History in India: An Historiographical Survey”. In Karen Offen, et al. Writing Women's History: International Perspectives. Houndsmill: McMillan, pp. 181-210.

Basu, Amrita. (2005). "The Transformation of Hindu Nationalism: Towards a Reappraisal,” in Francine Frankel et. al. eds., Transforming India, pp. 379-404.

Beneria, Lourdes. (2003). Gender, Development, and Globalization: Economics As If People Mattered. New York: Routledge.

Bhabha, Homi. (1994). The Location of Culture. London and New York: Routledge.

Bhabha, Homi. (1990). "DessemiNation: Time, Narrative, and the Margins of the Modern Nation”. In Nation and Narration. London: Verso.

Bhasin, Kamla and Menon, Ritu. (Eds). (1994). Against All Odds: Essays on Women, Religion, and Development from India and Pakistan.(New Delhi: Kali.

Bhavnani, Kumkum. (1995). "Tracing the Contours: Feminist Research and Feminist Objectivity". In The Dynamics of Race and Gender: Some Feminist Interventions. Maynard, Mary and Afsar, Haleh. (Eds). London: Taylor and Francis. Pp. 26-40.

Bordo, Susan and Jaggar, Alison, M. (1989). Gender/Body/Knowledge: Feminist Reconstructions of Being and Knowing. Rutgers University Press.

Borthwick, Meredith. (1984). The Changing Condition of Women in Bengal: 1850-1905 Princeton: Princeton University Press.

Bose, Sumantra. (1997) "Hindu Nationalism and the Crisis of the Indian State: A Theoretical Perspective," in Sugata Bose and Ayesha Jalal, (Eds.) Nationalism, Democracy and Development: State and Politics in India. New Delhi: Oxford University Press, pp. 104-64.

Bourdieu, Pierre. 2001. Masculine Domination. Stanford University Press.

Bumiller, Elisabeth. (1990). May You Be the Mother of a Hundred Sons: A Journey Among the Women of India. New York: Random House.

Burawoy, Michael et al. (2000). Global Ethnography: Forces, Connections, and Imaginations in a Postmodern World. University of California Press. 
Burton, Antoinette M. (1994). Burden of History: British Feminists, Indian Women, and Imperial Culture 1865-1915. University of North Carolina Press.

Butler, Judith. (1990). Gender Trouble: Feminism and the Subversion of Identity. Taylor and Francis Inc.

Carr, Anne E. and Van Leeuwen, Mary Stewart. (1996) Religion, Feminism, and the Family. Westminster John Knox Press.

Castells, Manuel. (2004). The Power of Identity, Malden, MA: Blackwell.

Chandra, Ramesh and Mittra, Sangh. (2003). Caste System in India. Commonwealth Publishers.

Chandra, Sudhir. (1998). Enslaved Daughters: Colonialism, Law and Women's Rights. New Delhi: Oxford University Press.

Channa, Subhadra Mitra. (1985). Tradition and Rationality in Economic Behaviour. New Delhi: Cosmo.

Chatterjee, Partha. (1993). The Nation and its Fragments: Colonial and Postcolonial Histories. Princeton: Princeton University Press.

Chatterjee, Partha. (1986). Nationalist Thought and the Colonial World: A Derivative Discourse. London: Zed Books.

Chowdhry, Geeta. (2000). "Communalism, Nationalism, and Gender: Bharatiya Janata Party (BJP) and the Hindu Right in India”. In S. Ranchod-Nelson and M.A Tetreault. Eds. Feminist Approaches To Contemporary Debates, pp. 98-118. London: Routledge.

Cohn Bernard, Singer, Milton. (2007). Structure and Change in Indian Society. Aldine Transaction.

Collins, P. H. (2000). Black Feminist Thought: Knowledge, Consciousness, and the Politics of Empowerment. NY: Routledge.

Corbridge, Stuart and Harriss, John (2000). Reinventing India: Liberalization, Hindu Nationalism and Popular Democracy. UK: Polity Press; Malden, MA : Blackwell Press.

Dasgupta, Kalpana. (2003). Women on the Indian Scene: An Annoted Bibliography. New Delhi: Abhinav Publications. 
Davidoff, Leonore and Hall, Catherine. (1987). Family Fortunes: Men and Women of the English Middle Class, 1780-1850. The University of Chicago Press.

de Beauvoir, Simone. (1973). The Second Sex. Vintage Books.

D'Cruze, Shani and Rao, Anupama. (2005).Violence, Vulnerability and Embodiment: Gender and History. Wiley-Blackwell Publishing.

DeKoven, Marianne. (2001). Feminist Locations: Global and Local, Theory and Practice. Rutgers University Press.

Desai, Manisha. (2002). “Transnational Solidarity: Women's Agency, Structural Adjustment and Globalization”. In Women's Activism and Globalization: Linking Local Struggles and Transnational Politics. Naples, Nancy A. and Desai, Manisha, (Eds). New York: Routledge, pp. 15-33.

Dewey, Susan. (2008). Making Miss India Miss World: Constructing Gender, Power and the Nation in Postliberalization India. New York: Syracuse University Press.

Dilip K. Chakrabarti. (2000). Colonial Indology-Sociopolitics of the Ancient Indian Past. Delhi: Munshiram Manoharlal.

Domosh, Mona and Seager, Joni. (2001). Putting Women in Place: Feminist Geographers Make Sense of the World. New York: Guilford Publications.

Donaldson, L.E. (1992). Decolonizing Feminisms: Race, Gender and Empire-Building. Chapel Hill: University of North Carolina Press.

Doniger, Wendy and Zola Emile, Translators. (1991). The Laws of Manu. Penguin Publishers.

Dreze, Jean and Sen, Amartya. (1995). India: Economic Development and Social Opportunity. Oxford: Oxford University Press.

Dube, Leela. (1997). Women and Kinship: Comparative Perspectives on Gender in South and South-East Asia. Tokyo: United Nations University Press.

Duley, Margot and Edwards, Mary. (1986). The Cross-Cultural Study of Women: A Comprehensive Guide. Feminist Press.

Duncan, Nancy. (1996). Bodyspace: Destabilizing Geographies of Gender and Sexuality. Routledge Publications. 
Dutt, Amitava Krishna. (2001). “Consumption, happiness and religion”, in A. K. Dutt and K. Jameson, eds., Crossing the Mainstream: Ethical and Methodological Issues in Economics. Notre Dame: University of Notre Dame Press.

Ehrenreich, Barbara and Hochschild, Arlie Russell. (2003). Global Woman: Nannies, Maids and Sex Workers in the New Economy Granta Books.

Einhorn, B and Yeo, Eileen James (Eds). (1995). Women and Market Societies: Crisis and Opportunity, Aldershot: Edward Elgar.

Enloe, Cynthia. (1989). Bananas, Beaches and Bases: Making Feminist Sense of International Politics. London: Pandora.

Findley, Ellison Banks. (1985). "Gargi at the King’s Court: Women and Philosophic Innovation in Ancient India”. In Women, Religion and Social Change. Yazbeck Haddad, Yvonne and Findley, Ellison Banks (Eds). Albany: State University of New York Press.

Flood, Gavin. (1996). Introduction to Hinduism. Cambridge University Press.

Forbes, Geraldine (Ed.). (1989). Shudha Mazumdar: Memoirs of an Indian Woman. York: Sharpe.

Foucault, M. (1977). Discipline and Punish: The Birth of the Prison, trans. A. Sheridan, Harmondsworth: Peregrine.

Foucault, M. (1978). The History of Sexuality, translated by R. Hurley, Penguin Books.

Foucault, M.. (1980). 'Body/Power' and 'Truth and Power' in C. Gordon (ed.) Michel Foucault: Power/Knowledge, U.K.: Harvester.

Frankel, Francine et al. (2000). Transforming India: Social and Political Dynamics of Democracy, eds. New Delhi: Oxford University Press.

Gedge, Evelyn C., and Mithan Choksi,(Eds). (1999). Women in Modern India: Fifteen Papers by Indian Writers. Bombay: D. P. Taraporevala Sons.

Geetha, V. (2007). Patriarchy, Theorizing Feminism Series. Stree Publications.

Ghurye, Govind Sadashiv. (1996). Caste and Race in India. Edition 5. Popular Prakashan.

Giddens, Anthony (2000) Runaway World. London : Routledge.

Gellner, Ernest. 1983. Nations and Nationalism. Routledge. 
Gokulsing, R. (2004). Soft-soaping India: The World of Indian Televised Soap Operas. Trentham Books.

Golwalkar, M.S. (1980). Bunch of Thoughts. Bangalore: Jagarana Prakashana.

Grant, Rebecca and Newland, Kathleen. (1991). Gender and International Relations. Indiana University Press.

Grewal, I. and C. Kaplan, (Eds). (1994). Scattered Hegemonies: Postmodernity and Transnational Feminist Practices. Minneapolis: University of Minnesota Press.

Grosz, Elizabeth. (2001). Architecture from the Outside: Essays on Virtual and Real Space. Cambridge: MIT Press.

Guha, Ramachandra. (1989). The Unquiet Woods: Ecological Change and Peasant Resistance in the Himalaya. Delhi: Oxford University Press.

Gullestead, Marianne. (1993). "Home Decorations as Popular Culture: Constructing Homes, Gender and Classes in Norway”. In Gendered Anthropology. Del Valle, Teresa. Editor. London, Routledge, pp. 128-160.

Gupta Charu. (2002). Sexuality, Obscenity, Community: Women, Muslims, and the Hindu Public in Colonial India. NY: Palgrave.

Hall, S. (1973) Encoding and Decoding in the Television Discourse. London: Macmillan.

Hall, S., Critcher, C., Jefferson, T., Clarke, J. \& Roberts, B. (1978) Policing the Crisis. London: Macmillan.

Harish, Ranjana and Harishankar, V. Bharathi. (2003). Shakti: Multidisciplinary Perspectives on Women's Empowerment in India. Rawat Publications.

Hawkesworth, Mary E. (2006). Globalization and Feminist Activism. Rowman \& Littlefield Publishers.

Heinz, Carolyn Brown. (1999). Asian Cultural Traditions. Illinois: Waveland Press, Inc.

Hobart, Mark. (Ed.) (1993). An Anthropological Critique of Development: The Growth of Ignorance. London: Routledge.

Holloway, Lewis and Hubbard, Phil. (2001). People and Place: The Extraordinary Geographies of Everyday Life. Prentice Hall. 
Howland, Courtney W. (1999). Religious Fundamentalisms and the Human Rights of Women. NY: St.Martin’s Press.

Hughes, Sarah Shaver, and Brady Hughes. (Eds). 91997). Women in World History: Readings from 1500 to the Present. Vol. 2. Armonk, NY: M.E. Sharpe.

Jaffrelot, Christopher (1996). The Hindu Nationalist Movement in India, New York: Columbia University Press.

Jain, Devaki. (1986). “Gandhian Contributions Toward a Feminist Ethic”. In CrossCultural Perspectives on Women, Religion and Social Change. Diane Eck and Devaki Jain (Eds.). New Delhi: Kali.

Jayawardena, Kumari and De Alwis, Malathi. (Eds). (1996). Embodied Violence: Communalizing Women's Sexuality in South Asia. New Jersey: Zed Publications.

Jayawardena, Kumari. (1986).Feminism and Nationalism in the Third World. New Jersey: Zed Publications.

Jeffrey, P. and Basu, A. (Eds). (1998). Appropriating Gender: Women's Activism and Politicized Religion in South Asia. NY: Routledge.

John, M. (1998). “Globalisation, Sexuality and the Visual Field: Issues and non-issues for cultural critique” In A Question of Silence? The Sexual Economies of Modern India. John, M.E. and Nair, J. New Delhi: Kali for Women.

John Paul Jones III, Heidi J. Nast, Susan M. Roberts. (1997). Thresholds in Feminist Geography: Difference, Methodology, Representation.. Rowman \& Littlefield Publishers, Inc.

Kapadia, Karin. (1995). Siva and Her Sisters: Gender, Caste, and Class in Rural South India. Boulder. Colorado: Westview Press.

Kapoor, J.D. (2002). Laws and Flaws in Marriage . How to Stay Happily Married. Delhi: Konark Publishers.

Karlekar, M. (1991). Voices from Within: Early Personal Narratives of Bengali Women. Delhi: Oxford University Press.

Kasturi, Leela. and Mazumdar, Vina, and Indian Association for Women's Studies. (1994). Women and Indian Nationalism. New Delhi: Vikas Publication House.

Kishwar, Madhu. (1998). Religion at the Service of Nationalism and Other Essays. New Delhi: Oxford. 
Kristeva, Julia. Nations Without Nationalism. (1993). NY: Columbia University Press.

Kumar, Radha. (1995). “From Chipko to Sati: The Contemporary Indian Women's Movement". In The Challenge of Local Feminisms: Women's Movements in Global Perspective. Amrita Basu (Ed.), pp. 58-86. Boulder: Westview Press.

Kumar, Radha. (1993). The History of Doing: An Illustrated Account of Movements for Women's Rights and Feminism in India 1800-1990. New Delhi: Zubaan.

Kumari, Abhilasha and Kidwai Sabina. (1998). Crossing the Sacred Line: Women's Search for Political Power. Orient Blackswan.

Lakha, S. (1999). “The State, Globalization, and the Indian Middle-Class Identity” In Culture and Privilege in Capitalist Asia. Pinches, M. (Ed). London: Routledge.

Lal, Ruby. (2005). Domesticity and Power in the Early Mughal World. Oxford: Cambridge University Press.

Lebra, Joyce, et al. (1984). Women and Work in India: Continuity and Change. New Delhi: Promilla and Company.

Lerner, Gerda. (1993). The Creation of Feminist Consciousness: From the Middle Ages to Eighteen Seventy. Volume II. New York: Oxford University Press.

Leslie, Julia. (1983). "Essence and Existence: Women and Religion in Ancient Indian Text”. In Women's Religious Experience. Totowa: Barnes and Nobles Books.

Liechty, Mark. (2003). Suitably Modern: Making Middle-Class Culture in a New Consumer Society. Princeton: Princeton University Press.

Mankekar, P. (1999). Screening Culture, Viewing Politics: An Ethnography of Television, Womanhood, and Nation in Postcolonial India. Durham: Duke University Press.

Mani. Lata. (1989). "Contentious Traditions: The Debate on Sati in Colonial India”. In Recasting Women. New Brunswick, NJ: Rutgers University Press, pp. 88-126.

Mani, Lata. (1998). Contentious Traditions: The Debate on Sati in Colonial India. Berkeley and Los Angeles: University of California Press.

Massey, Doreen. (1994). “A Global Sense of Place”. In Space, Place and Gender. Minneapolis: University of Minnesota Press.

Mazumdar, Vina. (1976). “The Social Reform Movement in India-From Ranade to 
Nehru.” In Indian Women from Purdah to Modernity. Nanda, B. R. (Ed.). New Delhi: Vikas Publication House, pp. 41-66.

McClintock, A., A. Mufti and E. Shohat (Eds). (1997). Dangerous Liaisons:

Gender, Nation and Postcolonial Perspectives. Minneapolis: University of Minnesota Press.

McQuail, D. (2000). Mass Communication Theory (4th ed.). London: Sage Publications.

Mencher, Joan. (1988). "Women's Work and Poverty: Women's Contribution to Household Maintenance in South India”. In A Home Divided: Women and Income in the World. Dwyer, D. and Bruce, J. (Eds). Stanford: Stanford University Press, pp. 99-120.

Menon, Ritu and Kamla Bhasin. (1998). Borders and Boundaries: Women in India's Partition. New Jersey: Rutgers University Press.

Mies, Maria. (1980). Indian Women and Patriarchy. New Delhi: Concept Publications.

Mies, Maria. (1986). Patriarchy and Accumulation on a World Scale. Zed Books.

Mies, Maria and Shiva, Vandana. Exofeminism. (1993). London: Zed Books.

Misra, Rekha. (1967). Women in Mughal India: 1526-1748. Delhi: Munshiram Manoharlal..

Misra, Amaresh. (2008). The War of Civilizations. Delhi: Rupa Publications.

Moghadam, Valentine, M. (1999). “Gender and the Global Economy”. In Revisioning Gender. M. Ferree, et al. (Eds). Thousand Oaks: Sage.

Moghadam, Valentine M. (1994). Identity Politics and Women: Cultural Reassertions and Feminisms in International Perspective. Boulder: Westview.

Mohanty, Chandra Talpade. (2003). Feminism Without Borders: Decolonizing Theory, Practicing Solidarity. Duke University Press.

Mohanty, Chandra Talpade. (1991). "Under Western Eyes: Feminist Scholarships and Colonial Discourses". In Third World Women and the Politics of Feminism. Chandra Mohanty et al. (Eds). Bloomington: Indiana University Press, pp.51-81.

Moriarty, M. (1991). Roland Barthes. Stanford University Press.

Moore, Erin P. (1998). Gender, Law and Resistance in India. Tucson: The University of Arizona Press. 
Mukherjee, Prabhati. (1978). Hindu Women: Normative Models. New Delhi: Orient Longman Ltd.

Mukherjee, Soma. (2001). Royal Mughal Ladies and Their Contributions. Gyan Books.

Nanda, Meera. (2010). The God Market: How Globalization Made India More Hindu. Random House.

Nandy, Asis. (1983). The Intimate Enemy: Loss and Recovery of Self Under Colonialism. New Delhi: Oxford University Press. 1983.

Narayan, Uma. (2000). "Essence of Culture and a Sense of History: A Feminist Critique of Cultural Essentialism.” Ed. Narayan and Harding. Decentering the Center. Bloomington: Indiana UP.

Offen, Karen. (2000). European Feminisms, 1700-1950: A Political History. Stanford: Stanford University Press.

Oldenburg, Veena Talwar. (1994). “The Roop Kanwar Case: Feminist Responses”. In Sati, The Blessing and the Curse: The Burning of Wives in India. John Stratton Hawley. (Ed).. New York: Oxford University Press, Inc.

Oza, Rupal. (2007). “The Geography of Hindu Right-Wing Violence in India,” in Derek Gregory and Allan Pred. (Eds). Violent Geographies: Fear, Terror and Political Violence, London and New York: Routledge.

Pandey, Rajendra. (1986) The Caste System in India: Myth and Reality. Criterion Publications.

Papanek, Hanna. (1982). “Purdah: Separate Worlds and Symbolic Shelter.” In Separate Worlds: Studies of Purdah in South Asia. Papanek, Hanna and Minault, Gail. (Eds). Delhi: Chanakya Publications. 1982.

Parker, A., M. Russo, D. Sommer and P. Yaeger. (Eds). (1992). Nationalisms and Sexualities. New York and London: Routledge.

Pearson, Gail. (1982). “The Female Intelligentsia in Segregated Society: Bombay, A Case Study”. In Women in India and Nepal. Allen, Michel and Mukherjee, S.N. Mukherjee. Eds. Canberra: Australian National University Monographs on South Asia, pp. 136-154.

Peterson, V. Spike. (1992). Gendered States: Feminist (Re) Visions of International Relations Theory. Boulder: Lynne Rienner. 
Phalkey, Jahnavi. (1999). "Right-wing Mobilization of Women in India: Hindutva's Willing Performers”. In Haleh Afshar and Stephanie Barrientos (Eds). Women, Globalization and Fragmentation in the Developing World, pp.38-53.

Houndmills, Basingstoke and London: Macmillan; New York: St Martin’s Press.

Pinches, Michael. (1999). Culture and Privilege in Capitalist Asia: New Rich In Asia. Routledge Publishers.

Potter, C. (1998). Martha Stewart Living: Decorating Details. Oxmoor House.

Pouchepadass, Jacques. (2002). "Subaltern Studies as Post-Colonial Critique of Modernity”. In Thinking Social Science in India: Essays in Honour of Alice Thorner. Patel, Sujata et al. (Eds). New Delhi: Sage Publications, pp. 84-102.

Procter, James. (2004). Stuart Hall, Routledge Publishers.

Puri, Jyoti. (2003). Encountering Nationalism. Blackwell Publishers.

Puri, Jyoti. (1999). Woman, Body, Desire in Post-Colonial India. Routledge Publishers.

Rajagopal, Arvind. (2001). Politics After Television: Hindu Nationalism and the Reshaping of the Public in India, Cambridge: Cambridge University Press.

Riddle, Joanna and Joshi, Rama. (1986). Daughters of Independence: Gender, Caste and Class in India. London: Zed Books.

Roy, Tathagatha. (2001). My People Uprooted: A Saga of the Hindus in East Bengal. Kolkata: Ratna Prakashan.

Sabin, Margery. (2002). Dissenters and Mavericks: Writings About India in English, 1765-2000. Oxford University Press.

Sanday, Peggy. (1981). Female Power and Male Dominance: On the Origins of Sexual Inequality. New York: Cambridge University Press.

Sandoval, Chela. (2000). Methodology of the Oppressed. Minneapolis: University of Minnesota Press.

Sangari, Kumkum and Vaid, Sudesh. (1990). Recasting Women: Essays in Indian Colonial History. Rutgers University Press.

Sangtin Writers Collective and Richa Nagar. (2004). Playing with Fire: Feminist Thought and Activism through Seven Lives in India. University of Minnesota Press. 
Sarkar, Tanika. (2001). Hindu Wife, Hindu Nation: Community, Religion, and Cultural Nationalism. New Delhi: Permanent Black.

Sarkar, Tanika and Butalia, Urvashi. (Eds). (1995). Women and the Hindu Right: A Collection of Essays. New Delhi: Kali.

Sarkar, Tanika and Sarkar, Sumit. (2008). Women and Social Reform in Modern India: A Reader. Indiana University Press.

Savarkar, Veer Damodar. (1971). Six Glorious Epochs of History. Translated by S.T Godbole. Bombay: Bal Savarkar.

Savarkar, Vinayak Damodar. (1969). Hindutva: Who is a Hindu? Nagpur, 1923. Reprint, Bombay: Veer Savarkar Prakashan.

Scott, J. W,. (1988). “Gender: A Useful Category of Historical Analysis”. In Gender and the Politics of History. New York: Columbia University Press.

Scott, J. W. (1993). Women’s History: New Perspectives on Historical Writing. American Feminist Thought at Century's End, ed. L. Kauffman, 234-57. London: Blackwell.

Scrase, T. (1993). Image, Ideology and Inequality: Cultural Domination, Hegemony and Schooling in India. London and New Delhi: Sage.

Sharma, Radha Krishna. (1981). Nationalism, Social Reform and Indian Women. Patna and New Delhi: Janaki Prakashan.

Sharma, Ursula. (1980). Women, Work and Property in North-West India. London and New York: Tavistock.

Shaver Hughes, Sarah and Hughes, Brady. (2005). "Women in Ancient Civilizations”. In Women's History in Global Perspective. Volume II. Urbana: University of Illinois Press.

Sinha, Mrinalini. (1995). Colonial Masculinity: The 'Manly Englishman' and the 'Effeminate Bengali' in the Late Nineteenth Century. Manchester: Manchester University Press.

Smith, Vincent A. (1999). The Early History of India. Atlantic Publications.

Srinivasan, Bina (2007). Negotiating Complexities: A Collection of Feminist Essays. Bibliophile South Asia. 
Somers, Margaret. (1999). "The Privatization of Citizenship: How to Unthink a Knowledge Culture.” In Bonnell, Victoria and Lynn Hunt, eds. Beyond the Cultural Turn: New Directions in the Study of Society and Culture. Berkeley: University of California Press.

Spivak, Gayatri Chakravorty. (1983). In Other Worlds: Essay in Cultural Politics. New York and London: Routledge.

Sunder-Rajan, Rajeshwari. (1993). Real and Imagined Women: Gender, Culture and Post-Colonialism. London: Routledge.

Talbot, Cynthia. (2001). Precolonial India in Practice: Society, Region, and Identity in Medieval Andhra. Oxford University Press.

Tandon, Rajesh and Mohanty, Ranjita. (2003). Does Civil Society Matter? Governance in Contemporary India. Sage.

Thakur, H. (1998). "Practical Steps Towards Eradicating Dowry and Bride-burning in India.” In W. Menski, Editor. South Asians and the Dowry Problem. Stoke on Trent: Trentham Books.

Tharu, Susie. (1990) "Tracing Savitri's Pedigree: Victorian Racism and the Image of Women in Indo-Anglican Literature". In Recasting Women: Essays in India's Colonial History.

Tickner, Ann. (1992). Gender in International Relations: Feminist Perspectives on Achieving Global Security. Columbia University Press.

Luke, T. W. and Tuathail, G. 1998. Global Flowmations, Local Fundamentalisms, and fast Geopolitics: 'America' in an Accelerating World Order, in Herod, A., Tuathail, G. and Roberts, S.M. (eds.) An Unruly World? Globalization, Governance and Geography. London/New York: Routledge.

Unnithan-Kumar, Maya. (1997). Identity, Gender and Poverty: New Perspectives on Caste and Tribe in Rajasthan. Oxford: Berghahn Books.

Van der Veer, Peter. (1994). Religious Nationalism: Hindus and Muslims in India, Berkeley: University of California Press.

Varshney, Ashutosh. (2002). Ethnic Conflict and Civic Life: Hindus and Muslims in India, New Haven: Yale University Press.

Vatuk, Sylvia. (1982). "Purdah: Separate Worlds and Symbolic Shelter." In Separate Worlds: Studies of Purdah in South Asia. Papanek, Hanna and Minault, Gail. (Eds). Delhi: Chanakya Publications. 
Walsh, Judith E. (2004). Domesticity in Colonial India: What Women Learned When Men Gave Them Advice. Rowman \& Littlefield.

Waltz, Kenneth. (1959). Man, the State, and War. Columbia University Press.

Wilson, H. H. (1997). Rig-Veda-Sanhitā: A Collection of Ancient Hindu Hymns. London, 1850-88. Reprint by Cosmo Publications.

Witzel, Michael. (2003). "Vedas and Upanishads”. In Flood, Gavin. Editor. The Blackwell Companion to Hinduism, Malden, MA: Blackwell.

Wright, Melissa. (2006). Disposable Women and Other Myths of Global Capitalism. New York and London: Routledge.

Young, Iris Marion. (1990). Throwing Like a Girl and Other Essays in Feminist Philosophy and Social Theory. Indiana University Press.

Yuval-Davis, Nira. (1997).Gender \& Nation. London \& NY: Sage.

Journals:

ACA Research. (2003). “The 2003 India Call Centre Industry Benchmarking Study”. ACA Research Private Ltd. Sydney, Australia.

Bachetta, Paula. (1993). “All Our Goddesses Our Armed: Religion, Resistance, and Revenge in the Life of a Militant Hindu Nationalist Women.” Bulletin of Concerned Asian Scholars. Vol. 25, pp.38-51.

Bahuguna, Minting Jug ran. (October-December, 1999). “Media On Women’s Issues”. Vidor. Vol. 36 (4).

Bhat, P.N Mari and Shiva S. Halli. (July 1999). "Demography of Brideprice and Dowry: Causes and Consequences of the Indian Marriage Squeeze.” Population Studies. Vol.53(2), pp.129-149.

Blanchard, Eric M. (2003, Summer). "Gender, International Relations, and the Development of Feminist Security Theory”. Signs. Vol. 28(i4), pp.1289.

Bondi, L. and Mehta, A. (1999). "Embodied Discourse On Gender and Fear of Violence”. Gender, Place \& Culture. Vol. 6, pp. 67-84.

Booth, Ken. (1991). “Security and emancipation”. Review of International Studies. Vol. 17(4), pp. 313-26. 
Chakravarti, Uma. (1993). "State, Market and Freedom of expression: Women and the Electronic Media”. Economic and Political Weekly. Special Issue:

Review of Women's Studies, pp. 12-17.

Chakravarti, Uma. (1993, April). “Conceptualising Brahmanical Patriarchy in Early India: Gender, Caste, Class and State”. Economic and Political Weekly. Vol. 28. No. 14, pp. 579-585.

Channa, Subhadra Mitra. (2004). “Globalization and Modernity in India: A Gendered Critique”. Urban Anthropology and Studies of Cultural Systems and World Economic Development.

Channa, Subhadra Mitra. “Gender and Social Space in a Haryana Village”. Indian Journal of Gender Studies. Volume 1. Pp. 21-34. 1997.

Channa, Subhadra Mitra. “Changing Gender Relations of a Traditional Occupationery Caste”. Eastern Anthropologist 45(4). Pp. 321-341. 1992.

Chatterjee, Partha. (1989). "Colonialism, Nationalism and Colonized Women: The Contest in India”. American Ethnologist Vol.16 (4), pp.622-633.

Cheng, Cliff. (1999, Spring). "Marginalized Masculinities and Hegemonic Masculinity: An Introduction”. The Journal of Men's Studies. Vol. 7 (3), pp. 295.

Connell, R.W. and Messerschmidt, James W. (2005). "Hegemonic Masculinity: Rethinking the Concept”. Gender \& Society. Vol. 19(6), pp.829-859.

Dalmia, Sonia and Lawrence, Pareena G. Spring 2005. “The Institution of Dowry in India: Why It Continues To Prevail”. The Journal of Developing Areas, Volume 38(2), pp. 71-93

Dalrymple, William. (1997). “The Survival of Suttee”. World Press Review. Vol. 44(7), pp.16-17.

Datta, Sangeeta. (2000, March-April). "Globalisation and Representations of Women in Indian Cinema.” Social Scientist. Vol. 28, pp. 71-82.

Deshpande, S. (1998). “After Culture: Renewed Agendas for the Political Economy of India”. Cultural Dynamics Vol. 10 (2), pp. 147-169.

Fernandes, Leela. (2000). "Nationalizing 'the Global': Media Images, Cultural Politics and the Middle Class in India”. Media, Culture \& Society. Vol. 22 (5), pp 611-628. 
Flavia Agnes. (1994, 17 May). "Women’s Movement within a Secular Framework: Redefining the Agenda”. Economic and Political Weekly. Vol. 29(19), pp. 112328.

Forbes, Geraldine. (2003). "Reflections on South Asian Women's/ Gender History: Past and Future". Journal of Colonialism and Colonial History. Vol. 4(1).

Fowler, Bridget. 2003. Pierre Bourdieu and La Domination Masculine.” Iran Bulletin. Volume 24.

Fukuyama, Francis. (1998). "Women and the Evolution of World Politics”. Foreign Affairs.

Ganesh, Gopala. (1997). "Spousal Influence in Consumer Decisions: A Study of Cultural Assimilation”. Journal of Consumer Marketing. Vol. 14(2), pp.132-155.

Ganguly-Scrase, Ruchira. (2003). "Paradoxes of Globalization, Liberalization, and Gender Equality: The Worldviews of the Lower Middle Class in West Bengal, India”. Gender \& Society. Vol. 17(4), pp. 544-566.

Ganguly-Scrase R and Scrase, T. (2001). "Who Wins? Who Loses? And Who Even Knows? - Responses to Economic Liberalisation and Cultural Globalisation”. South Asia Vol. 24 (1), pp. 141-158.

Glenn, Cheryl. (2000, January). "Comment: Truth, Lies, and Method: Revisiting Feminist Historiography.” College English Vol. 62, pp. 387-9.

Gosovic, Branislav. (2002). "Global Intellectual Hegemony and the International Development Agenda”. International Social Science Journal. Vol. 52(166), pp. $447-456$.

Gupta, Charu. (1998). “Articulating Hindu Masculinity and Femininity: 'Shuddhi' and 'Sangathan' Movements in the United Provinces in the 1920s". Economic and Political Weekly. Vol. 33(13), pp. 727-735.

Gupta, Namrata and Sharma, A.K. (2003). "Gender Inequality in the Work Environment at Institutes of Higher Learning in Science and Technology in India”. Work, Employment \& Society. Vol. 17(4), pp. 597-616.

Hanson, Susan and Monk, Janice. (1982). "On Not Excluding Half of the Human in Human Geography”. The Professional Geographer. Vol. 34, pp. 11-23.

Hyndman J. (2001). “Towards a Feminist Geopolitics”. The Canadian Geographer. Volume 45(2):210-222. 
Inkson, Kerr, Khapova, Svetlana N., and Parker, Polly. (2007). "Careers in Cross-

Cultural Perspective”. Career Development International. Vol. 12 (1), pp. 5-8.

John Mary. (1998). “Feminism in India and the West”. Cultural Dynamics. Vol. 10 (2).

John, Mary E. and Niranjana, Tejaswini. (1999, March). "Mirror Politics: Fire, Hindutva and Indian Culture”. Economic and Political Weekly. Vol. XXXIV, pp. 581-84.

Kaila, H.L. (2004). "Indian Women Managers: Their Stresses, Health and Coping Behaviour-A Survey in Mumbai”. Journal of Health Management. Vol. 6(2), pp. 147-161.

Kandiyoti, Deniz. (1988). “Bargaining with Patriarchy”. Gender and Society. Vol. 2(3), pp. 274-90.

Kapur, Naina. (2001).”Equality and the Truth of Brahma”. Violence Against Women. Vol. 7(9), pp. 1069-1096.

Katz, Cindi. (2001). "On the Grounds of Globalization: A Topography for Feminist Political Engagement”. Signs. Volume 26/4, pp. 1213-1234. The University of Chicago Press.

Khattak, Saba Gul. (1996). "Security Discourses and the State in Pakistan.” Alternatives. Vol. 21, pp. 341-362.

Kishwar, Madhu. (1990).“In Defense of Our Dharma.” Manushi. Vol. 60, pp.4.

Kishwar, Madhu. (1994). “A Code for Self-Monitoring Some Thoughts on Activism”. Manushi. Vol. 89, pp.5-9.

Kumar, Shashi Prabha. (1998). “Indian Feminism in Vedic Perspective”. Journal of Indian Studies. Vol. 1.

Lau, Lisa Ee Jia. (2006). "The New Indian Woman: Who is She, and What is "New" About Her?”. Women's Studies International Forum. Vol. 29(2), pp. 159-171.

Locher, Birgit and Prügl, Elisabeth. (2001). "Feminism and Constructivism: Worlds Apart or Sharing the Middle Ground?” International Studies Quarterly. Vol. 45, pp.111-129.

Lovell, Terry. 2002. “Thinking Feminism With and Against Bourdieu.” Feminist Theory 1.1, pp. 11-32. 
Lukose, Ritty. (2005, Summer). “Consuming Globalization: Youth and Gender in Kerala, India”. Journal of Social History. Vol. 38(4).

Mahajan, Preeti. (2009, September). "Use of Social Networking in a Linguistically and Culturally Rich India”. The International Information and Library Review. Vol. 41 (3), pp.129-136.

Mehrotra, Nilika. (2001). “Understanding Feminism in a Local Context”. Indian Anthropologist,Vol. 31(1), pp.1-17. 2001.

Menon, Usha. (2003, Spring). “Do Women Participate in Riots” Exploring the Notion of 'Militancy' among Hindu Women.” Nationalism and Ethnic Politics. Vol. 9(1), pp. 20-51.

Menon, Nivedita. (2004). "Refusing Globalisation and the Authentic Nation: Feminist Politics in Current Conjecture”. Economic and Political Weekly, pp. 100-104.

Meth, Paula. (2003, August). “Rethinking the 'Domus' in Domestic Violence: Homelessness, Space and Domestic Violence in South Africa”. Geoforum. Vol. 34 (3), pp 317-327.

Mirchandani, K. (2004). "Practices of Global Capital: Gaps, cracks and Ironies in Transnational Call Centres in India”. Global Networks, Vol. 4 (4), pp.355-373.

Mitra, Debarashmi. (2009). “Susan Dewey’s Making Miss India Miss World: Constructing Gender, Power and the Nation in Postliberalization India Review." Anthropological Quarterly Vol. 82 (4), pp.1097.

Munshi, S. (1998). "Wife/Mother/Daughter-in-law: Multiple Avatars of Homemaker in 1990’s Indian Advertising”. Media, Culture and Society 20 (4), pp.573-591.

Nagar, Richa, Lawson, Victoria, McDowell, Linda and Hanson, Susan. 2002. Locating Globalization: Feminist (Re)readings of the Subjects and Spaces of Globalization. Economic Geography 78:3:257-284.

Narayan, Uma. (2000). “Undoing the 'Package Picture' of Cultures”. Signs: Journal of Women in Culture and Society. Vol. 25 (4).

Nas, Peter, J.M. and Howeling, Antonia, J. (1998). “The Network Metaphor”. Journal of Social Sciences. Vol. 2(4), pp. 221-232.

Pandey, Gyanendra. (1991, December 28). "Hindus and the Others: The Militant Hindu Construction." Economic and Political Weekly. Vol. 26, pp. 2997-3009. 
Peterson, V. Spike. (June 1999). "Sexing Political Identities/Nationalism As Heterosexism.” International Feminist Journals of Politics. Volume 1, pp.34-65.

Rajan, Rajeswari Sunder. (2004, November). "Rethinking Law and Violence: The Domestic Violence (Prevention) Bill in India, 2002”. Gender \& History. Vol. 16 (3), pp. 769-793.

Ramusack, Barbara. (1990). "From Symbol to Diversity: The Historical Literature on Women in India”. South Asia Research, 2, pp.139-157.

Ramesh, B. (2004, January 31). “'Cyber Coolies’ in BPO: Insecurities and Vulnerabilities of Non-Standard Work”. Economic and Political Weekly, Vol. 1.

Roy-Chowdhury, Supriya. (2004, January 3). “Globalisation and Labour”. Economic and Political Weekly, pp.105-108.

Richard P., Appelbaum and Robinson, William I. (2005). Critical Globalization Studies. Routledge.

Saldanha, Indra Munshi. (1986, April). “Tribal Women in the Warli Revolt: 1945-47: 'Class' and 'Gender' in the Left Perspective”. Economic and Political Weekly. Vol. 21(17), pp. WS41-WS52.

Sangari, Kumkum. (2001). “New Patriotisms.” In Vikalp. Vol. IX, pp.1-18.

Sarkar, Tanika. (1987). "Nationalist Iconography: Image of Women in Nineteen-Century Bengali Literatures”. Economic and Political Weekly. Volume 21, pp. 2011-55.

Sassen, S. (2000). "Spacialities and Temporalities of the Global: Elements for a Theorisation”. Public Culture 12 (1). pp.215-232.

Scott, J. W. (1989). "History in Crisis: The Others' Side of the Story”. American Historical Review Volume 94, pp. 680-92.

Sen, Amartya. (1990). “More Than 100 Million Women Are Missing”. New York Review of Books.

Sen, Samita. (2002). “Toward a Feminist Politics? The Indian Women’s Movement in Historical Perspective”. Gender and Development. Working Paper Series Number 9.

Singh, Jaspal Kaur. (2003, June 22). “Globalization, Transnationalism, and Identity Politics in South Asian Women’s Texts”. Michigan Academician. 
Singh, Nandita. (2008). "Higher Education for Women in India-Choices and Challenges”. Forum on Public Policy.

Sridharan, E. (2004). “The Growth and Sectoral Composition of India's Middle Class: Its Impact on the Politics of Economic Liberalization”. India Review, 3(4), pp. 405-428.

Van den Broek, D. (2004). "Globalising Call Centre Capital: Gender, Culture and Work Identity”. Labour and Industry 14 (3).

Van Wessel, M. (1998). "Wealth and its Social Worth: Consumers in the Land of Gandhi”. Amsterdams Sociologisch Tijdschrif, 25 (4), pp. 562-67.

Vishwanath, Kalpana. (2007, April 28).““Shall We Go Out?’: Women’s Safety in Public Spaces in Delhi”. Economic and Political Weekly, pp. 1543.

Zacharias, Usha. (Winter 2001). "Trial by Fire: Gender, Power, and Citizenship in Narratives of the Nation”. Social Text-69, Vol. 19(4), pp. 29-51.

\section{Presentations:}

Basu, Asmita. (2005, April 14). "Violence Against Women: A Statistical Overview, Challenges and Gaps in Data Collection and Methodology and Approaches for Overcoming Them. Presented at the Expert Group Meeting of the UN Division for the Advancement of Women in collaboration with Economic Commission for Europe (ECE) and World Health Organization (WHO) in Geneva, Switzerland.

Capoor, Indu and Patel, Pallavi. (2006, November 20-21). “Adolescent and Young People's Issues and Concerns in South Asia: Challenges Ahead”. Presented at The International Conference on Best Practices for Scaling Reproductive Health and Family Planning Programme and Reducing Maternal and Neonatal Mortality, Islamabad, Pakistan.

Das, Runa. (2009, May 26). "How Strategic Culture Matters for Gender and (In)Security: Indian Women, Anti-Nuclear/Peace Activism, Civil Society, and Visions of a Sustainable Future-- Connecting the Local to the Global”. Presented at the annual meeting of the International Studies Association, Hilton Hawaiian Village, Honolulu, Hawaii.

Das, Runa. (2004, March 17). "Religious Nationalism, Brahmanical Patriarchy, and the Politics of Hindutva: Does Ideology Matter in International Relations?” Paper presented at the annual meeting of the International Studies Association, Le Centre Sheraton Hotel, Montreal, Quebec, Canada. 
Lawyers' Collective, Women's Rights Initiative, Campaign for a Civil Law on Domestic Violence. (2002). Update and Briefing Note presented by New Delhi: Lawyers' Collective, Women's Rights Initiative in New Delhi, India.

Lehtonen, Sanna. (2007, 14-17 June). Feminist Critical Discourse Analysis and Children's Fantasy Fiction-Modelling a New Approach. Presented at "Past, Present, Future - From Women's Studies to Post-Gender Research”, Umeå, Sweden.

McNeil, Tony. (1999, February 11). Mythologies (1957). Concept and Text. Presented at Lecture Series, The University of Sunderland, Great Britain.

Ganguly-Scrase, Ruchira and Van den Broek, Diane. (2005, December 5-8). "Women's Work in Call Centres in India: Contradictions and Constraints" (co-authored with Van den Broek 50\% contribution). Presented at The Australian Sociological Association, University of Tasmania.

Online Sources:

Atmavilas, Yamini. (2008). "Of love and labor: Women workers, modernity and changing gender relations in Bangalore, India”. Ph.D. dissertation, Emory University. Retrieved on March 3, 2010, from Dissertations \& Theses: A\&I.(Publication No. AAT 3310234)

Bhaskaran, Dimple Suparna. (1998). Made in India? Nationalized Genders and Colonized Sexualities. Ph. D. dissertation, Michigan State University. Retrieved on March 3, 2010, from Dissertations \& Theses: A\&I.(Publication No. AAT 9922289).

Bhowmick, Nilanjana. (2009, 28 December). "Report: Indian Working Women More At Risk From Domestic Violence”. Retrieved on February 12, 2010, from http://www.allheadlinenews.com/articles/7017372168\#ixzz0k2NeIVgt

Dewan, Anjali. (2009, August 16). "An Epidemiological Study of the Appraisal of the Emerging Issues and Challenges in Globalisation, Higher Education and the Changing Status of Indian Women”. Retrieved on March 12, 2010, from http://ssrn.com/abstract=1455423

Femmes et Villes International Report (2009). Retrieved in January-April, 2010 from http://www.femmesetvilles.org/english/index_en.htm

Inter-parliamentary Union (IPU) Report. Retrieved on March 22, 2010 from http://www.ipu.org/wmn-e/classif.htm 
Lal, Neeta. (2007, April 16). "Violence Against Women in India”. Retrieved on May 27, 2009 from: http://opinionasia.com/ViolenceagainstwomeninIndia

Mackey, Robert. (2009, February 13). "Indian Women Fight Violence with Facebook and Underwear". The New York Times News Blog. Retrieved on February 22, 2010 from http://thelede.blogs.nytimes.com/2009/02/13/indian-women-use-facebookfor-valentines-protest/

McChesney, Robert W. (1999, November 29). The New Global Media; It's a Small World of Big Conglomerates. The Nation Magazine. Retrieved on January 22, 2010 from http://www.thenation.com/doc/19991129/mcchesney

Laura Mulvey (1975). "Visual Pleasure and Narrative Cinema". Screen 16(3): 6-18. Retrieved August 22, 2010 from: https://wiki.brown.edu/confluence/display/ MarkTribe/Visual+Pleasure+and+Narrative+Cinema

Nijhwan, Amita. (2007). We are Cool Now...in Hamara India: Bikinis, Bike Races and Dancing Bodies in the "Age of Globalization". Ph.D. dissertation, University of California, Riverside. Retrieved on August 22, 2009, from Dissertations \& Theses: A\&I.(Publication No. AAT 3270451).

Radhakrishnan, S. (2008). "Global Indians" and the Knowledge Economy: Gender and the Making of a Middle-Class Nation. Ph.D. dissertation, University of California, Berkeley. Retrieved on March 3, 2010, from Dissertations \& Theses: A\&I.(Publication No. AAT 3254301).

Saakshi Report on Gender Violence and the Indian Legal System. Retrieved on multiple dates from http://www.un.org.in/gender/images/VIOLENCEAGAINSTWOMEN.pdf

Schechter, Danny. "Chapter 2, Peace Journalism and Media War: the Fight to Reform Journalism, Retrieved on January 22, 2010.What Are Journalists For?” from http://www.globalissues.org/article/535/what-are-journalists-for\#2c2

Sen, Swagata. (2009, February 13). “The Moral Brigand”. In India Today. Retrieved on March 29, 2010, from:

http://indiatoday.intoday.in/site/Story/28820/STATES/The+moral+brigand.html

Shenoy, S. Women and Work in India: (Re)engaging Class, Careers, and Occupations in a Globalizing Economy. (2008). Ph.D. dissertation, Purdue University, Indiana. Retrieved March 3, 2010, from Dissertations \& Theses: A\&I.(Publication No. AAT 3378866). 
Susan, Nisha. (2009, August 1). "Why Indian Men are Still Boys?” Retrieved on February 27, 2010, from http://www.tehelka.com/story_main42.asp?filename=Ne010809coverstory.asp

Swamy, Arun R. "Hindu Nationalism: What's Religion Got to Do With It?” Asia Pacific Center for Security Studies Occasional Paper Series. Retrieved on February 22, 2010, from http://www.apcss.org/Publications/Ocasional\%20Papers/OPHinduNationalism.pd $\underline{\mathrm{f}}$

Wright, Kimberly Anne. (2001). Consuming identities: Global advertising, marketing and cultural identity in India. Ph. D. dissertation, Duke University. Retrieved on March 3, 2010, from Dissertations \& Theses: A\&I.(AAT 3041323)

Manushi magazine Website: www.manushi.org

Self Employed Women’s Association Website: www.sewa.org

Indian Government Documents and Websites:

Bhagat, Pamela. National Commission for Women Report on Status of Women Journalists. 2004. Website: http://ncw.nic.in/pdfreports/Status\%20of\%20Women\%20Journalists\%20in\%20In dia.pdf

Delhi Government Planning Department Economic Survey of Delhi 2001-2002 Report. Website: http://delhiplanning.nic.in/Economic\%20Survey/Ecosur200102/PDF/chapter3.pdf

Guha, Phulrenu. Towards Equality: Report of the Committee on the Status of Women in India. 1974.

http://archive.cscs.res.in/MediaArchive/Library.nsf/(docid)/8D5818C7A2C38D79 65257132002AFB95?OpenDocument\&StartKey=Towards\&count=50

Indian Penal Code. Website: http://www.netlawman.co.in/acts/indian-penal-code-1860.php

National Crime Records Bureau, Ministry of Home Affairs, Government of India Website: http://ncrb.nic.in:

Publications:

Devraj, Ranjit. (2010, February 26). "MEDIA-INDIA: More Women Now, But Few in Top Posts”. IPS News. 
Drew, Ernest H. (1997, February 12). Advertising Age.

Overdorf, Jason. (2009, February 14). "Bare Necessities: While the Affluent Cut Back, Lower-Income People are Still Spending”. Newsweek.

Sinha, Ashish. (2010, January 4). "India to Have 100 Million Cable Homes This Year”. Business Standard.

Staff Writer. (2010, January 14). "In Madhya Pradesh [a central Indian state], Moral Police Against Lingerie Ads, Window Display”. The Times of India.

Susan, Nisha. (August 1, 2009). "Why Indian Men are Still Boys”. Tehelka Magazine, Vol. 6 (30).

Staff Writer, “Richard Gere’s Kiss Sets Nation on Fire”. International Business Times, April 18, 2007.

Television Soap Operas:

Bairi Piya. Colors TV Channel. Balaji Productions.

Balika Badhu. Colors TV Channel. Sphere Productions.

\section{Reports:}

CNN-IBN-Indian Express-CSDS Report. (2008). State of the Nation Survey- An Exclusive Survey of Indian Women.

Concerned Citizens Tribunal. (2002). Crime Against Humanity: An Inquiry into the Carnage in Gujarat. Volume 3.

Parekh, Angana. (2001). Bringing Women's Stories to a Reluctant Mainstream Press. Nieman Reports for Nieman Foundation for Journalism at Harvard. 


\section{APPENDIX A: Outline of Interview Questions}

1. What is your name, age and partner status? Do you have children?

2. Where are you from originally and how long have you lived in Delhi? What is your primary language of conversation?

3. Tell me about your academic career.

4. Tell me about your work experience.

5. Where do you work now?

6. Tell me about your organization. (In terms of structural hierarchy, gender ratio, HR policies with respect to sexual harassment, work benefits etc., gender sensitivity training, among others)

7. Tell me about your family structure. How long have been in your relationship/marriage?

8. Are you a practicing Hindu?

9. What does the word Hindutva mean to you?

10. How does Hindutva impact your life, if it does? For instance, your voting choices, lifestyle and travel choices among others. In other words, do you think Hindutva is more than just a political ideology but also a way of life?

11. Does Hindutva have any relevance in today's India?

12. Do you see the impact of patriarchal nationalism when you travel for your stories, interview the public etc.? In other words, India is a largely conservative country making its way towards globalization. Do you experience this clash?

13. How do you define Indian womanhood?

14. Do you identity with terms like adarsh Bharatiya nari (ideal Indian woman)? Do these notions matter in your family? If yes, how does it manifest itself? If no, why not?

15. Is virginity/sexual purity a matter of consideration today? Does promiscuity apply differently to men and women?

16. The Indian entertainment industry is filled with images of good woman/evil woman dichotomies that are defined by certain characteristics and mannerisms as defined by patriarchal nationalism. These definitions have persisted over time. Why have they not changed? How do these imageries impact real women and their lives, if at all?

17. One of the foundations of masculine domination is heterosexual matrimony. How important is marriage today, personally and professionally? Do you think being married implies security?

18. What does globalization mean to you? Do you separate it from westernization?

19. Is it a positive, negative or indifferent influence in your life?

20. Do you find that globalization has expanded or contracted your life choices?

21. Has globalization impacted the way you perceive and travel through public spaces/transportation?

22. How has globalization impacted family structures in general and yours, in specific?

23. While globalization has created multiple new opportunities, has it equalized the playing field, in terms of pay structure, benefits, maternity rights etceteras? 
24. Tell me about your work place. What is the hierarchy? How many "powerful" women do you have who are in positions of decision-making?

25. Do you see an attrition of women as you move up the ladder? If yes, why?

26. Who decides the content of your programming? How are the stories assigned? Is there gendering of the content?

27. Do you see any specific patterns of gendering in your work space?

28. Is the old-boys network still visible and effective? How do you network?

29. How important is visibility and appearance? Is there a double standard in the expectations between men and women?

30. Have you ever faced sexual harassment or other gender-based discrimination at your place of work? If yes, how have you handled it? What recourses does a woman have?

31. Has globalization made it easier for you to be an individual? Travel alone, go to clubs alone, drive alone etceteras?

32. You are an employed, educated woman. Do you see yourself as being empowered? Would you call yourself a feminist? What does feminism mean to you? 
APPENDIX B: Research Respondents' Profiles (at the time of the interviews)

1. Diya Bannerjee: Assistant News Editor (News and Current Affairs Programming), Times Now.

Age: 24 years

Marital Status: Single at the time of interview, since engaged.

2. Parul Malik: Reporter/Producer. $C N N-I B N$.

Age: 27 years

Marital Status: Single.

3. Juhi Chaudhury: Environmental Reporter. $C N N-I B N$.

Age: 25 years

Marital Status: Single.

4. Mridu Bhandari: Special Investigation Reporter (Rural and Development Sector), $C N N-I B N$.

Age: 30 years

Marital Status: Married with one child.

5. Neha Bhatnagar: Anchor/Principal Correspondent, TV Today.

Age: 28 years

Marital Status: Single at the time of interview, since married and residing in London.

6. Amulya Gopalakrishnan: Op-Ed Editor, Hindustan Times.

Age: 28 years

Marital Status: Single.

7. Alka Saxena: Consulting Editor, Zee News.

Age: 48 years

Marital Status: Married with one child.

8. Suman Kansra: Camerawoman, Aaj Tak.

Age: 42 years

Marital Status: Married with one child.

9. Aarti Chauhan: Political correspondent/Senior Special Correspondent (National Bureau), Aaj Tak.

Age: 36 years

Marital Status: Married.

10. Tina Baruah: Associate Editor, Lifestyle Magazine.

Age: 30 years

Marital Status: Married.

11. Abhilasha Ojha: Writer, Business Standard.

Age: 30 years

Marital Status: Married (Previously divorced).

12. Anoothi Vishal: Assistant Editor, Crest, Times of India.. Age: 34 years

Marital Status: Married with one child. 
13. Mallica Singh: Ex-Senior Copy Editor, Maxim.

Age: 32 years

Marital Status: Single, in a long term relationship.

14. Shruti Singh: Consulting Researcher (Photography department), Outlook.

Age: 33 years

Marital Status: Married.

15. Nisha Susan: Correspondent, Tehelka.

Age: 30 years

Marital Status: Single.

16. Shobita Dhar: Features Editor, Outlook.

Age: 30 years

Marital Status: Single.

17. Indrani Raj Khowa Banerjee: Senior Features Writer, Times Life, Times of India. Age: 34 years

Marital Status: Married and pregnant with her first child at the time of the interview.

18. Shailaja Tripathy: Principal Correspondent/Chief sub-editor, Metro Plus.

Age: 30 years

Marital Status: Separated at the time of interview.

19. Shikha Mishra: Associate Editor, Times of India.

Age: 30 years

Marital Status: Separated at the time of interview.

20. "Nandita": Political Reporter, NDTV.

Age: 48 years

Marital Status: Divorced at the time of interview, since married.

21. "Devika": Correspondent, Aaj Tak.

Age: 34 years

Marital Status: Single.

22. "Shipra”: Senior Political Reporter and Anchor, NDTV.

Age: 49 years

Marital Status: In a live-in relationship, with one child.

23. "Veda": Consulting Editor, Headlines Today.

Age: 45 years

Marital Status: Married with two children.

24. Ram Madhav: National Spokesperson, Rashtriya Swayamsevak Sangh.

Age: Early forties.

Marital Status: Single.

25. Asha: Member, Rashtriya Swayamsevika Sangh.

Age: Mid forties.

Marital Status: Single.

26. Bala Subrahmanian: Public Relations Officer, Bharatiya Janata Party. Age: Late forties.

Marital Status: Married with two children. 
APPENDIX C: Political Map of India

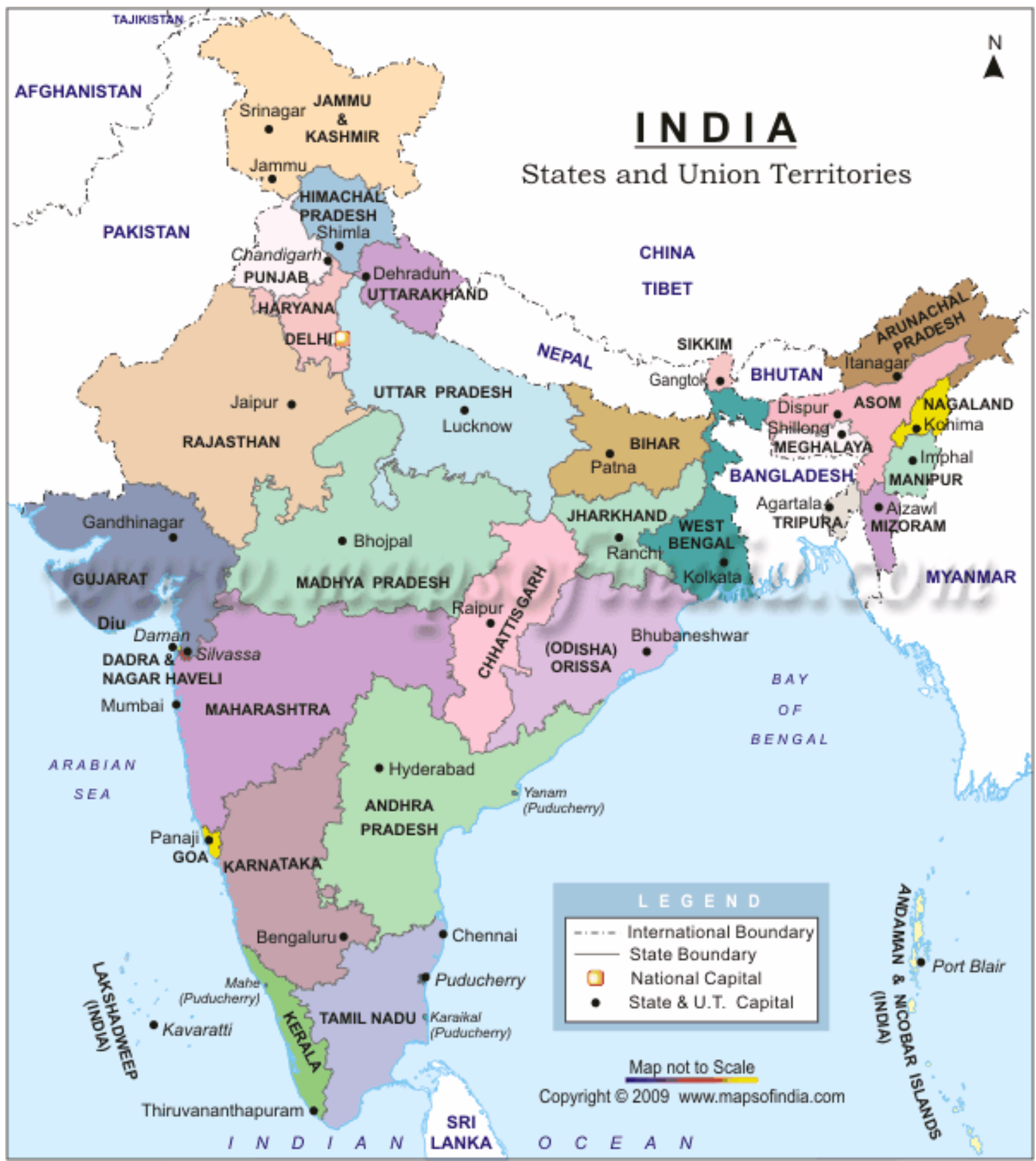


APPENDIX D: Gendered Images of India

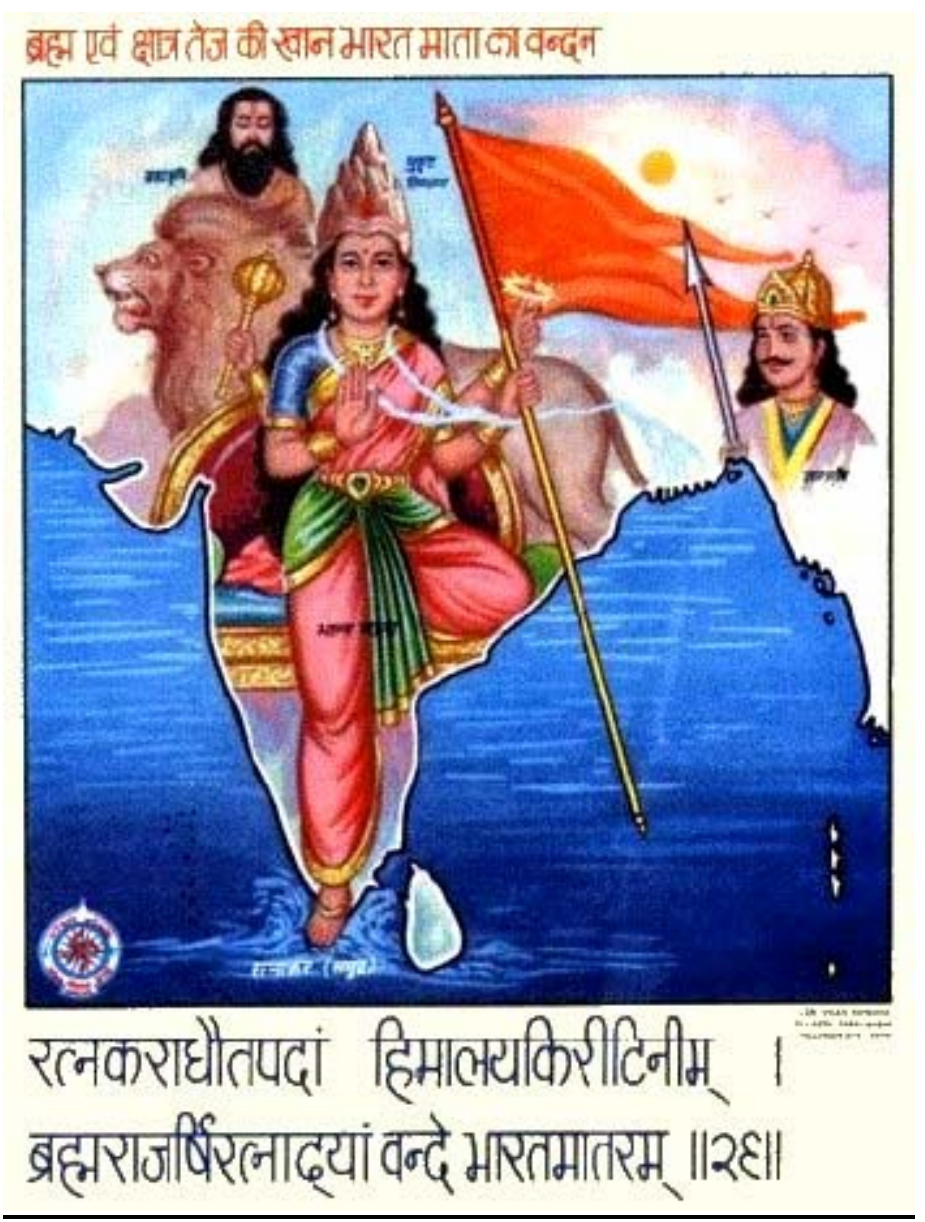

I pay my obeisance to mother Bharata, whose feet are being a washed by the ocean, who wears the mighty Himalaya as her crown, and who is exuberantly adorned with the gems of traditions set by Brahmarsis and Rajarsis.

Obtained from the RSS Office, New Delhi 


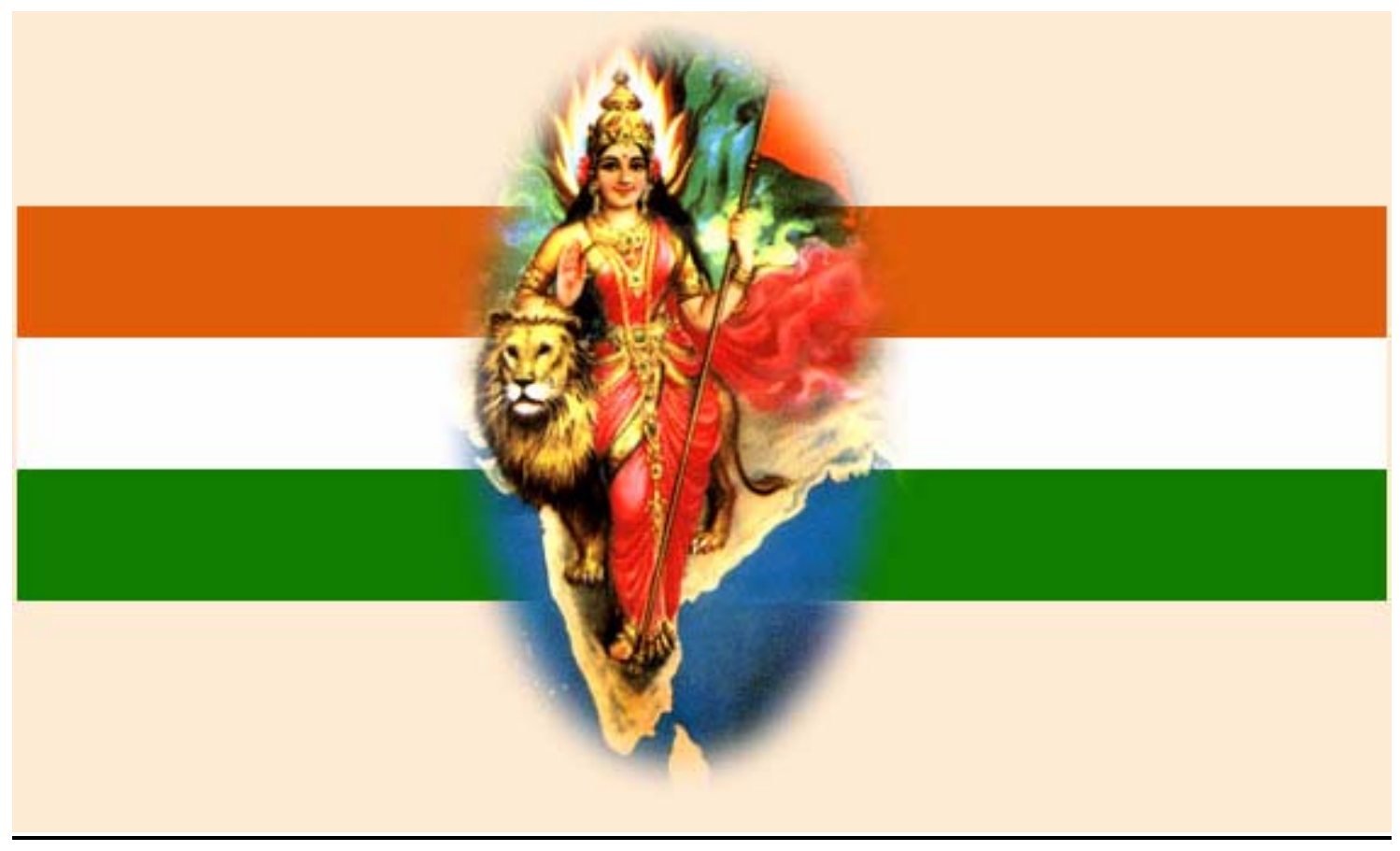

Calendar image found in BJP Office, New Delhi 
VITA

\section{MONALISA GANGOPADHYAY}

1993-1999: $\quad$ B. Arch., Architecture. Sushant School Of Art and Architecture, Gurgaon, India

January-July 2000: In-house Freelance Reporter, The Indian Express, New Delhi.

2000-2003. M.J., Journalism, Public Relations and Advertising. Temple University, Philadelphia.

Calendar Editor, Temple Times, Temple University. January 2001-December 2002.

Tutor and Science Project Coordinator, Temple University. September-December 2000.

2004-2007: M.A., International Relations. Florida International University, Miami. December 2008.

Student Outreach Coordinator Broad International Lecture Series, FIU. August 2005-August 2009.

Teaching Assistant, Department of Politics and International Relations, FIU. August 2004-August 2005.

2007-Present: $\quad$ Doctoral Candidate, International Relations. FIU. Expected Graduation: Fall 2010.

PUBLICATIONS AND PRESENTATIONS:

Gangopadhyay, Monalisa. 2009. Review of Global “Body Shopping”': An Indian Labor System in the Information Technology Industry by Xiang Biao. Political Geography (May). Volume 28, Issue 2. 146-147.

"Globalization and the Indian Woman" Paper presented at the $7^{\text {th }}$ Annual Women's Studies Graduate Student Symposium, Florida Atlantic University, Miami, FL, April 1, 2005.

"Patriarchy and Indian Womanhood". Presentation made at a panel organized by the Network of Indian Professionals, South Florida Chapter, Miami, FL, July 2, 2006. 